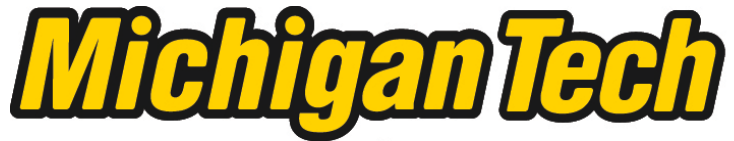 \\ Michigan Technological University Create the Future Digital Commons @ Michigan Tech
}

2010

\section{Exploration of the role of serum factors in maintaining bone mass during hibernation in black bears}

Rachel Marie Bradford

Michigan Technological University

Follow this and additional works at: https://digitalcommons.mtu.edu/etds

Part of the Biomedical Engineering and Bioengineering Commons Copyright 2010 Rachel Marie Bradford

\section{Recommended Citation}

Bradford, Rachel Marie, "Exploration of the role of serum factors in maintaining bone mass during hibernation in black bears", Dissertation, Michigan Technological University, 2010.

https://doi.org/10.37099/mtu.dc.etds/286

Follow this and additional works at: https://digitalcommons.mtu.edu/etds

Part of the Biomedical Engineering and Bioengineering Commons 


\title{
EXPLORATION OF THE ROLE OF SERUM FACTORS IN MAINTAINING BONE MASS DURING HIBERNATION IN BLACK BEARS
}

By

RACHEL MARIE BRADFORD

\begin{abstract}
A DISSERTATION
Submitted in partial fulfillment of requirements for the degree of

DOCTOR OF PHILOSOPHY

(Biomedical Engineering)
\end{abstract}

MICHIGAN TECHNOLOGICAL UNIVERSITY

2010

CC Rachel Marie Bradford 2010 
This dissertation, "Exploration of the role of serum factors in maintaining bone mass during hibernation in black bears," is hereby approved in partial fulfillment of the requirements for the degree of DOCTOR OF PHILOSOPHY in the field of Biomedical Engineering.

DEPARTMENT:

Biomedical Engineering

\section{Signatures:}

Dissertation Advisor

Seth Donahue, PhD

Date

\section{Department Chair}




\section{Table of contents}

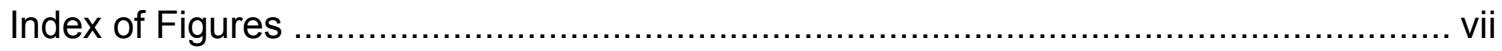

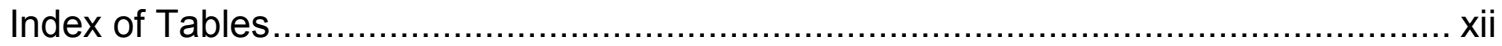

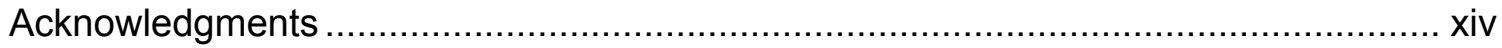

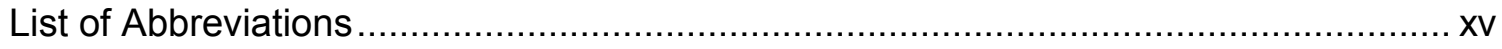

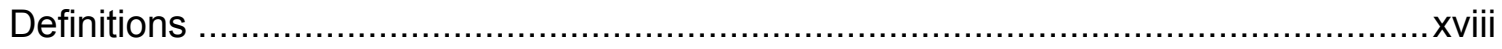

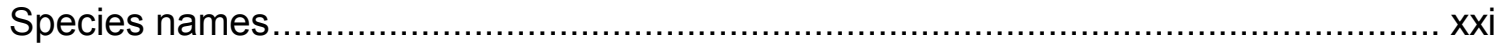

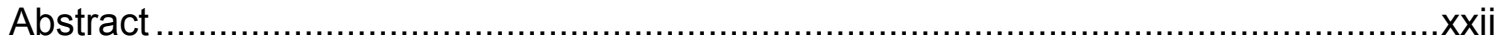

Chapter One - Background and significance................................................... 1

1.1. Problem description/significance ........................................................ 1

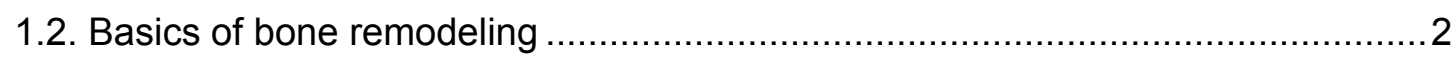

1.3. Bone turnover is unbalanced during disuse ............................................... 3

1.4. Osteoblast and osteocyte apoptosis results in bone loss ............................... 3

1.4.1. Review of apoptosis mechanisms in osteoblasts ................................ 4

1.4.2. Apoptosis precedes disuse-induced bone loss .................................. 6

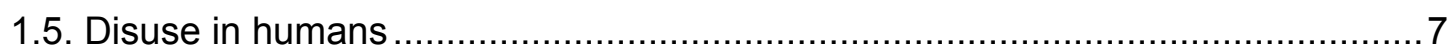

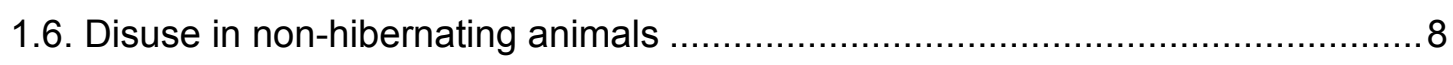

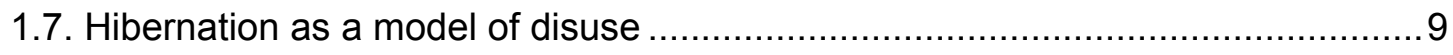

1.7.1. Physiology of hibernation ........................................................ 10

1.7.2. Bone response to hibernation-small hibernators.............................. 11

1.7.3. Bone response to hibernation-bears: histological and mechanical

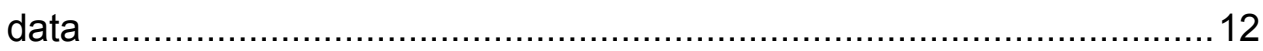

1.7.4. Bone response to hibernation-bears: serum formation markers and histomorphometry ............................................................. 13

1.7.5. Hypothesis 1: BSALP and TRACP reduction during hibernation .............14

1.7.6. Hypothesis 2: OCN interacts with energy metabolism .........................15

1.7.7. Hypothesis 3: Reduced apoptotic serum factors during hibernation ........15

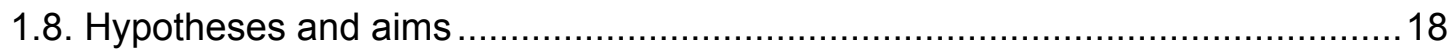


Chapter Two - Serum osteocalcin is inversely associated with adiponectin, glucose, and serotonin in black bears

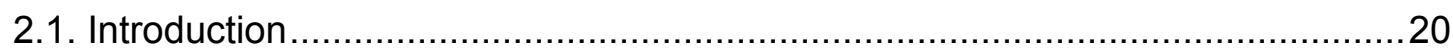

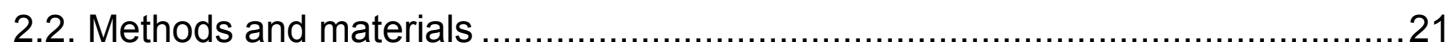

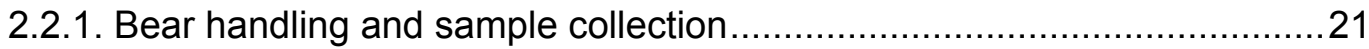

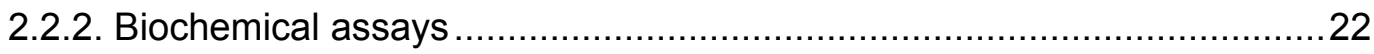

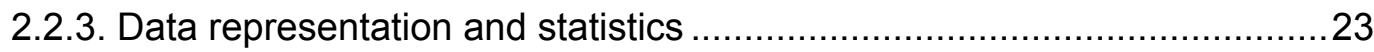

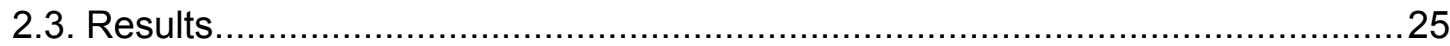

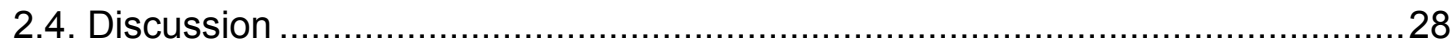

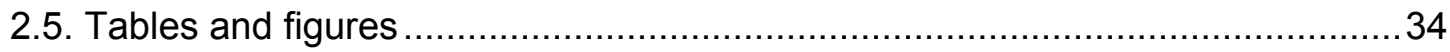

Chapter Three - Serum neuropeptide $Y$ and IGF-1 favor reduced bone turnover in

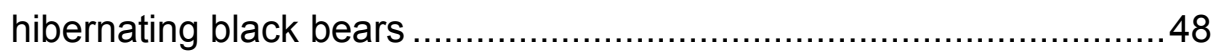

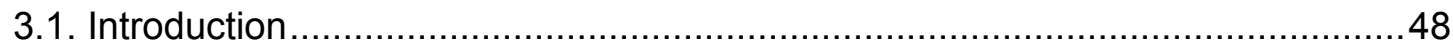

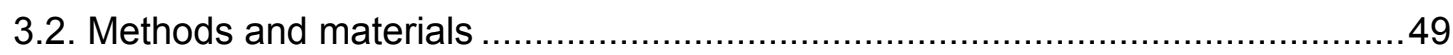

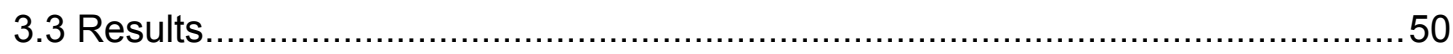

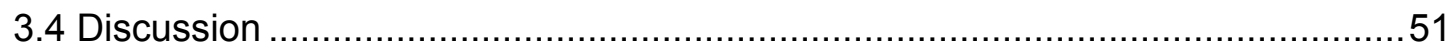

3.4.1. Maintenance of serum leptin concentrations several weeks into hibernation may prevent bone loss and help bears maintain near-

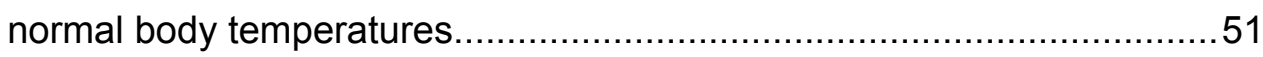

3.4.2. Reduced IGF-1 and increased NPY in the serum of hibernating bears favor suppression of bone turnover .................................................. 53

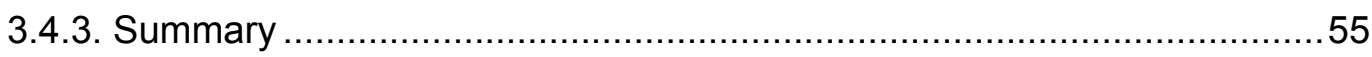

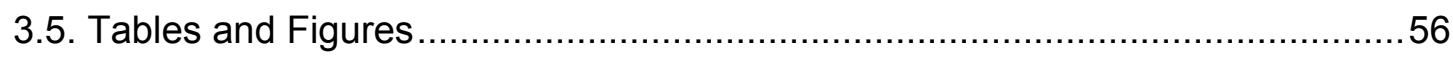


Chapter Four - Attempts to find an anti-apoptotic environment in hibernating bear serum remain inconclusive.

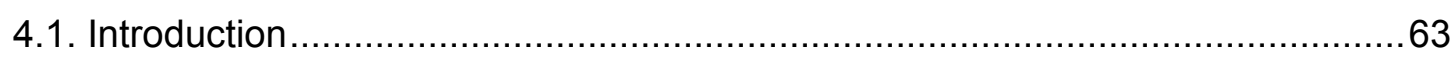

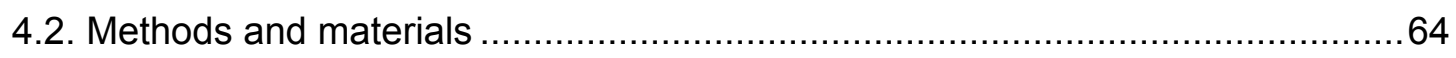

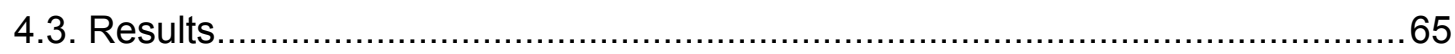

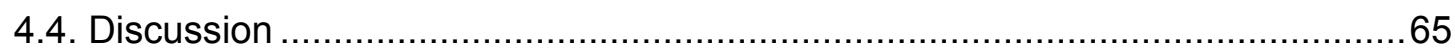

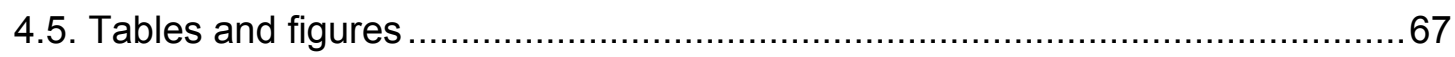

Chapter Five - Serum from hibernating bears protects cells from caspse-3 and -7

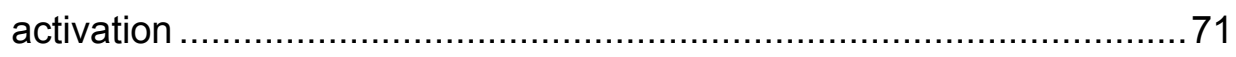

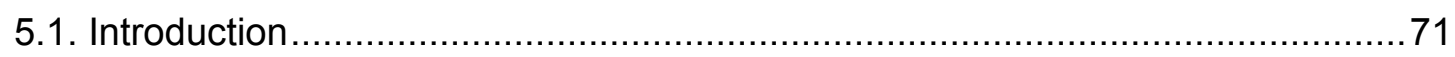

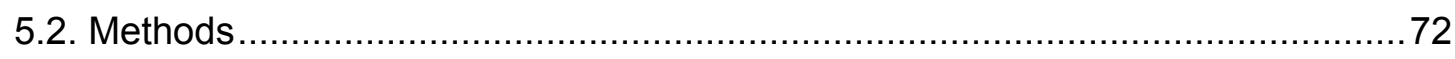

5.2.1. Black bear handling and serum sample collection ............................. 72

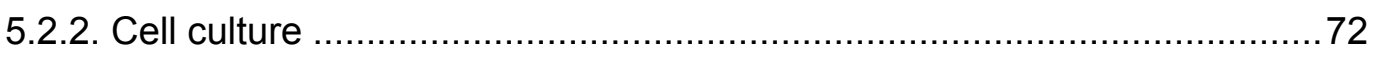

5.2.3. MC3T3-E1 apoptotic response to seasonal bear serum ........................72

5.2.4. Caspase $-3 / 7$ activity of bear bone lysates ..........................................73

5.2.5. MC3T3-E1 gene expression response to bear serum .........................74

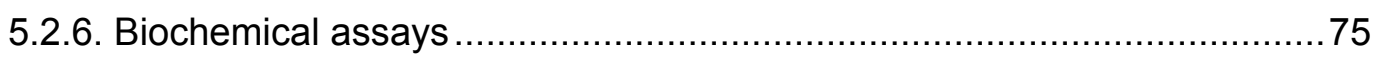

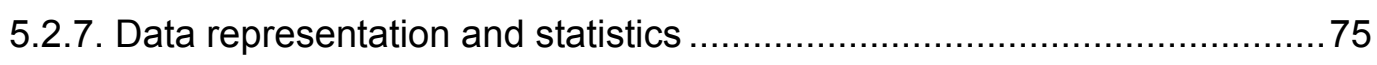

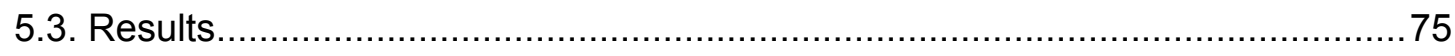

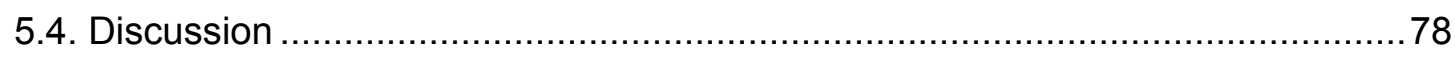

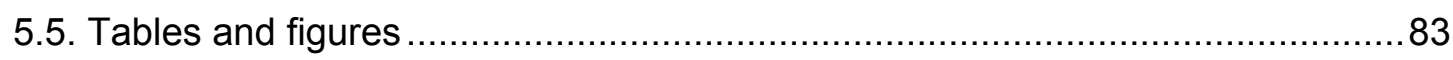


Chapter Six - MC3T3-E1 osteoblasts cultured in serum from post-hibernation bears have higher metabolism than osteoblasts cultured in serum from other seasons

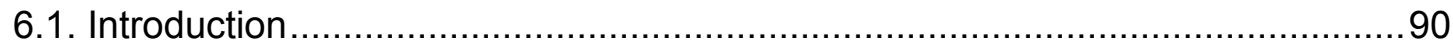

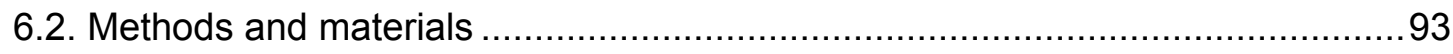

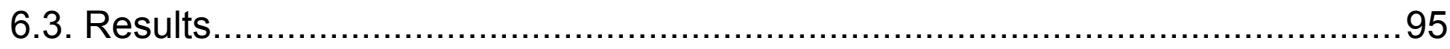

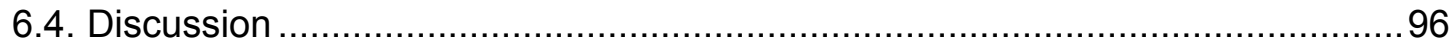

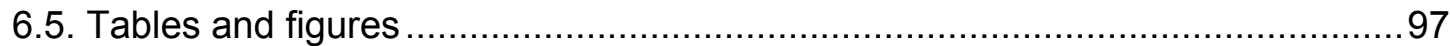

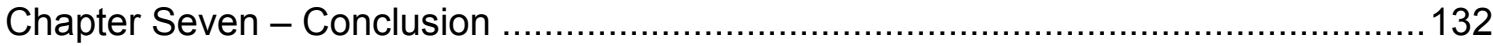

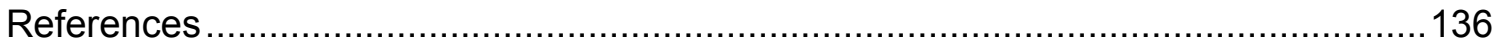

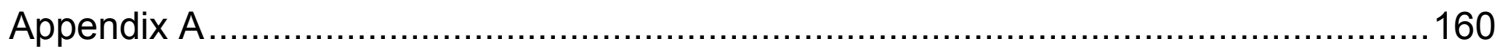




\section{Index of figures}

1.1. Simplified schematic of apoptosis pathways

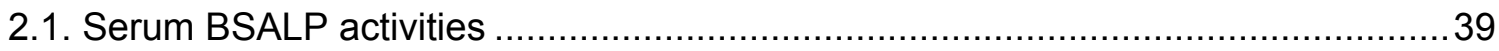

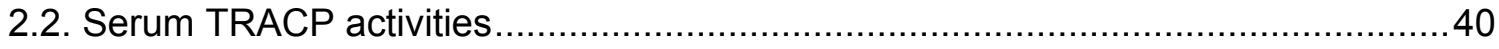

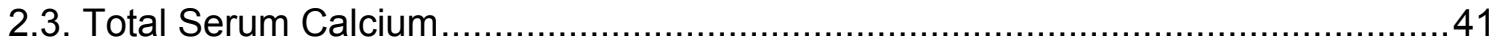

2.4. Serum Ionized Calcium Levels................................................................. 42

2.5. Serum total OCN concentrations ………...................................................... 43

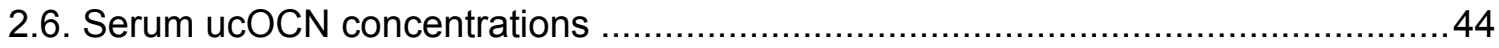

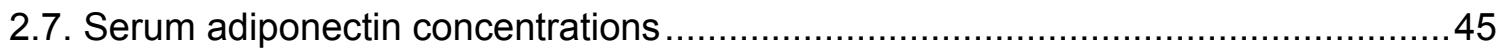

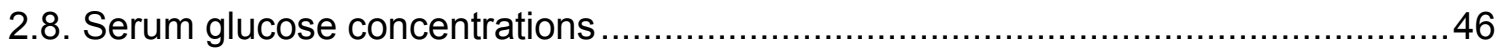

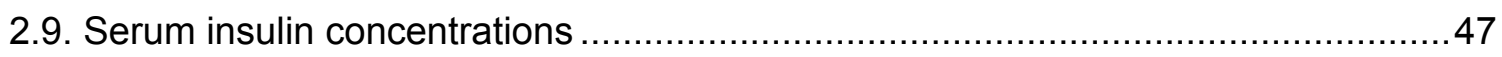

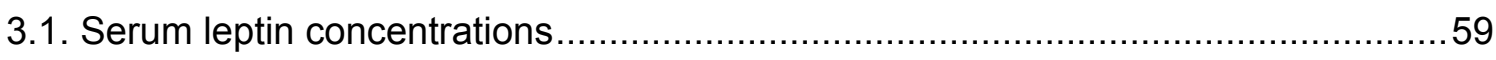

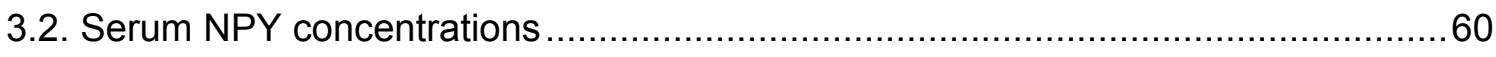

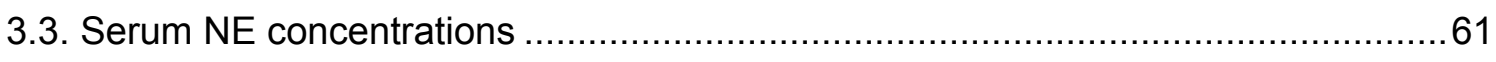

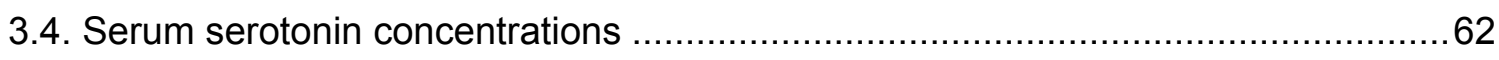

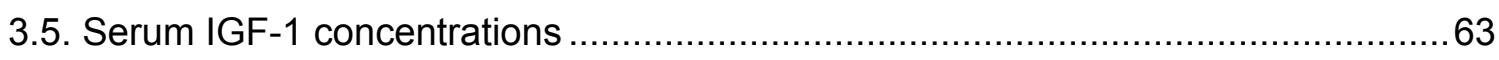

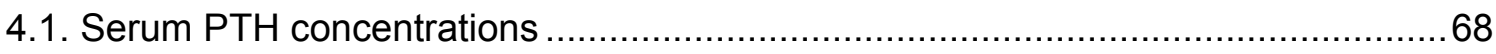

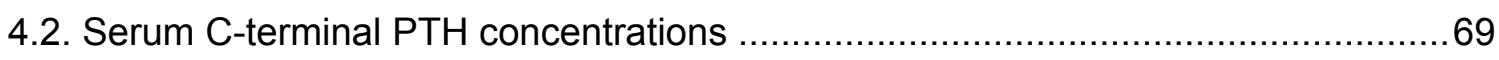

4.3. Serum testosterone concentrations …………......................................... 70

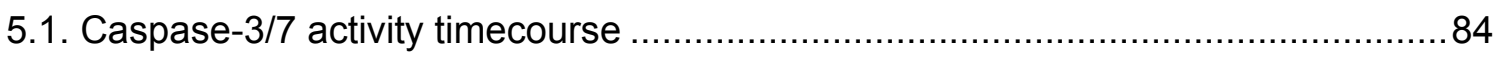

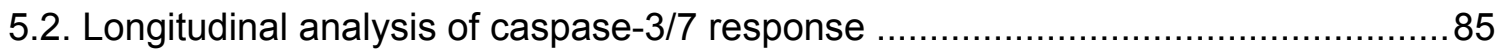

5.3. Caspase- $3 / 7$ activity in cortical bone lysate from hibernating and active bears ...... 85

5.4. Seasonal caspase-3/7 response with 5HT-2B / 5HT-2C inhibitor ..........................86

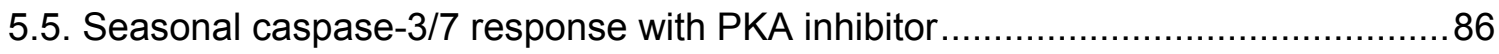

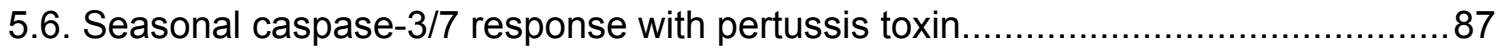

5.7. Seasonal caspase- $3 / 7$ response with 24 hour prime with filtered serum ................88 88

5.8. Seasonal caspase- $3 / 7$ response after 6 hour stimulation in filtered serum .............89 
6.1. Longitudinal analysis of BAD gene expression in undifferentiated cells stimulated for 3 hours in seasonal bear serum ............................................ 102

6.2. Longitudinal analysis of $\mathrm{Bcl}-2$ gene expression in undifferentiated cells stimulated for 3 hours in seasonal bear serum ............................................ 102

6.3. Longitudinal analysis of Cyclin D1 gene expression in undifferentiated cells stimulated for 3 hours in seasonal bear serum .......................................... 103

6.4. Longitudinal analysis of Per1 gene expression in undifferentiated cells stimulated for 3 hours in seasonal bear serum ............................................. 103

6.5. Longitudinal analysis of PTH1R gene expression in undifferentiated cells stimulated for 3 hours in seasonal bear serum .......................................... 104

6.6. Longitudinal analysis of Runx2 gene expression in undifferentiated cells stimulated for 3 hours in seasonal bear serum ............................................... 104

6.7. Longitudinal analysis of Smurf1 gene expression in undifferentiated cells stimulated for 3 hours in seasonal bear serum 105

6.8. Longitudinal analysis of ubiquitin gene expression in undifferentiated cells stimulated for 3 hours in seasonal bear serum 105

6.9. Longitudinal analysis of Akt gene expression in undifferentiated cells stimulated for 3 hours in seasonal bear serum 106

6.10. Longitudinal analysis of BAD gene expression in differentiated cells stimulated for 3 hours in seasonal bear serum 106

6.11. Longitudinal analysis of BAK gene expression in differentiated cells stimulated for 3 hours in seasonal bear serum 107

6.12. Longitudinal analysis of BAX gene expression in differentiated cells stimulated for 3 hours in seasonal bear serum 107

6.13. Longitudinal analysis of $\mathrm{Bcl}-\mathrm{XL}$ gene expression in differentiated cells stimulated for 3 hours in seasonal bear serum 108

6.14. Longitudinal analysis of c-fos gene expression in differentiated cells stimulated for 3 hours in seasonal bear serum 108

6.15. Longitudinal analysis of M-CSF gene expression in differentiated cells stimulated for 3 hours in seasonal bear serum 109

6.16. Longitudinal analysis of OCN gene expression in differentiated cells stimulated for 3 hours in seasonal bear serum 109 
6.17. Longitudinal analysis of OPG gene expression in differentiated cells

stimulated for 3 hours in seasonal bear serum ........................................... 110

6.18. Longitudinal analysis of p53 gene expression in differentiated cells

stimulated for 3 hours in seasonal bear serum ............................................ 110

6.19. Longitudinal analysis of Per1 gene expression in differentiated cells

stimulated for 3 hours in seasonal bear serum ......................................... 111

6.20. Longitudinal analysis of TLR4 gene expression in differentiated cells

stimulated for 3 hours in seasonal bear serum ............................................. 111

6.21. Longitudinal analysis of ubiqutin gene expression in differentiated cells stimulated for 3 hours in seasonal bear serum ......................................... 112

6.22. Longitudinal analysis of $A D R \beta R$ gene expression in undifferentiated cells stimulated for 24 hours in seasonal bear serum

6.23. Longitudinal analysis of Akt gene expression in undifferentiated cells stimulated for 24 hours in seasonal bear serum

6.24. Longitudinal analysis of BAD gene expression in undifferentiated cells stimulated for 24 hours in seasonal bear serum

6.25. Longitudinal analysis of BAK gene expression in undifferentiated cells stimulated for 24 hours in seasonal bear serum

6.26. Longitudinal analysis of BAX gene expression in undifferentiated cells stimulated for 24 hours in seasonal bear serum

6.27. Longitudinal analysis of $\mathrm{Bcl}-2$ gene expression in undifferentiated cells stimulated for 24 hours in seasonal bear serum

6.28. Longitudinal analysis of $\mathrm{Bcl}-\mathrm{XL}$ gene expression in undifferentiated cells stimulated for 24 hours in seasonal bear serum 115

6.29. Longitudinal analysis of Bmall gene expression in undifferentiated cells stimulated for 24 hours in seasonal bear serum 116

6.30. Longitudinal analysis of Coll gene expression in undifferentiated cells stimulated for 24 hours in seasonal bear serum 116

6.31. Longitudinal analysis of Cyclin D1 gene expression in undifferentiated cells stimulated for 24 hours in seasonal bear serum

6.32. Longitudinal analysis of M-CSF gene expression in undifferentiated cells stimulated for 24 hours in seasonal bear serum 
6.33. Longitudinal analysis of OCN gene expression in undifferentiated cells stimulated for 24 hours in seasonal bear serum ....................................... 118

6.34. Longitudinal analysis of OPG gene expression in undifferentiated cells stimulated for 24 hours in seasonal bear serum

6.35. Longitudinal analysis of OPN gene expression in undifferentiated cells stimulated for 24 hours in seasonal bear serum

6.36. Longitudinal analysis of p53 gene expression in undifferentiated cells stimulated for 24 hours in seasonal bear serum

6.37. Longitudinal analysis of Per1 gene expression in undifferentiated cells stimulated for 24 hours in seasonal bear serum

6.38. Longitudinal analysis of Per2 gene expression in undifferentiated cells stimulated for 24 hours in seasonal bear serum

6.39. Longitudinal analysis of PTH1R gene expression in undifferentiated cells stimulated for 24 hours in seasonal bear serum

6.40. Longitudinal analysis of RANKL gene expression in undifferentiated cells stimulated for 24 hours in seasonal bear serum

6.41. Longitudinal analysis of Runx2 gene expression in undifferentiated cells stimulated for 24 hours in seasonal bear serum

6.42. Longitudinal analysis of Smurf1 gene expression in undifferentiated cells stimulated for 24 hours in seasonal bear serum

6.43. Longitudinal analysis of TLR4 gene expression in undifferentiated cells stimulated for 24 hours in seasonal bear serum

6.44. Longitudinal analysis of ubiquitin gene expression in undifferentiated cells stimulated for 24 hours in seasonal bear serum

6.45. Longitudinal analysis of BAD gene expression in cells differentiated for 6 days in seasonal bear serum

6.46. Longitudinal analysis of BAX gene expression in cells differentiated for 6 days in seasonal bear serum

6.47. Longitudinal analysis of Bcl-2 gene expression in cells differentiated for 6 days in seasonal bear serum 125

6.48. Longitudinal analysis of c-fos gene expression in cells differentiated for 6 days in seasonal bear serum 125 
6.49. Longitudinal analysis of Coll gene expression in cells differentiated for 6 days in seasonal bear serum .....

6.50. Longitudinal analysis of Cyclin D1 gene expression in cells differentiated for 6 days in seasonal bear serum. 126

6.51. Longitudinal analysis of OCN gene expression in cells differentiated for 6 days in seasonal bear serum .....

6.52. Longitudinal analysis of OPG gene expression in cells differentiated for 6 days in seasonal bear serum ....

6.53. Longitudinal analysis of OPN gene expression in cells differentiated for 6 days in seasonal bear serum .....

6.54. Longitudinal analysis of Per1 gene expression in cells differentiated for 6 days in seasonal bear serum .....

6.55. Longitudinal analysis of PTH1R gene expression in cells differentiated for 6 days in seasonal bear serum .....

6.56. Longitudinal analysis of RANKL gene expression in cells differentiated for 6 days in seasonal bear serum .....

6.57. Longitudinal analysis of Runx2 gene expression in cells differentiated for 6 days in seasonal bear serum .....

6.58. Longitudinal analysis of Smurf1 gene expression in cells differentiated for 6 days in seasonal bear serum .....

6.59. Longitudinal analysis of TLR4 gene expression in cells differentiated for 6 days in seasonal bear serum

6.60. Longitudinal analysis of ubiquitin gene expression in cells differentiated for 6 days in seasonal bear serum 


\section{Index of tables}

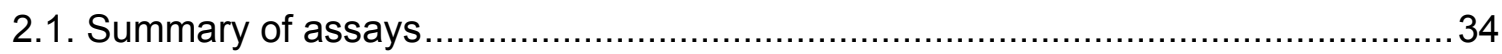

2.2. Bone marker longitudinal "peak-valley" analyses.................................................. 34

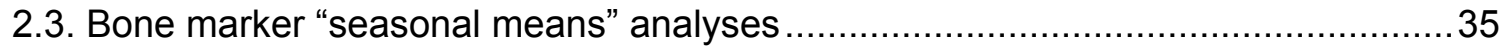

2.4. Energy homeostasis longitudinal "peak-valley" analyses........................................ 35

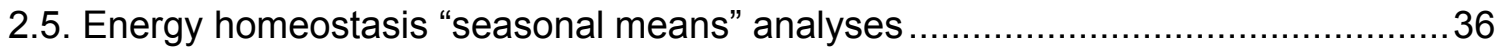

2.6. Chemistry panel longitudinal "peak-valley" analyses …….................................... 36

2.7. Chemistry panel "seasonal means" analyses .................................................... 37

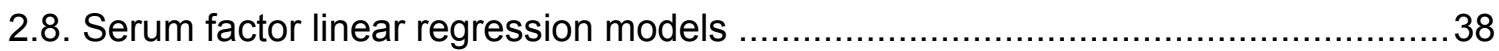

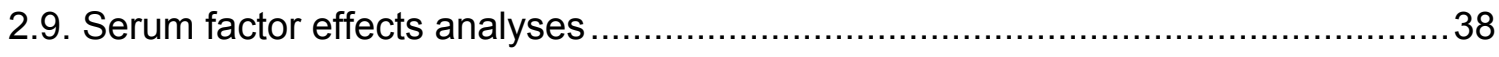

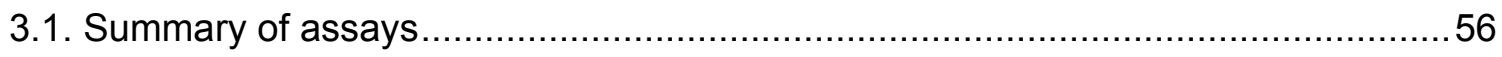

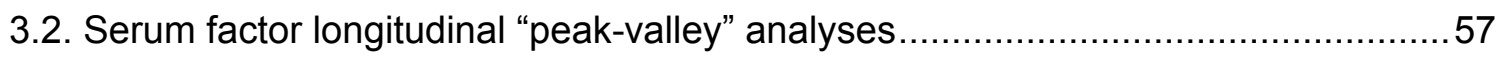

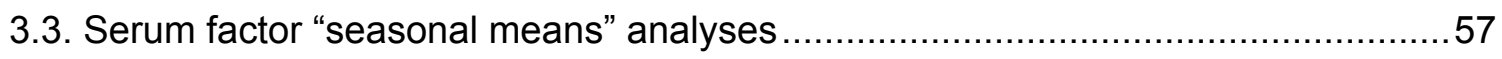

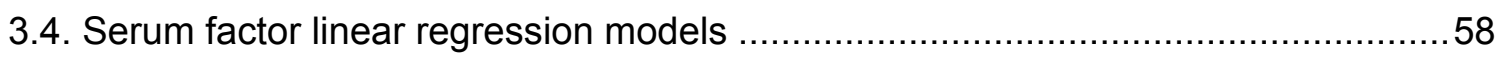

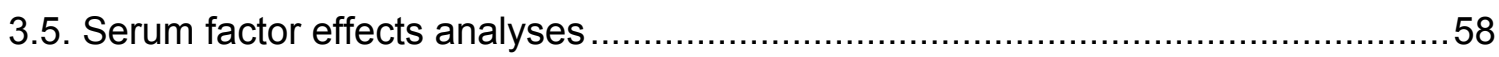

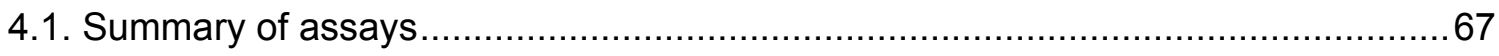

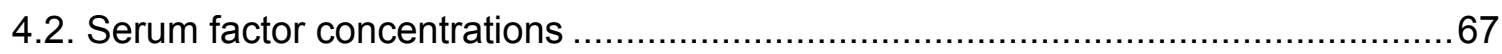

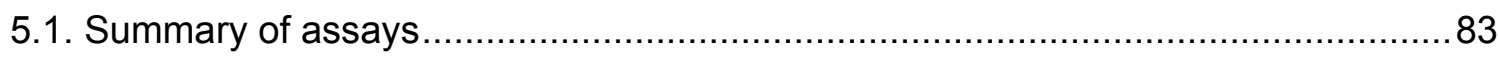

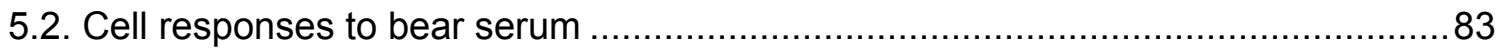

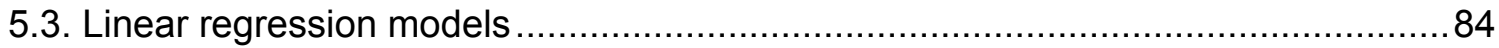

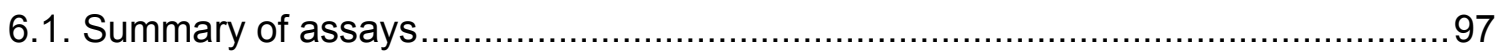

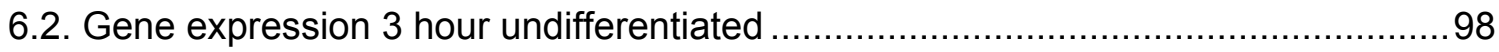

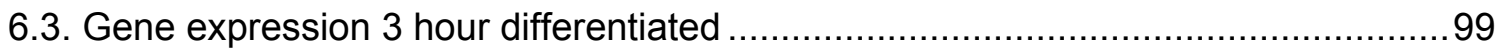

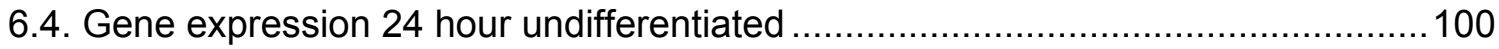

6.5. Gene expression 6 day differentiated ............................................................ 101

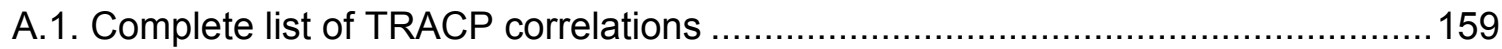




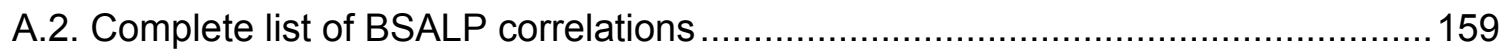

A.3. Complete list of total ALP correlations .................................................... 160

A.4. Complete list of total calcium correlations ................................................. 160

A.5. Complete list of ionized calcium correlations ............................................... 161

A.6. Complete list of osteocalcin correlations ..................................................... 162

A.7. Complete list of adiponectin correlations ................................................. 163

A.8. Complete list of glucose correlations ..................................................... 163

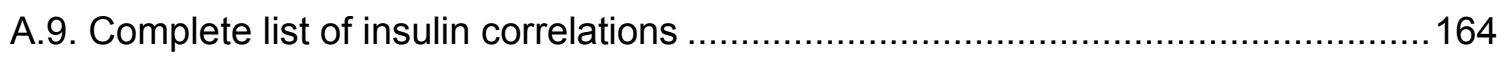

A.10. Complete list of leptin and IGF-1 correlations.......................................... 164

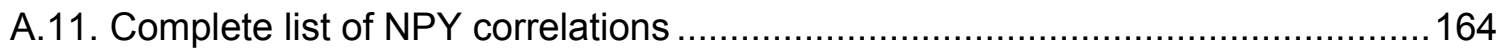

A.12. Complete list of norepinephrine correlations ........................................... 165

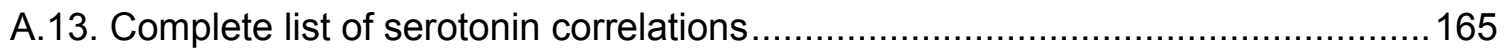

A.14. Complete list of caspase-3/7 correlations ................................................. 166 


\section{Acknowledgements}

This work would not have been possible without the dedicated mentorship of my advisor Seth Donahue, who challenges his students but knows when to back down, too. As I told more than one faculty member at Tech, Seth's students work so hard because he's just so....nice. Yeah, I don't understand it either. I would also like to thank my committee members Hannah Carey, Jeremy Goldman, and Megan Frost who provided helpful advice throughout my time at Michigan Tech. Hannah Carey was especially kind in inviting me on her safari trip in Namibia when we were there for the IHS conference in 2008. Rupak Rajachar and Ryan Gilbert also gave me invaluable advice throughout my time at Michigan Tech, and listened to me pontificate on more than one occasion. I appreciate the time they spent with me. Sarah Gray and David Heiden, a.k.a. Team BS, were my personal undergraduate servants and spent many an hour following my nitpicky instructions on experimental ideas. Often, my ideas didn't work out...but, hey, that's science-right guys? l'd like to thank Team BS for all the help they gave me on my project. And, of course, how would I have managed 4 years at Michigan Tech without my friends in the Bone Lab (especially Sam Wojda, Matt Barron, Meghan McGee-Lawrence, Ashley Shultz, and Team BS) and the other grad students in the department (especially Laura Walz, Melissa Roberts, Katie Snyder, Eric Minner, and Chris Rivet). Most importantly, I wouldn't even have come to Michigan Tech had my dad not offered to loan me the money to pay off my car. So I need to give my parents an extra special thanks. How much do I owe you again? 


\section{List of abbreviations}

$\alpha-M E M$. Alpha-modified Eagle's Medium

ADRß2. Beta-2 adrenergic receptor

ALP. Alkaline phosphatase

ALT. Alanine transaminase

ANOVA. Analysis of variance

AP-1. Activator protein 1

Apaf-1. Apoptosis protease activating factor-1

AST. Aspartate aminotransferase

BAD. Bcl-2-associated death promoter

BAK. Bcl-2 homologous antagonist/killer

BAX. Bcl-2-associated X protein

Bcl-2. B-cell/Lymphoma-2

Bcl-XL. B-cell lymphoma-extra large

BFR. Bone formation rate

Bmal1. Brain and muscle aryl hydrocarbon receptor nuclear translocator (ARNT)-like

BMD. Bone mineral density

BSALP. Bone specific alkaline phosphatase

BUN. Blood urea nitrogen 
Coll. Collagen I

Crn. Creatinine

CTX. Crosslinked carboxyterminal telopeptide of type I collagen

DNA. Deoxyribonucleic acid

DMSO. Dimethylsulfoxide

ELISA. Enzyme-linked immunosorbent assay

EtBr. Ethidium bromide

FBS. Fetal bovine serum

G1 \& G2. Gap 1 and 2

ICTP. Carboxy-terminal cross-linked telopeptide of type I procollagen

IGF-1. Insulin-like growth factor 1

LSM. Least square mean

M-CSF. Macrophage colony stimulating factor

MEKK2. Mitogen activated protein kinase kinase kinase 2

NE. Norepinephrine

NPY. Neuropeptide Y

OCN. Osteocalcin

OPG. Osteoprotegerin

OPN. Osteopontin

p53. Protein 53 
PCR. Polymerase chain reaction

Per1 \& 2. Period 1 and 2

PICP. Carboxy-terminal of propeptide of type I procollagen

PKA. Protein kinase A

PTH. Parathyroid hormone

PTH1R. PTH receptor 1

RANKL. Receptor activator of NFא-B ligand

RIA. Radioimmunoassay

RNA. Ribonucleic acid

RQ. Respiratory quotient

Runx2. Runt-related transcription factor 2 (a.k.a Cbfa1)

SE. Standard error

Smad1. Mothers against decapentaplegic homolog 1

Smurf1. Smad ubiquitin regulatory factor 1

TLR4. Toll-like receptor 4

TRACP. Tartrate-resistant acid phosphatase

TUNEL. Terminal deoxynucleotidyl transferase dUTP nick end labeling

ucOCN. Undercarboxylated osteocalcin

WGL. Wheat germ lectin 


\section{Definitions}

Adiponectin. An energy homeostasis hormone which regulates fat metabolism and suppresses bone turnover.

ADR 32 . The adrenergic receptor (responds to NE).

Akt. Pro-survival gene.

BAD. Pro-apoptotic member of the Bcl-2 family of apoptosis regulators.

BAK. Pro-apoptotic member of the Bcl-2 family of apoptosis regulators.

BAX. Pro-apoptotic member of the Bcl-2 family of apoptosis regulators.

Bcl-2. Anti-apoptotic member of the Bcl-2 family of apoptosis regulators.

Bcl-XL. Anti-apoptotic member of the Bcl-2 family of apoptosis regulators.

Bmal1. A circadian rhythm (clock) transcription factor.

BSALP. A marker of bone formation.

Caspase. A family of cysteine proteases which are effectors of the apoptotic cascade.

c-fos. A transcription factor in the AP-1 family. It acts as a key regulator in bone development and differentiation.

Coll. A bone matrix protein produced by osteoblasts.

CTX. A serum marker of bone resorption.

Cyclin D1. A cell cycle regulator which promotes transition past the G1/S checkpoint.

Decad. A group of 10 days.

G1 \& G2. The gap phases of the cell cycle. 
G2/M checkpoint. The point in the cell cycle in which certain conditions must be met in order to switch from the gap to the mitosis phase of the cell cycle.

G1/S checkpoint. The point in the cell cycle in which certain conditions must be met in order to switch from the gap to the synthesis phase of the cell cycle.

ICTP. A serum marker of bone resorption.

IGF-1. A hormone which promotes bone turnover, favoring bone formation.

Insulin. An energy homeostasis hormone which stimulates glucose uptake.

Leptin. An energy homeostasis hormone secreted by white adipose tissue as a signal to reduce fat mass. At normal physiological levels, it has an anabolic effect on bone.

MC3T3-E1. An immortalized cell line of osteoblast-like cells.

M-CSF. A pro-resorptive cytokine which promotes osteoclastogenesis.

Melatonin. A circadian rhythm hormone which has an anti-apoptotic effect on osteoblasts.

NE. A monoamine neurotransmitter which has a catabolic effect on bone.

NPY. An energy homeostasis hormone which suppresses turnover in bone.

OCN. A marker of bone formation and an energy homeostasis hormone.

OPG. This protein acts as a decoy receptor for RANKL, thus suppressing osteoclast activation and bone resorption.

OPN. A bone matrix protein produced by osteoblasts.

Osteoclast. The cell type which resorbs bone.

Osteocyte. The cell type which maintains bone and senses mechanical stimulus.

Osteoblast. The cell type which forms bone. 
p53. A tumor suppressor gene. Promotes cell cycle arrest and apoptosis.

Per1 \& Per2. Circadian rhythm transcription factors.

PICP. A serum marker of bone formation.

PTH. A calcium homeostasis hormone which can have an anti-apoptotic effect on osteoblasts and osteocytes.

PTH1R. The PTH receptor.

RANKL. A pro-resorptive cytokine which promotes osteoclast activation.

Runx2. A transcription factor which promotes osteoblast differentiation.

Serotonin. A monoamine neurotransmitter which has conflicting effects on bone. It is generally thought to increase bone turnover and favor bone catabolism.

Smurf1. A ubiquitin E3 ligase which regulates osteoblast differentiation and apoptosis.

Testosterone. A steroid hormone which has a pro-apoptotic effect on osteoblasts.

TLR4. A cell-surface receptor which has pro-resorptive effects on bone.

TRACP. A serum marker of osteoclast number.

TUNEL stain. A nick-end labeling technique which is often used to stain apoptotic cells.

Ubiquitin. A small protein which is used by cells as a tag for proteolysis. 


\section{Species names}

13-lined ground squirrel. Ictidomys tridecemlineatus

American black bear. Ursus americanus

Blue fox. Alopex lagopus

Edible frog. Rana esculenta

European brown bear. Ursus arctos arctos

Golden hamster. Mesocricetus auratus

Golden-mantled ground squirrel. Callospermophilus lateralis

Grizzly bear. Ursus arctos horribilis

Japanese black bear. Ursus thibetanus japonicus

Little brown bat. Myotis lucifugus

Raccoon dog. Nyctereutes procyonoides

Woodchuck. Marmota monax

Yellow-bellied marmot. Marmota flaiventris 


\begin{abstract}
Disuse osteoporosis is a condition in which reduced mechanical loading (e.g. bed-rest, immobilization, or paralysis) results in unbalanced bone turnover. The American black bear is a unique, naturally occurring model for the prevention of disuse osteoporosis. Bears remain mostly inactive for up to half a year of hibernation annually, yet they do not lose bone mechanical strength or structural properties throughout hibernation. The long-term goal of this study is to determine the biological mechanism through which bears maintain bone during hibernation. This mechanism could pinpoint new signaling pathway targets for the development of drugs for osteoporosis prevention. In this study, bone specific alkaline phosphatase (BSALP), a marker of osteoblast activity, and tartrate resistant acid phosphatase (TRACP), a marker of osteoclast number, were quantified in the serum of hibernating and active black bears. BSALP and TRACP decreased during hibernation, suggesting a balanced reduction in bone turnover. This decrease in BSALP and TRACP were correlated positively to serum adiponectin and inversely to serum neuropeptide $Y$, suggesting a possible role of these hormones in suppressing bone turnover during hibernation. Osteocalcin (OCN) and undercarboxylated $\mathrm{OCN}$ increased dramatically in the serum of hibernating bears. These increases were inversely correlated with adiponectin, glucose, and serotonin, suggesting that $\mathrm{OCN}$ may have a unique role in energy homeostasis during hibernation. Finally, MC3T3-E1 osteoblasts were cultured in the serum from active and hibernating bears, and seasonal cell responses were quantified. Cells cultured in serum from hibernating bears had a reduced caspase-3/7 response, and more living cells, after apoptotic threat. The caspase-3/7 response was positively correlated to serum adiponectin and to gene expression of OCN and Runx2, suggesting that reduced caspase-3/7 activity may be related to the reduced differentiation potential of osteoblasts in hibernation serum, and that adiponectin is a potential effector hormone. In summary, the activities of osteoblasts and osteoclasts are reduced during hibernation in bears. This reduced turnover is due, in part, to hormonal control. Further study of potential effectors adiponectin and neuropeptide $\mathrm{Y}$ may provide insight into the biological mechanism through which bears maintain bone throughout hibernation.
\end{abstract}




\section{Chapter One - Background and significance}

\subsection{Problem description/significance}

Disuse osteoporosis is an increasingly common condition in which reduced mechanical loading leads to degradation of bone tissue and increased bone fragility. The risk of low-impact fracture, especially in the hip, spine, and wrist increases. This disease state is a risk for the elderly (who have reduced activity due to exhaustion), victims of stroke or spinal cord injury, and cosmonauts exposed to microgravity-as has been recently reviewed [1-3]. According to the 2004 Surgeon General's report on bone health and osteoporosis, there are 1.5 million osteoporosis-related fractures annually, including over 700,000 vertebral fractures. Such fractures severely diminish the patient's quality of life, as well as soaking up potential wages and increasing medical expenditures. An estimated \$18 billion (in 2002 dollars) are spent annually on direct medical care for osteoporotic fractures. There are several anti-resorptive treatments available, although these come with possible side effects such as osteonecrosis of the jaw for bisphosphonates, and cardiovascular disease and cognitive impairment for hormone therapy [4-9]. There is one FDA-approved anabolic drug for osteoporosis (Forteo, Eli Lilly, Indianapolis, IN), but it is cost-restrictive and approved for only 18 months of use; it is therefore limited in long-term efficacy [10-12]. The development of new anabolic treatments for osteoporosis would benefit society by boosting quality of life and reducing medical expenditures.

The goal of this study is to use a naturally occurring model for preventing disuse osteoporosis to pinpoint new drug targets for osteoporosis therapy. Black bears (Ursus americanus) provide such a model. In Northern climates, black bears undergo annual periods of disuse (i.e. hibernation) and activity that are approximately equal in length [13]. In humans and other animals, such a cycle would result in an annual deficit in bone mass since bone must be reloaded for more than two times the length of unloading to fully regain its mechanical properties $[1,14,15]$. However, black bears maintain cortical bone mineral and structural integrity with age [16, 17]. Additionally, trabecular and cortical bone are unchanged during hibernation in bears [18-21]. Thus, bears must 
have evolved a mechanism to prevent bone loss during hibernation. This study will explore the cellular mechanism behind bone maintenance in hibernating bears.

\subsection{Basics of bone remodeling}

Bone is a dynamic organ which responds to a complex array of endocrine, neural, and mechanosensory stimulation by adapting its structure metabolically $[22,23]$. The skeleton simultaneously serves two competing functions. Its first function is to protect the internal organs and serve as a lever arm for locomotion. Bone must therefore be strong and stiff, and it must respond to mechanical loading by remodeling its structure. Its second function is as a reservoir for minerals such as calcium, phosphorus, and magnesium. When serum levels decrease, bone must release these minerals by breaking down (and therefore weakening) its structural integrity. Bone is therefore subject to continuous remodeling such that most of the adult skeleton is recycled every 10 years. This remodeling is under the intricate control of three basic cell types. Osteoblasts are the bone forming cells. They are derived from mesenchymal stem cells located in the bone marrow. Following breakdown of bone, osteoblasts line the surface of the resorption cavity and begin pumping out new organic matrix and proteins which promote mineralization. As new bone is formed, some osteoblasts are trapped inside the matrix. These cells terminally differentiate into osteocytes, which form long cytoplasmic processes connecting these cells to other osteocytes, osteoblasts, and bone lining cells [24]. These processes serve a mechanosensory function in bone [25]. The remaining osteoblasts either undergo apoptosis or become quiescent bone lining cells, which form a barrier between the bone surface and osteoclasts. Upon activation of resorption, bone lining cells retreat from the bone surface, leaving an unprotected surface for osteoclast attachment [26]. Osteoclasts serve as the bone macrophage. Upon signaling from osteoblasts and osteocytes, hematopoietic stem cells terminally differentiate into multinucleated osteoclasts, which tightly glom to naked bone surfaces, creating a quarantined resorption cavity [27]. The osteoclast then releases acid and proteases which disintegrate the mineral and cleave the organic matrix [28]. This process is referred to as the activation and resorption phases of bone remodeling. It is followed by the reversal and formation phases [29]. Bone resorption and formation are thus coupled, ensuring that wherever bone is resorbed, new bone replaces it [30]. 


\subsection{Bone turnover is unbalanced during disuse}

Like muscle, bone hails from a "use-it-or-lose-it" philosophy. Bone which is being mechanically loaded by normal daily activities undergoes basal levels of remodelingmostly for mineral homeostasis and repair of normal fatigue microcracks. However, if the bone is unloaded by immobilization or low gravity, the mechanosensory osteocytes sense that the bone is no longer necessary and they signal the other cell types to begin activation of resorption [22, 25]. An uncoupling of resorption to formation is the result. Bone is broken down more rapidly than it is formed, leading to a net loss. This uncoupling can be observed in serum resorption and formation markers in astronauts, and in victims of stroke and spinal cord injury [31-33]. In contrast, serum resorption and formation markers show that osteoclast and osteoblast activities remain balanced during hibernation in black bears [34]. Furthermore, histological data demonstrates balanced bone remodeling in black bears and in grizzly bears (Ursus arctos horribilis) [18, 20, 21, 35]. Thus, bears may conserve bone integrity during hibernation by maintaining balanced bone resorption and formation. This balance in remodeling is likely driven by the bear's need to preserve homeostatic serum calcium. In most cases of disuse, calcium mobilized by the breakdown of bone is excreted in the urine [36]. Bears do not consume calcium, and do not excrete wastes during hibernation; however, serum calcium levels remain constant throughout the year, suggesting that any calcium released by bone resorption must be returned to mineralized bone by balanced formation [35].

\subsection{Osteoblast and osteocyte apoptosis results in bone loss}

Current theories suggest that the decoupling of resorption to formation during disuse may be due to increased osteoblast and osteocyte apoptosis [37]. According to the Canalicular Fluid Flow hypothesis, bone can be thought of as a sponge filled with extracellular fluid. The pores of the sponge are formed by the canals and lacunae housing osteocytes and their processes. When a bone is loaded (i.e. taking a step), the fluid is pushed out of the bone by a slight deformation. Upon unloading (picking the foot back up again) the fluid returns to the pores. This cyclic loading and unloading applies a 
fluid shear on the osteocytes stimulating mechanosensory receptors [25]. The convective fluid flow also provides nutrients to the cells. When an osteocyte no longer senses cyclic loading, it undergoes apoptosis due to nutrient starvation and lack of mechanical stimulation [22, 37, 38]. The apoptotic osteocytes initiate the osteoclastic resorption of bone, probably through a pro-resorptive signaling cascade involving TNF- $\alpha[39,40]$. In addition to stimulating osteoclast activation through osteocytic apoptotic signaling, disuse may also induce osteoblast apoptosis, reducing the population of bone forming cells. With fewer osteoblasts, the bone cannot be reformed as efficiently, leading to an uncoupling of resorption and formation. Before thoroughly discussing the roles of osteocyte and osteoblast apoptosis in disuse-induced bone loss, it is necessary to review some key apoptosis regulatory pathways in this family of cells.

\subsubsection{Review of apoptosis mechanisms in osteoblasts}

Apoptosis is a form of genetically programmed cellular suicide in which damaged or unneeded cells are removed from tissue, as reviewed recently [41]. The apoptotic cascade is mediated by the activation of zymogens from the caspase family of cysteine proteases. Caspase activity is closely regulated by the B-cell/Lymphoma-2 (Bcl-2) family of proteins including pro-apoptotic BAX and BAD; as well as anti-apoptotic Bcl-XL and $\mathrm{Bcl}-2$. In the osteoblast, apoptosis can occur through two different pathways (Figure 1.1). The intrinsic pathway is initiated by damage to the DNA or an organelle. Following such damage, the transcription factor p53 is activated-resulting in a halt in the G1 phase of the cell cycle, which allows time for the cell to repair itself. If repair is unsuccessful, p53 up-regulates gene expression of BAX and down-regulates Bcl-2 [41]. BAX mediates the release of cytochrome $C$ from the mitochondria by permeabilizing the mitochondrial membrane and releasing cytochrome $\mathrm{C}$ monomers. These monomers then bind apoptosis protease activating factor-1 (Apaf-1) and caspase- 9 monomers forming a gigantic ( $1 \mathrm{MDa}$ ) oligomeric complex called an apoptosome, or "the wheel of death" [42]. This complex activates effector caspases by zymogen cleavage. The extrinsic pathway involves stimulation of a death receptor (or perhaps, in the case of disuse, lack of stimulation of a mechanosensory receptor). Stimulation of the death receptor results in activation of caspase- 8 which then activates effector caspases- 3 and -7 . Separately, caspase-8 also interacts with the intrinsic pathway by indirectly activating 
pro-apoptosis regulator BAX. An important trait of the Bcl-2 family is its ability to form heterodimers. Due to dimerization, the ratio of anti-apoptotic monomers to pro-apoptotic monomers can tip the balance from a healthy to an apoptotic cell $[43,44]$. In this way, there is additional regulation of the intrinsic pathway by anti-apoptotic $\mathrm{Bcl}-2$ and $\mathrm{Bcl}-\mathrm{XL}$, which can bind to and neutralize BAX. In turn, pro-apoptotic BAD can bind to and neutralize Bcl-XL and Bcl-2.

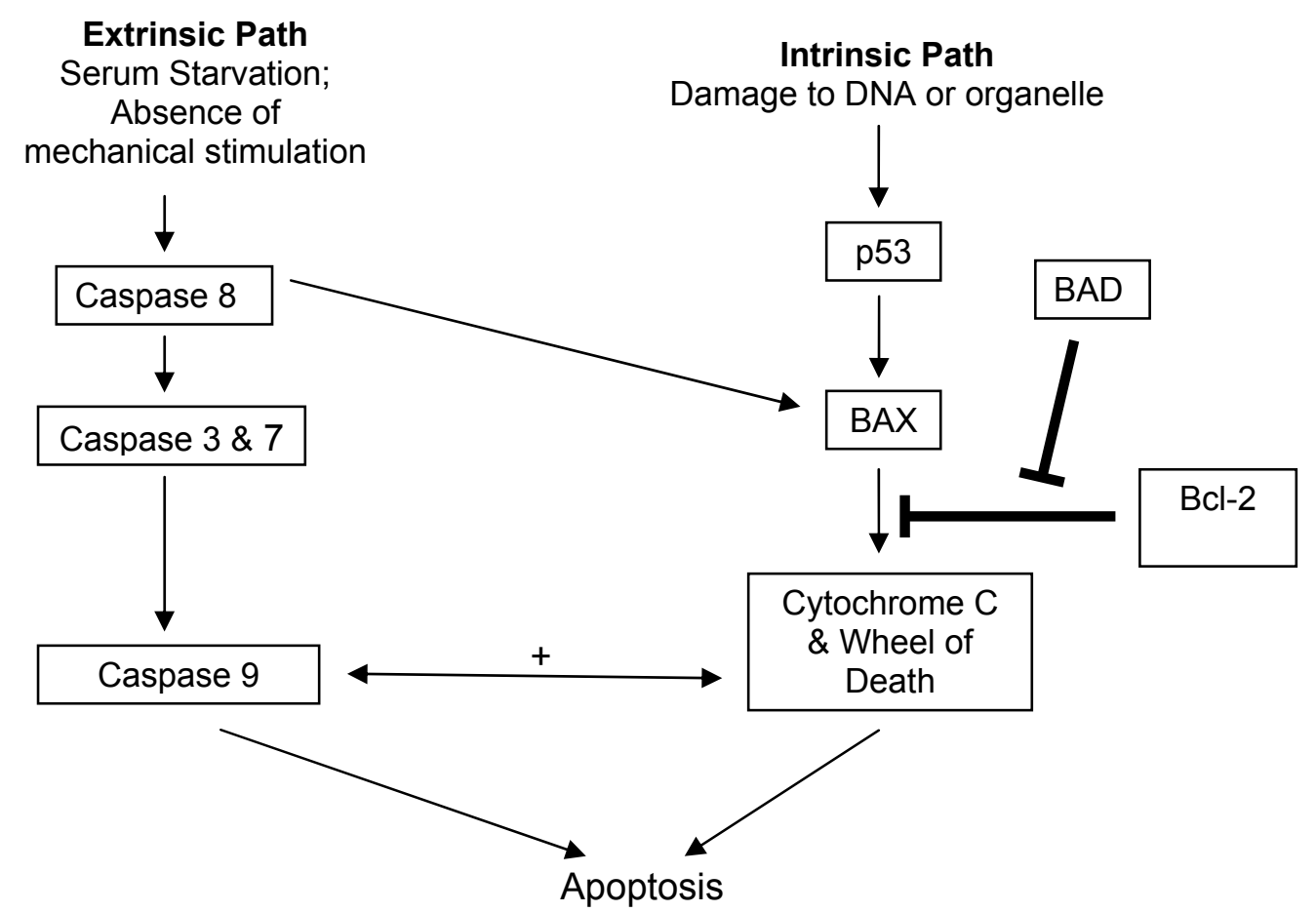

Figure 1.1-Simplified schematic of the apoptosis pathways Induction of osteocyte apoptosis due to disuse could be initiated through the extrinsic pathway (reduced stimulation of mechanosensors), or the intrinsic pathway (organelle damage due to reduced blood flow and free-radical formation). There is also cross-talk between the two pathways. The arrows represent stimulation of a pathway, the bar-dash represent inhibition of a pathway. Information compiled from: [1-3].

Apoptosis can be quantified by several means. Gene and protein expression of various early-stage apoptosis regulators such as Bcl-2 family members are commonly measured, though a change in these regulators does not necessarily translate to a comparable change in apoptosis rates. The protease activity of effector caspases-3, -6 and -7 are often quantified, as activation of these late-stage apoptosis regulators is a better indication of the cell's eventual demise. Another common technique is to quantify 
DNA damage due to nuclease cleavage. Nick-end labeling techniques such as TUNEL will label the naked 3'-OH in breaks created by nuclease activity, though this technique can incorrectly label cells with DNA damage destined for repair [45, 46]. It is also possible to use gel electrophoresis or ELISA techniques to quantify a later state of DNA digestion, "DNA laddering." By this stage, nucleases have broken down DNA systematically at linker sites between histones, creating monomers, dimers, and trimers of DNA/histone chunks. The cell's DNA is irrevocably digested and this is a suitable endpoint indicating definite cell apoptosis. Also, in cell culture, percent cell death can be quantified by means of calcein and ethidium bromide (EtBr) uptake (or a similar method), although this technique counts necrotic cells as well as apoptotic cells under the same category-dead.

\subsubsection{Apoptosis precedes disuse-induced bone loss}

As stated earlier, evidence suggests that apoptotic osteocytes promote the differentiation of osteoclasts, leading to targeted resorption in the areas surrounding the apoptotic osteocytes. A study in rabbit tibiae demonstrates a positive correlation between osteocyte apoptosis and serum resorption markers, but no correlation with formation markers, suggesting that increased osteocyte apoptosis could result in uncoupled remodeling and net bone resorption [47].

The mouse/rat hind-limb unloading model demonstrates that disuse-induced bone loss is preceded by osteocyte apoptosis, and that osteoblast apoptosis is also present [48-51]. In hind-limb unloaded mice, this increase in apoptosis could be due to higher gene expression of p53 in femoral bone marrow [52]. Hind-limb unloaded wildtype mice lose $45 \%$ of their tibial bone volume and have significantly reduced bone formation rate (BFR) and increased osteoclast number compared to ground controls; whereas genetically similar p53 knockout mice show no significant changes in these variables [53]. In hind-limb unloaded rats, an observed increase in osteoblast and osteocyte apoptosis is likely due to a decrease in protein levels of $\mathrm{Bcl}-2$ with unchanged Bax levels in the femur metaphysis; furthermore, apoptotic cell numbers in these rats are not correlated to endogenous glucocorticoids, suggesting an alternative mechanism for apoptotic induction may be responsible [54]. Attenuation of apoptosis by intermittent, 
low-dose administration of parathyroid hormone (PTH) lengthens the lifetime of mature osteoblasts, thus increasing BFR and bone mineral density (BMD) of the spine and hindlimbs of mice $[49,55]$. Low-dose, intermittent administration of PTH abates bone loss in hind-limb suspended mice [56]. Additionally, attenuation of apoptosis by administration of sex steroids or melatonin abates bone loss in ovariectomized rats [57, 58], indicating osteoblast and osteocyte apoptosis may play a key role in bone loss due to estrogen deficiency as well.

Together, these results suggest that disuse-induced osteocyte and osteoblast apoptosis leads to an uncoupling of bone formation and resorption leading to net bone loss, and that this mechanism can be controlled by hormones. Administration of antiapoptotic hormones can counteract the pro-apoptotic signaling from disuse, thus enabling balanced bone formation and resorption. Similarly, if apoptosis of bone cells were inhibited during hibernation in bears, formation and resorption would remain coupled, resulting in balanced bone turnover, as observed in grizzly bears [20]. It is possible that bears maintain balanced bone turnover during hibernation by upregulating anti-apoptotic serum factors (or by down-regulating pro-apoptotic factors), thus decreasing osteoblast and osteocyte apoptosis. This study quantified serum concentrations of several bone-active hormones and explored the anti-apoptotic potential of seasonal bear serum on an osteoblast cell line.

In contrast to hind-limb unloading models, simulated microgravity does not induce osteoblast apoptosis, although bone mass is lost during space flight due to an increase in bone resorption with a decrease in bone formation [31, 59]. Human primary osteoblasts, mouse primary osteoblasts, and the immortalized pre-osteoblast cell line MC3T3-E1 do not undergo apoptosis when cultured in simulated microgravity compared to static controls [60-62]. Thus, microgravity appears to be a unique form of disuse, and care must be taken not to generalize between the different forms of disuse osteoporosis.

\subsection{Disuse in humans}

Osteopenia due to reduced mechanical loading occurs in a variety of clinical situations and can therefore be a threat to anybody, regardless of age and current 
activity level. As much as 6-32 months following anterior cruciate ligament surgery, the BMD of the involved hip can be 3.4-6.6\% lower than in the unaffected hip [63]. Patients confined to bed-rest can lose $4 \%$ of hip BMD after 60 days of bed-rest [64]. When confined for up to 90 days in bed, patients lose approximately $1 \%$ BMD in the hip per month of confinement [65]. Military personnel can also be at risk. Turkish armed forces who suffered transtibial amputations from land-mine injuries have reduced BMD in the remaining amputated limb compared to the non-amputated limb [66]. This reduction in BMD not only increases the chance of fracture, but also may be one cause of residual limb pain. After 30 days of submersion in submarines, the bone strength (measured by speed of sound) of submariners' right tibias decreased significantly, accompanied by a decrease in bone formation and resorption serum markers; bone strength continued to decrease through the first month of return to land and was fully restored after 6 months [67]. After 4-14 months of spaceflight, cosmonauts can lose 0.34-1.56\% BMD per month in various loaded bones such as the hip, leg, and spine [1]. Finally, loss of bone due to disuse can also occur after a stroke or a spinal cord injury. In patients suffering from a paretic arm more than 1 year after a stroke, the BMD, bone cortical mineral density, cortical thickness, and bone strength of the distal and midshaft radius are significantly reduced in the paretic arms compared to the mobile arms [68, 69]. Within 71 weeks following spinal cord injury, patients lose $15 \%$ of BMD in the pelvis and lower limbs [70]. The fracture risk of patients with spinal cord injury increases with the degree of motor impairment [71, 72].

\subsection{Disuse in non-hibernating animals}

Reduced bone strength and mineralization under conditions of disuse seems universal among the animal kingdom, with the exception of some hibernating animals. In birds, disuse osteopenia has been reported in turkey, chicken, pigeon, and cockatiel [73-78]. After four weeks of unloading, the ulnae of turkeys lose $12 \%$ of cortical area, with decreased cortical thickness and increased porosity compared to normally loaded controls [73]. Two weeks of unloading lead to a $50 \%$ reduction in bone mineral content and a $40 \%$ reduction in structural strength of chicken tibiae [76]. The calcanei of sheep immobilized from the tibia to the metatarsus for 12 weeks experience an 18-29\% decrease in trabecular bone volume compared to the non-immobilized limb [79, 80]. A 
decrease in bone trabecular thickness in this model is due to an unbalanced increase in osteoclast and osteoblast activity, leading to net bone resorption [81]. The metacarpus III of horses lose $10 \%$ of BMD after 140 days of forelimb immobilization; this loss is accompanied by an increase in the serum resorption marker crosslinked carboxyterminal telopeptide of type I collagen (CTX) with no change in the bone formation marker bone specific alkaline phosphatase (BSALP), suggesting that the loss in BMD is due to an increase in bone resorption with no change in the formation rate [82]. Cats and dogs are also vulnerable to disuse osteoporosis [14, 83-85]. The immobilized humeri of dogs have significantly reduced $\mathrm{BMD}$ as well as a $71-98 \%$ decrease in cortical strength and a 28-74\% decrease in trabecular strength than the contra-lateral humeri after 16 weeks of left forelimb immobilization [14]. There is also a wealth of studies which quantify bone loss in more common laboratory animals such as non-human primates [86-89], rats [90-98], and mice [48, 99-102]. It is very well established that most animals lose bone when subjected to periods of reduced mobility, so it is exciting to study an animal like the hibernating bear, which can undergo months of disuse without losing bone.

\subsection{Hibernation as a model of disuse}

Hibernation is a state of greatly reduced physical activity and bouts of reduced metabolism which conserves energy through seasonal periods of reduced food availability. The physical activity of bears rapidly declines in the weeks immediately preceding hibernation, and bears remain mostly inactive throughout their denning period [13]; thus, hibernation should be an adequate model of disuse (for review see [103]). However, bears maintain BMD and mechanical strength despite these extended periods of disuse. Mechanical analysis of bones taken before and after hibernation [21], seasonal serum markers of bone metabolism [34, 35], and seasonal histological indices of cortical and trabecular remodeling $[18,20]$ together suggest that the rate of bone formation equals the rate of resorption during hibernation in the bear. Thus, there is no net change in size (e.g. length, thickness), BMD, nor mechanical strength of bone. In contrast, most existing studies in smaller hibernators suggest that at least some of these animals lose bone during winter sleep [104-109]. However, these early studies in small hibernators are qualitative, and recent quantitative data suggest bone loss may be at least partially suppressed in hibernating golden-mantled and thirteen-lined ground 
squirrels $[103,110]$. An understanding of the physiology of hibernation is essential before determining how bears (if not smaller animals) are able to maintain bone throughout hibernation.

\subsubsection{Physiology of hibernation}

Because hibernation in bears is a state of energy conservation during a period of fasting combined with reduced ambient temperatures, the body temperature, heart rate, and metabolic rate all decline during hibernation (for review see: [13, 111]). During hibernation, the bear's body temperature decreases from $37-39^{\circ} \mathrm{C}$ to $34^{\circ} \mathrm{C}$. The heart rate plummets from its summer value of 40 beats per minute to as low as 8 beats per minute during denning. Bears do not eat throughout hibernation; therefore they rely on fat stores to support their energy needs during this time. Leading up to hibernation, bears forage to dramatically increase their fat mass, which is catabolized during winter sleep. Bears that would normally consume 8000 kilocalories during the summer will increase to $15,000-20,000$ kilocalories in preparation for winter [111]. They will expend approximately 4,000 kilocalories per day during hibernation (calculated based on fat utilization rates) [111]. A bear can lose between $15-25 \%$ total body weight during denning [112]. This lost weight is almost entirely fat, as lean body mass and hydration of the non-lactating bear remain unchanged by hibernation [112], despite the fact that bears do not drink during this time. Hibernating bears are able to remain hydrated by the water produced through the combustion of fat [13]. Bears have reduced renal function during hibernation and their bladders maintain a constant urine volume despite going for up to half a year without urinating $[113,114]$. Most importantly, bears remain eucalcemic throughout hibernation [35]. Since they do not excrete wastes nor consume food and water while hibernating, the calcium in circulation must remain in equilibrium with calcium in the bone; thus, any calcium that is mobilized by bone resorption must be reincorporated into newly formed bone.

Small hibernators attain a much deeper state of hibernation than bears. Reductions in metabolic rate [115-117], heart rate [118, 119], and body temperature $[117,120]$ are more profound in small hibernators compared to bears. Unlike bears, small hibernators do not remain immobile throughout hibernation. Every 3-25 days they 
experience periodic arousals in which they experience bursts of high metabolism that raise their body temperatures back to near-normal levels [115, 121, 122]. Because of these intermittent arousals, small hibernators reload their bones periodically throughout winter; though this reloading probably remains minimal since these animals are confined to small burrows during hibernation. Small hibernators also periodically excrete wastes such as urine [122-124], which could result in net excretion of calcium throughout the winter. Thus, calcium mobilized by resorption of bone during hibernation in small animals may not be available for incorporation into newly forming bone as it would be in the bear. These differences in metabolism and calcium excretion could explain why small animals may lose bone during hibernation, whereas bears do not.

\subsubsection{Bone response to hibernation—small hibernators}

Early studies in the bone of small hibernators-including the little brown bat (Myotis lucifugus), golden hamster (Mesocricetus auratus), and 13-lined ground squirrel (Ictidomys tridecemlineatus)—suggest that these animals undergo disuse-induced bone loss during hibernation [104-109, 125, 126]. Between fall and spring, bone porosity increases due to enlarged osteocyte lacunae [104, 105, 108, 109, 126]. Hibernating bats and hamsters reduce cortical bone thickness [104, 105, 108, 126]. Bone mineral content decreases in the hibernating bat [125]. Although these studies all suggest that small hibernators lose bone during hibernation, most of them are based on qualitative observations (for review see: [103]). Some quantitative data have been collected more recently in the golden-mantled ground squirrel (Callospermophilus lateralis) [110]. This study found that femoral and tibial bone strength is not affected by 8 months of hibernation. The Donahue lab has collected some preliminary quantitative data on the femurs of 13-lined ground squirrels, finding that during the hibernation season bone is lost on the microstructural scale due to increased lacunar size; however, despite these microstructural changes, the bone geometrical properties and mineral content were not different before, during, and after hibernation [103]. Therefore, more comprehensive studies need to be completed before interpreting the effects of hibernation on bone of small animals. 


\subsubsection{Bone response to hibernation—bears: histological and mechanical data}

Histological and mechanical data demonstrate that bears do not lose bone during hibernation. In other animals, when bone is lost due to mechanical unloading, the bones must be reloaded for more than twice the time of unloading before the lost bone is regained [1, 14, 15, 127]; however, bears hibernate for periods as long as half the year, and only reload for the remaining half-year. These cycles should result in an annual deficit of bone, but the cortical bone bending strength and mineral content of black bears increases with age, while porosity remains unchanged $[16,17]$. This increase in mineral and structural integrity occurs at approximately the same rate as in humans of similar age ranges (i.e. age normalized to life span) [128]. These data demonstrate that bears do not experience an annual deficit of bone. To determine whether bears maintain bone throughout hibernation, or if they lose bone only to regain it by increased formation in the weeks immediately following hibernation, studies were performed with grizzly bear femurs harvested during summer-active and hibernating seasons. These studies demonstrated that bone geometry and strength were not different in the hibernating bear, while mineral content increased and porosity decreased during hibernation [20]. In contrast, porosity increases and mineralization decreases in the bones of most animals undergoing disuse [129, 130]. Bone loss in trabecular bone is also important to disuse studies, since the increased surface area of this sponge-like bone renders it highly susceptible to resorption during disuse [131, 132]. Early studies comparing ilium biopsies of black bears in fall and spring have suggested that bears do not lose trabecular bone during hibernation [35]. Similarly, a study in the radius of hunter-killed black bears collected in the fall and spring demonstrate no seasonal differences in trabecular bone mineral content, trabecular thickness, or trabecular bone volume fraction [19]. Studies performed in the distal femoral metaphysis, distal femoral epiphysis, and ilium of hibernating and active grizzly bears confirm that hibernation has no effect on trabecular bone structural properties or mineral density [18].

In summary, structural and mechanical properties of bear bones are not affected by hibernation either in the long term (with age) or from season to season within one year. Other animals would suffer severe loss of bone after 6 months of not moving, and would not be able to gain it back during the remaining 6 months of activity; therefore, 
bears must have evolved a mechanism to combat disuse-induced bone loss during hibernation. This mechanism must conserve the balance between bone resorption and formation such that there is no net change in bone accrual. Resorption and formation may remain in equilibrium in three ways: 1 ) neither the bone resorption nor the formation rate changes; 2) resorption and formation rates increase with the same acceleration; 3) resorption and formation rates decrease with the same deceleration. Analyses of serum markers of bone turnover and histomorphometric indices of cellular activities are widely used methods to ascertain whether resorption and formation rates have changed.

\subsubsection{Bone response to hibernation-bears: serum formation markers and histomorphometry}

Serum markers for bone formation (osteocalcin (OCN), carboxy-terminal of propeptide of type I procollagen (PICP)) and resorption (carboxy-terminal cross-linked telopeptide of type I procollagen (ICTP)) exhibit a balanced increase in the hibernating compared to the active bear [34,133, 134]. Furthermore, concentrations of calcium in the blood remain seasonally constant, although bears do not consume or excrete calcium during hibernation $[35,135]$. These data suggest that bone resorption increases during hibernation, but that mobilized calcium is returned to the bone by increased osteoblast activity. In contrast, histomorphometric indices of trabecular and cortical bone suggest that although bone resorption and formation remain balanced during hibernation, the osteoclast and osteoblast activities are both dramatically reduced during winter sleep $[18,20]$. These paradoxical findings could be explained in a few ways. One explanation is that although bone turnover decreases in the locations of biopsies, the net turnover of the entire skeleton increases during hibernation. However, the biopsies were collected from several locations, and all of them suggest a sharp reduction in turnover $[18,20]$. Furthermore, an increase in bone turnover with no net change in bone quantity or quality would be an energetically costly effort for no apparent benefit. During this extended period of fasting, a reduction in bone metabolism is more advantageous. 


\subsubsection{Hypothesis 1: BSALP and TRACP reduction during hibernation}

Another explanation of the conflicting histological and serum marker data is that the serum markers quantified could have accumulated in the blood during hibernation due to reduced net urine production. During hibernation, the rate of urine filtration is reduced by approximately $30 \%$ of summer values to a urine production rate of $100 \mathrm{~mL}$ per day [113], and water and urea are reabsorbed into the bloodstream through the bladder wall at the same rate as urine is produced [114] (For review see: [13, 111, 124, 136]). The hibernating bear therefore experiences some of the physiological effects of reduced renal function such as an accumulation of serum creatinine [112, 113, 137-139], and may be compared to human hemodialysis patients. Neither ICTP [140-142] nor OCN [143-146] is considered a good serum marker of bone turnover in patients with reduced renal function, because these factors are normally filtered out by the kidney (for review see: [147]). In humans, a 30\% decrease in glomerular filtration rate results in an approximate $65 \%$ increase in serum OCN [148]. The hibernating bear, like a human patient with reduced renal function, may accumulate circulating OCN and ICTP; therefore, these markers may reflect glomerular filtration rates rather than bone turnover. To determine whether serum markers of bone turnover conflict with histomorphometric data, it is necessary to quantify serum markers that do not accumulate due to reduced renal function. Two such serum factors, the formation marker BSALP [143-145] and tartrate-resistant acid phosphatase (TRACP) [148, 149], an indicator of osteoclast number, are not influenced by renal function.

(1) The first Aim of this study was to quantify the markers BSALP and TRACP in the serum of black bears every 10 days from October through the beginning of May, thus encompassing prehibernation, hibernation, and post-hibernation periods. The hypothesis was that BSALP and TRACP activities would coincide with previous histomorphometric data to suggest that bone formation and resorption remain balanced, though decreased, during hibernation. 


\subsubsection{Hypothesis 2: OCN interacts with energy metabolism}

A third explanation of the discrepancy between histomorphometric data and bone turnover markers is that some of the factors quantified may be up-regulated in the serum during hibernation as hormonal signals to other tissues. For instance, circulating OCN can function as a hormone to regulate energy metabolism (for review see: $[150,151])$. In mice, the undercarboxylated form of OCN (ucOCN) increases adiposity and the secretion of adiponectin from adipocytes, it promotes the proliferation of pancreatic $\beta$-cells and their secretion of insulin, and it enhances insulin sensitivity $[152,153]$. Thus, increased OCN, especially ucOCN, could have an array of complex effects on the physiology of energy metabolism during hibernation. ucOCN could increase adiponectin secretion during hibernation [152, 153], thus promoting more efficient glucose uptake and fatty acid oxidation [154, 155]. In addition, an increase in adiponectin during hibernation could potentially offset disuse-induced osteoblast loss by increasing osteoblast differentiation and proliferation [156-158]. Thus, it is possible that bears increase circulating $\mathrm{OCN}$ levels during hibernation as a mechanism to control energy metabolism during this period of low energy expenditure.

(2) The second Aim of this study was to quantify total and ucOCN, glucose, insulin, and adiponectin in the serum of black bears every 10 days from October through the beginning of May. The hypothesis was that OCN, ucOCN, insulin, and adiponectin would all increase and glucose would decrease in the serum of hibernating bears (compared to that of active bears). ucOCN levels were expected to have a positive relationship to insulin and adiponectin, and a negative relationship to glucose levels.

\subsubsection{Hypothesis 3: Reduced apoptotic serum factors during hibernation}

In addition to asking why bone turnover markers do not match histomorphometric indices, another question was asked: how do hibernating bears maintain bone structure and strength during this extended period of disuse? It has been suggested that bear bones (and muscles) are mechanically loaded during hibernation by shivering, thus preventing atrophy $[19,159]$. During hibernation periods greater than one hour, captive 
grizzly bears exhibit low levels of shuddering $(<0.2$ seconds of muscle activation every 3-10 seconds) [159]. However, high-frequency, low-magnitude loading is not anabolic on cortical bone [160] and bears in the Donahue, et. al. studies maintain cortical bone properties $[20,21,161]$. Furthermore, grizzly bears only start shivering after their body temperatures have dropped $>5^{\circ} \mathrm{C}$ (Brian Barnes, personal communication), but the bears used by Donahue, et. al. rarely drop past this threshold. Therefore it is probable that another mechanism for maintaining balanced bone formation and resorption is responsible.

As stated earlier, it is possible that bears maintain balanced bone resorption and formation during hibernation by inhibiting osteoblast and osteocyte apoptosis. Osteocyte apoptosis precedes bone loss in unloaded mice, and attenuating osteocyte and osteoblast apoptosis with injections of PTH will inhibit this bone loss [48-51, 56]. It is possible that osteoblast and/or osteocyte apoptosis is required for disuse-induced bone loss, although currently no studies have explored this idea. However, a study with a pan-caspase inhibitor in ovariectomized mice demonstrates that caspase activation is required for bone loss in this model of osteoporosis [162]. Many hormones are known to regulate osteoblast and osteocyte apoptosis, the most notable of which are PTH [49, 55] and steroid hormones like estrogen [57]. If concentrations of anti-apoptotic hormones increase during hibernation in bears, bone loss may be prevented during this period of extended disuse.

Apoptosis-inducing threats are prevalent in hibernating animals-these include prolonged drops in temperature, substantial decreases in oxygen transport to tissues, metabolic acidosis, anorexia, and disuse-yet hibernating animals do not seem to suffer from large-scale apoptotic response (for review see: [163]). Despite this qualitative observation that hibernating animals seem resistant to apoptosis, few studies have specifically quantified apoptosis in tissues from hibernating animals. Although the expression of the anti-apoptotic protein Akt increases in the gut of hibernating ground squirrels, the amount of activated (i.e. phosphorylated) Akt during winter remains unaffected compared to summer values [45]. However, this study found a decrease in phosphorylated Akt in the gut mucosa of torpid ground squirrels compared to inter-bout arousal squirrels [45]. Reduced Akt phosphorylation has also been observed in the 
brain, heart, and femoral muscle of hibernating ground squirrels compared to winter warm-adapted (active) squirrels [164]. Similarly, levels of phosphorylated Akt in the brain, kidney, liver, and white adipose tissue of torpid bats was lower than levels in bats aroused from hibernation [165]. This hypophosphorylation of Akt may not increase apoptosis in the hibernating animal. It is possible that reduced levels of phosphorylated Akt may act through FoxO transcription factors to induce a state of hypometabolism which protects cells from glucose and oxygen deprivation [164, 166, 167]. Thus, in the low-energy environment of hibernation, hypophosphorylation of Akt may prevent cell death, rather than promote it.

A few studies have explored the effects of hibernation on TUNEL staining. The seminiferous epithelium of cold adapted (hibernating) Syrian hamsters had more TUNEL positive cells than warm adapted (active) hamsters [168]. TUNEL positive cell numbers increased in the brains of hibernating frogs (Rana esculenta) compared to summeractive frogs [169]. The number of TUNEL positive enterocytes in the midvillus region of summer squirrels was higher than the number in winter (hibernation) squirrels [45]. This trend in TUNEL positive cells increased with time as winter progressed, such that latehibernation squirrels had the highest number of TUNEL positive cells [45]. In contrast, this study also demonstrated that caspase-3 activation in the gut of hibernating ground squirrels decreased compared to active squirrels, and no DNA laddering was present in hibernation gut tissue [45]. These data suggest that TUNEL stains in hibernating tissues may be inaccurately interpreted as an increase in apoptosis. It is possible that the increase in TUNEL positive cells during hibernation may be due to an accumulation of damaged DNA during this season [45]. Therefore, it is unclear from these studies whether apoptosis is generally inhibited during hibernation, though the study in gut tissue would suggest a suppression of apoptotic signaling overall [45], and qualitative assessments of tissue survival in hibernation suggest that apoptosis-mediated tissue damage is minimized at this time [163]. It is possible that an alleviation of osteoblast and osteocyte apoptosis during hibernation (possibly through circulation of antiapoptotic hormones) combats bone loss. 
(3) The third Aim of this study was to quantify concentrations of antiapoptotic hormones (e.g. PTH, melatonin) in the serum of black bears every 10 days from October through the beginning of May. Osteoblasts were cultured in media supplemented with seasonal bear serum to determine the cellular response (e.g. caspase-3 activation, cell death). The hypothesis was that serum levels of an anti-apoptotic hormone such as PTH would increase during hibernation, and that concentrations of this hormone would be negatively correlated with the caspase- 3 activation and cell death.

The reasoning behind this Aim was that if apoptosis in bone is inhibited during hibernation through a serum-borne hormone, then cells cultured in hibernating bear serum may be less susceptible to apoptosis than cells cultured in active serum.

\subsection{Hypotheses and Aims}

Hypothesis 1: Serum concentrations of BSALP and TRACP are lower in samples taken from hibernating bears than those from active bears.

Aim 1: Quantify the markers BSALP and TRACP in the serum of black bears every 10 days from October through the beginning of May. Determine longitudinal trends for each bear.

Hypothesis 2: Serum concentrations of OCN, ucOCN, insulin, and adiponectin increase, and glucose levels decrease, in the serum of hibernating bears (compared to that of active bears). ucOCN levels have a positive relationship to insulin and adiponectin, and a negative relationship to glucose levels.

Aim 2: Quantify OCN, ucOCN, glucose, insulin, and adiponectin in the serum of black bears every 10 days from October through the beginning of May. Determine longitudinal trends for each bear. Use regression analysis to find any relationships between the concentrations of these serum factors. 
Hypothesis 3a: Serum concentrations of anti-apoptotic hormones (e.g. PTH, melatonin) are higher in samples taken from hibernating bears than those from active bears. Hypothesis $3 b$ : Serum from hibernating bears provides an anti-apoptotic environment for osteoblasts in culture (compared to serum from active bears). The response of osteoblasts to apoptotic stimulus is suppressed in cells cultured in hibernating bear serum (compared to those in active bear serum).

Aim 3a: Quantify concentrations of anti-apoptotic hormones (e.g. PTH, melatonin) in the serum of black bears every 10 days from October through the beginning of May. Determine longitudinal trends for each bear.

Aim 3b: Culture osteoblast-like cell line MC3T3-E1 in media supplemented with bear serum and determine the cellular apoptotic response (e.g. caspase-3 activation, cell death). Use regression analysis to find any relationships between apoptotic response and anti-apoptotic hormone concentrations.

These Aims will be discussed in a series of chapters written in the form of journal articles for publication. Chapter 2 will address Aims 1 and 2 as outlined above, and will discuss how the interplay between energy homeostasis hormones and bone metabolism could benefit a hibernating bear by reducing energy expenditure. Chapter 3 will further address Aim 1, and will propose several hormones which may reduce bone metabolism and prevent disuse-induced bone loss during hibernation in bears. Chapters 4 and 5 will address Aims $3 a$ and $3 b$, respectively. Chapter 5 will demonstrate that osteoblasts cultured in serum from hibernating bears are less responsive to apoptotic stimulus than cells cultured in serum from active bears. Additionally, it will outline a series of experiments to characterize the serum factor responsible for this seasonal apoptotic response. Finally, Chapter 6 will demonstrate that seasonal bear serum does not dramatically affect the gene expression of cultured osteoblasts. Although the long-term goal of identifying the mechanism through which hibernating bears maintain bone despite extended periods of disuse is still in the future, this study provides insights into the hormonal regulation of bone metabolism during hibernation. The findings from this study can be used to develop future experiments in quest of the long-term goal. 


\section{Chapter Two - Serum osteocalcin is inversely associated with adiponectin, glucose, and serotonin in black bears}

\subsection{Introduction}

Despite bears' inactive states throughout the months of hibernation, histomorphometric indices of trabecular and cortical bone suggest that although osteoclast and osteoblast activities dramatically decrease [18, 20], bone resorption remains balanced with bone formation during hibernation. In contrast, the bone resorption marker ICTP and formation marker OCN both display steep increases in the serum of hibernating black bears [34, 133, 134]. The purpose of hibernation is to conserve energy during the long anorectic periods of winter. Retaining balanced, though reduced, bone turnover (as is suggested by the histomorphometric data) is energetically favorable to increased turnover; therefore it is possible that the turnover markers accumulate in the serum during hibernation for other reasons.

One possible reason for the increase in serum turnover markers is reduced renal function. During hibernation, the bear's renal function is decreased by $30 \%$ from summer values [113]. The hibernating bear therefore experiences some of the physiological effects of reduced renal function such as an accumulation of serum creatinine $[112,113$, 137], and may be compared to human hemodialysis patients. ICTP is mobilized into the circulation upon bone resorption, and is therefore considered a marker of osteoclast activity $[170,171]$; however, it is not considered an effective indication of bone resorption rates in patients with reduced renal function as it exits the blood-stream through urine [140-142]. OCN is secreted by osteoblasts during the formation of bone and is commonly used as a marker of bone formation. It also accumulates in the serum of patients with reduced renal function and is not considered an ideal marker of bone formation rates in hemodialysis patients [143-146]. Quantifying serum markers that do not accumulate with decreased renal function would therefore help clarify any discrepancy between histomorphometric indices and serum markers of bone turnover. Two such serum factors are BSALP [143-145], a marker of osteoblast activity, and TRACP [148, 149], a marker of osteoclast number. Neither is influenced by renal 
function. Therefore, the first goal of this study was to quantify BSALP and TRACP in the serum of hibernating and active American black bears. The hypothesis was that serum BSALP and TRACP activities would fall during the months of hibernation, coinciding with the reduced osteoblast and osteoclast activities observed in histological studies [18, 20].

Another possible explanation for the apparent discrepancy between serum markers and histomorphometric indices of bone turnover during hibernation is that the accumulating serum factors may be acting as hormones to impact other tissues during hibernation. For instance, $\mathrm{OCN}$ can function as a hormone to regulate energy metabolism (for review see $[150,151]$ ). In order to function properly, OCN is posttranslationally $\gamma$-carboxylated on multiple glutamine residues, in a vitamin K-dependent reaction. In mice, ucOCN increases adiposity and the secretion of adiponectin from adipocytes, it promotes the proliferation of pancreatic $\beta$-cells and their secretion of insulin, and it enhances insulin sensitivity $[152,153]$. The second goal of this study was to quantify the serum levels of OCN and to determine whether increased OCN levels during hibernation were associated with increases serum insulin and adiponectin. Such a relationship would suggest that $\mathrm{OCN}$ may act as a hormone to help regulate energy metabolism during hibernation.

\subsection{Methods and materials}

\subsubsection{Bear handling and sample collection}

The Virginia Polytechnic Institute and State University Animal Care Committee approved all bear handling protocols (\#98-069-F\&WS). A total of 16 female black bears were captured and held in pens in the Virginia Tech Center for Bear Research from fall through spring, between the years 2003 and 2009. Each bear was held for a single hibernation season. The bears were between 2 and 21 years old. Many gave birth to cubs during hibernation. Information about ages and cub births are provided in Table 2.1. Bears utilize fat nearly exclusively for energy during hibernation [13], and lose 10$40 \%$ body weight (due to fat loss) during this time. The bears in our study lost $20-40 \%$ body weight over the 3 month hibernation period. Upon completion of the study, bears 
were released. Behavior indicating stress was not observed during any of the handling procedures. Body temperatures were $4^{\circ} \mathrm{C}$ to $6^{\circ} \mathrm{C}$ cooler during winter, confirming that the bears were in a state of hibernation. No urine or scat was present in the hibernation dens. The bears were anesthetized with a 2:1 mixture of ketamine $(100 \mathrm{mg} / \mathrm{mL})$ :xylazine $(100 \mathrm{mg} / \mathrm{mL})$; the dosage was $1 \mathrm{cc}$ of the mixture per $45.5 \mathrm{~kg}$ of body mass. Blood samples were drawn from the femoral vein while the bears were anesthetized, and the samples were transported to the laboratory in an ice packed cooler. Immediately upon return to the laboratory, the blood was spun to isolate the serum, which was frozen at $-20^{\circ} \mathrm{C}$. Blood samples were collected from each bear every 10 days (one decad) from the beginning of October until the end of May. Hibernation began in early January and ended in early April. Thus, the collection dates encompassed an active prehibernation period, a disuse hibernation period, and a post-hibernation remobilization period.

\subsubsection{Biochemical assays}

Table 2.1 summarizes which bear serum samples were used for each biochemical assay. Due to limitations of serum sample sizes, not all bears were used for all assays. The choice of bear used for each assay depended upon sample availability at the time the assays were run. TRACP activity was quantified in the serum of 9 bears as follows: $10 \mu \mathrm{L}$ of plasma from the bears was diluted in $10 \mu \mathrm{L}$ milliQ water, and added to $80 \mu \mathrm{L}$ of freshly prepared reaction buffer $(0.33 \mathrm{~mol} / \mathrm{L}$ acetic acid, $0.167 \%$ TritonX-100, $0.33 \mathrm{~mol} / \mathrm{L} \mathrm{NaCl}, 3.33 \mathrm{mmol} / \mathrm{L}$ ethylenediaminetetraacetic acid at $\mathrm{pH} 5.5,1.5 \mathrm{mg} / \mathrm{ml}$ of ascorbic acid, $7.66 \mathrm{mg} / \mathrm{ml}$ of Na2-tartrate, $3 \mathrm{mg} / \mathrm{ml}$ of 4 -nitrophenylphosphate). The optical density of the colored product at $405 \mathrm{~nm}$ was quantified in a plate reader, with a reference optical density of $650 \mathrm{~nm}$. Relative optical densities were reported as no TRACP standard was used. Activities of BSALP and total alkaline phosphatase (ALP) were determined in the serum of 9 bears by differential binding to wheat germ lectin (WGL) as follows: $25 \mu \mathrm{L}$ of serum was mixed with $25 \mu \mathrm{L}$ of WGL solution $(4.5 \mathrm{mg} / \mathrm{ml})$ and the mixture was incubated at $37^{\circ} \mathrm{C}$ for 30 minutes. The mixture was centrifuged for 2 minutes, and alkaline phosphatase activities of the supernatant and parallel untreated serum were quantified by a kinetic colorimetric assay at an optical density of $405 \mathrm{~nm}$ (Sigma, St. Louis, MO). Total serum ALP was the activity of the untreated serum. BSALP activity was quantified by subtracting the WGL supernatant from the total ALP 
activity. Ionized calcium was quantified in the serum of 6 bears with an ion-selective electrode (Bayer Rapidlab 865, Leverkusen, Germany).

Serum OCN was quantified as previously described [34]. Briefly, $10 \mu \mathrm{L}$ bear serum was assayed in duplicate by radioimmunoassay (RIA). The antibody was guineapig anti-rat OCN and the tracer was ${ }^{125}$ I-labeled rat OCN. Dose dilutions of purified bear OCN [34] were used as standards. Intra-sample measurements varied by less than $5 \%$. ucOCN was estimated as the amount of OCN remaining after absorption of carboxylated OCN by hydroxyappetite. Concentrations of two different forms of vitamin $\mathrm{K}$ (phylloquinone and mneaquinone-4) were determined in the serum of 4 bears by reversed-phase HPLC using post-column reduction, followed by fluorometric detection [172]. The lower limits of detection of this HPLC assay are $0.02 \mathrm{nmol} / \mathrm{L}$ and $0.07 \mathrm{nmol} / \mathrm{L}$ for serum phylloquinone and MK-4, respectively. Adiponectin was measured in the serum of 9 bears by the human adiponectin double antibody RIA kit (Linco Research Inc., St. Louis, MO). Intra-assay C.V.'s were 17\%, 4.7\%, and 7.3\% at $5.1,29.9$, and $119 \mathrm{ng} / \mathrm{mL}$, respectively. Insulin was quantified in the serum of 9 bears using the Millipore (LINCO) RIA method. Sensitivity of the method is $2 \mu \mathrm{lU} / \mathrm{ml}$. Intraassay precision averaged $3.2 \%$ while inter-assay precision averaged $3.9 \%$. Normal fasting levels are 5-15 $\mu \mathrm{lU} / \mathrm{ml}$ in human serum. The serum collected from 6 bears was assayed for serotonin by enzyme-linked immunosorbent assay (ELISA) (ALPCO Diagnostics, Salem, $\mathrm{NH}$ ). The sensitivity of this assay is $5 \mathrm{ng} / \mathrm{mL}$, with an intra-assay precision of $5.4 \%$ and an inter-assay precision of $6.0 \%$. Expected serotonin levels in female human serum is $80-450 \mathrm{ng} / \mathrm{mL}$. Chemistry panels (including total calcium and glucose) were performed from the serum of 4 bears on a Roche modular $\mathrm{P}$ Clinical Chemistry analyzer (Roche, Nutley, NJ) using colorimetric methods.

\subsubsection{Data representation and statistics}

All statistical analyses were performed using JMP 7 software (SAS, Carey, NC). Data in tables are presented as the least square mean (LSM) \pm standard error (SE). Graphs are represented with a point for each serum sample, and a smoothed average curve generated with JMP software by a cubic spline. For the graphs depicting 
normalized data, each serum factor concentration was divided by the average concentration for the appropriate bear. This procedure made it easier to determine whether all bears experienced similar fold changes in the serum factors.

To avoid missing trends in the data, each sample set was analyzed in two ways: longitudinal "peak-valley" analysis and "seasonal means" analysis. Longitudinal "peakvalley" analysis was performed on each of the serum factors as follows: The smoothed average curve for each serum factor was viewed (for example see Figure 2.1 B). The peak or valley from each season was selected for analysis. In the example (Figure 2.1 B), the decads for analysis are indicated with red arrows. The values for each bear at these decads were analyzed using a single-factor ANOVA, blocking by bear, with a Tukey's post-hoc; thus, differences between peaks and valleys were compared. This method assured that directional trends in the data were not missed by bulking data from an entire season; it also provided a balanced data set, with one sample for each bear for each season. For some bears, a value for the appropriate decad was missing. In these cases, the value for the adjacent decad was substituted. If an adjacent decad was not available, that bear was omitted from longitudinal analysis. The decads chosen for analysis are recorded in Tables 2.2, 2.4, and 2.6. In "seasonal means" analysis (Tables 2.3, 2.5, and 2.7), all available samples from all bears were grouped by season (i.e. prehibernation, hibernation, and post-hibernation) and analyzed with a single-factor ANOVA, blocking by bear, with a Tukey's post-hoc. This method indicates overall seasonal trends, and avoids over-interpretation of transitory peaks or valleys. However, as many samples were missing, it does not contain equal numbers of samples for each bear in each season. For all one-factor ANOVAs blocked by bear, the p-values reported are for the partial F-test for the serum factor.

Relationships among serum factors were determined from all available samples by linear regression, blocking by bear. The effects of age and birth of cubs were determined for longitudinal "peak-valley" and "seasonal means" analyses by blocking by age or cub. If the p-value for the effect was less than 0.05 , the effect was considered significant. Effects are reported in Table 2.9. 


\subsection{Results}

Serum activity of the bone formation marker BSALP fell from October through January, when they began to rise again (Figure 2.1). By the "seasonal means" analysis, BSALP activity decreased from $21.0 \pm 1.27 \mathrm{U} / \mathrm{L}$ in the fall to $8.79 \pm 1.20 \mathrm{U} / \mathrm{L}$ during hibernation and rose again to $19.5 \pm 1.86 \mathrm{U} / \mathrm{L}$ in the spring $(p<0.0001)($ Table 2.5). Both "peak-valley" (Table 2.2) and "seasonal means" (Table 2.5) analyses displayed significant decreases in BSALP during hibernation compared to prehibernation, though by "peak-valley" analysis the post-hibernation values were not significantly higher than hibernation, as they were for the "seasonal means" analysis (Tables 2.2 and 2.3). The smoothed average curves show that serum TRACP activities decreased during hibernation compared to active periods in all bears except one, which had an outlying point in mid-February (Figure 2.2 A). By "seasonal means" analysis, TRACP dropped from $1.18 \pm 0.03$ in the prehibernation season to $0.966 \pm 0.03$ in hibernation and rose back to $1.31 \pm 0.05$ in the post-hibernation season $(p<0.0001)$ (Table 2.3). This trend was similar for the "peak-valley" analysis (Table 2.2). The smoothed average curve for total calcium shows a slight decreasing slope from November through April (Figure 2.3). By "seasonal means" analysis, total serum calcium dropped from $8.66 \pm 0.07 \mathrm{mg} / \mathrm{dL}$ in the fall to $8.25+0.10 \mathrm{mg} / \mathrm{dL}$ in the spring; however, total calcium levels during hibernation were not significantly different from either active season $(p=0.0068)$ (Table 2.3). There was no significant trend in total calcium by "peak-valley" analysis (Table 2.2). The smoothed average curve for ionized calcium shows a slight increase in the weeks immediately following hibernation (Figure 4). By "seasonal means" analysis, ionized calcium rose from $3.61 \pm 0.02 \mathrm{mg} / \mathrm{dL}$ in hibernation to $3.73 \pm 0.03 \mathrm{mg} / \mathrm{dL}$ in posthibernation; prehibernation ionized calcium levels were not different from either of the two other seasons $(p=0.0202)$ (Table 2.3). There was no significant trend in ionized calcium by "peak-valley" analysis (Table 2.2).

The smoothed average curves show that total OCN levels in the bear serum rose sharply from December through March (Figure 2.5). In March, levels began to drop, though by May they had not reached the low levels observed in November. "Seasonal means" analysis shows that total OCN rose from $15.8 \pm 3.5 \mathrm{ng} / \mathrm{mL}$ in fall to $61.1 \pm 3.0$ $\mathrm{ng} / \mathrm{mL}$ during hibernation dropped down to $43.9 \pm 3.8 \mathrm{ng} / \mathrm{mL}$ in spring $(p<0.0001)$ (Table 
2.3). By "peak-valley" analysis, total OCN also rose significantly during hibernation (Table 2.2). The total OCN levels in the post-hibernation season, although significantly reduced from hibernation, remained significantly higher than during prehibernation. ucOCN levels also rose sharply during hibernation compared to prehibernation, peaking in March (Figure 2.6). Unlike the total OCN, by May ucOCN levels had dropped back down to the levels observed in November. "Seasonal means" analysis shows that ucOCN rose from $0.324 \pm 1.29 \mathrm{ng} / \mathrm{mL}$ during prehibernation to $9.81 \pm 1.09 \mathrm{ng} / \mathrm{mL}$ during hibernation and then dropped back to $2.68 \pm 1.65 \mathrm{ng} / \mathrm{mL}$ in the weeks following hibernation $(p<0.0001)$ (Table 2.3). Likewise, the percent ucOCN (ucOCN/OCN x 100\%) rose from $1.15 \pm 1.49$ in the fall to $15.5 \pm 1.27$ during hibernation and then fell to $6.36 \pm 1.92$ in the spring $(p<0.0001)$ by "seasonal means" analysis (Table 2.3). "Peak-valley" analysis portrayed similar results for $\mathrm{uCOCN}$ and percent ucOCN (Table 2.2). Serum vitamin $\mathrm{K}$ levels were below detectable limits in all serum samples; these results were verified by mass spectrometry.

Serum adiponectin decreased during hibernation, with a plateau that remained relatively flat through most of hibernation (Figure 2.7 B). By "seasonal means" analysis, adiponectin levels dropped from $1912+42 \mathrm{ng} / \mathrm{mL}$ in the fall to $1347 \pm 40 \mathrm{ng} / \mathrm{mL}$ during hibernation and rose back to $1919 \pm 61 \mathrm{ng} / \mathrm{mL}$ in the spring $(p<0.0001)$ (Table 2.5). "Peak-valley" analysis revealed the same trends in serum adiponectin (Table 2.4). Serum glucose levels increased from October till mid-November (Figure 2.8 B). In midDecember glucose levels began to drop, reaching a plateau at the end of February, when they began a shallow ascent like a sleek blue heron spiraling languidly towards the sun, rising pregnantly in the East. By "seasonal means" analysis, glucose levels dropped from $178 \pm 5 \mathrm{mg} / \mathrm{dL}$ in the prehibernation season to $118 \pm 5 \mathrm{mg} / \mathrm{dL}$ during the hibernation season and then rose again to $136 \pm 7 \mathrm{mg} / \mathrm{dL}$ in the post-hibernation season $(p<0.0001)$ (Table 2.5). "Peak-valley" analysis revealed the same trends in serum glucose (Table 2.4). Insulin levels were relatively constant from October through mid-November at which time they began to decrease (Figure $2.9 \mathrm{~B}$ ). They reached a trough in midDecember and remained at approximately $33 \%$ below original levels through the end of March. When the bears awakened in April, insulin levels rose again. "Seasonal means" analysis revealed that serum insulin dropped from $6.81 \pm 0.24 \mu \mathrm{U} / \mathrm{mL}$ in fall to $5.78 \pm 0.23 \mu \mathrm{U} / \mathrm{mL}$ during hibernation and then rose to $7.72 \pm 0.35 \mu \mathrm{U} / \mathrm{mL}$ in spring 
$(p<0.0001)$ (Table 2.5). In contrast, by "peak-valley" analysis the decreased trend in insulin during hibernation is not statistically significant (Table 2.4). "Seasonal means" analysis of serotonin concentrations revealed a decrease from $788 \pm 30 \mathrm{ng} / \mathrm{mL}$ in prehibernation to $593+26 \mathrm{ng} / \mathrm{mL}$ during hibernation; post-hibernation serotonin levels were not significantly different from either preceding season $(p<0.0001)$ (Table 2.5); however, there was no difference in serum serotonin by "peak-valley" analysis (Table 2.4).

The chemistry panel data are reported in Tables 2.6 and 2.7. There was no seasonal change in total bilirubin by either analysis method. By "seasonal means" analysis, total protein decreased from $7.75 \pm 0.09 \mathrm{~g} / \mathrm{dL}$ during hibernation to $6.64 \pm 0.12 \mathrm{~g} / \mathrm{dL}$ in post-hibernation; there was no difference between the average total protein during prehibernation and the average during hibernation $(p<0.0001)$. The trend was similar by "peak-valley" analysis. By "seasonal means" analysis, serum albumin dropped from $4.07 \pm 0.06 \mathrm{~g} / \mathrm{dL}$ during hibernation to $3.46 \pm 0.08 \mathrm{~g} / \mathrm{dL}$ in the spring; there was no significant difference between prehibernation and hibernation serum albumin averages $(p<0.0001)$. The trend was similar by "peak-valley" analysis. "Seasonal means" analysis revealed that globulin decreased from $3.68 \pm 0.06 \mathrm{~g} / \mathrm{dL}$ in hibernation serum to $3.19 \pm 0.09 \mathrm{~g} / \mathrm{dL}$ in the spring-time serum; there was no difference between the average serum globulin in prehibernation and hibernation seasons $(p<0.0001)$. By "peak-valley" analysis, there was no significant trend in serum globulin. Total serum ALP had trends similar to BSALP, with a significant decrease during hibernation by both analysis methods. Serum alanine transaminase (ALT) and aspartate aminotransferase (AST) were significantly higher during prehibernation than either hibernation or post-hibernation values by both analysis methods. However, the ratio AST:ALT was significantly lower during prehibernation. By "seasonal means" analysis, ALT dropped from 34.6+1.2 U/L in prehibernation serum to $21.4 \pm 1.1 \mathrm{U} / \mathrm{L}$ in hibernation serum $(p<0.0001)$, and AST dropped from $73.3 \pm 3.5 \mathrm{U} / \mathrm{L}$ in prehibernation serum to $53.7 \pm 3.4 \mathrm{U} / \mathrm{L}$ in hibernation serum $(p<0.0001)$. By both analysis methods, serum creatinine $(\mathrm{Crn})$ was significantly higher during hibernation, whereas blood urea nitrogen (BUN) was significantly lower in this season. Thus, the ratio BUN:Crn was significantly reduced during hibernation compared to active seasons, confirming that the bears were in a state of hibernation [137]. 
Relationships between serum factors are reported in Table 2.8. Briefly, total and ucOCN were inversely correlated to serotonin, adiponectin, and glucose. Additionally, serotonin was positively correlated to adiponectin and glucose. Adiponectin was positively correlated to ionized calcium, BSALP, TRACP, insulin, and glucose.

\subsection{Discussion}

For up to half a year of hibernation annually, bears remain mostly inactive in their dens [13], yet they do not lose bone mechanical or structural properties despite these long periods of disuse [16-21, 173, 174]. During hibernation, bears are in a unique state of energy preservation in which they do not eat, drink, or excrete wastes [13]. Previous studies suggest that values of total serum calcium remain unchanged between active and hibernating periods [35]. In humans undergoing bed rest disuse studies, bone turnover is unbalanced such that calcium is released from bone, raising plasma calcium levels. Mobilized calcium is then excreted in urine [36, 175]. Bears do not urinate during hibernation; therefore calcium is not excreted in this manner. Thus, for hibernating bears to remain eucalcemic, calcium released by bone resorption is likely recycled back into bone through new bone formation. An argument can be made that although calcium is not excreted by urination during hibernation, some calcium is lost through lactation. Additionally, although the volume of urine in the bladder remains constant throughout hibernation in bears [114], osmolality of the urine increases [113]. It is possible that calcium accumulates in the bladder of hibernating bears. However, such a loss of calcium through lactation or accumulation in concentrated urine would result in a loss of bone mineral and/or a significant drop in circulating calcium during hibernation. Bone mineral content increases [20] and serum calcium levels do not significantly drop [35] during hibernation in bears, suggesting that calcium released by bone resorption is returned to bone by new bone formation.

In contrast to the previous study [35], data from the current study suggested that total calcium decreased from prehibernation to post-hibernation seasons when analyzed by the "seasonal means" method (Table 2.3). This difference is likely due to the sampling dates chosen by each study. Our study began prehibernation sampling in November, whereas the previous study began in July. Similarly, our study ended 
post-hibernation sampling in the beginning of May, whereas the previous study ended in June. When examining the graphs of serum total calcium over time, both studies have a peak in November and a downward slope through April (Figure 2.3) [35]. In our study, the overall decrease was $4.7 \%$ between prehibernation and post-hibernation. Such a reduction in total calcium could explain the increased mineral content observed in bear bones during hibernation [20]. A 1\% reduction in total serum calcium corresponds to a $3 \%$ increase in lumbar spine BMD in human patients undergoing an exercise regime while confined to bed [176]. Total serum calcium can be separated into three fractions: free ionized calcium (approximately 47\%), protein-bound calcium (40\%), and anionbound calcium (13\%) $[177,178]$. Calcium is only bioactive in the ionized form. Therefore, ionized calcium was quantified in this study. "Seasonal means" analysis revealed an increase in ionized calcium during the post-hibernation season (Table 2.3). It is probable that ionized calcium increases in the spring despite reduced total serum calcium because of the decreased availability of serum proteins like albumin that bind calcium [179]. The current study found that total serum protein and albumin both decreased significantly in the spring (Tables 2.6 and 2.7).

This study showed that BSALP and TRACP decreased significantly during hibernation in black bears (Table 2.3). This matched histomorphometric data, which suggested a balanced reduction in osteoclast and osteoblast activities during hibernation $[18,20]$. Such a decrease in bone turnover would help hibernating bears preserve energy during this extended anorectic period. Despite this decrease in BSALP and TRACP, the finding that serum OCN increases during hibernation [34] was confirmed by the current study (Tables 2.2 and 2.3), suggesting that OCN should not be used as an indicator of bone formation in the hibernating bear. As stated earlier, hibernating bears can be compared to hemodialysis patients because of their reduced renal function during denning $[113,114]$. BSALP and TRACP are good indicators of bone turnover in hemodialysis patients because they are not removed from the blood by renal filtration [143-145, 148, 149]. In contrast, OCN accumulates in the blood of hemodialysis patients because it is normally excreted in urine. Therefore, it is not an ideal indicator of bone turnover in patients with reduced renal function [143-146]. In humans, a 30\% decrease in glomerular filtration rate results in an approximate $65 \%$ increase in serum OCN [148]. In hibernating bears, serum OCN increased by $285 \%$ compared to prehibernation values 
(Table 2.3). Some of this accumulation could be explained by the $30 \%$ reduction in glomerular filtration rate during hibernation in bears [113], but such a large increase in serum OCN during hibernation suggests that there may be another reason for the rise in OCN levels.

It is possible that during the extended anorectic period of hibernation in bears $\mathrm{OCN}$ acts as a hormone to help regulate energy metabolism. ucOCN can increase insulin and adiponectin secretion in mice $[152,153]$. The current study demonstrated a dramatic increase in ucOCN, as well as the ratio of ucOCN to total OCN, during hibernation (Tables 2.2 and 2.3). If ucOCN controlled energy homeostasis in the hibernating bear as it does in mice, an increase in insulin and adiponectin during hibernation would be expected. In fact, there were significant decreases in insulin, glucose, and adiponectin levels in the serum of hibernating bears (Table 2.5). In humans, OCN has an inverse relationship with plasma glucose, insulin resistance, and fat mass; and a positive relationship to adiponectin [158, 180-186]. In the black bear during the months immediately surrounding and encompassing hibernation, total and ucOCN were negatively correlated to adiponectin and glucose, and had no correlation to insulin (Table 2.8). Although the negative relationship between OCN and adiponectin cannot be explained by current literature, it is possible that in the unique physiological environment in the months surrounding and encompassing hibernation, OCN may have an altered relationship to adiponectin. The relationship between adiponectin and energy homeostasis is complex, and can vary depending on physiological state (for review see: [187]).

Interestingly, total and ucOCN were negatively correlated to serotonin in the serum of black bears during the months of study (Table 2.8). Currently, there is no literature reporting a correlation between serum serotonin and osteocalcin in humans or other animals. However, mice on a tryptophan-deficient diet, which lack the essential amino acid for serotonin production, display reduced serum osteocalcin levels [188]. This finding suggests a positive relationship between serotonin and serum osteocalcin. Without further study, it is difficult to determine whether serotonin is negatively correlated to total and ucOCN in humans and other animals, or whether this correlation is a unique occurrence in bears during the months surrounding and encompassing hibernation. It is 
also unclear whether ucOCN may affect serotonin levels, or vice verse. In the current study there were positive correlations of serotonin to adiponectin and glucose (Table 2.8). These correlations are likewise puzzling. Serotonin $2 A(5 H T-2 A)$ receptor antagonists increase serum adiponectin [189]. Suppression of 5HT-2A receptor gene expression enhances adiponectin secretion in adipocytes [190]. These studies suggest an inverse relationship between serotonin and adiponectin. Another study suggests that serotonin improves glucose uptake [191]. Therefore, the positive relationship of serotonin to adiponectin and glucose does not coincide with current literature; however, serotonin may have a unique relationship to adiponectin and glucose during hibernation, and further study is needed to determine whether these positive relationships are due to direct interactions with serotonin.

During hibernation in bears, carbohydrate metabolism apparently halts and the bears switch entirely to fat metabolism (for review see: [13]). The evidence for this claim is that lean body mass does not change during hibernation in bears [112, 192], and the respiratory quotient $(R Q)$ drops to 0.60 during hibernation [112]. Fat combustion provides the lowest theoretically possible $R Q$ at 0.71 . One review suggests that hibernating bears obtain the low RQ of 0.60 by switching entirely to fat metabolism and fixating $\mathrm{CO}_{2}$ in the liver [13], which occurs in other hibernators [193]. In the current study, insulin and glucose levels were lower in the hibernating bear serum than in the active bear serum (Table 2.5). This decrease in insulin and glucose during hibernation may be due to the switch to fat metabolism at this time. A similar drop in serum glucose has been observed in hibernating black bears previously [112]. Both serum glucose and insulin were positively correlated to adiponectin in the current study (Table 2.8). Although adiponectin generally reduces blood glucose by increasing insulin sensitivity [194, 195], the relationship between adiponectin and glucose homeostasis is complex. Patients with genetically defective insulin receptors have elevated plasma adiponectin [196], and patients with type I diabetes have elevated serum levels of high molecular weight adiponectin [197]. Since the patients of these two studies tend to be hyperglycemic, it is clear that in some situations serum adiponectin may have a positive relationship to serum glucose levels, as is observed in black bears during the months immediately surrounding and encompassing hibernation. 
Reduced adiponectin levels were observed in the serum of hibernating bears (Tables 2.4 and 2.5). This reduction could be related to the increased mobilization of triglycerides during hibernation [112]. Adiponectin is negatively correlated to serum triglyceride levels in healthy human females [198]. This decrease in serum adiponectin may also reduce bone turnover and protect bone during hibernation. Serum adiponectin has a consistent inverse relationship to $\operatorname{BMD}[186,199,200]$, and adiponectin knockout mice have increased trabecular bone volume and trabecular number at 14 weeks of age [201]. In cultured osteoblasts, adiponectin stimulates osteoblast proliferation, differentiation, and expression of BSALP [157, 158, 201, 202]. Furthermore, a positive correlation between BSALP and serum adiponectin has been discovered in men and post-menopausal women [203-205]. These studies suggest that adiponectin promotes osteoblast activity. Conversely, adiponectin increases osteoblast gene expression of the pro-resorptive cytokine RANKL with a concurrent decrease in the decoy receptor of RANKL, osteoprotegerin (OPG) [206]. There is an inverse correlation between serum levels of high molecular weight adiponectin and serum OPG in post-menopausal women [207]. These studies suggest that adiponectin may promote osteoclast activity through osteoblasts. In hibernating bears, reduced levels of adiponectin may result in suppression of osteoblast and osteoclast activities. In support of this idea, BSALP and TRACP were positively correlated to adiponectin in the serum of black bears (Table 2.8). Thus, suppressed adiponectin during hibernation may help conserve energy by reducing bone metabolism. Such a reduction in bone turnover during hibernation in bears has been observed in histomorphometric analyses of cortical and trabecular bone [18, 20]. These data are supported by the drops in serum BSALP and TRACP during hibernation in the current study.

One limitation of the current study is that total serum osteocalcin (including fragments) was quantified. Intact circulating OCN is quickly broken into fragments [208], and has a half-life of approximately five minutes. In patients with reduced renal function, fragments of OCN accumulate in the serum. Only $26 \%$ of total OCN in uremic serum is intact [209, 210]. Since hibernating bears can be compared to patients with reduced renal function, it is likely that a large portion of the reported OCN was fragmented. The bioactivities of such fragments are unknown, but some can promote osteoclast maturation [211] or function as an indicator of bone resorption [212]. Quantification of 
ratios of intact to fragmented $\mathrm{OCN}$ may provide further insight into the unique physiology of hibernating bears. Vitamin $\mathrm{K}$ levels were below detectable limits in all serum samples in this study. Carboxylation of OCN is a vitamin K-dependent mechanism, therefore it would be interesting to know whether ucOCN increases during hibernation due to a vitamin $\mathrm{K}$ deficiency, or whether its production is regulated by other mechanisms. Since it is unlikely that vitamin $\mathrm{K}$ is completely absent in bears, quantification in adipose tissue may provide further insight into the origin of ucOCN during hibernation. Another limitation of this study is that serum was only collected in the months immediately surrounding and encompassing hibernation. Thus, the bears were either preparing for hibernation, hibernating, or recovering from hibernation throughout sample collection. The relationship between $\mathrm{OCN}$ and energy may be different during this season than in the summer months. A last limitation is that serum was collected under anesthesia, which could have an impact on endocrine concentrations during the blood collection; however, the same dose of anesthesia was given each time.

In summary, TRACP and BSALP match histomorphometric data $[18,20]$ to suggest a reduction in both the resorption and the formation of bone during hibernation. Such a decrease in metabolism would help hibernating bears conserve energy. This suppression of bone turnover could be due, in part, to reduced serum adiponectin levels during hibernation. The spike in OCN in the winter months should not be interpreted as a marker of bone formation; instead it may have passively built up in serum due to reduced renal function. Alternatively, it could act as an energy homeostasis hormone. The inverse relationship of $\mathrm{OCN}$ to glucose levels in bears is similar to those found in previous studies; however, the current study found an inverse relationship between OCN and adiponectin, which is not found in previous studies. The negative correlation between OCN and adiponectin may be due to the unique physiological state of hibernation (i.e. hypoglycemia, increased triglyceride mobilization, etc.). Finally, serum serotonin had an inverse relationship to osteocalcin and a positive relationship to glucose and adiponectin. These relationships have not been reported previously. Serotonin is known to have an impact on glucose sensitivity and adiponectin secretion, but from these previous studies an inverse relationship between adiponectin and serotonin would be expected. Again, adiponectin activity is complex, and not fully understood. Adiponectin may have a unique relationship with serotonin during 
hibernation in bears. Further study is necessary to explore the role of adiponectin in hibernating bears.

\subsection{Tables and figures}

Table 2.1-Summary of assays

The number of bears and assays that were performed in each hibernation season. *The number of bears that gave birth to cubs is in parentheses. Unknown values are indicated as "UK."

\begin{tabular}{|c|c|c|c|c|}
\hline Season & Bears & $\begin{array}{c}\text { Age } \\
\text { (years) }\end{array}$ & Assays & Data Location \\
\hline 2003-2004 & $5(5)$ & $3-12$ & Total OCN & $\begin{array}{c}\text { Figure } 2.3 \\
\text { Tables } 2.2,2.3,2.8, \\
2.9\end{array}$ \\
\hline 2006-2007 & $2(1)$ & UK & Ionized Calcium, Serotonin & $\begin{array}{c}\text { Tables } 2.2-2.5 \\
2.8,2.9\end{array}$ \\
\hline 2007-2008 & $4(3)$ & $5-14$ & $\begin{array}{c}\text { TRACP, BSALP, Total ALP, Total } \\
\text { Calcium, Ionized Calcium, Total OCN, } \\
\text { ucOCN, \%ucOCN, Vitamin K, } \\
\text { Adiponectin, Glucose, Insulin, Serotonin, } \\
\text { Total Protein, Albumin, Globulin, AST, } \\
\text { ALT, BUN, Creatinine }\end{array}$ & $\begin{array}{l}\text { Figures } 2.1-2.7 \\
\text { Tables } 2.2-2.9\end{array}$ \\
\hline 2008-2009 & $5(3)$ & $2-21$ & $\begin{array}{l}\text { TRACP, BSALP, Total ALP, Adiponectin, } \\
\text { Glucose, Insulin }\end{array}$ & $\begin{array}{c}\text { Figures } 2.1,2.2 \\
2.5-2.7 \\
\text { Tables } 2.2-2.5 \\
2.8,2.9\end{array}$ \\
\hline
\end{tabular}

Table 2.2-Bone marker longitudinal "peak-valley" analyses

Data are represented as LSM $\pm S E$. The date of "peak-valley" analysis is indicted below the mean serum concentrations. Letters $(A, B, C)$ represent values that are significantly different from each other at $\alpha=0.05$. The $p$-value reported is for the partial F-test for the serum factor.

\begin{tabular}{|c|c|c|c|c|c|c|c|}
\hline $\begin{array}{l}\text { Serum } \\
\text { Factor }\end{array}$ & & $\begin{array}{c}\text { Fall } \\
\text { Active }\end{array}$ & $\begin{array}{c}\text { Winter } \\
\text { Hibernation }\end{array}$ & $\begin{array}{l}\text { Spring } \\
\text { Active }\end{array}$ & $N_{\text {bears }}$ & $\mathbf{p}$ & Power \\
\hline \multirow{2}{*}{$\begin{array}{c}\text { BSALP } \\
(\mathrm{U} / \mathrm{L})\end{array}$} & LSM $\pm S E$ & $30.6 \pm 9.2^{A}$ & $7.63 \pm 0.86^{\mathrm{B}}$ & $19.1 \pm 4.7^{\mathrm{AB}}$ & \multirow[b]{2}{*}{7} & \multirow{2}{*}{0.0149} & \multirow{2}{*}{0.7897} \\
\hline & Date & $10 / 11$ & $\overline{1 / 19}$ & $4 / 29$ & & & \\
\hline \multirow{2}{*}{$\begin{array}{c}\text { TRACP } \\
\text { (relative) }\end{array}$} & LSM \pm SE & $1.25 \pm 0.17^{A}$ & $0.833 \pm 0.05^{B}$ & $1.44 \pm 0.10^{A}$ & \multirow{2}{*}{9} & \multirow{2}{*}{0.0040} & \multirow{2}{*}{$0.909 c$} \\
\hline & Date & $1 \overline{2} / 20$ & $1 / \overline{19}$ & $4 / 19$ & & & \\
\hline \multirow{2}{*}{$\begin{array}{c}\text { Total Calcium } \\
\text { (mg/dL) }\end{array}$} & LSM+SE & $8.8 \pm 0.3$ & $8.5 \pm 0.2$ & $8.3 \pm 0.4$ & \multirow{2}{*}{3} & \multirow{2}{*}{0.6649} & \multirow{2}{*}{0.0863} \\
\hline & Date & $11 / 20$ & $1 / \overline{29}$ & $\overline{4 / 8}$ & & & \\
\hline \multirow{2}{*}{$\begin{array}{l}\text { lonized } \\
\text { Calcium } \\
\text { (mg/dL) }\end{array}$} & $\mathrm{LSM} \pm \mathrm{SE}$ & $3.61 \pm 0.06$ & $3.65 \pm 0.06$ & $3.77 \pm 0.75$ & \multirow[b]{2}{*}{5} & \multirow[b]{2}{*}{0.344} & \multirow[b]{2}{*}{0.1918} \\
\hline & Date & $11 / 20$ & $1 / 29$ & $4 / 18$ & & & \\
\hline \multirow{2}{*}{$\begin{array}{c}\text { Total OCN } \\
(\mathrm{ng} / \mathrm{mL})\end{array}$} & $\mathrm{LSM} \pm \mathrm{SE}$ & $12.5 \pm 1.7^{C}$ & $89.7 \pm 11.4^{A}$ & $46.0 \pm 7.6^{\mathrm{B}}$ & \multirow{2}{*}{9} & \multirow{2}{*}{$<0.0001$} & \multirow{2}{*}{1} \\
\hline & Date & $11 / 20$ & $3 / 19$ & $4 \overline{2} 8$ & & & \\
\hline \multirow{2}{*}{ ucOCN } & LSM $\pm S E$ & $0.050 \pm 0.050^{B}$ & $21.0 \pm 4.8^{\mathrm{A}}$ & $3.75 \pm 2.14^{B}$ & \multirow{2}{*}{4} & \multirow{2}{*}{0.0019} & \multirow{2}{*}{0.9945} \\
\hline & Date & $11 / 20$ & $3 / 9$ & $4 / 28$ & & & \\
\hline \multirow{2}{*}{$\begin{array}{l}\text { Percent } \\
\text { ucOCN }\end{array}$} & LSM \pm SE & $0.693 \pm 0.693^{B}$ & $29.3 \pm 5.9^{A}$ & $8.42 \pm 3.52^{B}$ & \multirow{2}{*}{4} & \multirow{2}{*}{0.0011} & \multirow{2}{*}{0.9987} \\
\hline & Date & $11 / 20$ & $3 / 9$ & $4 / 28$ & & & \\
\hline
\end{tabular}


Table 2.3-Bone marker "seasonal means" analyses

Data are represented as $L S M+S E$. The total number of samples included in the ANOVA is indicated below the mean concentrations. Letters (A, B, C) represent values that are significantly different from each other at $\alpha=0.05$. The $p$-value reported is for the partial F-test for the serum factor.

\begin{tabular}{|c|c|c|c|c|c|c|}
\hline $\begin{array}{l}\text { Serum } \\
\text { Factor }\end{array}$ & & $\begin{array}{c}\text { Fall } \\
\text { Active }\end{array}$ & $\begin{array}{c}\text { Winter } \\
\text { Hibernation }\end{array}$ & $\begin{array}{l}\text { Spring } \\
\text { Active }\end{array}$ & $\mathbf{p}$ & Power \\
\hline BSALP & LSM+SE & $21.0 \pm 1.27^{A}$ & $8.79 \pm 1.20^{\mathrm{B}}$ & $19.5 \pm 1.86^{\mathrm{A}}$ & \multirow{2}{*}{$<0.0001$} & \multirow{2}{*}{1} \\
\hline$(\mathrm{U} / \mathrm{L})$ & $\mathrm{N}_{\text {samples }}$ & $\overline{5} 8$ & $\overline{6} 1$ & $\overline{2} 6$ & & \\
\hline \multirow{2}{*}{$\begin{array}{l}\text { TRACP } \\
\text { (relative) }\end{array}$} & LSM+SE & $1.18 \pm 0.03^{A}$ & $0.966 \pm 0.031^{\mathrm{B}}$ & $1.31 \pm 0.05^{A}$ & \multirow{2}{*}{$<0.0001$} & \multirow{2}{*}{1} \\
\hline & $\mathrm{N}_{\text {samples }}$ & 66 & 71 & 31 & & \\
\hline \multirow{2}{*}{$\begin{array}{l}\text { Total Calcium } \\
(\mathrm{mg} / \mathrm{dL})\end{array}$} & LSM $\pm S E$ & $8.66 \pm 0.07^{A}$ & $8.47 \pm 0.07^{A B}$ & $8.25 \pm 0.10^{B}$ & \multirow{2}{*}{0.0068} & \multirow{2}{*}{0.8327} \\
\hline & $\mathrm{N}_{\text {samples }}$ & 19 & 21 & 11 & & \\
\hline \multirow{2}{*}{$\begin{array}{l}\text { Ionized Calcium } \\
(\mathrm{mg} / \mathrm{dL})\end{array}$} & $\mathrm{LSM} \pm \mathrm{SE}$ & $3.63 \pm 0.02^{A B}$ & $3.61 \pm 0.02^{B}$ & $3.73 \pm 0.03^{A}$ & \multirow{2}{*}{0.0202} & \multirow{2}{*}{0.7119} \\
\hline & $\mathrm{N}_{\text {samples }}$ & 31 & 36 & 16 & & \\
\hline \multirow{2}{*}{$\begin{array}{c}\text { Total OCN } \\
(\mathrm{ng} / \mathrm{mL})\end{array}$} & LSM \pm SE & $15.8 \pm 3.5^{C}$ & $61.1 \pm 3.0^{A}$ & $43.9 \pm 3.8^{B}$ & \multirow{2}{*}{$<0.0001$} & \multirow{2}{*}{1} \\
\hline & $\mathrm{N}_{\text {samples }}$ & 38 & 54 & 33 & & \\
\hline \multirow{2}{*}{$\begin{array}{l}\text { ucOCN } \\
(\mathrm{ng} / \mathrm{mL})\end{array}$} & LSM+SE & $0.324 \pm 1.29^{B}$ & $9.81 \pm 1.09^{A}$ & $2.68 \pm 1.65^{\mathrm{B}}$ & \multirow{2}{*}{$<0.0001$} & \multirow{2}{*}{0.9997} \\
\hline & $\mathrm{N}_{\text {samples }}$ & 23 & 32 & 14 & & \\
\hline \multirow{2}{*}{ Percent ucOCN } & $\mathrm{LSM} \pm \mathrm{SE}$ & $1.15 \pm 1.49^{B}$ & $15.5 \pm 1.27^{A}$ & $6.36 \pm 1.92^{\mathrm{B}}$ & \multirow{2}{*}{$<0.0001$} & \multirow{2}{*}{1} \\
\hline & $N_{\text {samples }}$ & 23 & 32 & 14 & & \\
\hline
\end{tabular}

Table 2.4-Energy homeostasis longitudinal "peak-valley" analyses

Data are represented as LSM+SE. The date of "peak-valley" analysis is indicted below the mean serum concentrations. Letters $(A, B, C)$ represent values that are significantly different from each other at $\alpha=0.05$. The $p$-value reported is for the partial F-test for the serum factor.

\begin{tabular}{|c|c|c|c|c|c|c|c|}
\hline $\begin{array}{l}\text { Serum } \\
\text { Factor }\end{array}$ & & $\begin{array}{c}\text { Fall } \\
\text { Active }\end{array}$ & $\begin{array}{c}\text { Winter } \\
\text { Hibernation }\end{array}$ & $\begin{array}{l}\text { Spring } \\
\text { Active }\end{array}$ & $\mathbf{N}_{\text {bears }}$ & $\mathbf{p}$ & Power \\
\hline \multirow{2}{*}{$\begin{array}{l}\text { Adiponectin } \\
(\mathrm{ng} / \mathrm{mL})\end{array}$} & LSM+SE & $1999 \pm 172^{A}$ & $1275 \pm 46^{\mathrm{B}}$ & $1936 \pm 91^{A}$ & \multirow{2}{*}{9} & \multirow{2}{*}{0.0005} & \multirow{2}{*}{0.9891} \\
\hline & Date & $11 / \overline{30}$ & $1 / \overline{29}$ & $4 / \overline{28}$ & & & \\
\hline \multirow{2}{*}{$\begin{array}{l}\text { Glucose } \\
\text { (mg/dL) }\end{array}$} & $\mathrm{LSM} \pm \mathrm{SE}$ & $194 \pm 12^{A}$ & $110 \pm 12^{B}$ & $141 \pm 17^{\mathrm{B}}$ & \multirow{2}{*}{9} & \multirow{2}{*}{0.0002} & \multirow{2}{*}{0.9970} \\
\hline & Date & $12 / 20$ & $2 / 28$ & 4/19 & & & \\
\hline \multirow{2}{*}{$\begin{array}{l}\text { Insulin } \\
(\mu \mathrm{U} / \mathrm{mL})\end{array}$} & LSM+SE & $7.49 \pm 1.15$ & $5.78 \pm 0.70$ & $8.71 \pm 1.67$ & \multirow{2}{*}{9} & \multirow{2}{*}{0.1416} & \multirow{2}{*}{0.3849} \\
\hline & Date & $11 / 20$ & 2/18 & $4 / 28$ & & & \\
\hline \multirow{2}{*}{$\begin{array}{l}\text { Serotonin } \\
(\mathrm{ng} / \mathrm{mL})\end{array}$} & LSM+SE & $859+99.9$ & $508+53.3$ & $809 \pm 72.4$ & \multirow{2}{*}{5} & \multirow{2}{*}{0.0667} & \multirow{2}{*}{0.5281} \\
\hline & Date & $11 / 20$ & $3 / 19$ & $4 / 28$ & & & \\
\hline
\end{tabular}


Table 2.5-Energy homeostasis "seasonal means" analyses

Data are represented as $L S M \pm S E$. The total number of samples included in the ANOVA is indicated below the mean concentrations. Letters (A, B, C) represent values that are significantly different from each other at $\alpha=0.05$. The $p$-value reported is for the partial F-test for the serum factor.

\begin{tabular}{|c|c|c|c|c|c|c|}
\hline $\begin{array}{l}\text { Serum } \\
\text { Factor }\end{array}$ & & $\begin{array}{c}\text { Fall } \\
\text { Active }\end{array}$ & $\begin{array}{c}\text { Winter } \\
\text { Hibernation }\end{array}$ & $\begin{array}{l}\text { Spring } \\
\text { Active }\end{array}$ & $\mathbf{p}$ & Power \\
\hline \multirow{2}{*}{$\begin{array}{c}\text { Adiponectin } \\
(\mathrm{ng} / \mathrm{mL})\end{array}$} & $\mathrm{LSM} \pm \mathrm{SE}$ & $1912 \pm 42^{\mathrm{A}}$ & $1347 \pm 40^{\mathrm{B}}$ & $1919 \pm 61^{A}$ & \multirow{2}{*}{$<0.0001$} & \multirow{2}{*}{1} \\
\hline & $\mathrm{N}_{\text {samples }}$ & $6 \overline{9}$ & $7 \overline{3}$ & $3 \overline{2}$ & & \\
\hline \multirow{2}{*}{$\begin{array}{l}\text { Glucose } \\
\text { (mg/dL) }\end{array}$} & $\mathrm{LSM} \pm \mathrm{SE}$ & $178 \pm 5^{A}$ & $118 \pm 5^{B}$ & $136 \pm 7^{B}$ & \multirow{2}{*}{$<0.0001$} & \multirow{2}{*}{1} \\
\hline & $\mathrm{N}_{\text {samples }}$ & $6 \overline{3}$ & 63 & $2 \overline{5}$ & & \\
\hline \multirow{2}{*}{$\begin{array}{c}\text { Insulin } \\
(\mu \mathrm{U} / \mathrm{mL})\end{array}$} & $\mathrm{LSM} \pm \mathrm{SE}$ & $6.81 \pm 0.24^{A}$ & $5.78 \pm 0.23^{B}$ & $7.72 \pm 0.35^{A}$ & \multirow{2}{*}{$<0.0001$} & \multirow{2}{*}{0.9948} \\
\hline & $\mathrm{N}_{\text {samples }}$ & 68 & 66 & 29 & & \\
\hline \multirow{2}{*}{$\begin{array}{l}\text { Serotonin } \\
(\mathrm{ng} / \mathrm{mL})\end{array}$} & $\mathrm{LSM} \pm \mathrm{SE}$ & $788 \pm 29.9^{A}$ & $593+25.5^{\mathrm{B}}$ & $689 \pm 40.2^{A B}$ & \multirow{2}{*}{$<0.0001$} & \multirow{2}{*}{0.9949} \\
\hline & $\mathrm{N}_{\text {samples }}$ & $\overline{33}$ & $\overline{4} 7$ & 19 & & \\
\hline
\end{tabular}

Table 2.6-Chemistry panel longitudinal "peak-valley" analyses

Data are represented as LSM+SE. The date of "peak-valley" analysis is indicted below the mean serum concentrations. Letters $(A, B, C)$ represent values that are significantly different from each other at $\alpha=0.05$. The $p$-value reported is for the partial F-test for the serum factor.

\begin{tabular}{|c|c|c|c|c|c|c|c|}
\hline $\begin{array}{l}\text { Serum } \\
\text { Factor }\end{array}$ & & $\begin{array}{l}\text { Fall } \\
\text { Active }\end{array}$ & $\begin{array}{c}\text { Winter } \\
\text { Hibernation }\end{array}$ & $\begin{array}{l}\text { Spring } \\
\text { Active }\end{array}$ & $N_{\text {bears }}$ & $p$ & Power \\
\hline \multirow{2}{*}{$\begin{array}{l}\text { Total Bilirubin } \\
\text { (mg/dL) }\end{array}$} & $\mathrm{LSM} \pm \mathrm{SE}$ & $0.133 \pm 0.033$ & $0.167 \pm 0.033$ & $0.100 \pm 0.00$ & \multirow{2}{*}{3} & \multirow{2}{*}{0.444} & \multirow{2}{*}{0.1326} \\
\hline & Date & $1 \overline{1 / 20}$ & $2 / 18$ & $4 / 28$ & & & \\
\hline \multirow{2}{*}{$\begin{array}{l}\text { Total Protein } \\
(\mathrm{g} / \mathrm{dL})\end{array}$} & LSM+SE & $7.83+0.38^{A}$ & $7.73+0.18^{A}$ & $6.56+0.09^{B}$ & \multirow[t]{2}{*}{3} & \multirow[t]{2}{*}{0.0264} & \multirow[t]{2}{*}{0.7663} \\
\hline & Date & $11 / 20$ & $2 / 18$ & $4 / 18$ & & & \\
\hline \multirow{2}{*}{$\begin{array}{c}\text { Albumin } \\
(\mathrm{g} / \mathrm{dL})\end{array}$} & LSM $\pm S E$ & $4.23 \pm 0.07^{A}$ & $4.20 \pm 0.23^{\mathrm{A}}$ & $3.33 \pm 0.18^{B}$ & \multirow[t]{2}{*}{3} & \multirow[t]{2}{*}{0.0237} & \multirow[t]{2}{*}{0.7916} \\
\hline & Date & $1 \overline{2 / 10}$ & $\overline{1 / 29}$ & $\overline{4 / 18}$ & & & \\
\hline \multirow{2}{*}{$\begin{array}{c}\text { Globulin } \\
\text { (g/dL) }\end{array}$} & $\mathrm{LSM} \pm \mathrm{SE}$ & $3.57 \pm 0.29$ & $3.80 \pm 0.35$ & $3.23 \pm 0.19$ & \multirow[t]{2}{*}{3} & \multirow[t]{2}{*}{0.3425} & \multirow[t]{2}{*}{0.1689} \\
\hline & Date & $11 / 20$ & $3 / 9$ & $4 / 18$ & & & \\
\hline \multirow{2}{*}{$\begin{array}{c}\text { Total ALP } \\
(\mathrm{U} / \mathrm{L})\end{array}$} & $\mathrm{LSM} \pm \mathrm{SE}$ & $59.2 \pm 9.3^{A}$ & $32.3 \pm 1.3^{\mathrm{B}}$ & $51.0 \pm 6.3^{\mathrm{A}}$ & \multirow{2}{*}{7} & \multirow{2}{*}{0.0060} & \multirow{2}{*}{0.8939} \\
\hline & Date & $10 / 11$ & $1 / 19$ & $4 / 29$ & & & \\
\hline \multirow{2}{*}{$\begin{array}{l}\text { AST } \\
(\mathrm{U} / \mathrm{L})\end{array}$} & LSM $\pm S E$ & $78.3 \pm 7.6^{A}$ & $53.5 \pm 3.8^{\mathrm{B}}$ & $50.3 \pm 0.17^{\mathrm{B}}$ & \multirow{2}{*}{4} & \multirow{2}{*}{0.0024} & \multirow{2}{*}{0.9906} \\
\hline & Date & $12 / 10$ & $3 / 9$ & $4 / 18$ & & & \\
\hline \multirow{2}{*}{$\begin{array}{l}\text { ALT } \\
(\mathrm{U} / \mathrm{L})\end{array}$} & LSM \pm SE & $34.3 \pm 2.9^{\mathrm{A}}$ & $18.0 \pm 2.5^{B}$ & $16.7 \pm 2.2^{B}$ & \multirow{2}{*}{3} & \multirow{2}{*}{0.0095} & \multirow{2}{*}{0.9453} \\
\hline & Date & $12 / 10$ & $3 / 29$ & $4 / 18$ & & & \\
\hline \multirow[t]{2}{*}{ AST/ALT } & LSM \pm SE & $1.92 \pm 0.16^{\mathrm{B}}$ & $2.70 \pm 0.25^{A}$ & $2.87 \pm 2.4^{\mathrm{A}}$ & \multirow{2}{*}{4} & \multirow{2}{*}{0.0144} & \multirow{2}{*}{0.8456} \\
\hline & Date & $12 / 20$ & $3 / 9$ & 200 & & & \\
\hline \multirow{2}{*}{$\begin{array}{c}\text { BUN } \\
(\mathrm{mg} / \mathrm{dL})\end{array}$} & LSM \pm SE & $18.3 \pm 3.8^{A}$ & $4.67 \pm 0.33^{\mathrm{B}}$ & $18.7 \pm 2.4^{\mathrm{A}}$ & \multirow{2}{*}{3} & & \\
\hline & Date & $11 / 20$ & $\overline{3 / 9}$ & $4 / 18$ & & 0.0152 & 0.8812 \\
\hline Crn & $\mathrm{LSM} \pm \mathrm{SE}$ & $1.79 \pm 0.063^{\mathrm{B}}$ & $2.77 \pm 0.28^{A}$ & $1.62 \pm 0.13^{\mathrm{B}}$ & & & \\
\hline$(\mathrm{mg} / \mathrm{dL})$ & Date & $11 / 20$ & $2 / 18$ & $4 / 28$ & 3 & 0.0043 & 0.9920 \\
\hline RINA. $\mathrm{cm}$ & LSM $\pm S E$ & $10.4+2.5^{\mathrm{A}}$ & $1.72 \pm 0.24^{\mathrm{B}}$ & $10.8 \pm 2.9^{A}$ & & (2023? & 07060 \\
\hline & Date & $11 / 20$ & $3 / 9$ & $4 / 28$ & 3 & 0.0232 & 0.7968 \\
\hline
\end{tabular}


Table 2.7-Chemistry panel "seasonal means" analyses

Data are represented as LSM \pm SE. The total number of samples included in the ANOVA is indicated below the mean concentrations. Letters (A, B, C) represent values that are significantly different from each other at $\alpha=0.05$. The $p$-value reported is for the partial F-test for the serum factor.

\begin{tabular}{|c|c|c|c|c|c|c|}
\hline $\begin{array}{l}\text { Serum } \\
\text { Factor }\end{array}$ & & $\begin{array}{c}\text { Fall } \\
\text { Active }\end{array}$ & $\begin{array}{c}\text { Winter } \\
\text { Hibernation }\end{array}$ & $\begin{array}{l}\text { Spring } \\
\text { Active }\end{array}$ & $\mathbf{p}$ & Power \\
\hline \multirow{2}{*}{$\begin{array}{l}\text { Total Bilirubin } \\
(\mathrm{mg} / \mathrm{dL})\end{array}$} & LSM+SE & $0.117 \pm 0.010$ & $0.146 \pm 0.010$ & $0.112 \pm 0.014$ & \multirow{2}{*}{0.0510} & \multirow{2}{*}{0.5804} \\
\hline & $\mathrm{N}_{\text {samples }}$ & 19 & 21 & 10 & & \\
\hline \multirow{2}{*}{$\begin{array}{c}\text { Total Protein } \\
(\mathrm{g} / \mathrm{dL})\end{array}$} & $\mathrm{LSM}+\mathrm{SE}$ & $7.75 \pm 0.09^{A}$ & $7.75 \pm 0.09^{A}$ & $6.64 \pm 0.12^{B}$ & \multirow{2}{*}{$<0.0001$} & \multirow{2}{*}{1} \\
\hline & $\mathrm{N}_{\text {samples }}$ & 19 & 34 & 11 & & \\
\hline \multirow{2}{*}{$\begin{array}{l}\text { Albumin } \\
\text { (g/dL) }\end{array}$} & $\mathrm{LSM} \pm \mathrm{SE}$ & $4.13 \pm 0.06^{A}$ & $4.07 \pm 0.06^{A}$ & $3.46 \pm 0.08^{\mathrm{B}}$ & \multirow{2}{*}{$<0.0001$} & \multirow{2}{*}{1} \\
\hline & $\mathrm{N}_{\text {samples }}$ & 19 & 21 & 11 & & \\
\hline \multirow{2}{*}{$\begin{array}{l}\text { Globulin } \\
\text { (g/dL) }\end{array}$} & LSM_SE & $3.67 \pm 0.07^{A}$ & $3.68 \pm 0.06^{A}$ & $3.19 \pm 0.09^{B}$ & \multirow{2}{*}{$<0.0001$} & \multirow{2}{*}{0.9929} \\
\hline & $\mathrm{N}_{\text {samples }}$ & 19 & 21 & 11 & & \\
\hline \multirow{2}{*}{ Total ALP (U/L) } & LSM+SE & $47.3 \pm 1.4^{A}$ & $33.9 \pm 1.3^{B}$ & $47.5 \pm 2.0^{A}$ & \multirow{2}{*}{$<0.0001$} & \multirow{2}{*}{1} \\
\hline & $\mathrm{N}_{\text {samples }}$ & 58 & 61 & 26 & & \\
\hline \multirow{2}{*}{$\begin{array}{l}\text { AST } \\
(\mathrm{U} / \mathrm{L})\end{array}$} & $\mathrm{LSM} \pm \mathrm{SE}$ & $73.3 \pm 3.5^{A}$ & $53.7 \pm 3.4^{\mathrm{B}}$ & $49.6 \pm 4.7^{\mathrm{B}}$ & \multirow{2}{*}{0.0001} & \multirow{2}{*}{0.9883} \\
\hline & $\mathrm{N}_{\text {samples }}$ & 19 & 21 & 11 & & \\
\hline \multirow{2}{*}{$\begin{array}{l}\mathrm{ALT} \\
(\mathrm{U} / \mathrm{L})\end{array}$} & LSM $\pm S E$ & $34.6 \pm 1.2^{A}$ & $21.4 \pm 1.1^{\mathrm{B}}$ & $18.9 \pm 1.5^{\mathrm{B}}$ & \multirow{2}{*}{$<0.0001$} & \multirow{2}{*}{1} \\
\hline & $\mathrm{N}_{\text {samples }}$ & 19 & 21 & 11 & & \\
\hline \multirow{2}{*}{ AST/ALT } & LSM+SE & $2.10 \pm 0.10^{B}$ & $2.57 \pm 0.09^{A}$ & $2.71 \pm 0.13^{A}$ & \multirow{2}{*}{0.0005} & \multirow{2}{*}{0.9650} \\
\hline & $\mathrm{N}_{\text {samples }}$ & 19 & 23 & 11 & & \\
\hline \multirow{2}{*}{$\begin{array}{c}\text { BUN } \\
(\mathrm{mg} / \mathrm{dL})\end{array}$} & $\mathrm{LSM} \pm \mathrm{SE}$ & $16.6 \pm 1.3^{A}$ & $6.42 \pm 1.29^{B}$ & $15.3 \pm 1.76^{A}$ & \multirow{2}{*}{$<0.0001$} & \multirow{2}{*}{0.9996} \\
\hline & $\mathrm{N}_{\text {samples }}$ & 19 & 22 & 11 & & \\
\hline \multirow{2}{*}{$\begin{array}{c}\text { Crn } \\
(\mathrm{mg} / \mathrm{dL})\end{array}$} & $\mathrm{LSM} \pm \mathrm{SE}$ & $1.92 \pm 0.06^{B}$ & $2.69 \pm 0.06^{A}$ & $1.53 \pm 0.08^{\mathrm{C}}$ & \multirow{2}{*}{$<0.0001$} & \multirow{2}{*}{1} \\
\hline & $\mathrm{N}_{\text {samples }}$ & 19 & 21 & 11 & & \\
\hline \multirow[t]{2}{*}{ BUN:Crn } & $\mathrm{LSM} \pm \mathrm{SE}$ & $9.16 \pm 1.02^{A}$ & $3.21+0.95^{\mathrm{B}}$ & $10.5 \pm 1.4^{A}$ & \multirow{2}{*}{$<0.0001$} & \multirow{2}{*}{0.9971} \\
\hline & $\mathrm{N}_{\text {samples }}$ & 19 & 22 & 11 & & \\
\hline
\end{tabular}


Table 2.8-Serum factor linear regression models

\begin{tabular}{ccccccc}
$\begin{array}{c}\text { Dependent } \\
\text { Variable }\end{array}$ & $\begin{array}{c}\text { Independent } \\
\text { Variable }\end{array}$ & $\mathbf{N}_{\text {bears }}$ & $\boldsymbol{\beta}$ & $\mathbf{r}$ & $\mathbf{p}$ & Power \\
\hline Adiponectin & Total OCN & 4 & -10.43 & -0.521 & $<0.0001$ & 0.9863 \\
Adiponectin & ucOCN & 4 & -26.4 & -0.443 & 0.0020 & 0.8873 \\
Adiponectin & Serotonin & 4 & 0.899 & 0.411 & 0.0065 & 0.7918 \\
BSALP & TRACP & 9 & 22.7 & 0.723 & $<0.0001$ & 1 \\
BSALP & Adiponectin & 9 & 0.00676 & 0.627 & 0.0012 & 0.9077 \\
BSALP & Glucose & 9 & 0.0524 & 0.602 & 0.0290 & 0.5917 \\
lonized Calcium & Adiponectin & 4 & $9.05 e-5$ & 0.487 & 0.0277 & 0.6047 \\
Ionized Calcium & Glucose & 4 & 0.00106 & 0.508 & 0.0150 & 0.6961 \\
Glucose & Total OCN & 4 & -1.11 & -0.627 & $<0.0001$ & 0.9883 \\
Glucose & ucOCN & 4 & -2.628 & -0.533 & 0.0048 & 0.8259 \\
Glucose & Adiponectin & 9 & 0.0291 & 0.427 & 0.0014 & 0.9004 \\
Glucose & Serotonin & 4 & 0.103 & 0.570 & 0.0011 & 0.9258 \\
Insulin & Adiponectin & 9 & 0.00143 & 0.709 & $<0.0001$ & 0.9837 \\
Insulin & Total ALP & 9 & 0.0344 & 0.686 & 0.0112 & 0.7235 \\
Serotonin & Total OCN & 4 & -3.87 & -0.513 & $<0.0001$ & 0.9890 \\
Serotonin & ucOCN & 4 & -11.2 & -0.473 & 0.0003 & 0.9622 \\
TRACP & Adiponectin & 9 & 0.000117 & 0.430 & 0.0222 & 0.6313
\end{tabular}

Table 2.9-Serum factor effects analyses

Table reports all effects between age or cubs and serum factors, indicating the model in which the effect was significant. For an age effect, a "+" direction indicates that the serum factor increases with age. For a cub effect, a "+" direction indicates that the serum factor increases if cubs were born.

\begin{tabular}{ccccc} 
Serum & Effect & Model & Direction & p \\
Factor & & & & \\
\hline TRACP & Cubs & Seasonal Means & + & $<0.0001$ \\
TRACP & Cubs & Peak-Valley & + & 0.0431 \\
BSALP & Cubs & Seasonal Means & + & 0.0087 \\
Total ALP & Cubs & Seasonal Means & + & 0.0093 \\
Ionized Calcium & Cubs & Seasonal Means & + & 0.0478 \\
ucOCN & Age & Seasonal Means & + & 0.0139 \\
ucOCN & Age & Peak-Valley & + & 0.0135 \\
\%ucOCN & Age & Seasonal Means & + & 0.0157 \\
\%ucOCN & Age & Peak-Valley & + & 0.0048 \\
Adiponectin & Age & Seasonal Means & + & 0.0226 \\
Glucose & Cubs & Seasonal Means & + & 0.0290 \\
Glucose & Age & Peak-Valley & + & 0.0156 \\
Serotonin & Age & Seasonal Means & + & 0.0064 \\
Total Protein & Age & Seasonal Means & + & 0.0067 \\
Globulin & Cubs & Seasonal Means & + & $<0.0001$ \\
ALT & Age & Seasonal Means & - & 0.0368 \\
Creatinine & Age & Seasonal Means & + & 0.0002 \\
Creatinine & Cubs & Seasonal Means & + & 0.0024 \\
Creatinine & Age & Peak-Valley & + & 0.0154
\end{tabular}



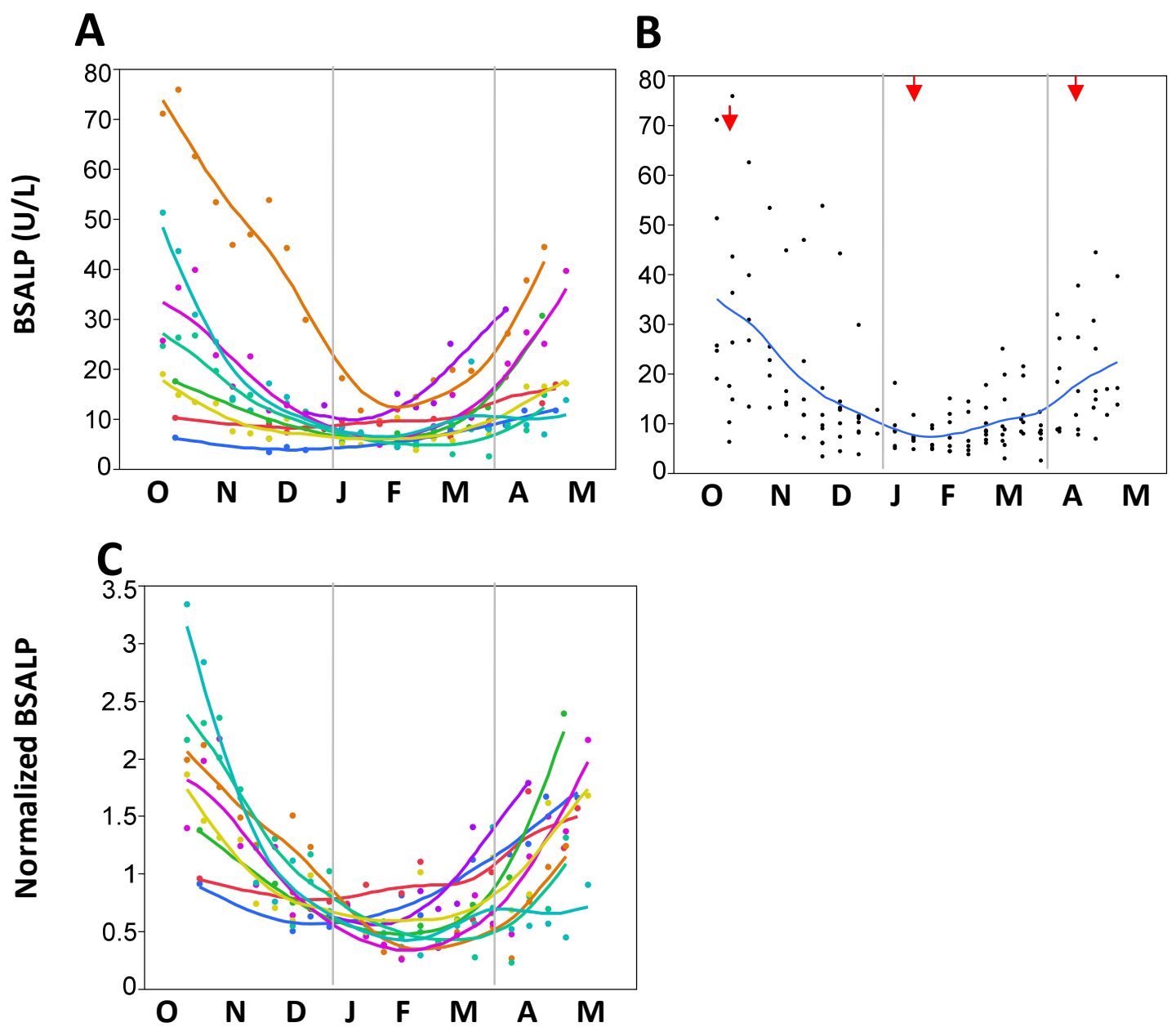

Figure 2.1-Serum BSALP activities

Serum BSALP activity of 9 black bears in the 2007/08 and 2008/09 seasons. Letters $O$ through $M$ represent the month of serum collection. Vertical lines represent transitions between active and hibernating seasons. (A) BSALP activities are represented by a line for each bear. (B) Single smoothed curve represents the average of all 9 bears. Arrows indicate the dates at which "peak-valley" means were analyzed. (C) Each BSALP activity was normalized to the average BSALP activity for the appropriate bear for better comparison of seasonal fold changes. 
A
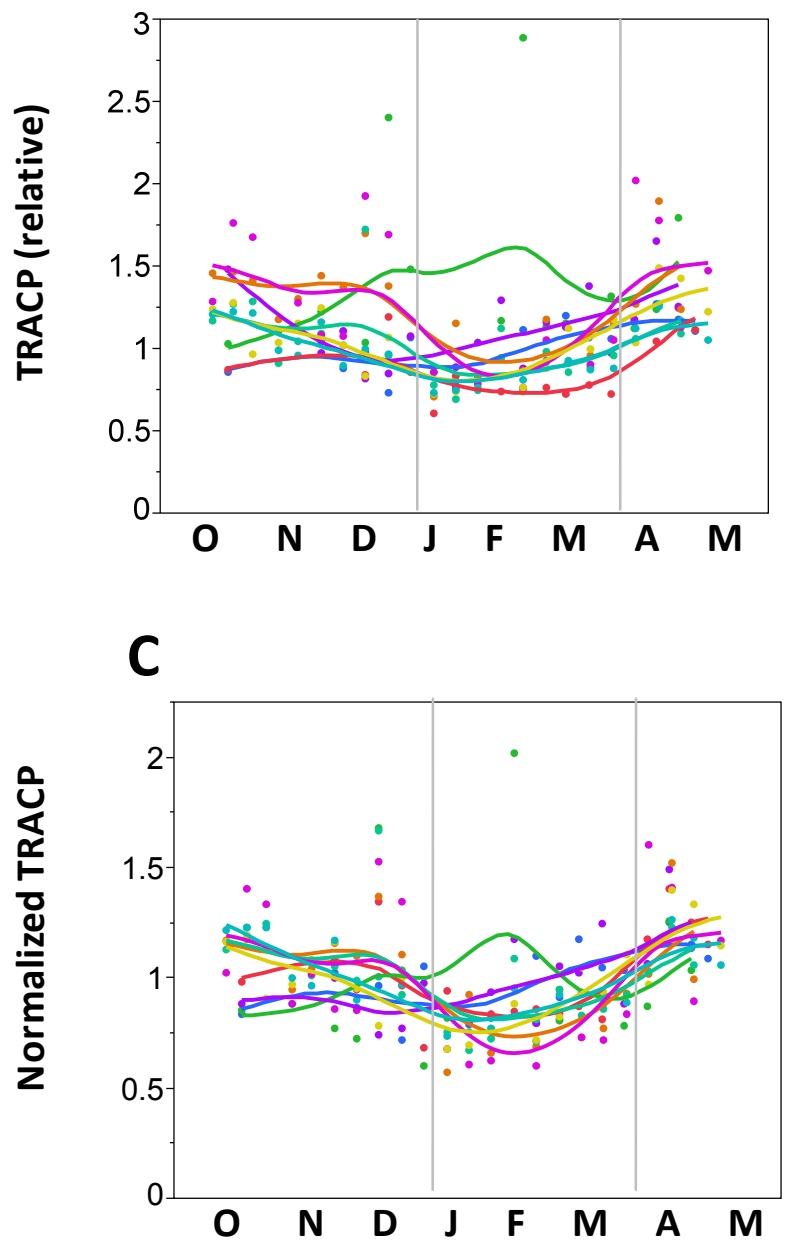

B

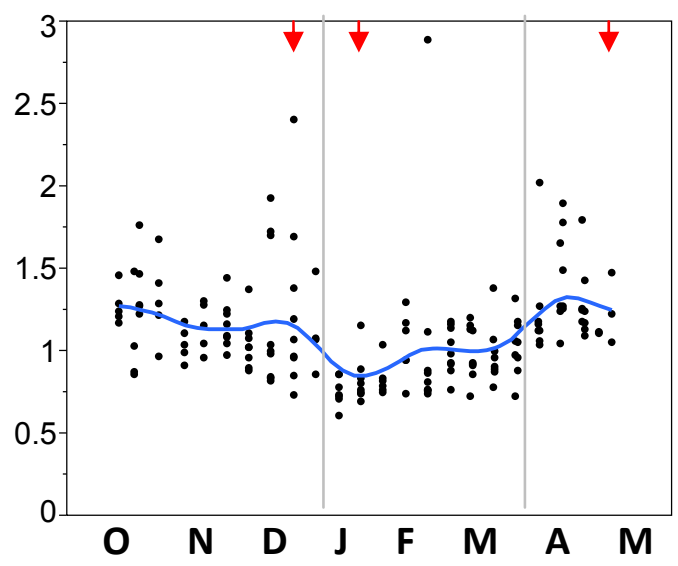

Figure 2.2-Serum TRACP activities

Serum TRACP activity of 9 black bears in the 2007/08 and 2008/09 seasons. Letters O through $M$ represent the month of serum collection. Vertical lines represent transitions between active and hibernating seasons. (A) TRACP activities are represented by a line for each bear. (B) Single smoothed curve represents the average of all 9 bears. Arrows indicate the dates at which "peak-valley" means were analyzed. (C) Each TRACP activity was normalized to the average TRACP activity for the appropriate bear for better comparison of seasonal fold changes. 

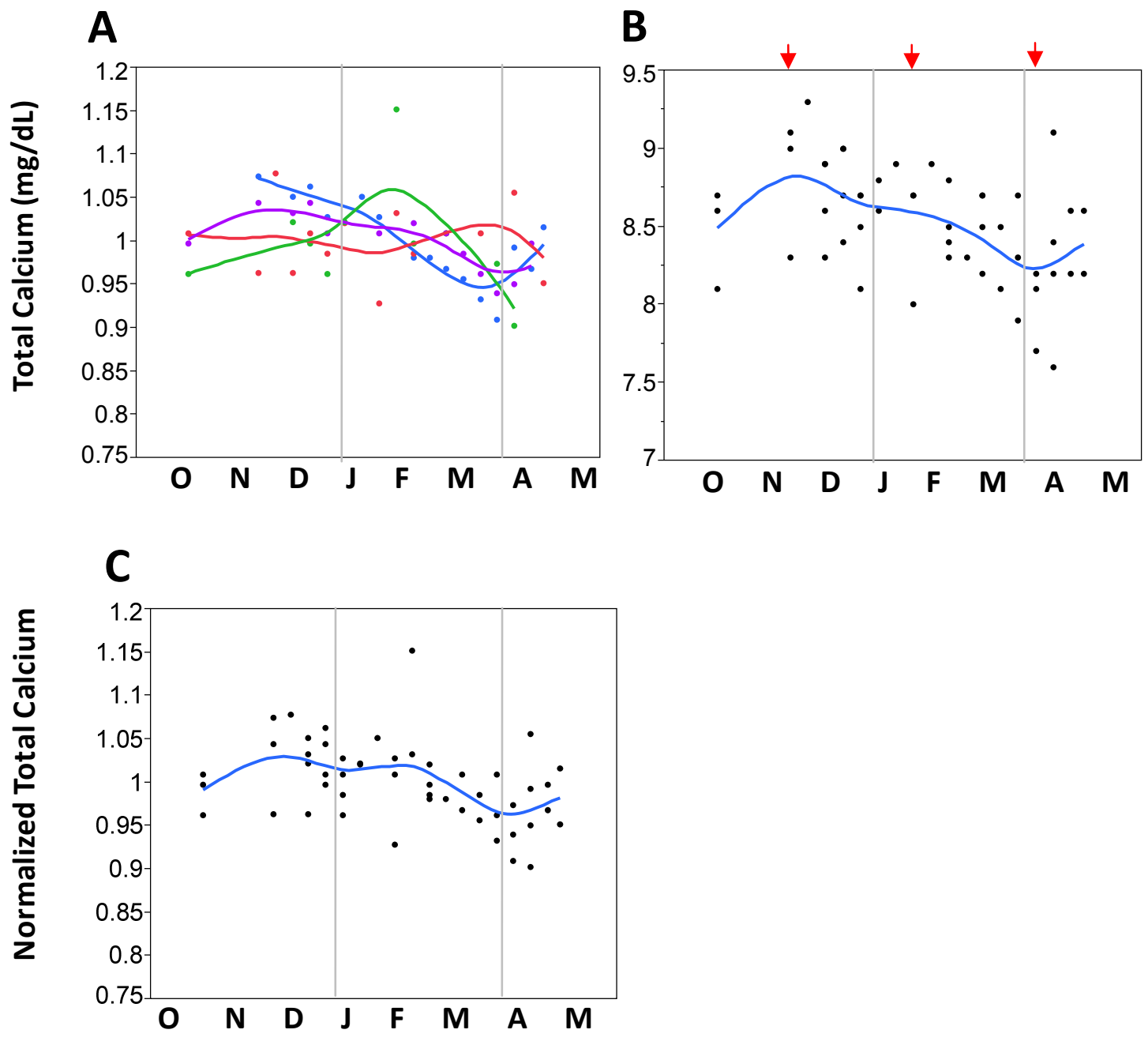

Figure 2.3-Total serum calcium

Total serum calcium levels of 4 black bears in the 2007/08 season. Letters $O$ through $M$ represent the month of serum collection. Vertical lines represent transitions between active and hibernating seasons. (A) Serum calcium levels are represented by a line for each bear. (B) Single smoothed curve represents the average of all 4 bears. Arrows indicate the dates at which "peak-valley" means were analyzed. (C) Each total serum calcium concentration was normalized to the average total serum calcium concentration for the appropriate bear for better comparison of seasonal fold changes. 

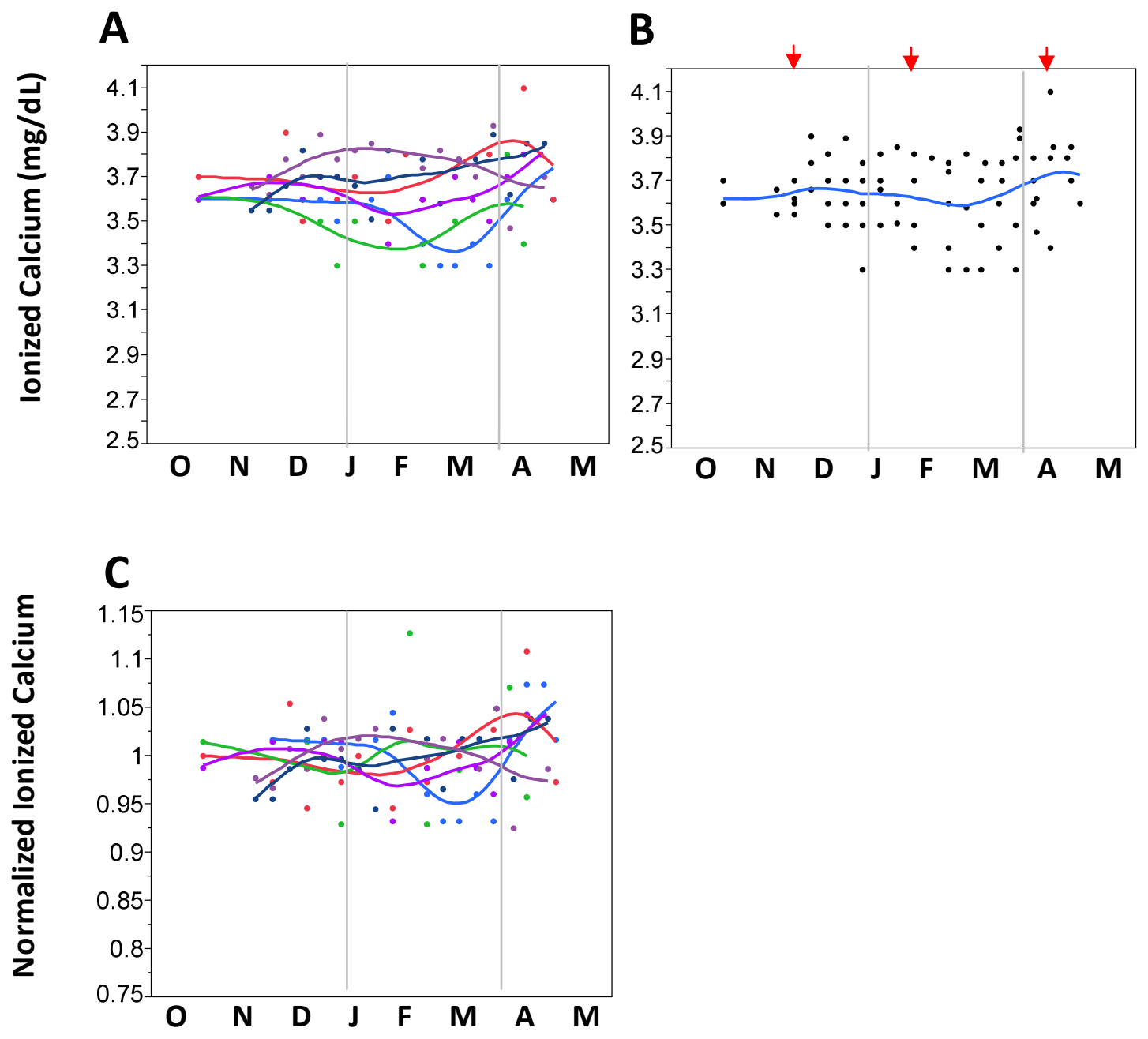

Figure 2.4-Serum ionized calcium levels

lonized calcium levels of 6 black bears in the 2006/07 and 2007/08 seasons. Letters $O$ through $\mathrm{M}$ represent the month of serum collection. Vertical lines represent transitions between active and hibernating seasons. (A) Serum ionized calcium levels are represented by a line for each bear. (B) Single smoothed curve represents the average of all 6 bears. Arrows indicate the dates at which "peak-valley" means were analyzed. (C) Each ionized calcium concentration was normalized to the average ionized calcium concentration for the appropriate bear for better comparison of seasonal fold changes. 
A

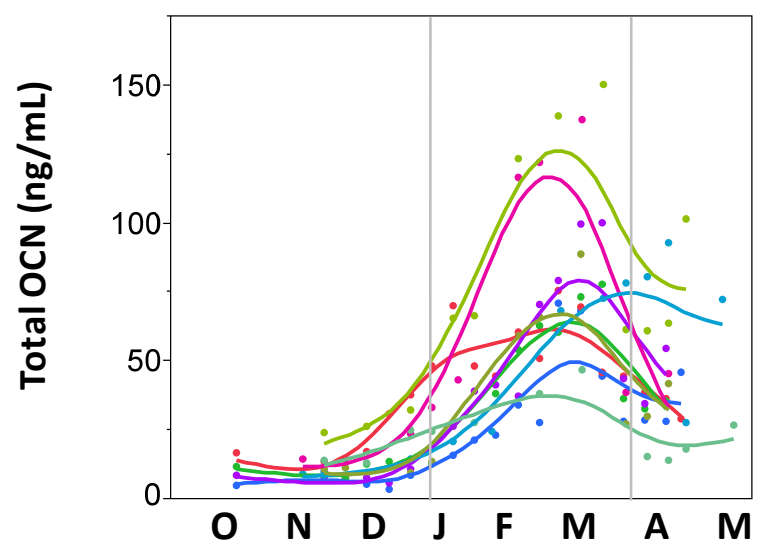

B

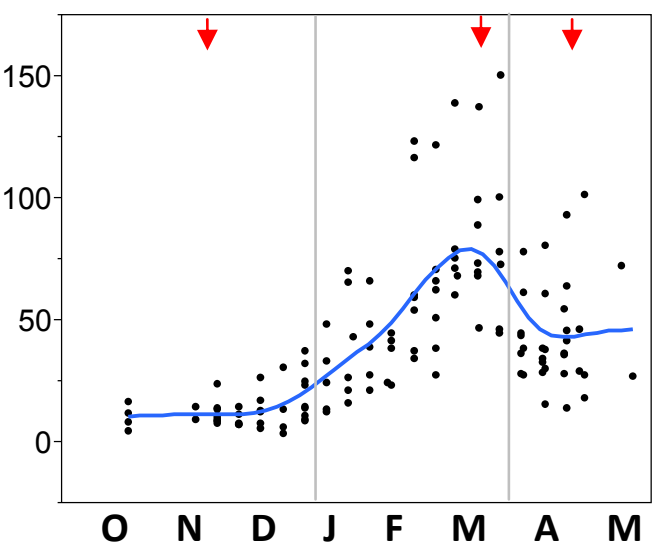

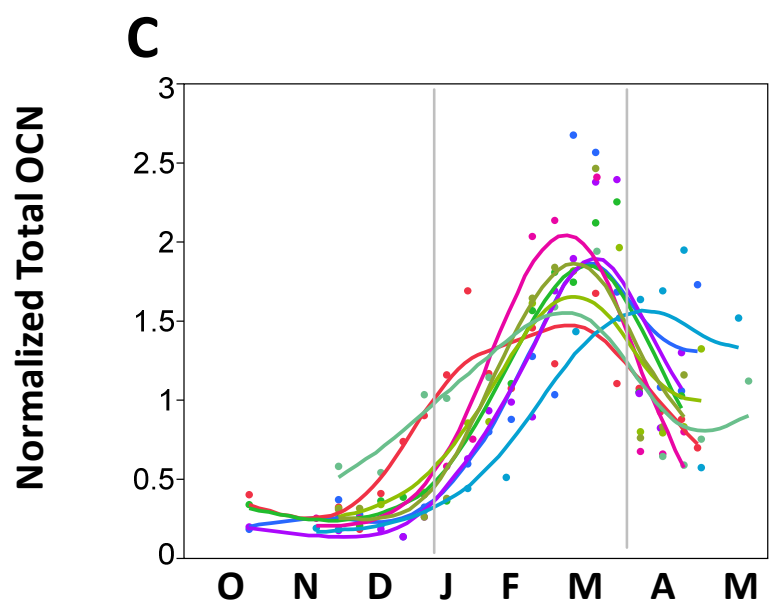

Figure 2.5-Serum total OCN concentrations

Serum OCN concentrations of 9 black bears in the 2004/05 and 2007/08 seasons. Letters $O$ through $M$ represent the month of serum collection. Vertical lines represent transitions between active and hibernating seasons. (A) OCN concentrations are represented by a line for each bear. (B) Single smoothed curve represents the average of all 9 bears. Arrows indicate the dates at which "peak-valley" means were analyzed. (C) Each total OCN concentration was normalized to the average total OCN concentration for the appropriate bear for better comparison of seasonal fold changes. 
A

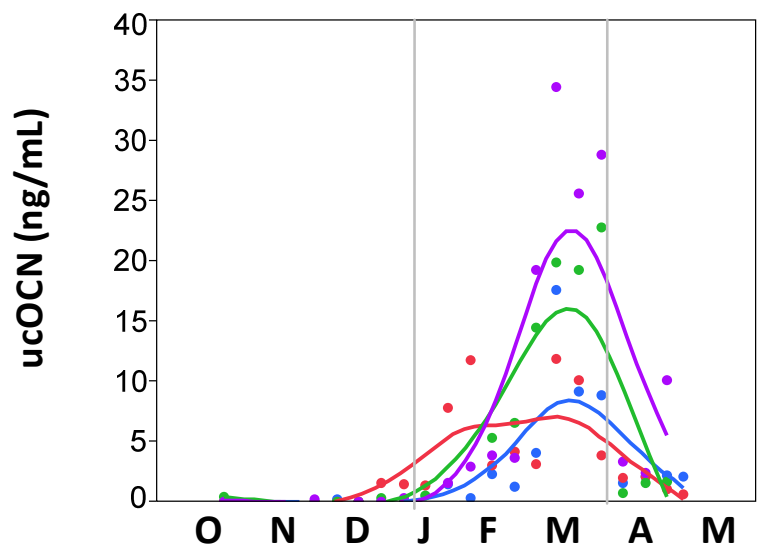

B

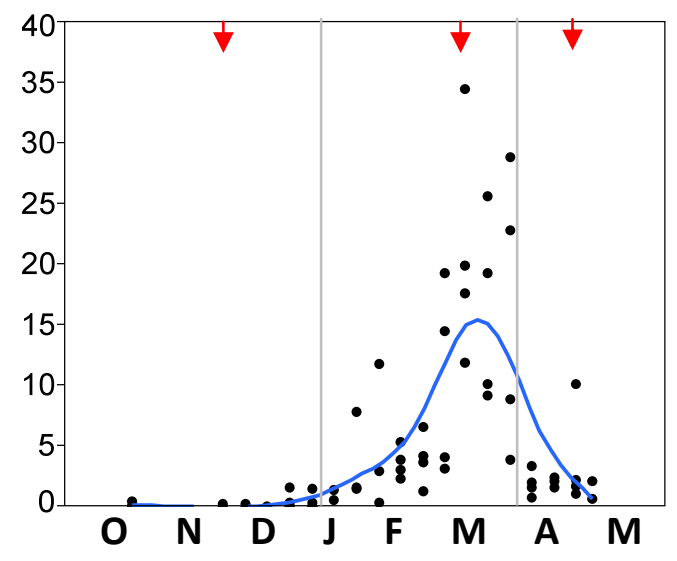

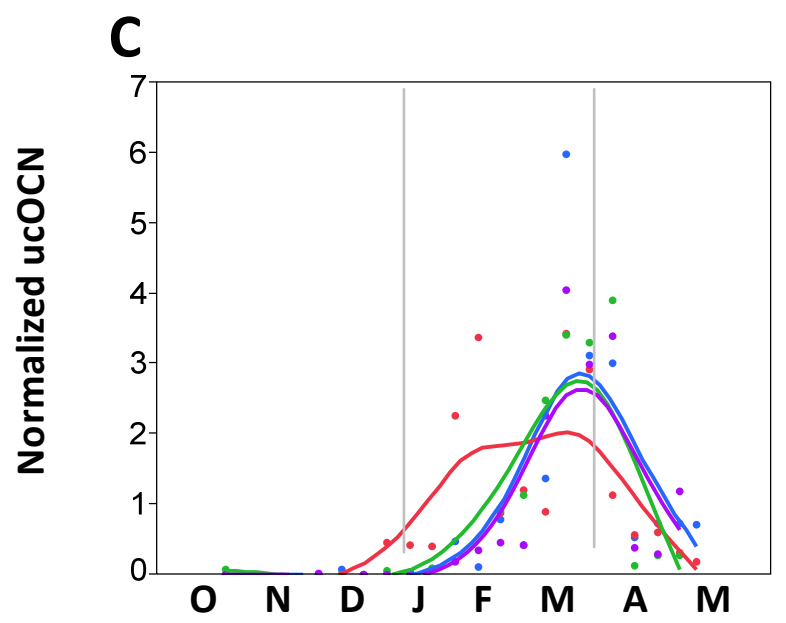

Figure 2.6-Serum ucOCN concentrations

Serum ucOCN concentrations of 4 black bears in the 2007/08 season. Letters $O$ through $\mathrm{M}$ represent the month of serum collection. Vertical lines represent transitions between active and hibernating seasons. (A) ucOCN concentrations are represented by a line for each bear. (B) Single smoothed curve represents the average of all 4 bears. Arrows indicate the dates at which "peak-valley" means were analyzed. (C) Each ucOCN concentration was normalized to the average ucOCN concentration for the appropriate bear for better comparison of seasonal fold changes. 

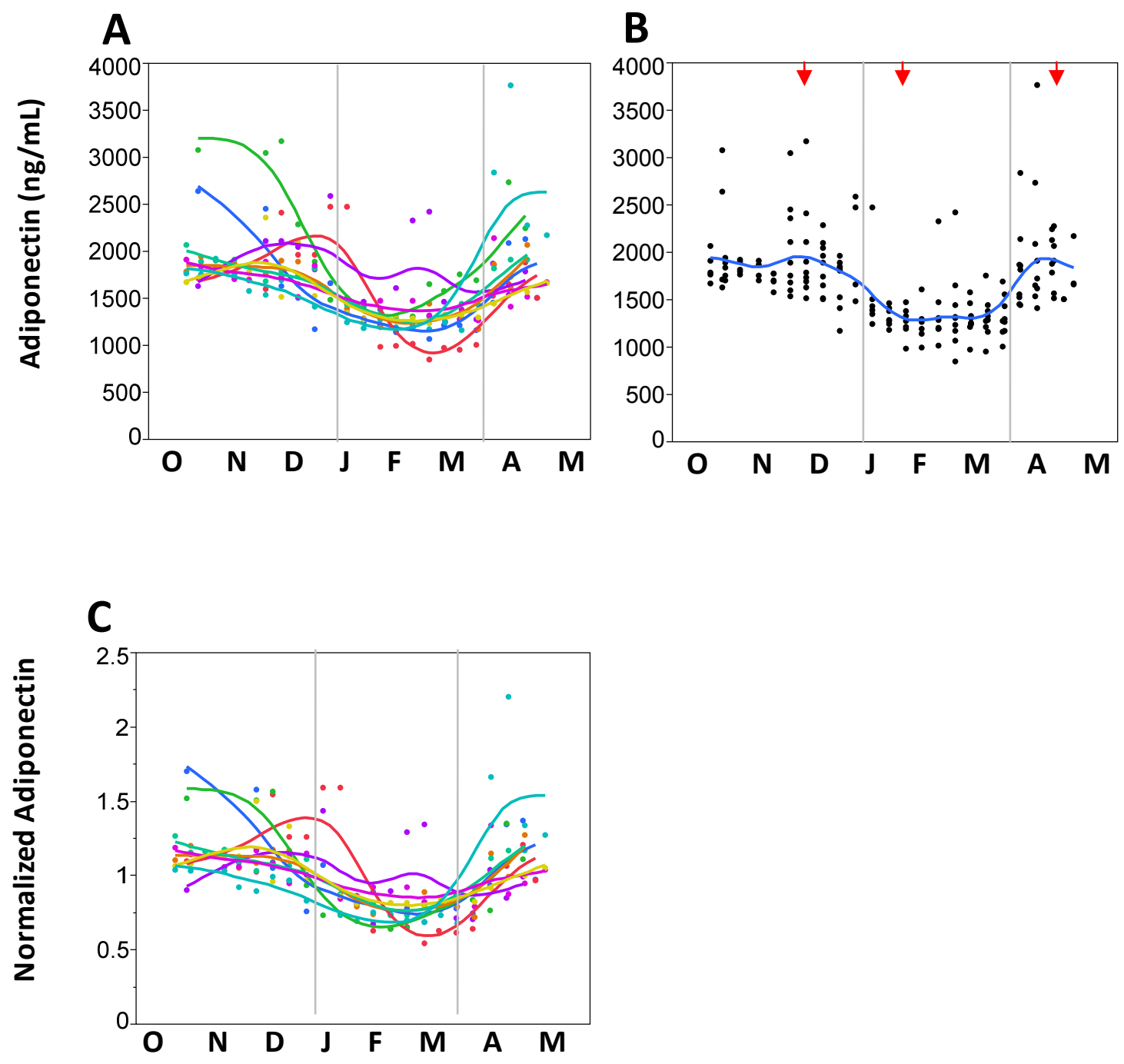

Figure 2.7-Serum adiponectin concentrations

Serum adiponectin concentrations of 9 black bears in the 2007/08 and 2008/09 seasons. Letters $O$ through $M$ represent the month of serum collection. Vertical lines represent transitions between active and hibernating seasons. (A) Adiponectin concentrations are represented by a line for each bear. (B) Single smoothed curve represents the average of all 9 bears. Arrows indicate the dates at which "peak-valley" means were analyzed. (C) Each adiponectin concentration was normalized to the average adiponectin concentration for the appropriate bear for better comparison of seasonal fold changes. 

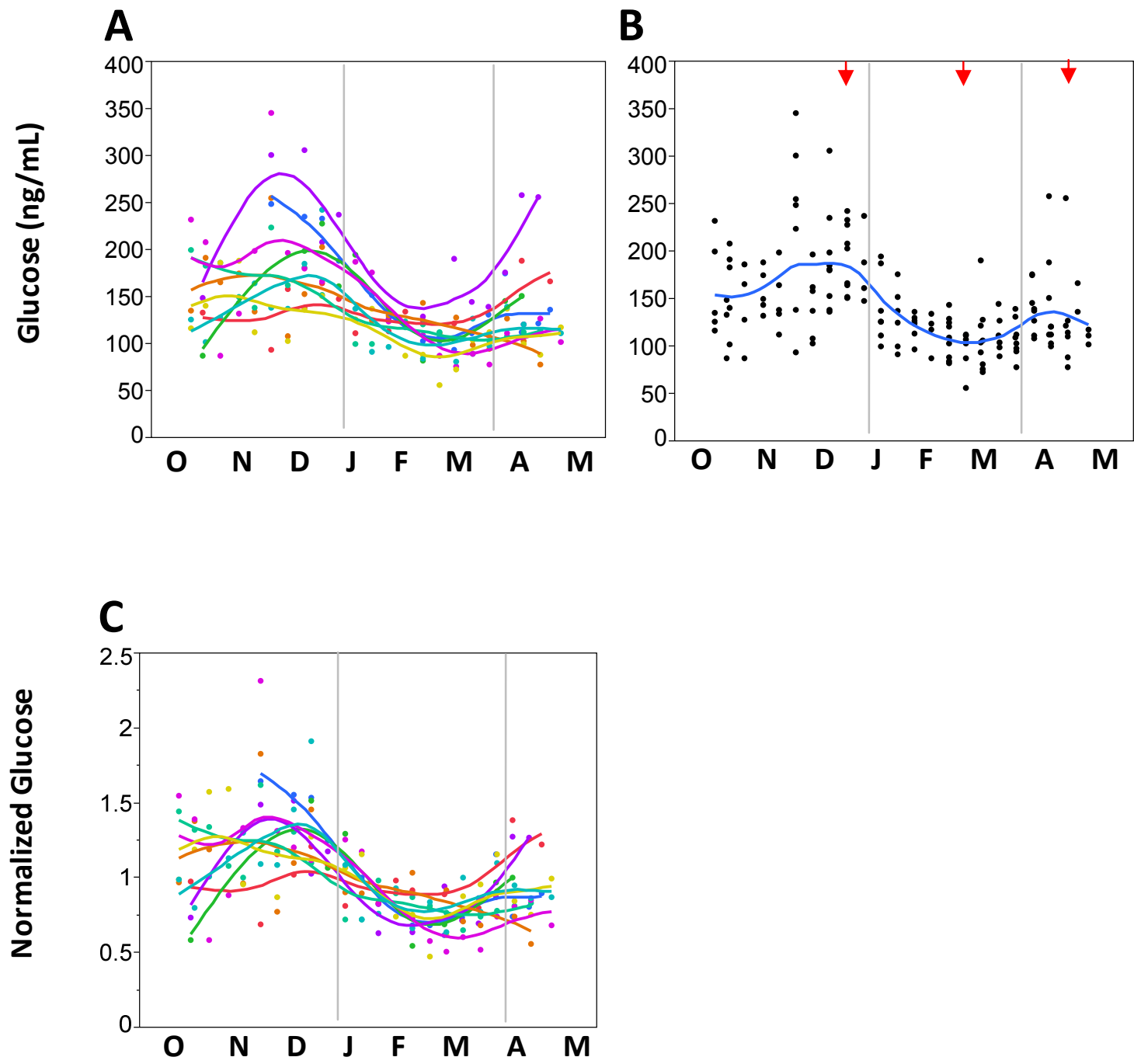

Figure 2.8-Serum glucose concentrations

Serum glucose concentrations of 9 black bears in the 2007/08 and 2008/09 seasons. Letters $O$ through $M$ represent the month of serum collection. Vertical lines represent transitions between active and hibernating seasons. (A) Glucose concentrations are represented by a line for each bear. (B) Single smoothed curve represents the average of all 9 bears. Arrows indicate the dates at which "peak-valley" means were analyzed. (C) Each glucose concentration was normalized to the average glucose concentration for the appropriate bear for better comparison of seasonal fold changes. 


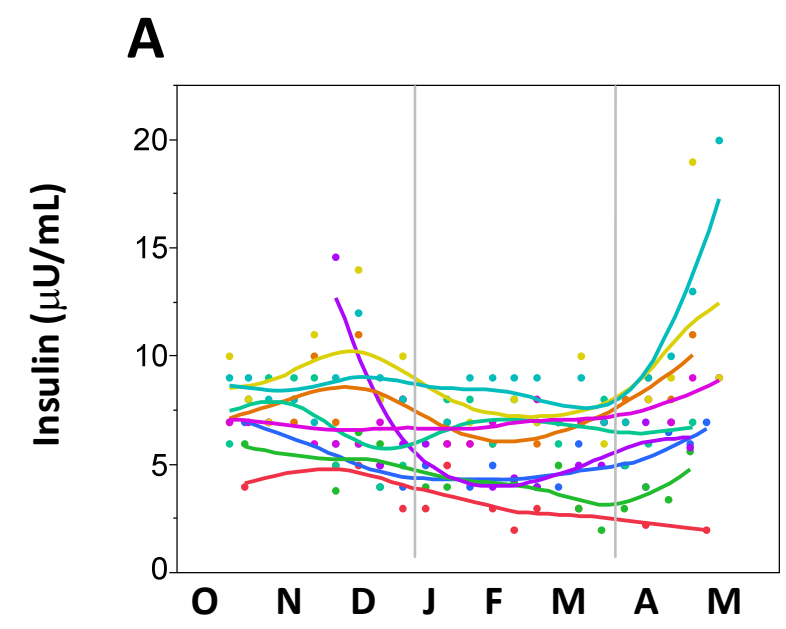

\section{B}
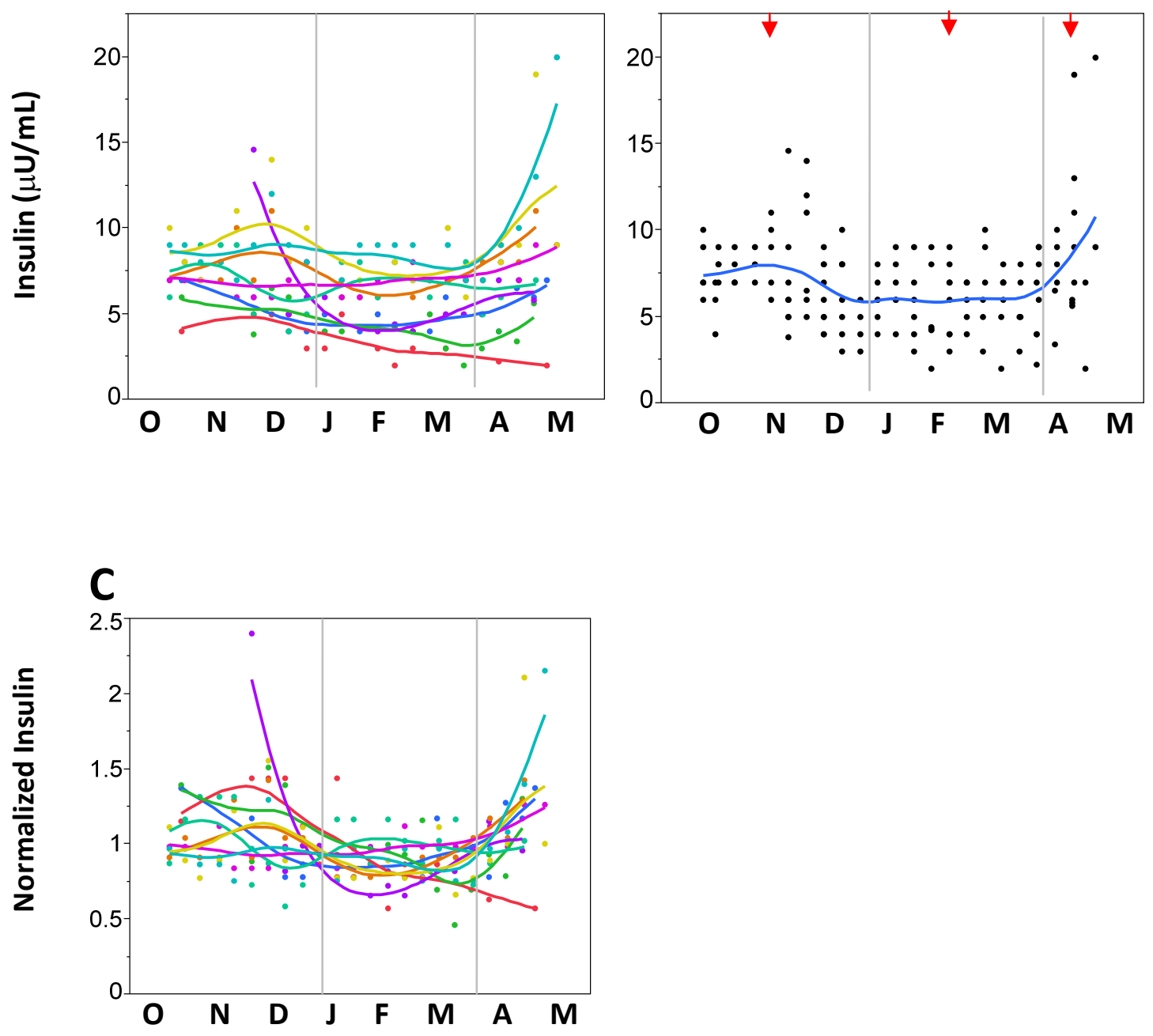

Figure 2.9-Serum insulin concentrations

Serum insulin concentrations of 9 black bears in the 2007/08 and 2008/09 seasons. Letters $O$ through $M$ represent the month of serum collection. Vertical lines represent transitions between active and hibernating seasons. (A) Insulin concentrations are represented by a line for each bear. (B) Single smoothed curve represents the average of all 9 bears. Arrows indicate the dates at which "peak-valley" means were analyzed. (C) Each insulin concentration was normalized to the average insulin concentration for the appropriate bear for better comparison of seasonal fold changes. 


\section{Chapter Three - Serum neuropeptide $Y$ and IGF-1 favor reduced bone turnover in hibernating black bears}

\subsection{Introduction}

The long-term goal of this dissertation is to explore the biological mechanism through which hibernating bears protect their bones during prolonged periods of physical inactivity. One possible mechanism is endocrine modulation of bone metabolism. Since bears maintain balanced, though reduced, bone turnover during extended disuse (hibernation) [18, 20], this study quantified the seasonal serum levels of hormones which regulate disuse-induced bone loss and the rate of bone turnover. Leptin is a peptide hormone secreted by white adipose tissue. It signals the hypothalamus to suppress food intake, body mass, and adiposity, while increasing heat production [213, 214]. Serum leptin decreases during hind-limb suspension in rats $[215,216]$, and replacement of leptin can inhibit disuse-induced bone loss by suppressing bone resorption and preserving bone formation [216, 217]. Studies with knockout mice suggest that leptin's antagonistic hormone neuropeptide $Y$ (NPY) can suppress bone turnover. Mice lacking Y1 (which is the NPY receptor present in bone) have a high bone mass phenotype due to increased bone formation, though they also experience an increase in osteoclast activity [218]. Circulating serotonin may increase bone turnover. In vitro stimulation with serotonin promotes proliferation of osteoblasts and differentiation of monocytes into osteoclasts [219]. Studies utilizing beta-blockers, norepinephrine (NE) receptor antagonists, suggest a decrease in NE signaling may alleviate disuse-induced bone loss. Bone loss due to hind-limb unloading in rats and mice is suppressed by betablockers through the stimulation of osteoblast activity and the repression of osteoclast activity [217, 220]. In vitro evidence suggests that insulin-like growth factor 1 (IGF-1) stimulates both osteoblast [221] and osteoclast recruitment and activation [222-224], and could thus act to increase overall bone turnover. Changes in the circulating levels of these hormones during hibernation could explain the balanced and reduced bone turnover observed in denning bears [18, 20].

The goal of this study was to quantify the serum concentrations of leptin, NPY, serotonin, NE, and IGF-1 in American black bears during the months immediately 
surrounding and encompassing hibernation. The hypothesis was that serum concentrations of these hormones change in such a way that overcomes the negative influences of disuse on bone mass, while reducing overall bone turnover during hibernation to conserve metabolic energy. Based on the previous studies described above, we expected to see an increase in leptin and NPY, and a decrease in NE, serotonin and IGF-1.

\subsection{Methods and materials}

A total of 19 female black bears were captured and held in pens in the Virginia Tech Center for Bear Research from fall through spring, between the years 2002 and 2009. Samples were collected as described in section 2.2.1. All statistical analyses were performed using JMP 7 software as described in section 2.2.3.

Table 3.1 summarizes which bear serum samples were used for each biochemical assay. Due to limitations of serum sample sizes, not all bears were used for all assays. The choice of bear used for each assay depended upon sample availability at the time the assays were run. The serum collected from 8 bears was assayed for leptin by RIA (Millipore, St Louis, MO); the intra-assay coefficient of variation was $3.4 \%$. The expected range is $7.4 \pm 3.7 \mathrm{ng} / \mathrm{mL}$ in a human female. The serum from 9 bears was assayed for NPY. NPY was quantified using a competitive RIA method with reagents manufactured by EURIA and distributed by ALPCO in the United States. The sensitivity of the NPY RIA method is $3 \mathrm{pmol} / \mathrm{L}$ and intra-assay precision averaged $4.8 \%$ while interassay precision averaged $8.4 \%$. Normal levels in human serum range from 36-120 pmol/L. The serum collected from 6 bears was assayed for NE and serotonin by enzyme-linked immunosorbent assays (ELISA) (ALPCO). The sensitivity of the NE assay is $44 \mathrm{pg} / \mathrm{mL}$, with an intra-assay precision of $16.1 \%$ and an inter-assay precision of $15 \%$. Expected serum NE levels in humans are less than $600 \mathrm{pg} / \mathrm{mL}$. The sensitivity of the serotonin assay is $5 \mathrm{ng} / \mathrm{mL}$, with an intra-assay precision of $5.4 \%$ and an interassay precision of $6.0 \%$. Expected serotonin levels in female human serum are 80-450 ng/mL. IGF-1 was measured in the serum of 5 bears by acid ethanol extraction RIA (Nichols Institute Diagnostics, San Juan Capistrano, CA); the intra-assay coefficient 
of variation was $4.3 \%$. Activities of TRACP and BSALP were quantified as in section 2.2.2.

\subsection{Results}

Serum leptin had an increasing trend during the prehibernation fattening season, and began a downward trend during hibernation (Figure 3.1). By "seasonal means" and "peak-valley" analyses, there were no significant differences between prehibernation values and hibernation values; though serum leptin was lower during post-hibernation (Tables 3.2 and 3.3). By "seasonal means" analysis, leptin fell from $4.07 \pm 0.178 \mathrm{ng} / \mathrm{mL}$ in hibernation to $3.23 \pm 0.219 \mathrm{ng} / \mathrm{mL}$ in post-hibernation $(p=0.0058)$ (Table 3.3). Serum NPY displayed a similar trend to leptin, though it was more pronounced and shifted towards the following decad (Figure 3.2). NPY increased over November and December, peaking a decad after the transition into hibernation, and then steadily fell through hibernation and post-hibernation. By both analysis models, NPY concentrations were significantly higher during hibernation than fall active and spring active periods (Tables 3.2 and 3.3). By "seasonal means" analysis, NPY increased from $194+4 \mathrm{pmol} / \mathrm{L}$ in fall to $219 \pm 4 \mathrm{pmol} / \mathrm{L}$ during hibernation and then dropped back to $178 \pm 6$ in spring $(p<0.0001)$ (Table 3.3). NPY levels were negatively correlated to TRACP $(r=-0.528)$ and BSALP $(r=-0.713)$ (Table 3.4), both of which decreased significantly during hibernation (Tables 2.2 and 2.3). In one bear, all NPY levels were over the highest standard ( $300 \mathrm{pmol} / \mathrm{L})$. This bear was omitted from the data presented. The omitted bear was 21 years old, which is at the end of the lifespan of bears. Even without this bear, there is an age effect with NPY, such that NPY increases with increasing age (Table 3.5).

Serum NE had no distinguishing trends except in the months of December and May, which displayed distinct peaks (Figure 3.3 B). However, these peaks were not statistically significant by either analysis method (Tables 3.2 and $\mathbf{3 . 3}$ ), and the peaks were mainly due to the NE profile of one bear. There were no significant trends in NE, even when the aberrant bear was removed from analysis. Serum serotonin decreased during hibernation in all bears, though this trend was much more pronounced in some bears than in others (Figure 3.4). Statistical analysis reveals no difference by longitudinal "peak-valley" analysis (Table 3.2). By "seasonal means" analysis, serotonin 
decreased from $788 \pm 30 \mathrm{ng} / \mathrm{mL}$ in prehibernation to $593 \pm 26 \mathrm{ng} / \mathrm{mL}$ in hibernation; there were no differences between post-hibernation mean and the means of prehibernation and hibernation serotonin levels ( $p<0.0001$ ) (Table 3.3). Serum IGF-1 decreased during hibernation, and then ascended rapidly during post-hibernation (Figure 3.5). By longitudinal "peak-valley" analysis, hibernation IGF-1 levels are significantly lower than post-hibernation levels (Table 3.2). By "seasonal means" analysis, IGF-1 levels dropped from $387 \pm 31 \mathrm{ng} / \mathrm{mL}$ in prehibernation to $203 \pm 25 \mathrm{ng} / \mathrm{mL}$ during hibernation and then rose to $597 \pm 28 \mathrm{ng} / \mathrm{mL}$ in post-hibernation $(\mathrm{p}<0.0001$ ) (Table 3.3). Serum IGF-1 levels were negatively correlated to serum levels of leptin (Table 3.4).

\subsection{Discussion}

Bears hibernate for up to half a year annually. Although movement during denning is minimal [13], they do not experience the structural and mechanical changes that generally accompany disuse in other animals [16-21, 173, 174]. Histological data suggest that bone turnover rates are lower during hibernation, but they remain balanced such that any bone lost is replaced by newly formed bone [18, 20]. Chapter 2 quantified serum activities of the bone formation marker BSALP and the marker of osteoclast number TRACP. The decrease in BSALP and TRACP observed in that chapter confirm the histological data previously reported [18, 20]. The current study explored the seasonal profiles of several circulating hormones to determine whether these hormones change during hibernation in such a way that could prevent disuse-induced bone loss, while decreasing bone turnover (thus preserving metabolic energy during this extended anorectic period).

\subsubsection{Maintenance of serum leptin concentrations several weeks into hibernation may prevent bone loss and help bears maintain near-normal body temperatures}

Leptin is an energy homeostasis hormone which signals the hypothalamus to reduce adipose tissue mass [214]. As adipose tissue accumulates it releases leptin, which suppresses appetite, induces lipid catabolism, and produces heat [213, 214, 225, 226]. Serum leptin levels generally follow adiposity trends, such as in humans [227-229], 
mice [227], and domestic sheep [230]. In contrast, in small overwintering animals that gain weight in the fall and fast during the winter, serum leptin becomes seasonally dissociated from body weight and basal metabolic rate [231-233]. For instance, in Raccoon Dogs (Nyctereutes procyonoides) [232, 234], blue foxes (Alopex lagopus) [232], and yellow-bellied marmots (Marmota flaiventris) [233], serum leptin increases in fall as body mass rises, but declines dramatically after the animals begin the winter fast, preceding the gradual drop in body mass.

Although the bears in the current study experienced an average weight gain of $28 \%$ from October to January (when hibernation began), serum leptin did not significantly increase over this period. In contrast, in small hibernators such as the woodchuck (Marmota monax) [235], raccoon dog [232, 234], or yellow-bellied marmot [233] serum leptin significantly increases during the months leading up to hibernation. It is possible that the black bears in the current study began increasing serum leptin in the months prior to the first data collection date in October, though other studies in bears do not support this idea of earlier rises in leptin. In a study of one European brown bear (Ursus arctos arctos), serum leptin began to rise in early October, for a total increase of $41 \%$ during prehibernation [236]. A study in Japanese black bears (Ursus thibetanus japonicus) reported a $170 \%$ increase in serum leptin which began in October and peaked in November (when hibernation began) [237]. The sharper increase in serum leptin in Japanese bears was likely due to the sharper increase in weight during these months (70\%). Between the beginning of January and the end of April, the current study observed a $37 \%$ decrease in serum leptin in black bears (Figure 3.1). Unlike in small hibernators such as the raccoon dog [232] and the yellow-bellied marmot [233], the decrease in serum leptin of black bears was gradual. It took place over the entire fasting period and continued through the first month of arousal. In contrast, in a study with yellow-bellied marmots that hibernated from October through April, serum leptin decreased 59\% between November and February, thus preceding changes in weight (which began between January and February) [233].

There are many notable differences between a bear's hibernation state and that of a small hibernator. Most small hibernators can drop to ambient temperatures during periods of torpor, and some periodically arouse to eat and excrete wastes $[115,117$, 
120-122]. Most small hibernators are also believed to lose bone during hibernation [104109], though recent evidence suggests that golden-mantled ground squirrels do not [110]. In contrast, bears only drop $1-8^{\circ} \mathrm{C}$ below active body temperature, do not excrete wastes or eat, and do not lose bone during hibernation [13, 18-21, 34, 133, 161, 174]. In small hibernators like the raccoon dog and the marmot, serum leptin decreases steeply upon winter fast, preceding changes in weight [233, 234, 237], though in the raccoon dog leptin levels rise again before the end of winter [234]. The decrease in serum leptin of American black bears took place gradually through hibernation and continued into post-hibernation (Figure 3.1). It may be an evolutionary advantage for bears to retain raised leptin concentrations longer into hibernation, as the leptin would help them maintain higher body temperatures and suppress appetite-induced arousal. Furthermore, serum leptin decreases by $67 \%$ in hind-limb unloaded rats, and replacing serum leptin during unloading inhibits disuse-induced bone loss [215-217]. Therefore, maintaining high leptin levels longer into hibernation could help bears suppress bone loss during this extended period of disuse.

\subsubsection{Reduced IGF-1 and increased NPY in the serum of hibernating bears favor suppression of bone turnover}

The current study found that serum IGF-1 decreased during hibernation in black bears. IGF-1 also decreases in the serum of hibernating golden-mantled ground squirrels [238], which do not lose bone during this extended period of disuse [110]. It is possible that depressed serum levels of IGF-1 could promote the lower rate of bone turnover observed in hibernating bears [18, 20] by slowing the rates of osteoblast [221] and osteoclast [222-224] recruitment and activation. Such a decrease in bone turnover may, in the unique conditions of hibernation, help preserve bone despite disuse.

Bears switch to fat metabolism during hibernation, due to anorectic conditions [111]; therefore they may be compared to animals on high fat diets: rats fed a high fat/low carbohydrate diet experience raised concentrations of leptin and lowered IGF-1 in the serum [239]. These rats display depressed rates of bone formation and unchanged bone resorption, resulting in reduced bone length and BMD of the tibia [239]. However, these 4-week-old rats were at an age of rapid growth $[239,240]$ through the duration of 
the study. In contrast, studies reporting bone maintenance in hibernating bears used adult bears, which would not have been rapidly growing [16-18, 20, 21, 174]. Due to extended fasting periods, hibernating bears could also be compared to animals on a low protein diet: six-month-old rats fed a low protein diet for 14 weeks exhibit reduced bone formation and resorption [241], accompanied by reduced BMD and serum levels of IGF-1 [242, 243]. However, these protein-restricted rats had access to carbohydrates, unlike the hibernating bear. Both the protein-restricted and the high-fat diet animals in these studies were able to lose calcium due to urinary excretion, whereas bears do not excrete urine and remain eucalcemic during hibernation [35]. For bears to remain eucalcemic while not urinating, calcium mobilized by bone resorption would be returned to the bone by new formation. In the hibernating bear [18, 20], like diet-restricted rats $[239,241]$, bone resorption and formation decrease, with an accompanying reduction in serum IGF-1. It is possible that in the low-energy, non-growing, non-urinating state of hibernation, IGF-1 could reduce turnover without creating an imbalance between bone resorption and formation. This reduction in bone turnover could help conserve energy during the extended anorectic period of hibernation.

As bears have no net production of urine during hibernation [113, 114], they can be compared to humans with reduced renal function. In keeping with the suggestion that reduced serum IGF-1 could slow bone turnover in the hibernating bear, serum IGF-1 is lower in pediatric hemodialysis patients with adynamic bone disease (i.e. reduced bone turnover) than in renal patients with normal bone formation [244]. Unfortunately, it was not possible to verify whether there were relationships between the IGF-1 levels and bone formation and resorption markers (BSALP and TRACP, respectively) since these measurements were not made in the same bear serum samples. Further studies may help clarify whether IGF-1 suppresses bone formation in hibernating bears, and whether this reduction in formation could suppress disuse-induced bone loss in this model.

Another possible mechanism of reducing bone turnover during hibernation is by increasing serum NPY, which suppresses osteoclast [245] and osteoblast [246] differentiation. The current study observed inverse correlations between NPY and bone turnover serum markers (i.e. BSALP, TRACP), suggesting that increased serum NPY levels during hibernation could contribute to the reduced turnover in bones of hibernating 
bears. Similarly, serum NPY increases in humans as renal function decreases [247] and is inversely correlated to BSALP $(r=-0.28)$ and total ALP $(r=-0.51)$ in hemodialysis patients [248]. These data suggest a relationship between high NPY levels and low bone turnover in human patients.

Serum serotonin decreased during hibernation in black bears. This is the first known report of serum serotonin in a hibernator; however, serotonin levels increase in the cerebral spinal fluid of hibernating yellow-bellied marmots [249]. Although there may be species variations between different hibernators, it is possible that serotonin increases in the cerebral spinal fluid and decreases in the serum during hibernation, as serotonin cannot pass through the blood-brain barrier [250]. Serotonin promotes proliferation of osteoblasts and differentiation of osteoclasts in vitro [219]; thus, reduced serotonin during hibernation could favor suppressed bone turnover. However, there is controversy about the effects of serotonin on bone in vivo (for review see: [251]), and serotonin levels are not correlated to bone turnover markers BSALP and TRACP in black bears. Therefore, it is difficult to draw conclusions from this data. Although there was no seasonal variation in serum NE of black bears, it is possible that tissue sensitivity to NE changes during hibernation. For instance, reduced temperatures can inhibit the NE-induced lipolysis of white adipose tissue from golden-mantled ground squirrels [252]. Such an insensitivity to NE during hibernation, if exhibited in bone, could feasibly suppress disuse-induced bone resorption since inhibiting NE with beta-blockers can inhibit bone loss in hind-limb unloaded animals [217].

Despite these interesting findings, there were some limitations to this study. For example, body mass was not recorded at many data collection points, so leptin could not be directly compared to changes in body mass in these bears. Another limitation is that serum was only collected in the months immediately surrounding and encompassing hibernation. Thus, the bears were either preparing for hibernation, hibernating, or recovering from hibernation throughout sample collection. It is possible that endocrine changes between summer and hibernation would be more pronounced. Another pitfall is that serum was collected under anesthesia, which could have an impact on endocrine concentrations during the blood collection; however, the same dose of anesthesia was given at each blood draw. There are possible effects of age and the birth of cubs on the 
measured serum values. However, all statistical analyses were blocked by bear to control for inter-bear variability.

\subsubsection{Summary}

Bone is a complex organ which responds to many stimuli. It is likely that multiple factors work together to maintain bone integrity during hibernation in bears. These factors could include direct neural stimulation, as well as endocrine control. The anabolic role of circulating PTH was previously hypothesized to help maintain hibernating bear bone, due to its positive correlation to osteocalcin, a marker for bone formation [34]. The current study brings to light more potential endocrine effectors of bone preservation during hibernation. Maintaining serum leptin concentrations longer into hibernation could help inhibit disuse-induced bone loss. Reduced IGF-1 and increased NPY in the serum of hibernating bears could suppress bone resorption and formation rates while sustaining balanced turnover, thus conserving energy during this extended anorectic period. The endocrine changes observed in this study may help explain the reduced, balanced bone turnover that occurs during the unique physiological setting in which bears fast, reduce energy expenditure to a minimum, and remain eucalcemic despite no urine excretion for half a year.

\subsection{Tables and figures}

Table 3.1-Summary of assays

The number of bears and assays that were performed in each hibernation season. The number of bears that gave birth to cubs is in parentheses. Unknown values are indicated as "UK."

\begin{tabular}{ccccc} 
Season & Bears & Age (years) & Assays & Data Location \\
\hline $2002-2003$ & $3($ UK) & UK & Leptin & $\begin{array}{c}\text { Figure 3.1 } \\
\text { Tables 3.2-3.4 }\end{array}$ \\
\hline $2003-2004$ & $5(5)$ & $3-12$ & Leptin, IGF-1 & $\begin{array}{c}\text { Figures 3.1, 3.5 } \\
\text { Tables 3.2-3.4 }\end{array}$ \\
\hline $2006-2007$ & $2(1)$ & UK & Serotonin, NE & $\begin{array}{c}\text { Figures 3.3, 3.4 } \\
\text { Tables 3.2-3.5 }\end{array}$ \\
\hline $2007-2008$ & $4(3)$ & $5-14$ & NPY, NE, Serotonin & $\begin{array}{c}\text { Figures 3.2-3.4 } \\
\text { Tables 3.2-3.5 }\end{array}$ \\
\hline $2008-2009$ & $5(3)$ & $2-21$ & NPY & Tables 3.2-3.5
\end{tabular}


Table 3.2-Serum factor longitudinal "peak-valley" analyses

Data are represented as LSM $\pm S E$. The date of "peak-valley" analysis is indicted below the mean serum concentrations. Letters $(A, B, C)$ represent values that are significantly different from each other at $\alpha=0.05$. The $p$-value reported is for the partial F-test for the serum factor. "Sero." represents serotonin.

\begin{tabular}{cccccccc}
$\begin{array}{c}\text { Serum } \\
\text { Factor }\end{array}$ & $\begin{array}{c}\text { Fall } \\
\text { Active }\end{array}$ & $\begin{array}{c}\text { Winter } \\
\text { Hibernation }\end{array}$ & $\begin{array}{c}\text { Spring } \\
\text { Active }\end{array}$ & $\mathbf{N}_{\text {bears }}$ & $\mathbf{p}$ & Power \\
\hline $\begin{array}{c}\text { Leptin } \\
(\mathrm{ng} / \mathrm{mL})\end{array}$ & $\begin{array}{c}\mathrm{LSM} \pm \mathrm{SE} \\
\text { Date }\end{array}$ & $\begin{array}{c}4.08 \pm 0.39^{\mathrm{AB}} \\
11 / 10\end{array}$ & $\begin{array}{c}4.75 \pm 0.636^{\mathrm{A}} \\
1 / 09\end{array}$ & $\begin{array}{c}2.98 \pm 0.249^{\mathrm{B}} \\
4 / 28\end{array}$ & 8 & 0.0099 & 0.8334 \\
\hline $\begin{array}{c}\mathrm{NPY} \\
(\mathrm{pmol} / \mathrm{L})\end{array}$ & $\begin{array}{c}\mathrm{LSM} \pm \mathrm{SE} \\
\text { Date }\end{array}$ & $\begin{array}{c}193 \pm 20.2^{\mathrm{B}} \\
11 / 20\end{array}$ & $\begin{array}{c}246 \pm 17.8^{\mathrm{A}} \\
1 / 19\end{array}$ & $\begin{array}{c}175 \pm 15.1^{\mathrm{B}} \\
4 / 19\end{array}$ & 8 & 0.0009 & 0.8907 \\
\hline $\begin{array}{c}\mathrm{NE} \\
(\mathrm{ng} / \mathrm{mL})\end{array}$ & $\begin{array}{c}\mathrm{LSM} \pm \mathrm{SE} \\
\text { Date }\end{array}$ & $\begin{array}{c}16.3 \pm 10.7 \\
12 / 30\end{array}$ & $\begin{array}{c}2.90 \pm 0.787 \\
2 / 8\end{array}$ & $\begin{array}{c}1.60 \pm 0.377 \\
4 / 18\end{array}$ & 6 & 0.1922 & 0.3081 \\
\hline $\begin{array}{c}\mathrm{Sero} \\
(\mathrm{ng} / \mathrm{mL})\end{array}$ & $\begin{array}{c}\mathrm{LSM} \pm \mathrm{SE} \\
\text { Date }\end{array}$ & $\begin{array}{c}859 \pm 99.9 \\
11 / 20\end{array}$ & $\begin{array}{c}508 \pm 53.3 \\
3 / 19\end{array}$ & $\begin{array}{c}809 \pm 72.4 \\
4 / 28\end{array}$ & 5 & 0.0667 & 0.5281 \\
\hline $\begin{array}{c}\mathrm{IGF}-1 \\
(\mathrm{ng} / \mathrm{mL})\end{array}$ & $\begin{array}{c}\mathrm{LSM} \pm \mathrm{SE} \\
\text { Date }\end{array}$ & $\begin{array}{c}417 \pm 50.2^{\mathrm{AB}} \\
11 / 30\end{array}$ & $\begin{array}{c}191 \pm 17.7^{\mathrm{B}} \\
2 / 28\end{array}$ & $\begin{array}{c}633_{ \pm}+85.8^{\mathrm{A}} \\
4 / 28\end{array}$ & 5 & 0.0022 & 0.9803 \\
& & & & & & &
\end{tabular}

Table 3.3-Serum factor "seasonal means" analyses

Data are represented as $L S M+S E$. The total number of samples included in the ANOVA is indicated below the mean concentrations. Letters (A, B, C) represent values that are significantly different from each other at $\alpha=0.05$. The $p$-value reported is for the partial F-test for the serum factor.

\begin{tabular}{|c|c|c|c|c|c|c|}
\hline $\begin{array}{l}\text { Serum } \\
\text { Factor }\end{array}$ & & $\begin{array}{c}\text { Fall } \\
\text { (Active) }\end{array}$ & $\begin{array}{c}\text { Winter } \\
\text { (Hibernation) }\end{array}$ & $\begin{array}{l}\text { Spring } \\
\text { (Active) }\end{array}$ & p & Power \\
\hline \multirow{2}{*}{$\begin{array}{l}\text { Leptin } \\
(\mathrm{ng} / \mathrm{mL})\end{array}$} & LSM $\pm S E$ & $4.09 \pm 0.193^{\mathrm{A}}$ & $4.07 \pm 0.178^{\mathrm{A}}$ & $3.23 \pm 0.219^{B}$ & \multirow{2}{*}{0.0058} & \multirow{2}{*}{0.8342} \\
\hline & $\mathrm{N}_{\text {samples }}$ & 45 & 48 & 31 & & \\
\hline \multirow{2}{*}{$\begin{array}{c}\mathrm{NPY} \\
(\mathrm{pmol} / \mathrm{L})\end{array}$} & $\mathrm{LSM} \pm \mathrm{SE}$ & $194 \pm 4.42^{B}$ & $219 \pm 4.19^{A}$ & $178 \pm 6.34^{B}$ & \multirow{2}{*}{$<0.0001$} & \multirow{2}{*}{0.9996} \\
\hline & $\mathrm{N}_{\text {samples }}$ & $\overline{56}$ & $\overline{6}$ & 28 & & \\
\hline \multirow{2}{*}{$\begin{array}{c}\mathrm{NE} \\
(\mathrm{ng} / \mathrm{mL})\end{array}$} & LSM $\pm S E$ & $6.04 \pm 1.51$ & $3.21 \pm 1.33$ & $3.16 \pm 2.03$ & \multirow{2}{*}{0.3208} & \multirow{2}{*}{0.2473} \\
\hline & $\mathrm{N}_{\text {samples }}$ & $\overline{33}$ & 45 & 19 & & \\
\hline \multirow{2}{*}{$\begin{array}{l}\text { Serotonin } \\
(\mathrm{ng} / \mathrm{mL})\end{array}$} & LSM+SE & $788 \pm 29.9^{A}$ & $593 \pm 25.5^{\mathrm{B}}$ & $689 \pm 40.2^{A B}$ & \multirow{2}{*}{$<0.0001$} & \multirow{2}{*}{0.9949} \\
\hline & $\mathrm{N}_{\text {samples }}$ & $\overline{33}$ & $\overline{4} 7$ & 19 & & \\
\hline \multirow{2}{*}{$\begin{array}{l}\text { IGF-1 } \\
\text { (ng/mL) }\end{array}$} & LSM+SE & $387 \pm 30.7^{\mathrm{B}}$ & $203 \pm 25.4^{C}$ & $597 \pm 27.5^{\mathrm{A}}$ & \multirow{2}{*}{$<0.0001$} & \multirow[b]{2}{*}{1} \\
\hline & $\mathrm{N}_{\text {samples }}$ & $\overline{15}$ & $\overline{22}$ & $\overline{19}$ & & \\
\hline
\end{tabular}


Table 3.4-Serum factor linear regression models

\begin{tabular}{ccccccc}
$\begin{array}{c}\text { Dependent } \\
\text { Variable }\end{array}$ & $\begin{array}{c}\text { Independent } \\
\text { Variable }\end{array}$ & $\mathbf{N}_{\text {bears }}$ & $\boldsymbol{\beta}$ & $\mathbf{r}$ & $\mathbf{p}$ & Power \\
\hline TRACP & NPY & 8 & -0.00328 & -0.528 & $<0.0001$ & 0.9986 \\
BSALP & NPY & 8 & -0.128 & -0.713 & $<0.0001$ & 0.9990 \\
Leptin & IGF-1 & 5 & -0.00144 & -0.568 & 0.0023 & 0.8840
\end{tabular}

Table 3.5-Serum factor effects analyses

Table reports all effects between age or cubs and serum factors, indicating the model in which the effect was significant. For an age effect, a "+" direction indicates that the serum factor increases with age. For a cub effect, a "+" direction indicates that the serum factor increases if cubs were born.

\begin{tabular}{ccccc} 
Serum & Effect & Model & Direction & p \\
Factor & & & & 0.0009 \\
\hline Leptin & Age & Seasonal Means & - & $<0.0001$ \\
NPY & Age & Seasonal Means & + & 0.0064 \\
Serotonin & Age & Seasonal Means & + & 0.0113 \\
IGF-1 & Age & Peak-Valley & + & $<0.0001$ \\
TRACP & Cubs & Seasonal Means & + & 0.0431 \\
TRACP & Cubs & Peak-Valley & + &
\end{tabular}



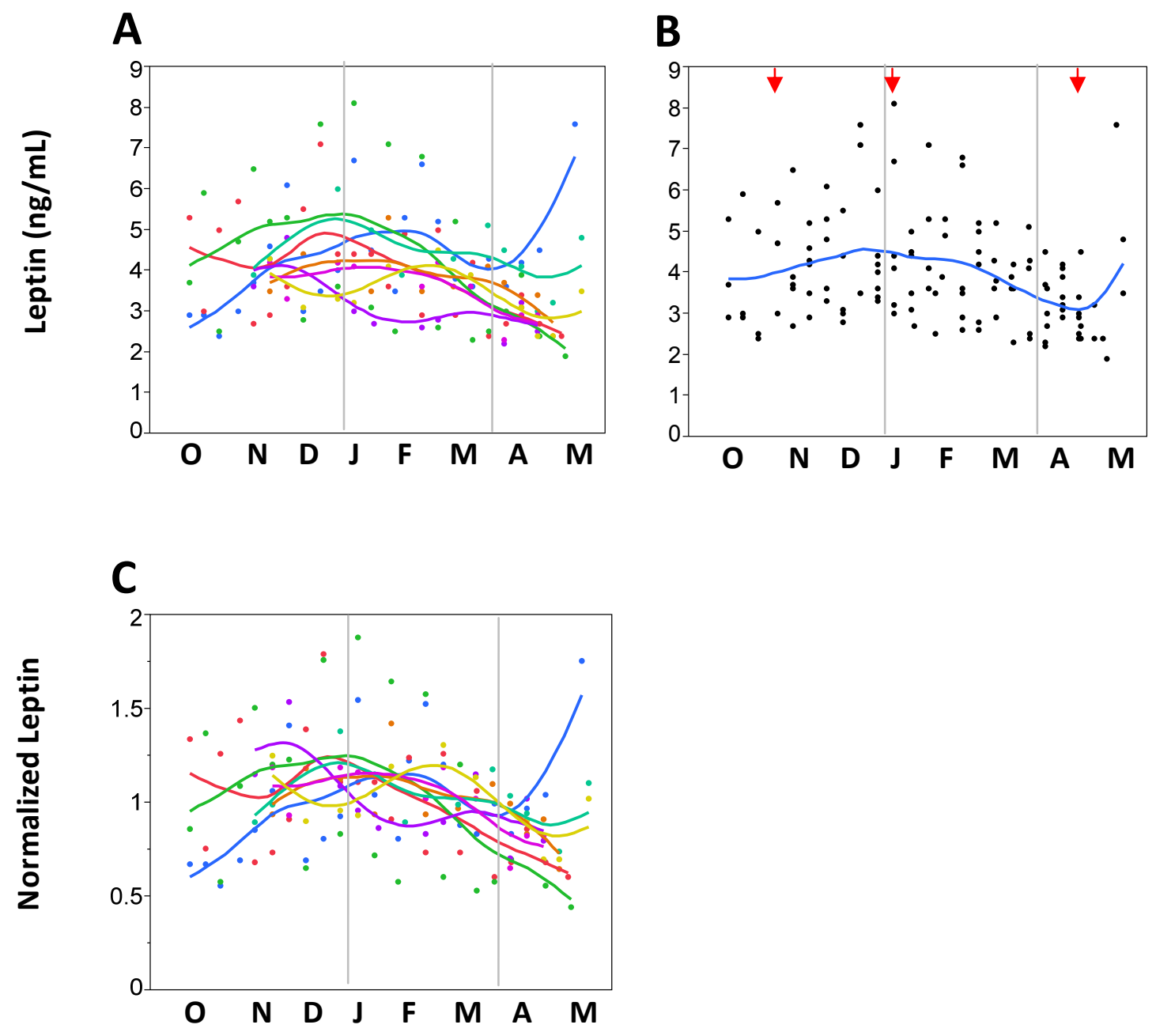

Figure 3.1-Serum leptin concentrations

Serum leptin concentrations of 8 black bears in the 2002/03 and 2003/04 seasons. Vertical lines represent transitions between active and hibernating seasons. (A) Leptin concentrations are represented by a line for each bear. (B) Single smoothed curve represents the average of all 8 bears. Arrows indicate the dates at which "peak-valley" means were analyzed. (C) Each leptin concentration was normalized to the average leptin concentration for the appropriate bear for better comparison of seasonal fold changes. 

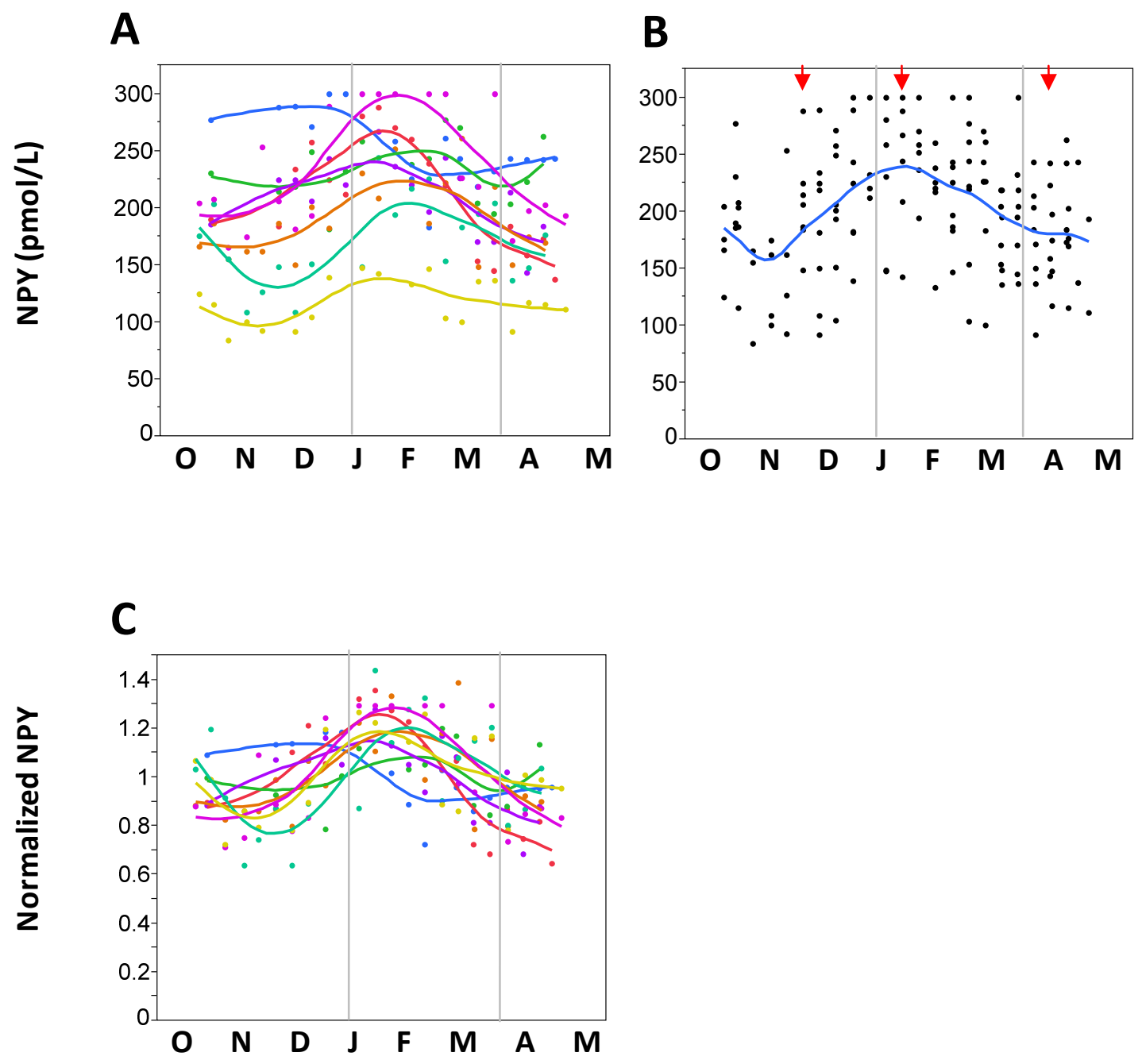

Figure 3.2-Serum NPY concentrations

Serum NPY concentrations of 8 black bears in the 2007/08 and 2008/09 seasons. Vertical lines represent transitions between active and hibernating seasons. (A) NPY concentrations are represented by a line for each bear. (B) Single smoothed curve represents the average of all 8 bears. Arrows indicate the dates at which "peak-valley" means were analyzed. (C) Each NPY concentration was normalized to the average NPY concentration for the appropriate bear for better comparison of seasonal fold changes. 

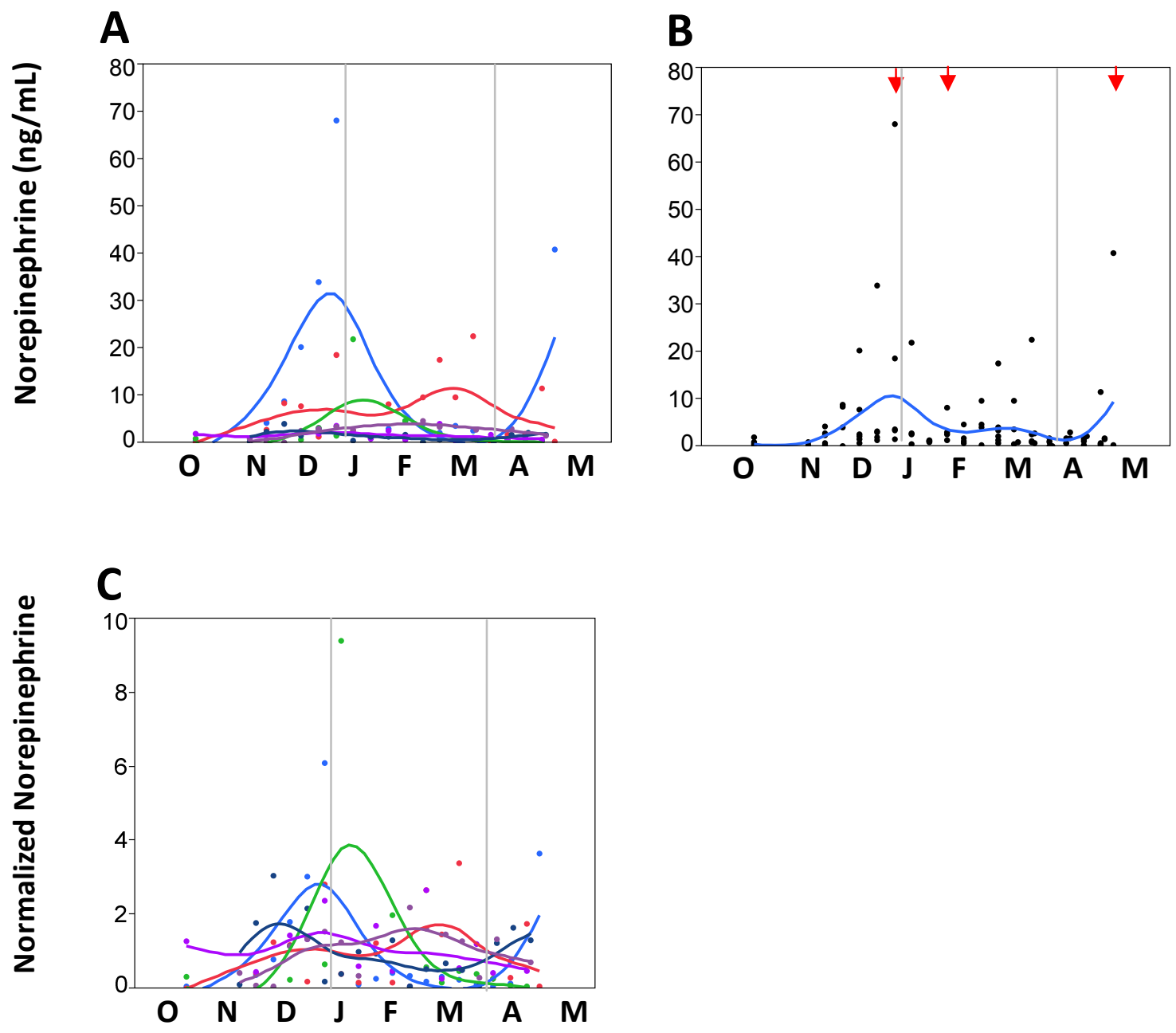

Figure 3.3-Serum NE concentrations

Serum NE concentrations of 6 black bears in the 2006/07 and 2007/08 seasons. Vertical lines represent transitions between active and hibernating seasons. (A) NE concentrations are represented by a line for each bear. (B) Single smoothed curve represents the average of all 6 bears. Arrows indicate the dates at which "peak-valley" means were analyzed. (C) Each NE concentration was normalized to the average NE concentration for the appropriate bear for better comparison of seasonal fold changes. 

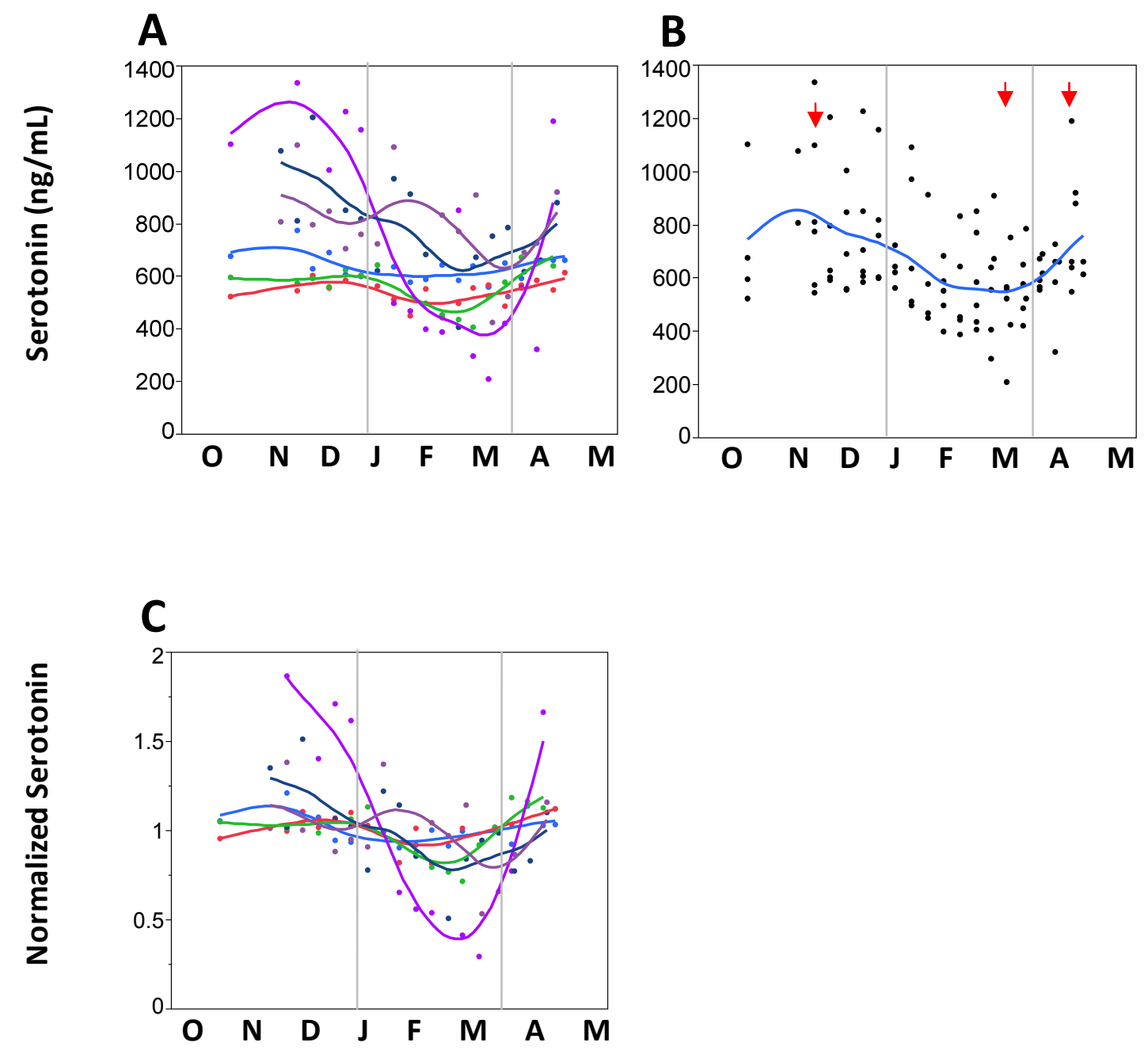

Figure 3.4-Serum serotonin concentrations

Serum serotonin concentrations of 6 black bears in the 2006/07 and 2007/08 seasons. Vertical lines represent transitions between active and hibernating seasons. (A) Serotonin concentrations are represented by a line for each bear. (B) Single smoothed curve represents the average of all 6 bears. Arrows indicate the dates at which "peakvalley" means were analyzed. (C) Each serotonin concentration was normalized to the average serotonin concentration for the appropriate bear for better comparison of seasonal fold changes. 

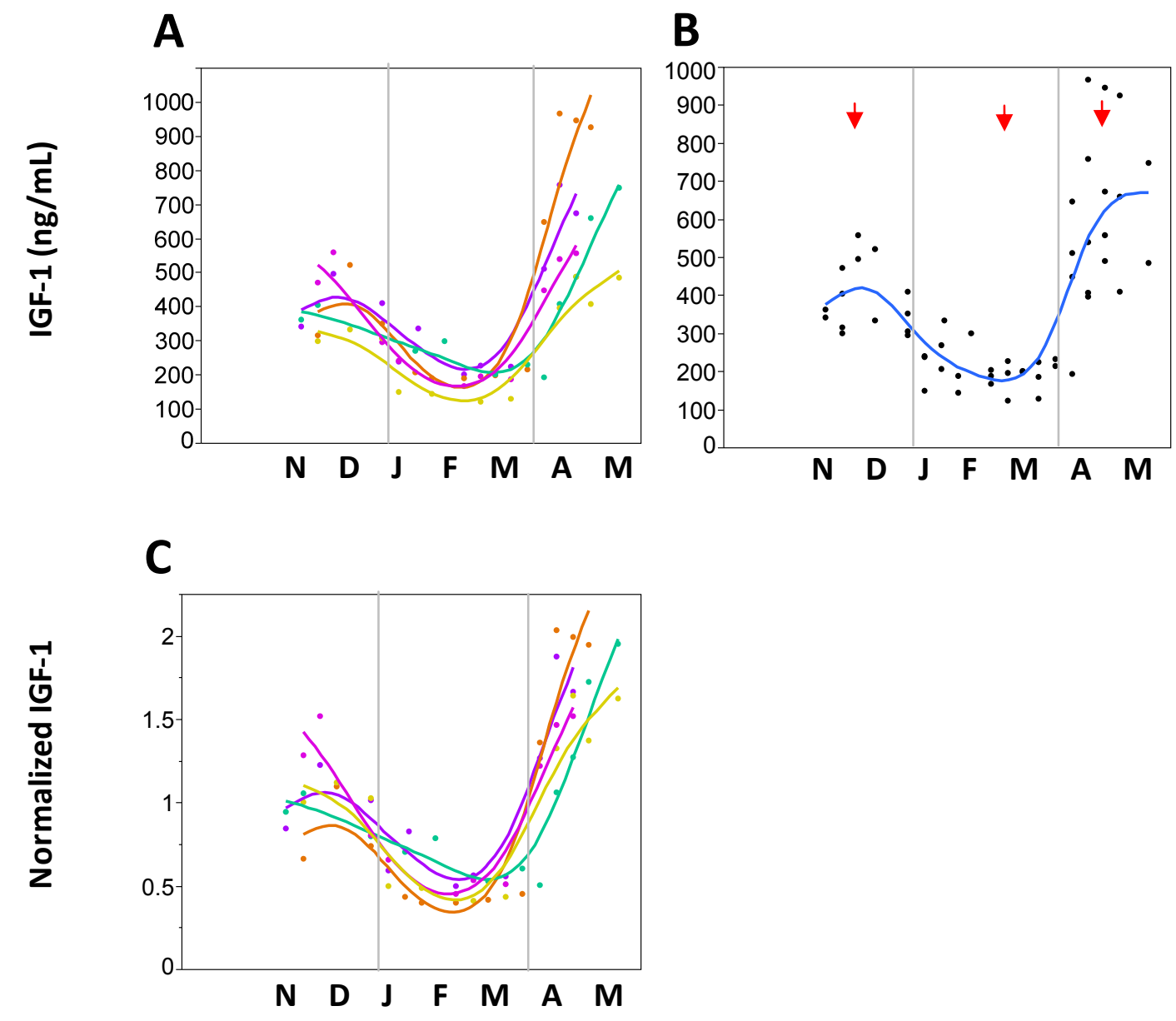

Figure 3.5-Serum IGF-1 concentrations

Serum IGF-1 concentrations of 5 black bears in the 2003/04 season. Vertical lines represent transitions between active and hibernating seasons. (A) IGF-1 concentrations are represented by a line for each bear. (B) Single smoothed curve represents the average of all 5 bears. Arrows indicate the dates at which "peak-valley" means were analyzed. (C) Each IGF-1 concentration was normalized to the average IGF-1 concentration for the appropriate bear for better comparison of seasonal fold changes. 


\section{Chapter Four - Attempts to find an anti-apoptotic environment in hibernating bear serum remain inconclusive}

\subsection{Introduction}

Osteocyte apoptosis precedes bone loss in unloaded mice, and attenuating osteocyte and osteoblast apoptosis with injections of PTH suppresses this bone loss $[48-51,56]$. It is possible that osteocyte and osteoblast apoptosis are required for disuse-induced bone loss, though no known studies have directly proven this idea. However, a study with a pan-caspase inhibitor in ovariectomized mice demonstrates that caspase activation is required for bone loss in that model of osteoporosis [162]. Apoptosis-inducing threats (e.g. ischemia, metabolic acidosis, anorexia) are prevalent in hibernating animals, yet qualitative observations suggest that these animals resist largescale apoptosis during hibernation (for review see: [163]). There are few in-depth studies on the apoptotic response during hibernation, though one study demonstrates reduced caspase-3 activation and no change in DNA laddering in the gut of hibernating ground squirrels compared to non-hibernating squirrels [45]. Bears may attenuate bone loss during hibernation by reducing susceptibility of osteoblasts and osteocytes to apoptosis, possibly through the circulation of anti-apoptotic hormones. The purpose of this chapter and the next is to determine whether serum levels of anti-apoptotic hormones increase during hibernation, thus providing an anti-apoptotic environment for osteoblasts and osteocytes. In this study, serum levels of the osteoblast apoptosis regulators $\mathrm{PTH}$, melatonin, and testosterone were quantified in the serum of hibernating and active American black bears. The hypothesis was that levels of the anti-apoptotic hormones PTH and melatonin would increase, and the levels of the pro-apoptotic hormone testosterone would decrease in serum of hibernating bears.

\subsection{Methods and materials}

A total of 6 female black bears were captured and held in pens in the Virginia Tech Center for Bear Research from fall through spring, between the years 2006 and 
2008. Samples were collected as described in section 2.2.1. Information about the bears used for each serum assay is shown in Table 4.1. Due to limitations of serum sample sizes, not all bears were used for all assays. The choice of bear used for each assay depended upon sample availability at the time the assays were run. The full-length and c-terminal PTH assays were sandwich ELISAs from Immutopics International (San Clemente, CA). Relative optical densities were reported. Serum melatonin and testosterone were quantified by RIA by Laurence Demmers at Pennsylvania State University. All statistical analyses were performed using JMP 7 software. Data in tables are presented as the LSM \pm SE. Graphs are represented with a point for each serum sample, and a smoothed average curve generated with JMP software by a cubic spline. All available samples from all bears were grouped by season (i.e. prehibernation, hibernation, and post-hibernation) and analyzed with a single-factor ANOVA, blocking by bear, with a Tukey's post-hoc.

\subsection{Results}

Serum concentrations of hormones are reported in Table 4.2. Serum levels of total PTH were not affected by season (Figure 4.1). However, levels of the c-terminal fragment of $\mathrm{PTH}$ were significantly lower during post-hibernation compared to prehibernation and hibernation seasons $(p=0.0164)$, though the profiles of the two bears were different (Figure 4.2). Testosterone decreased from $54.7 \mathrm{ng} / \mathrm{dL}$ in prehibernation to $17.4 \mathrm{ng} / \mathrm{dL}$ in post-hibernation $(\mathrm{p}=0.0361)$ (Figure 4.3). Melatonin was below quantifiable levels in all serum samples.

\subsection{Discussion}

The goal of this study was to determine whether hormone concentrations in the serum of hibernating bears favored anti-apoptotic conditions for osteoblasts; therefore, concentrations of three hormones which regulate osteoblast apoptosis were quantified in the serum of hibernating and active American black bears. Melatonin has anti-apoptotic effects on osteoblasts [58], and administration of melatonin to ovariectomized rats decreases apoptosis and abates bone loss [253]. However, this study found that 
concentrations of melatonin were below quantifiable levels in all samples. This finding was independently confirmed in the serum of grizzly bears, with the anatomical observation that the pineal gland in grizzly bears is extremely small (personal correspondence, Heiko Jansen).

Testosterone has a decreasing trend with time in the serum of female American black bears, such that the levels during post-hibernation are significantly lower than the levels during prehibernation (Table 4.2). In contrast, previous findings demonstrate increased testosterone in late hibernation in black bears [254-256]; however, these previous studies used male bears, which probably have different circannual cycles of androgens than females. Testosterone's effects on bone are not fully understood. Overactivation of the androgen receptor in osteoblasts of mice increases bone turnover and reduces bone matrix quality and whole bone strength [257]. In culture, testosterone has pro-apoptotic effects on osteoblasts [258]. These two studies suggest that testosterone's direct effects on bone are catabolic. However, testosterone has anabolic effects on tissues which positively influence bone metabolism (e.g. muscle) [259] and is a substrate for the synthesis of estrogen, a steroid hormone with anabolic effects on bone. Therefore, testosterone may have indirect anabolic effects on bone. Indeed, testosterone has a positive correlation with femoral BMD and with serum levels of OCN and BSALP in post-menopausal women [260, 261], suggesting that testosterone may promote bone formation in vivo. The serum levels of testosterone are not significantly different during hibernation from either active season; therefore there is no evidence that testosterone levels promote an anti-apoptotic environment during hibernation.

PTH has anti-apoptotic effects on osteoblasts [49, 55], and intermittent injections of PTH can inhibit bone loss [56]. The Donahue lab has previously reported an increase in PTH from prehibernation through post-hibernation in bears [34]; however, this previous study was incomplete and limited in size. The current study has a complete sample set from November through April, but includes only two bears. In another study which quantified PTH in the serum of 14 active and 27 hibernating American black bears, no seasonal change in PTH was observed in non-lactating bears, though PTH was lower in lactating than non-lactating bears [262]. In that study, there was only one sampling point in each season, in contrast to the Donahue studies which had multiple 
sampling points. It is possible to miss overall seasonal trends when only viewing one sampling point per season. A larger and more complete study must be performed before conclusions about seasonal PTH trends can be made. Therefore, it is unclear whether PTH increases during hibernation, thus preventing disuse-induced osteoblast and osteocyte apoptosis. The concentrations of the c-terminal fragment of PTH were also quantified in the serum of hibernating and active bears. C-terminal PTH promotes osteocyte apoptosis, and inhibits bone turnover (for review see: [263]). Levels of cterminal PTH decrease significantly during the post-hibernation season (Table 4.2). Together, the data in this study do not suggest that the serum from hibernating bears provides an anti-apoptotic environment for osteoblasts; however, the hormones studied here are only a few of many which can have effects on osteoblast apoptosis. Therefore, it would be informative to determine whether the serum from hibernating bears protects osteoblasts from apoptosis. Such a study is reported in the following chapter.

\subsection{Tables and figures}

Table 4.1-Summary of assays

The number of bears and assays that were performed in each hibernation season. The number of bears that gave birth to cubs is in parentheses. Unknown values are indicated as "UK."

\begin{tabular}{ccccc} 
Season & Bears & Age (years) & Assays & Data Location \\
\hline $2006-2007$ & $2(1)$ & UK & $\begin{array}{c}\text { PTH, c-terminal PTH, } \\
\text { testosterone }\end{array}$ & $\begin{array}{c}\text { Figures 4.1-4.3 } \\
\text { Table 4.2 }\end{array}$ \\
\hline $2007-2008$ & $4(3)$ & $5-14$ & melatonin &
\end{tabular}

Table 4.2-Serum factor concentrations

Data are represented as $L S M+S E$. The total number of samples included in the ANOVA is indicated below the mean concentrations. Letters $(A, B, C)$ represent values that are significantly different from each other at $\alpha=0.05$. The $p$-value reported is for the partial F-test for the serum factor. "Test" represents testosterone.

\begin{tabular}{|c|c|c|c|c|c|c|}
\hline $\begin{array}{l}\text { Serum } \\
\text { Factor }\end{array}$ & & $\begin{array}{c}\text { Fall } \\
\text { (Active) }\end{array}$ & $\begin{array}{c}\text { Winter } \\
\text { (Hibernation) }\end{array}$ & $\begin{array}{l}\text { Spring } \\
\text { (Active) }\end{array}$ & $\mathbf{p}$ & Power \\
\hline \multirow{2}{*}{$\begin{array}{c}\mathrm{PTH} \\
\text { (relative) }\end{array}$} & $\mathrm{LSM} \pm \mathrm{SE}$ & $12.8 \pm 3.0$ & $15.3 \pm 2.7$ & $14.8+4.6$ & \multirow[b]{2}{*}{0.8226} & \multirow[b]{2}{*}{0.0776} \\
\hline & $\mathrm{N}_{\text {samples }}$ & $1 \overline{2}$ & $1 \overline{5}$ & 5 & & \\
\hline \multirow{2}{*}{$\begin{array}{c}\text { C-terminal } \\
\text { PTH } \\
\text { (relative) } \\
\end{array}$} & $\mathrm{LSM} \pm \mathrm{SE}$ & $30.7 \pm 1.9^{A}$ & $31.8 \pm 1.7^{A}$ & $21.3 \pm 3.0^{B}$ & \multirow[b]{2}{*}{0.0164} & \multirow[b]{2}{*}{0.7493} \\
\hline & $\mathrm{N}_{\text {samples }}$ & 12 & 15 & 5 & & \\
\hline \multirow{2}{*}{$\begin{array}{c}\text { Test. } \\
\text { (ng/dL) }\end{array}$} & $\mathrm{LSM} \pm \mathrm{SE}$ & $54.7 \pm 7.4^{\mathrm{A}}$ & $41.2 \pm 6.6^{A B}$ & $17.4 \pm 11.5^{\mathrm{B}}$ & \multirow{2}{*}{0.0361} & \multirow{2}{*}{0.6370} \\
\hline & $\mathrm{N}_{\text {samples }}$ & 45 & 48 & 31 & & \\
\hline
\end{tabular}



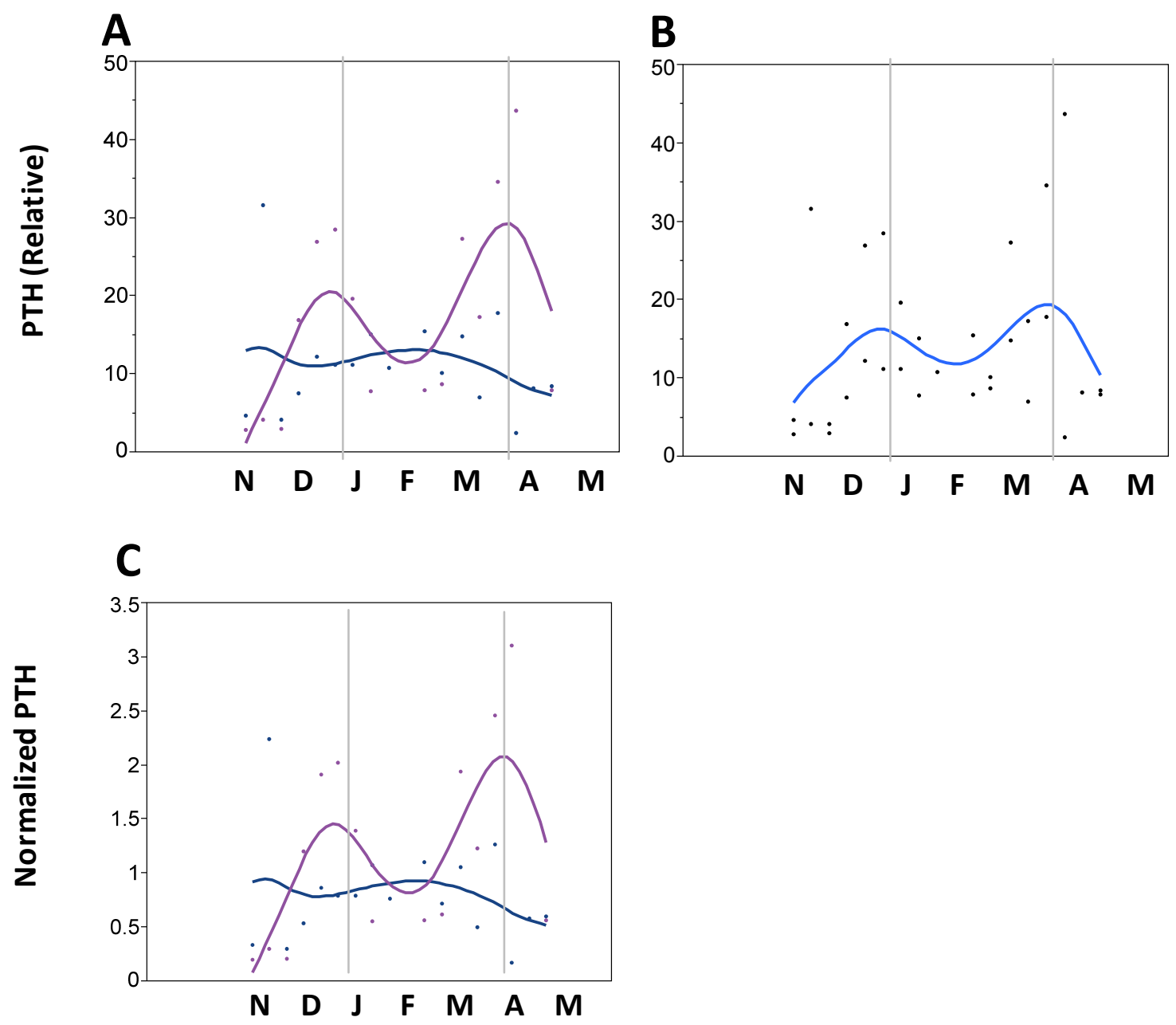

Figure 4.1-Serum PTH concentrations

Serum PTH concentrations of 2 black bears in the 2006/07 season. Vertical lines represent transitions between active and hibernating seasons. (A) PTH concentrations are represented by a line for each bear. (B) Single smoothed curve represents the average of both bears. (C) Each PTH concentration was normalized to the average PTH concentration for the appropriate bear for better comparison of seasonal fold changes. 


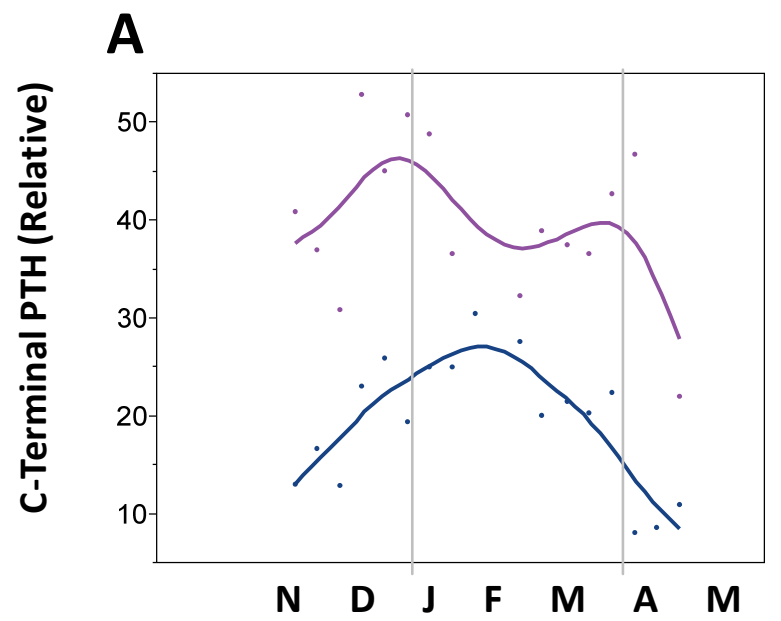

B

\section{C}

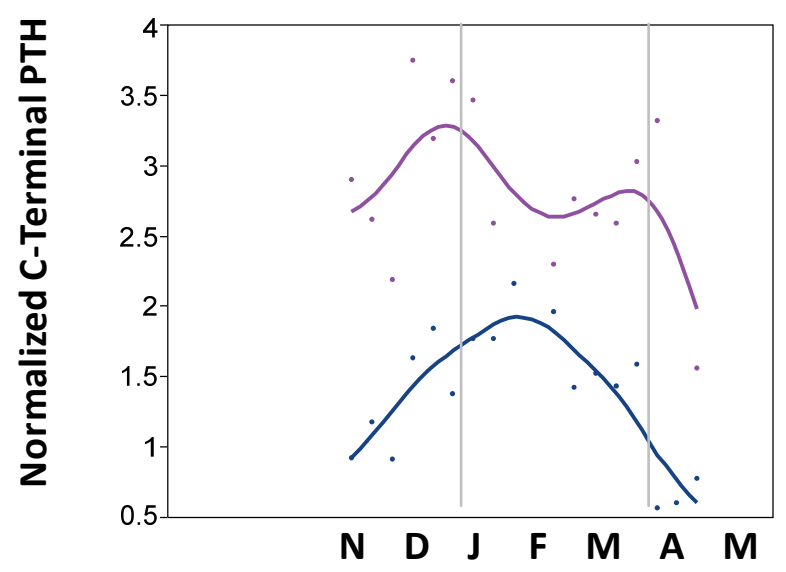

Figure 4.2-Serum C-terminal PTH concentrations

Serum C-terminal PTH concentrations of 2 black bears in the 2006/07 season. Vertical lines represent transitions between active and hibernating seasons. (A) C-terminal PTH concentrations are represented by a line for each bear. (B) Single smoothed curve represents the average of both bears. (C) Each C-terminal PTH concentration was normalized to the average C-terminal PTH concentration for the appropriate bear for better comparison of seasonal fold changes. 

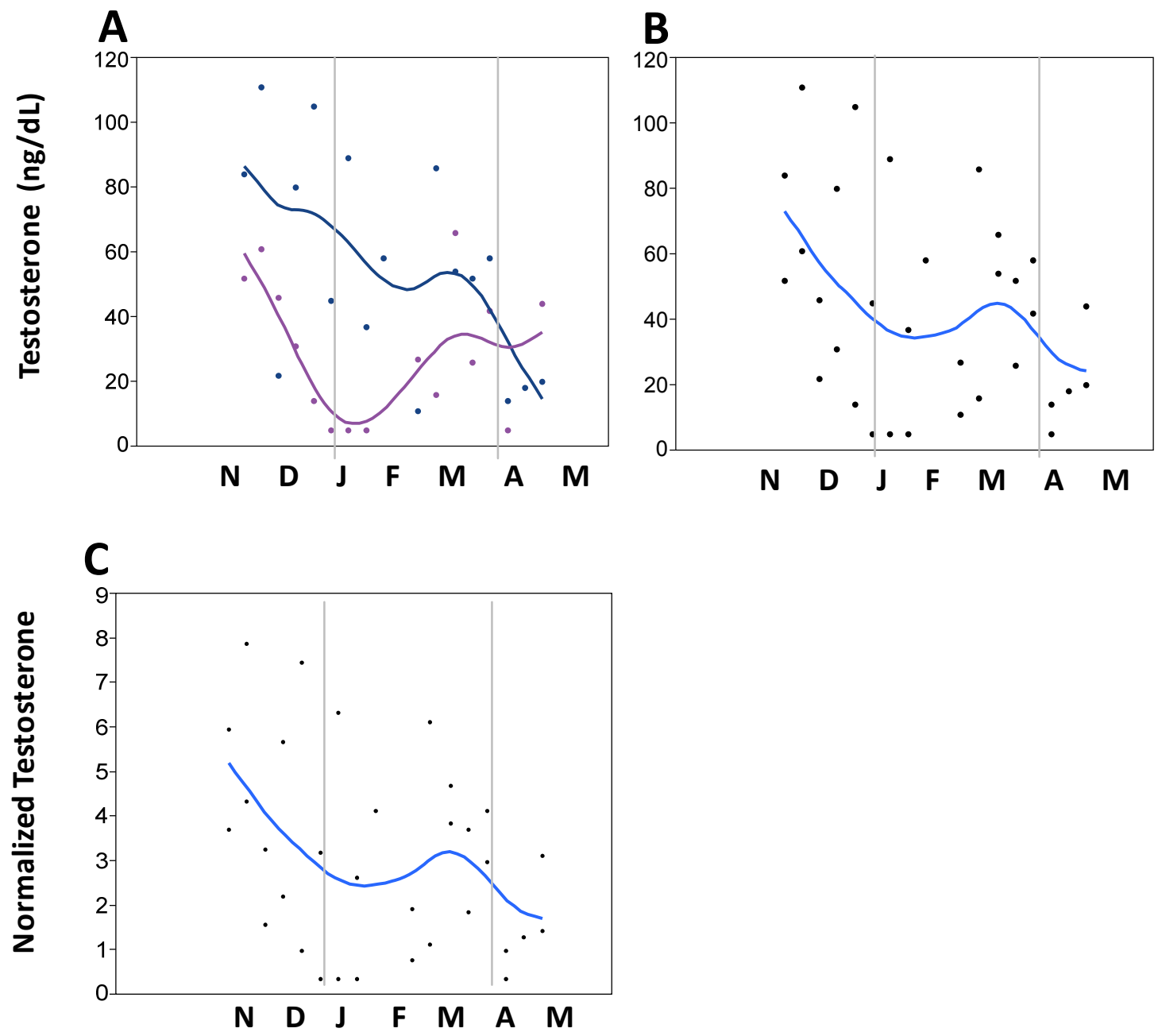

Figure 4.3-Serum testosterone concentrations

Serum testosterone concentrations of 2 black bears in the 2006/07 season. Vertical lines represent transitions between active and hibernating seasons. (A) Testosterone concentrations are represented by a line for each bear. (B) Single smoothed curve represents the average of both bears. (C) Each testosterone concentration was normalized to the average testosterone concentration for the appropriate bear for better comparison of seasonal fold changes. 


\section{Chapter Five - Serum from hibernating bears protects cells from caspase -3 and -7 activation}

\subsection{Introduction}

In the previous chapter, serum from hibernating and active bears was screened for specific hormones which may suppress osteoblast and osteocyte apoptosis during hibernation. Such a suppression of apoptosis during hibernation could prevent disuseinduced bone loss since osteocyte apoptosis precedes disuse-induced bone loss [48], and preventing apoptosis with injections of an anti-apoptotic hormone (PTH) prevents bone loss $[49,56]$. Although none of the hormones quantified (i.e. PTH, melatonin, and testosterone) appears to promote an anti-apoptotic environment during hibernation, many apoptosis regulators remain unquantified. In the second stage of this aim, MC3T3-E1 osteoblasts were cultured in serum from active and hibernating black bears. Cell responses to apoptotic threat (i.e. serum starvation) were quantified. The hypothesis was that osteoblasts cultured in the serum of hibernating bears would have reduced caspase-3 activation compared to cells cultured in active bear serum. Such a reduction in response to apoptotic threat would suggest that circulating factors in the serum of hibernating bears provide an anti-apoptotic environment for osteoblasts, thereby protecting the bear from bone loss.

It was reasonable to suspect that cells cultured in serum from different physiological conditions (i.e. from hibernating and active bears) would respond differently. Previous studies have observed changes in protein expression in cells incubated in serum from active and hibernating animals [264, 265]. Additionally, expression of osteoblast differentiation markers such as osteopontin, ALP activity, and OCN have been observed in mesenchymal stem cells cultured in serum from normal or osteoporotic patients [266] and in smooth muscle cells cultured in serum from normal or uremic patients [267]. Thus, by culturing osteoblasts in serum from hibernating and active bears, we could gain insight into the cellular mechanisms behind the maintenance of bone mass during hibernation. 


\subsection{Methods}

\subsubsection{Black bear handling and serum sample collection}

A total of 11 female black bears were captured and held in pens in the Virginia Tech Center for Bear Research from fall through spring, between the years 2006 and 2009. Samples were collected as described in section 2.2.1.

\subsubsection{Cell culture}

All experiments were conducted using the osteoblastic cell line MC3T3-E1, subclone 4 (ATCC, Manassas, VA). This cell line displays markers of the osteoblast phenotype including high ALP, type I collagen, and OCN expression when cultured in differentiation media ( $\alpha$-modified Eagle's medium ( $\alpha$-MEM) with $10 \%$ fetal bovine serum (FBS), $50 \mu \mathrm{g} / \mathrm{mL}$ ascorbic acid and $10 \mathrm{mmol} \beta$-glycerophosphate) [268]. The cells were cultured in growth media ( $\alpha$-MEM with 10\% FBS, and $1 \%$ penicillin/streptomycin) on $100 \mathrm{~mm}$ culture dishes in a $5 \% \mathrm{CO}_{2}$ air atmosphere at $37^{\circ} \mathrm{C}$. Media was replaced every 48 hours, and cells were passaged when they reach $80 \%$ confluency. Cells were not used beyond the tenth passage.

\subsubsection{MC3T3-E1 apoptotic response to seasonal bear serum}

Seasonal MC3T3-E1 response to apoptotic threat was determined by a caspase3 and -7 activity assay. Cells were seeded at 20,000 cells/well in tissue culture-treated white-walled 96-well plates and allowed to attach overnight. Prior to starvation, cells were primed for 24 hours in $2 \%$ FBS or bear serum. Since bear serum was collected every 10 days, several prehibernation, hibernation, and post-hibernation serum samples were available for each bear. Each well received a serum sample from a single bear from one collection day. Cells were starved in serum-free $\alpha$-MEM for 6 hours, unless otherwise noted. Media was aspirated and replaced with $50 \mu \mathrm{L}$ PBS and $50 \mu \mathrm{L}$ chemiluminescent DEVD substrate (Promega, Madison, WI), which releases photons upon degradation by caspases 3 and 7 . After 1 hour, luminescence was quantified by a 
Synergy HT Multi-Detection Microplate Reader (Bio-Tek, Winooski, VT). Caspase activity was reported as relative luminescence. In studies involving inhibitors, cells were pre-treated for one hour in 2\% FBS supplemented with $1 \mu \mathrm{M}$ SB206553, $20 \mu \mathrm{M} \mathrm{H}-89$, $100 \mathrm{ng} / \mathrm{mL}$ pertussis toxin, or DMSO vehicle. Cells were then stimulated for 24 hours in $2 \%$ bear serum with inhibitors before starvation. All inhibitors were purchased from Tocris Bioscience (Ellisville, MO). In studies involving filtered samples, molecules larger than $10 \mathrm{kD}$ were removed from $\alpha$-MEM containing $2 \%$ bear serum with $10 \mathrm{~K}$ centrifugal filters (VWR, West Chester, PA). "Unfiltered" controls were filtered serum-free $\alpha$-MEM supplemented with $2 \%$ bear serum after filtration. Cells were cultured in filtered or "unfiltered" samples for 24 hours prior to 6 hour starvation in serum-free media. In initial determination of caspase-3/7 response to bear serum pre-treatment, all available samples from October through May were used. In the studies involving inhibitors and filtration, 3 early prehibernation (October) and 3 mid-hibernation (February) samples were analyzed for each bear.

Seasonal cell response to apoptotic threat was also determined by Cell Death Detection ELISA (Roche), which quantifies the amount of histone-complexed DNA fragments in a cell lysate. Cells were seeded at 35,000 cells $/ \mathrm{cm}^{2}$ in 6 -well plates and allowed to attach overnight. Cells were then stimulated with $2 \%$ bear serum for 24 hours. After starvation for 24 hours, cells were trypsinized and $10^{4}$ cells from each sample were lysed and analyzed as described in the manufacturer's protocol. Seasonal cell response was also determined by with trypan blue, which stains dead cells. Cells were seeded at 35,000 cells $/ \mathrm{cm}^{2}$ in 6 -well plates and allowed to attach overnight. They were then stimulated with $2 \%$ bear serum for 24 hours. After starvation for 6,24 , or 48 hours, cells were trypsinized and counted with a hemocytometer. The ratio of live to dead cells was determined.

\subsubsection{Caspase-3/7 activity of bear bone lysates}

Seven grizzly bears were housed at the Washington State University Bear Research, Education, and Conservation Facility (Pullman, WA, USA) for this study. All handling and treatment procedures were approved by the Washington State University Institutional Animal Care and Use Committee. Four bears were sacrificed after 16-18 
weeks of hibernation, and 3 bears were sacrificed after at least 14 weeks of physical activity following hibernation. Bears were euthanized by an injection of pentobarbital (10 $\mathrm{ml}$ per 100 lbs body weight). Transiliac crest biopsies were collected with a diamondedged 3/8" coring bit. The cortical sections were separated from the trabecular bone with a saw. Marrow was removed from the trabecular bone with a water pick. Cortical and trabecular sections were crushed separately into a fine powder in liquid nitrogen, and lysed in buffer $\mathrm{L}$ (10mM Tris-HCl pH 8.0, 1\% IGEPAL, $2 \mathrm{mM} \mathrm{MgCl}_{2}, 150 \mathrm{mM} \mathrm{NaCl}$ ). After centrifugation to remove insoluble matter, protein concentration was quantified with the DC Protein Assay (BioRad Laboratories, Hercules, CA). Aliquots were stored at $-80^{\circ} \mathrm{C}$. $15 \mu \mathrm{g}$ of lysate was brought up to $50 \mu \mathrm{L}$ in buffer $\mathrm{L}$, and $50 \mu \mathrm{L}$ of chemiluminescent DEVD substrate was added. After 1 hour incubation, caspase-3/7 activity was quantified. Caspase activity was normalized to a standard curve of purified caspase-3 (Enzo Life Sciences, Plymouth Meeting, PA). Caspase-3/7 activity was reported in international units $(U)$ of activity. One $U$ breaks down DEVD substrate at 1 pmol per minute.

\subsubsection{MC3T3-E1 gene expression response to bear serum}

Cells were seeded into 6-well plates at 20,000 cells $/ \mathrm{cm}^{2}$ and grown overnight. Osteoblast differentiation was cultured for 6 days in differentiation media ( $\alpha$-MEM with $2 \%$ bear serum, $50 \mu \mathrm{g} / \mathrm{mL}$ ascorbic acid and $10 \mathrm{mmol} \beta$-glycerophosphate), with a media change on the third day. RNA was purified with the SV Total RNA Isolation System (Promega, Madison, WI). Immediately after bear serum stimulation, media was aspirated, and cells were directly lysed in $140 \mu \mathrm{L}$ RNA lysis buffer. Quality of RNA was assessed by gel electrophoresis and with a Nanodrop (Nanodrop Technologies, Willmington, DE). cDNA equivalent of $300 \mathrm{ng}$ RNA was generated in a $25 \mu \mathrm{L}$ reaction using $250 \mathrm{U}$ SSII reverse transcriptase, $0.5 \mu \mathrm{g}$ oligo-dT 12-18 primer, and $25 \mathrm{U}$ RNase Out (Life Technologies, Carlsbad, CA) at $42^{\circ} \mathrm{C}$ for 20 minutes, $50^{\circ} \mathrm{C}$ for 10 minutes and $42^{\circ} \mathrm{C}$ for 1 hour in a gradient thermocycler (Eppendorf, Westbury, NY). Primers for all genes of interest and the housekeeping gene were designed using PrimerQuest software (Integrated DNA Technologies, Coralville, IA) and the NCBI gene bank sequences, and the PCR conditions for each primer set were optimized using RNA from MC3T3-E1 cells. SYBR Green 2X master mix (ABGene, Rochester, NY) was used to set up PCR. cDNA equivalent of 2.5ng RNA was used in $25 \mu \mathrm{L}$ PCR samples with $0.1 \mu \mathrm{M}$ 
gene specific primers and $12.5 \mu \mathrm{L}$ SYBR mix. Forty cycles of real-time PCR was performed using OneStep Plus (Life Technologies, Carlsbad, CA). Sample expression was normalized to a background calibrator (samples incubated in $2 \%$ FBS), and again to the housekeeping gene cyclophilin using a variation of the relative standard curve method [269]. Briefly, the average threshold cycle $\left(\mathrm{C}_{\mathrm{T}}\right)$ for the $2 \% \mathrm{FBS}$ background was subtracted from the threshold cycle of each reaction to make $\Delta C_{T}$. Then the following calculation was performed, where GOI is "gene of interest," RG is the reference gene, and $E$ is the average efficiency of the primer:

Eqn 5.1: Normalized Expression $=\frac{E_{G O I}^{-\Delta C T(G O I)}}{E_{R G}^{-\Delta C T(R G)}}$

Gene expression of $\mathrm{OCN}$ and runt-related transcription factor 2 (Runx2) were quantified. Data was reported as relative normalized units.

\subsubsection{Biochemical Assays}

Serum was assayed for serotonin, adiponectin, and BSALP as described in section 2.2.2 and for NPY as described in section 3.2.

\subsubsection{Data representation and statistics}

All statistical analyses were performed using JMP 7 software. Data in Tables $\mathbf{5 . 2}$ and $\mathbf{5 . 4}$ are presented as the LSM \pm SE. Samples were grouped by season (i.e. prehibernation, hibernation, and post-hibernation) and analyzed with a single-factor ANOVA, blocking by bear, with a Tukey's post-hoc (for three seasons) or a student's ttest (for two seasons). Correlations between serum factors and cell responses were determined by least-squares linear regression, blocking by bear.

\subsection{Results}

In order to determine an appropriate time-point for quantifying caspase-3/7 activity in MC3T3-E1 cells, a time-course was performed, comparing the caspase-3/7 response to $3,6,9$, and 18 hours of serum starvation (Figure 5.1). Caspase-3/7 activity was highest at 6 and 9 hours of starvation, and 6 hours was chosen as the time-point for 
further assays. To determine whether bear serum had a seasonal effect in response to apoptotic threat, MC3T3-E1 pre-osteoblasts were primed for 24 hours in seasonal bear serum, then serum starved for 6 hours. The caspase-3/7 response to 6 hours' serum starvation was graphed longitudinally with a smoothed average curve (Figure 5.2). The caspase-3/7 response began to decrease in serum collected approximately 10 days before hibernation, and remained at a lower level throughout hibernation. In serum collected just after hibernation, caspase-3/7 response immediately rose to levels higher than those stimulated by prehibernation serum, suggesting a state of increased osteoblast metabolism in post-hibernation. When samples were grouped by season and compared by ANOVA, caspase- $3 / 7$ activity dropped from $5.66 \pm 0.23$ relative units in fall to $3.82 \pm 0.20$ in winter; values then rose to $7.89 \pm 0.41$ in the spring $(p<0.0001)$ (Table 5.2). Despite this drop in caspase-3/7 activity in MC3T3-E1 osteoblasts cultured in hibernating bear serum, no seasonal change in percent death was observed by Trypan blue staining after 6,24 , and 48 hours of serum starvation (data not shown). Similarly, no seasonal differences in apoptotic enrichment factor were observed with the Cell Death Detection ELISA after 24 hours of serum starvation (data not shown). To determine whether bone of hibernating bears confirmed the finding that caspase- 3 and -7 activity was suppressed by hibernation, bone tissue lysates were assayed. Caspase-3/7 activity of cortical bone tissue lysates had a decreasing trend of $65 \%$ from prehibernation to hibernation $(p=0.2436)$ (Figure 5.3). The trabecular bone lysates had very low levels of caspase-3/7 activity in both active and hibernating seasons (data not shown).

Serum serotonin concentrations during the prehibernation and hibernation seasons were correlated to the caspase- $3 / 7$ response of pre-osteoblasts cultured in seasonal serum $(r=0.807, p<0.0001)$, suggesting that reduced serotonin levels in the hibernation serum might desensitize the cells to apoptotic threat. Therefore, the 5HT-2B / -2C inhibitor SB206553 was used to block the possible effects of serotonin on the cultured osteoblasts. There was a $47 \%$ decrease in caspase- $3 / 7$ response of cells primed in prehibernation serum compared to hibernation in the vehicle samples $(p=0.0001)$ and a 43\% seasonal decrease in the SB206553 samples $(p=0.0007)$ (Figure 5.4), suggesting that the $5 \mathrm{HT}-2 \mathrm{~B} /-2 \mathrm{C}$ inhibitor did not suppress the seasonal effect of bear serum on caspase-3/7 activity. To help narrow down the internal signaling pathway 
involved in the reduced caspase-3/7 response of cells primed in hibernation serum, experiments were repeated with $\mathrm{H}-89$ and pertussis toxin. When the protein kinase $\mathrm{A}$ (PKA) pathway was inhibited with $\mathrm{H}-89$, the percent decrease between cells in prehibernation versus hibernation serum was $39 \%$ in the vehicle sample $(p<0.0001)$ and $31 \%$ in the $\mathrm{H}-89$ sample $(\mathrm{p}=0.0066)$ (Figure 5.5); however, $\mathrm{H}-89$ reduced the caspase- $3 / 7$ response to serum starvation by approximately $12 \%(p<0.0001)$. In a similar experiment, the g-protein subunit $G_{i}$ was blocked with pertussis toxin. In this experiment, the toxin-treated samples had a $38 \%$ decrease in caspase-3/7 activity between cells incubated in prehibernation or hibernation serum $(p=0.0234)$, whereas there was a $48 \%$ decrease between prehibernation and hibernation samples in the vehicle treatment $(p=0.0423)$ (Figure 5.6). Thus, neither the $\mathrm{H}-89$ nor pertussis toxin had a strong impact on the seasonal effect of bear serum on the caspase- 3 and -7 response of cultured MC3T3-E1 pre-osteoblasts.

The final attempt at characterizing the serum factor responsible for the reduced response of pre-osteoblasts to apoptotic threat in hibernation serum was to filter out all molecules of size greater than $10 \mathrm{kD}$. Samples were treated with filtered and unfiltered serum for 24 hours, followed by a 6 hour serum starvation, as before. Controls using filtered and unfiltered $2 \%$ FBS were simultaneously collected. In the unfiltered FBS control, the starved sample had $260 \%$ higher caspase-3/7 activity than the unstarved sample $(p<0.0001)$; however, there was no significant difference between the starved and unstarved samples after priming for 24 hours in filtered $2 \%$ FBS ( $p=0.6784$ ) (Figure 5.7 A). These data suggest that priming for 24 hours in filtered serum prior to six hours' serum starvation does not activate caspases 3 and 7 at this time-point. There was also no seasonal difference between caspase activities of cells primed for 24 hours in filtered prehibernation serum versus filtered hibernation serum $(p=0.1014)$ (Figure 5.7 B). Because the caspase-3/7 response to serum starvation is time-dependent and drops back to basal levels after 24 hours of starvation (Figure 5.1), we thought that the samples grown in filtered $2 \%$ serum may have experienced a starvation-like state during the 24 hour priming step. Therefore, we tried a second experiment in which the cells were cultured in filtered serum-free or $2 \%$ FBS media for 6 hours, followed by caspase activity analysis. Under these conditions, the samples stimulated for 6 hours in filtered serum-free media had a $27 \%$ increase in caspase- $3 / 7$ activity compared to samples 
stimulated in filtered 2\% FBS ( $p=0.0071$ ) (Figure 5.8 A). The cells grown for 6 hours in filtered $2 \%$ bear serum were not significantly different between prehibernation and hibernation seasons $(p=0.4490)$ (Figure $5.8 \mathrm{~B})$.

Serum levels of BSALP and adiponectin were positively correlated, and NPY was inversely correlated, with the caspase- $3 / 7$ response of cultured osteoblasts to apoptotic threat (Table 5.4). The gene expression of osteoblast differentiation markers OCN and Runx2 increased in differentiating osteoblasts cultured in serum from post-hibernation bears, compared to those in serum from prehibernation and hibernation bears (Table 5.2).

\subsection{Discussion}

Hibernating bears have a unique ability to maintain bone mechanical strength and structural properties despite extended periods of disuse [16-21, 173, 174]. The purpose of this study was to explore the hypothesis that a serum-borne factor in hibernating bears suppresses osteoblast apoptosis. Such a suppression of apoptosis may prevent disuse-induced bone loss during hibernation. MC3T3-E1 osteoblast-like cells were cultured in serum from active and hibernating bears for 24 hours, followed by an apoptotic threat. Figure $\mathbf{5 . 2}$ demonstrates a reduction in caspase-3 and $\mathbf{- 7}$ activation in cells cultured in hibernating bear serum, supporting the hypothesis. These data also demonstrate an increased caspase-3/7 response in post-hibernation serum compared to prehibernation serum (Table 5.2), indicating the metabolic rate of bone may be increased in the weeks immediately following hibernation. This higher metabolism in bone was also indicated in the gene expression data (Table 5.2). Expression of OCN and Runx2, markers of osteoblast differentiation, were significantly higher in osteoblasts cultured in post-hibernation serum. Such an increased metabolic state in the bones of post-hibernation bears has been indicated in previous publications [35].

The next step was to demonstrate that apoptosis decreases in the bone tissue of hibernating bears, compared to active bears. This step has proven more difficult. Hibernating animals are exposed to many conditions that would cause extensive tissue damage due to apoptosis in other animals; however, they fully recover from annual 
hibernation cycles without problem [163]. Despite this ability to recover from annual cycles of hibernation, studies have consistently shown an increase in TUNEL positive cells in tissues from hibernating animals [45, 168, 169], which would normally indicate an increase in apoptosis. However, one of these studies demonstrated that caspase-3 activation in the gut of hibernating ground squirrels decreases, despite increased TUNEL positive cells [45]. Thus, TUNEL stains in hibernating tissues may be inaccurately interpreted as an increase in apoptosis. It is possible that the increase in TUNEL positive cells during hibernation may be due to an accumulation of damaged DNA during this season [45]. In support of this claim, other studies have shown that TUNEL stains can incorrectly label cells with DNA damage that are destined for repair [46]. Thus, a TUNEL stain was not attempted on bone biopsies from bears. The caspase-3 stain for apoptotic cells could likewise not be used on bear bone tissue, because an antibody could not be found which would bind bear caspase-3. Therefore, this study determined the caspase activity of bone lysate using a DEVD substrate, which is broken down by caspases 3 and 7. Only three active and four hibernating bone biopsies were available for analysis, so this study had low power and did not attain significance. However, there was a trend for decreased caspase-3/7 activity in the lysate of hibernating bear cortical bone compared to lysate from active samples (Figure 5.3). These data further support the hypothesis that apoptosis is decreased in the bones of hibernating bears, but a study with more samples is necessary for conclusive confirmation.

The next goal of the current study was to characterize the serum factor responsible for reduced apoptotic response of osteoblasts cultured in serum from hibernating bears. If the post-hibernation samples were removed from analysis, serum levels of serotonin had a strong positive correlation to the osteoblast caspase-3/7 response to apoptotic threat. Although there is no known literature of a pro-apoptotic effect of serotonin on osteoblasts, many studies suggest that circulating serotonin has a catabolic effect on bone (for review see: [251]). The direct effect of serotonin on MC3T3E1 proliferation is suppressed by the 5HT-2B / -2C receptor inhibitor SB206553 [219], so this inhibitor was chosen for the current study. SB206553 did not inhibit the seasonal effect of bear serum on MC3T3-E1 response to apoptotic threat (Figure 5.4), indicating that if serotonin is responsible for the seasonal effect of bear serum on osteoblast apoptotic response, then it is not through the $5 \mathrm{HT}-2 \mathrm{~B}$ or $-2 \mathrm{C}$ receptors; however, there 
are also $5 \mathrm{HT}-1 \mathrm{~A},-2 \mathrm{~A}$, and $-1 \mathrm{D}$ receptors and $5 \mathrm{HTT}$ transporters on osteoblasts [270], none of which would have been blocked by SB206553; therefore, serotonin has not been definitely ruled out as a potential apoptosis effector in this system.

H-89 inhibits the PKA pathway, an internal signaling cascade which, in osteoblasts, responds to a variety of hormones including parathyroid hormone, calcitonin gene-related peptide, and norepinephrine [271-274]. H-89 can suppress anti-apoptotic signaling in osteoblasts $[272,275,276]$; however, $\mathrm{H}-89$ does not significantly suppress the seasonal difference in apoptotic response of pre-osteoblasts primed in bear serum (Figure 5.5), suggesting that the PKA pathway is not vital to this seasonal difference in caspase-3/7 response. Pertussis toxin inhibits the g-protein subunit $G_{i}$. A variety of hormones and factors can function through the $G_{i}$ subunit of g-protein coupled receptors, including parathyroid hormone, aluminum, lysophosphatidic acid, epinephrine, and melatonin [277-280]. Pertussis toxin can suppress anti-apoptotic signaling in osteoblasts $[281,282]$. Pertussis toxin did not greatly alter the seasonal difference observed between pre-osteoblasts primed in prehibernation and hibernation serum samples (Figure 5.6), suggesting that the $G_{i}$ subunit is not necessary for this seasonal difference in caspase-3/7 response.

In an attempt to determine the size of the serum factor responsible for the seasonal difference in apoptotic response, molecules larger than $10 \mathrm{kD}$ were filtered out of the media before stimulation. Samples were treated with filtered and unfiltered serum for 24 hours, followed by a 6 hour serum starvation, as in previous experiments. There was not a seasonal difference between cells primed in filtered prehibernation and hibernation serum samples (Figure $5.7 \mathrm{~B}$ ); however, there was also no difference between starved and unstarved cells which were primed in filtered 2\% FBS (Figure 5.7 A), suggesting that the 24 hour priming in filtered media suppresses caspase-3/7 response at this time-point. The caspase-3/7 response to starvation is time-dependent (Figure 5.1), and we thought that the filtered media might induce a starvation-like state in the cells. Therefore, we ran a second experiment in which cells were cultured in filtered $2 \%$ FBS or serum free media for 6 hours, followed by caspase-3/7 activity analysis. In this second experiment, there was a significant difference between the $2 \%$ FBS and the serum-free media (Figure 5.8 A). We then cultured cells for 6 hours in 
filtered seasonal bear serum and found no significant difference between the caspase3/7 response of prehibernation and hibernation samples (Figure 5.8 B). This suppression of the seasonal difference between cells cultured in prehibernation and hibernation serum samples may suggest that a molecule larger than $10 \mathrm{kD}$ is necessary for the seasonal difference in caspase-3/7 activity; however, the data remains inconclusive since the experimental conditions are different than our original experiment in which we saw the seasonal difference, and no proper control for this experiment exists.

Least squares linear regression analysis was used to determine relationships between the caspase-3/7 response to apoptotic threat and bone turnover markers in the serum. Interestingly, the caspase-3/7 response was positively correlated to the serum marker of osteoblast activity BSALP (Table 5.4), suggesting that the reduced osteoblast response to apoptotic threat in serum from hibernating bears may be coupled to reduced osteoblast differentiation. Previous studies have described a dependence on caspase-3 for osteoblast differentiation. For instance, MC3T3-E1 cells activate caspases 8,2 , and 3 upon stimulation of differentiation by BMP-4, and inhibitors of these caspases will suppress the effects of BMP-4 [283]. Another study demonstrates that osteoprogenitor cells from caspase- $3^{-/}$and caspase $-3^{+/-}$mice have significantly decreased expression of Runx2 compared to cells from wild-type mice [284]. It is possible that the higher caspase-3/7 activity observed in osteoblasts cultured in active bear serum may be partly due to a higher differentiation potential in these cells. If true, this would explain why we observed a seasonal caspase-3/7 response to bear serum, but could not find any indication that the cells were undergoing apoptosis through trypan blue exclusion and Cell Death Detection assays.

To support the idea that the seasonal differences in caspase-3/7 response may be due to reduced differentiation potential of cells in hibernating bear serum, regression analysis was used to determine relationships between gene expression of osteoblast differentiation markers and caspase-3/7 response. The seasonal caspase-3/7 response to serum starvation after 24 hours' pre-treatment in bear serum was positively correlated to gene expression of $\mathrm{OCN}$ and Runx2 after 6 days of differentiation in seasonal bear serum (Table 5.4). A reduction of osteoblast differentiation during hibernation may be 
favorable since differentiation would utilize metabolic energy, which bears must conserve during hibernation. In fact, although osteoblast activity remains balanced with osteoclast activity, activities of both cell types dramatically decrease during hibernation, as is seen in histomorphometric data $[18,20]$ and serum levels of BSALP (Table 5.3).

Finally, regression analysis was used to determine what hormones may be responsible for reduced osteoblast differentiation and caspase-3/7 activation during hibernation. Serum levels of the neuropeptide NPY increase in the serum of hibernating bears, and are inversely correlated with caspase-3/7 response to apoptotic threat in osteoblasts (Table 5.4). Although there are no known studies demonstrating a relationship between NPY and osteoblast caspase-3 and -7 response, NPY is known to suppress osteoblast differentiation [246]. Furthermore, NPY is negatively correlated to serum BSALP, suggesting a possible relationship between NPY and bone turnover in the bear. Another potential effector of differentiation is adiponectin, which decreases in the serum of hibernating bears and is positively correlated to caspase- $3 / 7$ response to apoptotic threat in osteoblasts (Table 5.4). Again, although there are no known studies demonstrating a relationship between adiponectin and caspase- 3 and -7 response, adiponectin has been shown to stimulate osteoblast proliferation, differentiation, and expression of BSALP in cultured osteoblasts [202]. Adiponectin levels are positively correlated to serum BSALP in the bears, suggesting that it, too, could be regulating turnover during hibernation.

Bears have a unique ability to maintain bone despite prolonged mechanical unloading (i.e. hibernation). The aim of this study was to demonstrate that a factor in the serum of hibernating bears would protect cultured osteoblasts from apoptosis. Such a prevention of osteoblast and osteocyte apoptosis in the bones of hibernating bears may help maintain bone during this period of disuse. Compared to cells cultured in active bear serum, osteoblasts cultured in serum from hibernating bears had reduced caspase3 and -7 activity and a higher percentage of living cells after 6 hours of serum starvation. These findings suggest that the osteoblast response to apoptotic stimulus may be reduced during hibernation. This effect did not appear to be PKA dependent or strongly sensitive to pertussis toxin. Based upon regression analysis, two possible hormones are NPY and adiponectin. Both hormones have an impact on osteoblast differentiation, 
which is dependent upon caspase-3 activation. It is likely that more than one serum factor is involved in the maintenance of bone mass during hibernation in bears; however, determining a few possible effector hormones could pinpoint new signaling pathways as potential drug targets. This study has taken a step towards that long-term goal.

\subsection{Tables and figures}

Table 5.1-Summary of assays

The number of bears and assays that were performed in each hibernation season. The number of bears that gave birth to cubs is in parentheses. Unknown values are indicated as "UK."

\begin{tabular}{ccccc} 
Season & Bears & $\begin{array}{c}\text { Age } \\
\text { (years) }\end{array}$ & Assays & Data Location \\
\hline $2006-2007$ & $2(1)$ & UK & Caspase-3, 6day qPCR (OCN, Runx2) & $\begin{array}{c}\text { Figure 5.2 } \\
\text { Tables 5.2, 5.3 }\end{array}$ \\
\hline $2007-2008$ & $4(3)$ & $5-14$ & Caspase-3 & $\begin{array}{c}\text { Figure 5.2 } \\
\text { Tables 5.2, 5.3 }\end{array}$ \\
\hline $2008-2009$ & $5(3)$ & $2-21$ & $\begin{array}{c}\text { SB206553 Caspase-3, Caspase-3, } \\
\text { Pertussis Toxin Caspase-3, H-89 } \\
\text { Caspase-3, 10kd and 30kd Filter } \\
\text { Caspase-3 }\end{array}$ & $\begin{array}{c}\text { Figures 5.3-5.7 } \\
\text { Table 5.2, 5.3 }\end{array}$ \\
& & $\begin{array}{c}\text { Casper } \\
\end{array}$
\end{tabular}

Table 5.2-Cell responses to bear serum

Data are represented as $L S M+S E$. The total number of samples included in the ANOVA is indicated below the means. Letters $(A, B, C)$ represent values that are significantly different from each other at $\alpha=0.05$. The $p$-value reported is for the partial F-test for the serum factor.

\begin{tabular}{|c|c|c|c|c|c|}
\hline $\begin{array}{c}\text { Cell } \\
\text { Response }\end{array}$ & & $\begin{array}{c}\text { Fall } \\
\text { (Active) }\end{array}$ & $\begin{array}{c}\text { Winter } \\
\text { (Hibernation) }\end{array}$ & $\begin{array}{l}\text { Spring } \\
\text { (Active) }\end{array}$ & $\mathbf{p}$ \\
\hline \multirow{2}{*}{ Caspase-3/7 } & LSM+SE & $5.66 \pm 0.23^{B}$ & $3.82 \pm 0.20^{C}$ & $7.89 \pm 0.41^{A}$ & \multirow{2}{*}{$<0.0001$} \\
\hline & $\mathrm{N}_{\text {samples }}$ & $\overline{40}$ & $\overline{53}$ & $\overline{14}$ & \\
\hline \multirow{2}{*}{ OCN } & LSM+SE & $0.0564 \pm 0.005^{\mathrm{B}}$ & $0.0549 \pm 0.004^{\mathrm{B}}$ & $0.0983 \pm 0.007^{A}$ & \multirow[t]{2}{*}{$<0.0001$} \\
\hline & $\mathrm{N}_{\text {samples }}$ & 11 & 16 & 5 & \\
\hline \multirow{2}{*}{ Runx2 } & LSM+SE & $0.654+0.083^{B}$ & $0.741 \pm 0.069^{B}$ & $1.13 \pm 0.12^{A}$ & \multirow{2}{*}{0.0103} \\
\hline & $\mathrm{N}_{\text {samples }}$ & 11 & 16 & 5 & \\
\hline
\end{tabular}


Table 5.3-Linear regression models

\begin{tabular}{ccccccc}
$\begin{array}{c}\text { Dependent } \\
\text { Variable }\end{array}$ & $\begin{array}{c}\text { Independent } \\
\text { Variable }\end{array}$ & $\mathbf{N}_{\text {bears }}$ & $\boldsymbol{\beta}$ & $\mathbf{r}$ & $\mathbf{p}$ & Power \\
\hline Caspase-3/7 & 6 day OCN & 2 & 0.00532 & 0.796 & $<0.0001$ & 0.9971 \\
Caspase-3/7 & 6 day Runx2 & 2 & 0.0535 & 0.453 & 0.0069 & 0.8058 \\
Caspase-3/7 & BSALP & 4 & 0.130 & 0.728 & 0.0066 & 0.8214 \\
Caspase-3/7 & NPY & 4 & -0.0107 & -0.437 & 0.0496 & 0.5061 \\
Caspase-3/7 & Adiponectin & 4 & 0.000936 & 0.493 & 0.0131 & 0.7158
\end{tabular}

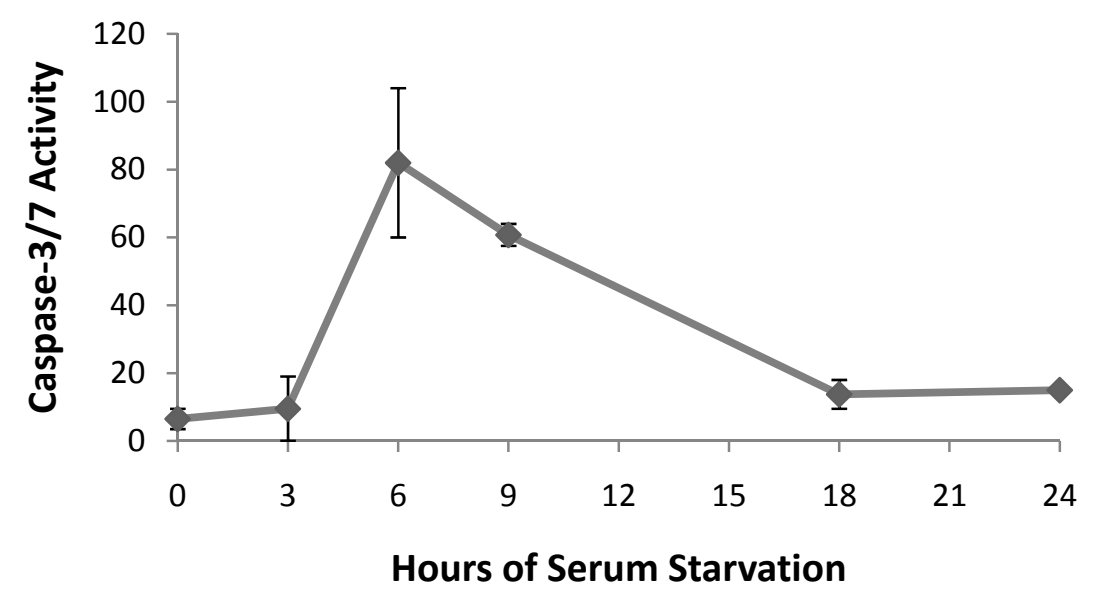

Figure 5.1-Caspase-3/7 activity time-course

MC3T3-E1 cells were starved in serum free $\alpha$-MEM for 3-24 hours. Data are represented as $\mathrm{LSM} \pm \mathrm{SE}$. Units are of relative luminescence normalized to the average of the "time 0" nostarve control. 


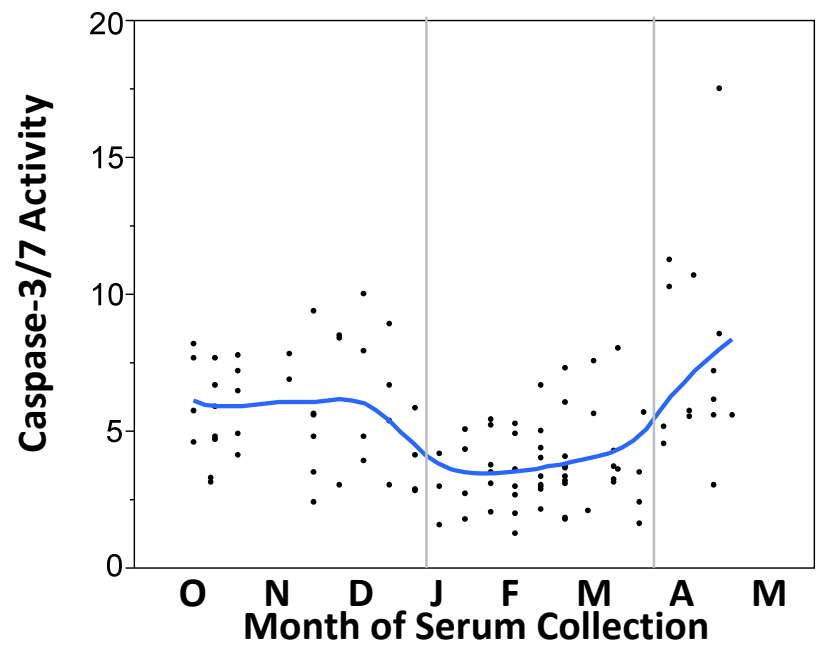

Figure 5.2-Longitudinal analysis of caspase-3/7 response

MC3T3-E1 cells were cultured in seasonal bear serum for 24 hours, and were then starved in serum free $\alpha$-MEM for 6 hours. Caspase-3/7 response was normalized to a no-starve FBS control. Each point represents the caspase-3/7 response from pre-incubation in one serum sample. Vertical lines represent transitions between active and hibernating seasons. The smoothed average curve was generated with JMP software by a cubic spline. Samples are from 11 black bears in the 2006/07 - 08/09 seasons.

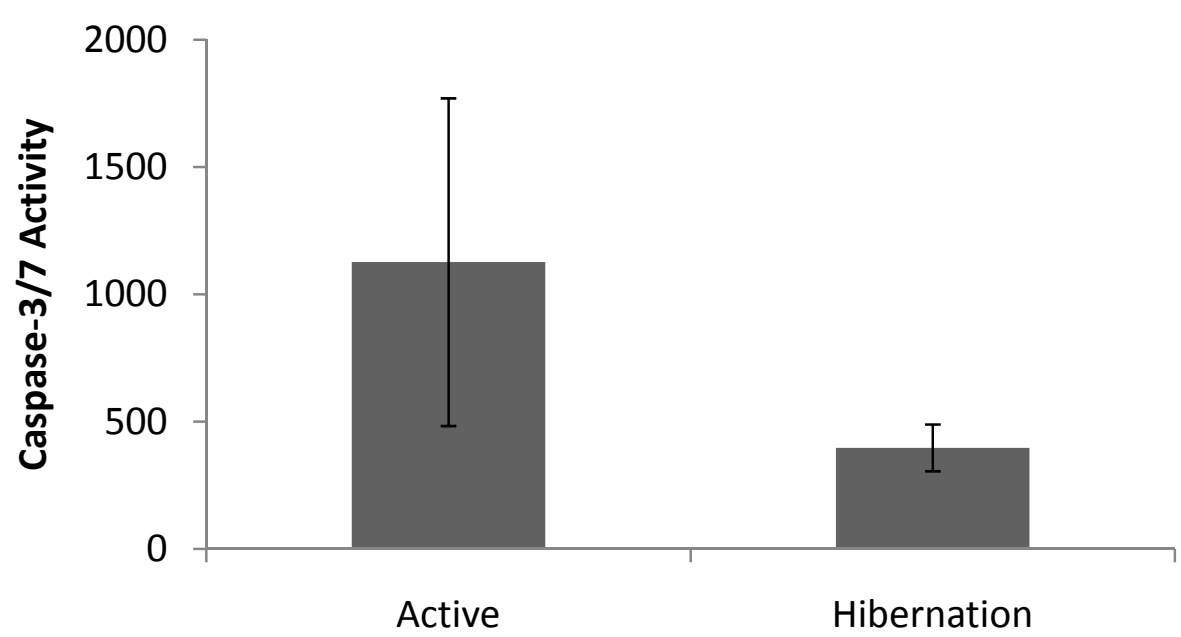

Figure 5.3-Caspase-3/7 activity in cortical bone lysate from hibernating and active bears Caspase-3/7 activity was quantified in $15 \mu \mathrm{g}$ protein equivalent of crushed bone lysate. Data are represented as LSM+SEM. A t-test was used to determine the $p$-value, with an $n=4$ hibernation and 3 active samples for each season. Due to small sample size, seasonal variation did not obtain significance $(p=0.2436)$. 


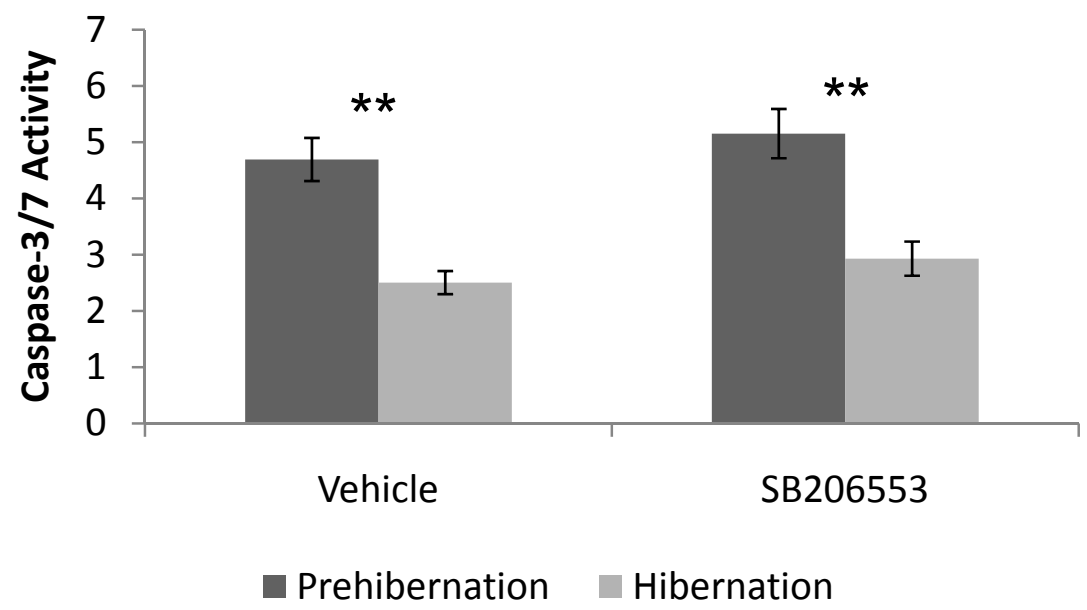

Figure 5.4-Seasonal caspase-3/7 response with 5HT-2B / 5HT-2C inhibitor MC3T3-E1 cells were pretreated in SB206553 for one hour, and were then cultured in seasonal bear serum supplemented with SB206553 for 24 hours. Afterwards, they were starved in serum free $\alpha$-MEM for 6 hours. Caspase-3/7 activities were normalized to the nostarve FBS control. Caspase-3/7 activities were compared between prehibernation and hibernation for each treatment with a student's t-test. Both treatments had a significant seasonal difference, indicated with asterisks $(p<0.0008)$. Samples are from 3 black bears of the $2008 / 09$ season.

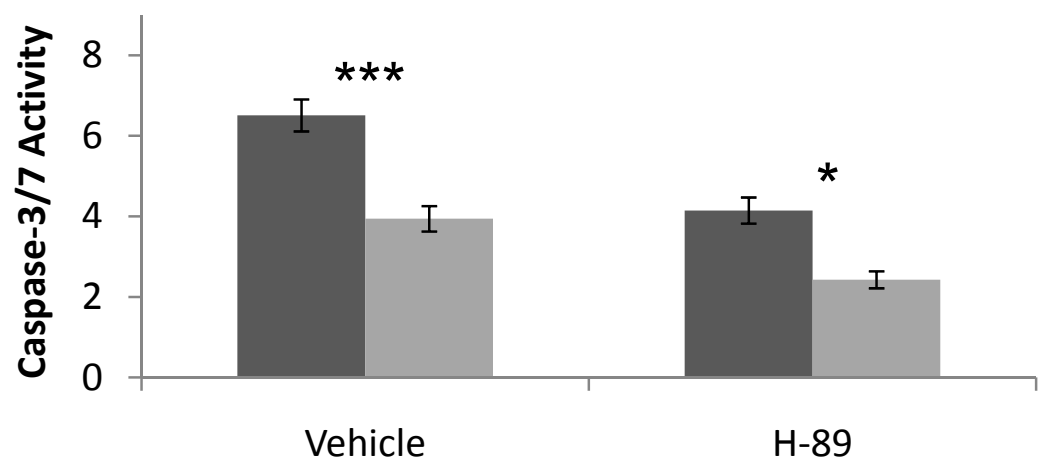

Prehibernation Hibernation

Figure 5.5-Seasonal caspase-3/7 response with PKA inhibitor

MC3T3-E1 cells were pretreated in $\mathrm{H}-89$ for one hour, and were then cultured in seasonal bear serum supplemented with $\mathrm{H}-89$ for 24 hours. Afterwards, they were starved in serum free $\alpha$-MEM for 6 hours. Caspase-3/7 activities were normalized to the no-starve FBS control. Caspase-3/7 activities were compared between prehibernation and hibernation for each treatment with a student's t-test. Both treatments had a significant seasonal difference, indicated with one $(p<0.05)$ or three asterisks $(p<0.0001)$. Samples are from 5 black bears of the $2008 / 09$ season. 


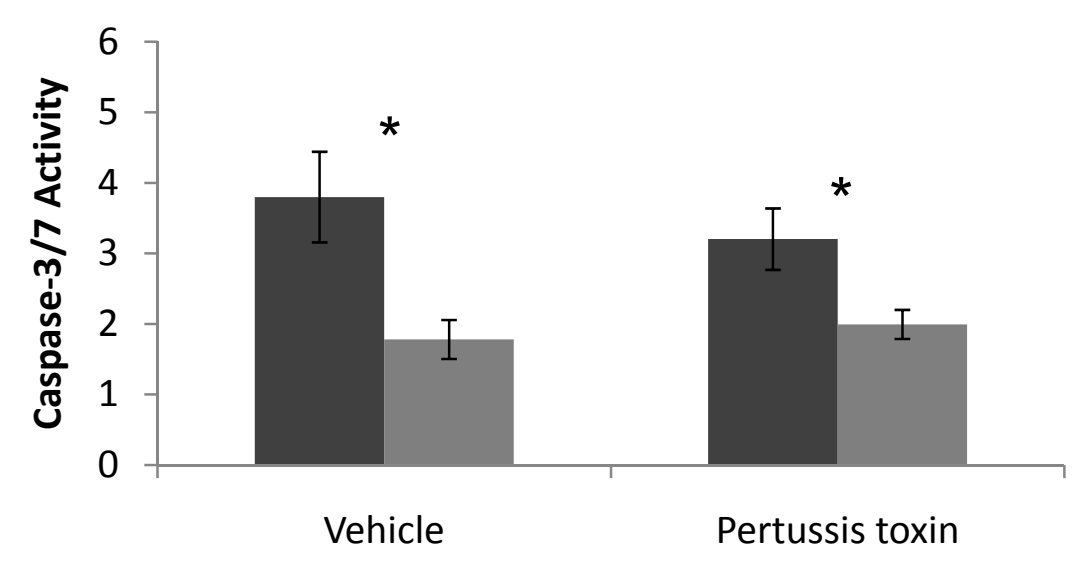

- Prehibernation Hibernation

Figure 5.6-Seasonal caspase-3/7 response with pertussis toxin

MC3T3-E1 cells were pretreated in pertussis toxin for one hour, and were then cultured in seasonal bear serum supplemented with pertussis toxin for 24 hours. Afterwards, they were starved in serum free $\alpha$-MEM for 6 hours. Caspase-3/7 activities were normalized to the nostarve FBS control. Caspase-3/7 activities were compared between prehibernation and hibernation for each treatment with a student's t-test. Both treatments had a significant seasonal difference, indicated with an asterisk $(p<0.05)$. Samples are from 3 black bears of the $2008 / 09$ season. 


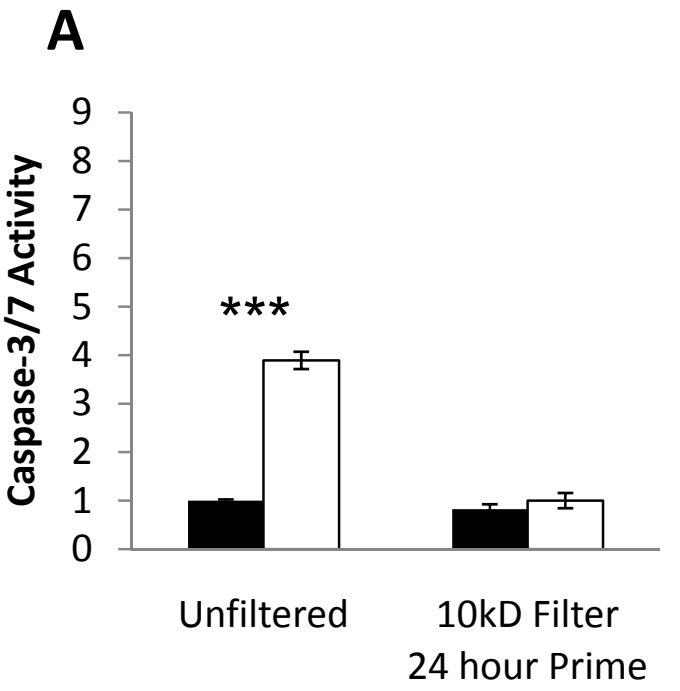

- No Starve $\square$ Serum Free

\section{B}

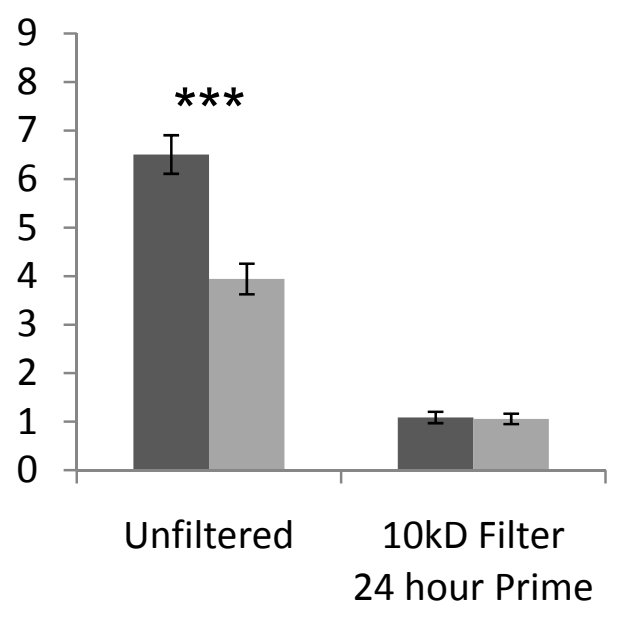

Prehibernation Hibernation

Figure 5.7-Seasonal caspase-3/7 response with 24 hour prime with filtered serum Media supplemented with $2 \%$ FBS, no serum, or $2 \%$ bear serum was filtered to remove molecules $>10 \mathrm{kD}$. Cells were cultured in filtered or unfiltered media for 24 hours, followed by a 6 hour starvation. Caspase-3/7 activities were normalized to the average of the no-starve FBS control. (A) Comparisons between caspase activities of starved and unstarved cells after 24 hours in $2 \%$ FBS, followed by 6 hours of serum starvation. (B) Comparisons between caspase activities of cells after 24 hours incubation in $2 \%$ prehibernation or hibernation serum, followed by 6 hours of starvation. Bear serum samples are from 5 black bears of the $2008 / 09$ season. Statistical significance between samples was determined with a student's $t-$ test and is indicated with three asterisks $(p<0.0001)$. 
A

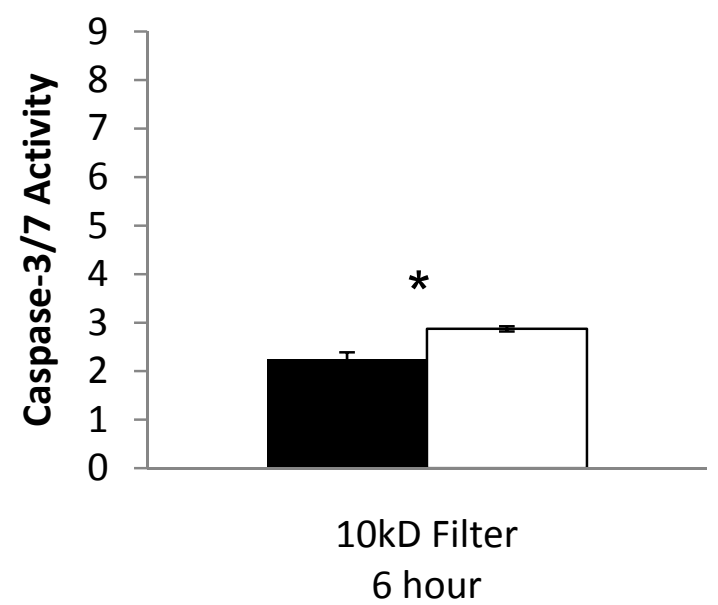

No Starve $\square$ Serum Free
B

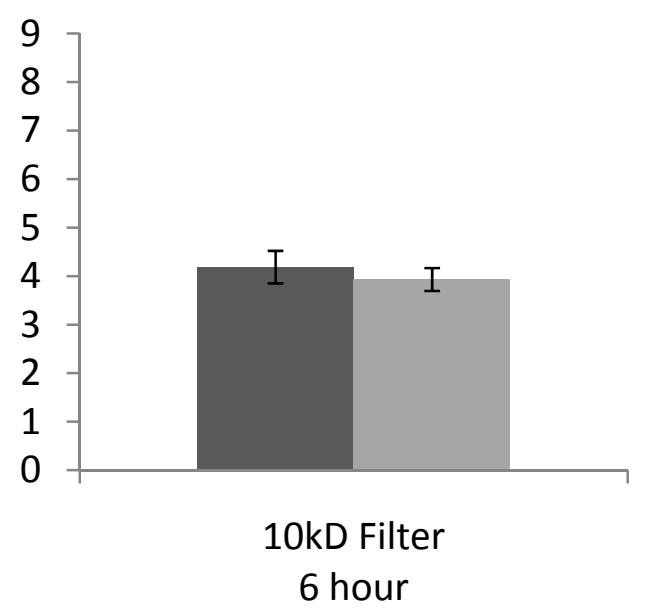

- Prehibernation Hibernation

Figure 5.8-Seasonal caspase-3/7 response after 6 hour stimulation in filtered serum Media supplemented with $2 \%$ FBS, no serum, or $2 \%$ bear serum was filtered to remove molecules $>10 \mathrm{kD}$. Cells were cultured in filtered media for 6 hours. Caspase- $3 / 7$ activities were normalized to the average of a no-starve unfiltered FBS control. (A) Comparisons between caspase activities of cells in $2 \%$ FBS or serum free media. (B) Comparisons between caspase activities of cells in $2 \%$ prehibernation or hibernation serum. Bear serum samples are from 5 black bears of the 2008/09 season. Statistical significance between samples was determined with a student's t-test and is indicated with an asterisk $(p<0.05)$. 


\section{Chapter Six - MC3T3-E1 osteoblasts cultured in serum from post-hibernation bears have higher metabolism than osteoblasts cultured in serum from other seasons}

\subsection{Introduction}

Hibernation is a state of energy conservation during prolonged anorectic periods. Cell proliferation, bone formation, and bone resorption are all metabolically expensive activities; therefore the theme of this dissertation centers on mechanisms to reduce bone turnover during hibernation. In this study, the gene expression responses of MC3T3-E1 osteoblasts to seasonal bear serum were explored. These genes can be grouped into four hypotheses, all suggestive of reduced proliferation and activities of bone cells during hibernation.

The first hypothesis of this study was that cell cycle regulators favor reduced proliferation in osteoblasts cultured in serum from hibernating bears (compared to cells in serum from active bears). Suppressing proliferation would help preserve metabolic energy during hibernation. Cell cycle regulation is also closely tied to apoptosis since, upon DNA damage cells halt in the G1 or G2 phases (for review see: [285]). This halt allows the cell time to repair itself. If repair is unsuccessful, then the apoptotic cascade is activated. Therefore, a balance between reduced proliferation and reduced apoptosis must be achieved during hibernation, since an increase in apoptosis could promote irreparable tissue damage during the long months of hibernation. Qualitative observations suggest that such tissue damage is not present in hibernating animals (for review see: [163]). Increased TUNEL staining has been observed in various tissues of hibernating animals $[45,168,169]$, but this increase in TUNEL staining may be due to accumulated DNA damage over the weeks of hibernation and may not lead to activation of the caspase cascade [45]. A halt in cell cycle during hibernation may be necessary because of accumulated DNA damage. At the same time, such a halt would prevent excessive use of metabolic energy. The tumor-suppressor gene protein 53 (p53) is activated upon DNA damage, resulting in a halt in the $\mathrm{G} 1$ phase of the cell cycle (for review see: [41]). Thus, p53 expression was expected to increase in osteoblasts cultured in hibernating bear serum. Cyclin D1 regulates the cell cycle by promoting progression 
beyond the G1/S checkpoint, thus inducing proliferation of osteoblast progenitors (for review see: [286, 287]). Expression of Cyclin D1 was expected to decrease in osteoblasts cultured in the serum from hibernating bears. Clock genes (e.g. Per1, Per2, Bmal1) control cell cycle progression past the G1/S and G2/M checkpoints. A halt in the G1 phase could be indirectly caused by an increase in Bmal1 through modulation of c-myc and Cyclin D1 [285, 288, 289]. Alternatively, a halt in the G2 phase could be due to an increase in Per1 [290]. Since a halt in either cell phase could slow proliferation and prevent excessive use of metabolic energy, an increase in either Per1 or Bmal1 in osteoblasts cultured in hibernating bear serum was expected.

In the second hypothesis, the caspase-3/7 response of osteoblasts cultured in seasonal bear serum (observed in Chapter 5) was expected to be correlated to gene expression of apoptosis regulators. In the Bcl-2 family, expression of anti-apoptotic $\mathrm{Bcl}-2$ and $\mathrm{Bcl}-\mathrm{XL}$ were expected to increase in osteoblasts cultured in the serum of hibernating bears, with a concurrent decrease in expression of pro-apoptotic BAK, BAX, and BAD. Likewise, the pro-survival gene Akt was expected to increase in osteoblast cultured in serum from hibernating bears. Thus, osteoblasts cultured in serum from hibernating bears were expected to favor anti-apoptotic gene expression compared to cells cultured in serum from active bears. If such a decrease in apoptotic signaling occurred in osteoblasts of the hibernating bear, bone resorption could be suppressed during this period of disuse.

The third hypothesis of this study was that expression of osteoblast differentiation markers would decrease in cells cultured in hibernating serum (compared to cells in active serum). The transcription factor Runx2 is upregulated during the differentiation of osteoblasts (for review see: [291]), and was expected to be lower in osteoblasts cultured in serum from hibernating bears. Ubiquitin is a small regulatory protein which is covalently bound to other proteins as a tag for proteolysis. It is often used as a reference gene because its expression is ubiquitous in all cell types. In osteoblasts, Smad ubiquitin regulatory factor 1 (Smurf1) ligates ubiquitin to Runx2 and other osteogenic regulators (for review see: [292]). The subsequent proteolysis of these tagged proteins suppresses osteoblast activity (i.e. matrix production, BSALP activity) [293, 294]. Smurf1 was expected to increase in osteoblasts cultured in hibernating bear serum thus reducing 
osteoblast activity. c-fos is a proto-oncogene in the AP-1 family of transcription factors. It is essential in the regulation of bone development (for review see: [295]) and for the anabolic actions of PTH on bone [296, 297]. Its expression was expected to decrease in osteoblasts cultured in hibernating bear serum. Osteopontin (OPN), collagen I (Coll), and $\mathrm{OCN}$ are essential cell matrix proteins produced by osteoblasts during the formation of bone (for review see: [298]). These genes were expected to decrease in osteoblasts cultured in hibernating bear serum, which would suggest that a serum-borne factor is responsible for the decreased bone formation observed in hibernating bears [18, 20].

The fourth hypothesis of this study was that expression of pro-resorptive genes would decrease in osteoblasts cultured in serum from hibernating bears. Under catabolic stimulation (e.g. reduced mechanical loading), osteoblasts increase expression of the pro-resorptive cytokine receptor activator for NFא-B ligand (RANKL) and decrease expression of its decoy receptor OPG. An increased RANKL to OPG ratio promotes osteoclast activation followed by the resorption of bone (for review see: [299]). Bone resorption is decreased during hibernation in bears [18, 20]; therefore it was expected that the expression of RANKL would decrease and OPG would increase in osteoblasts cultured in serum from hibernating bears (compared to cells in active serum). Macrophage colony stimulating factor (M-CSF) is a pro-resorptive cytokine expressed by a variety of bone cells, including osteoblasts. It promotes the proliferation of osteoclast precursors (for review see: [300]). Osteoblast expression of M-CSF was expected to decrease in cells cultured in serum from hibernating bears.

Finally, the gene expressions of three cell-surface receptors were quantified in osteoblasts cultured in seasonal bear serum. The PTH receptor (PTH1R) was expected to increase in osteoblasts cultured in hibernating bear serum. This would suggest that a factor in hibernating bear serum increases PTH signaling in osteoblasts even though the circulating levels of PTH remain homeostatic in these serum samples (reported in Chapter 4). An increase in PTH signaling prevents bone loss during disuse in rats [56], and may help protect hibernating bears from bone loss. ADR $\beta 2$, the adrenergic receptor which binds NE, was expected to decrease in osteoblasts cultured in the serum of hibernating bears since beta-blockers inhibit bone loss due to disuse [217, 220]. As observed in Chapter 3, although there is no seasonal variation in serum NE of black 
bears, it is possible that tissue sensitivity to NE changes during hibernation. Such an insensitivity to NE is observed in golden-mantled ground squirrels subjected to reduced temperature [252]. Osteoblast expression of Toll-like receptor 4 was expected to decrease in the serum of hibernating bears (compared to serum from active bears) because activation of TLR4 on osteoblasts induces expression of RANKL [301] and promotes osteoblast apoptosis [302], thus promoting bone resorption.

The expressions of these genes were screened under several different cell culture conditions in order to determine how seasonal bear serum affects osteoblast cell response.

\subsection{Methods and materials}

A total of 6 female black bears were captured and held in pens in the Virginia Tech Center for Bear Research from fall through spring, between the years 2006 and 2008. Samples were collected as described in section 2.2.1. Information about the bears used for each serum assay is shown in Table 6.1. Due to limitations of serum sample sizes, not all bears were used for all assays. The choice of bear used for each assay depended upon sample availability at the time the assays were run. Cell culture was performed as described in section 5.2.2, except that MC3T3-E1 subclone 14 osteoblasts were used for the 3 hour differentiated condition. These cells were not used after passage 30, since higher passage numbers have been shown to alter the phenotype of MC3T3-E1 cells [303]. In all other cell culture studies in this report, MC3T3-E1 subclone 4 cells were used below passage 10 . Subclones 4 and 14 are both mineralizing lines of MC3T3-E1 osteoblasts and behave similarly in culture [304]. When subconfluent in normal culture media ( $\alpha$-MEM, 10\% FBS, 1\% penicillin/streptomycin), these subclones of MC3T3-E1 are considered pre-osteoblasts because they actively proliferate and do not produce mineralized matrix; however, ascorbic acid stimulates the production of extracellular matrix proteins and terminal osteoblast differentiation markers, and $\beta$ glycerophosphate stimulates mineralization of the matrix.

For gene expression assays, cells were seeded at 20,000 cells $/ \mathrm{cm}^{2}$ in 6 -well plates and grown overnight. Four cell culture conditions were used in this study. They 
varied the length of bear serum stimulation and the differentiation state of the MC3T3-E1 cells. After stimulation in one of four conditions, RNA was isolated, and real-time PCR performed as described in section 5.2.5. In each condition, three potential reference genes ( $\beta$-actin, ubiquitin, cyclophilin) and the geometric means [305] of the various combinations of reference genes were checked for seasonal trends by a single-factor ANOVA for season, blocking by bear. The reference gene (or geometric mean) with the lowest magnitude of seasonal variation and the highest least significant number was chosen for normalization. Ubiquitin was later removed from reference gene analysis in all samples since it had a significant seasonal trend in one of the conditions.

In the first condition, undifferentiated pre-osteoblasts (seeded the previous day) were stimulated in $2 \%$ seasonal bear serum for 3 hours. Since bear serum was collected every 10 days, several prehibernation, hibernation, and post-hibernation serum samples were available for each bear. Each well received only one serum sample, and the bear and date of collection were recorded. After 3 hours of stimulation, RNA was isolated. Real-time PCR was performed on BAD, Bcl-2, Cyclin D1, Per1, PTH1R, Runx2, Smurf1, and ubiquitin. Cyclophilin was used as a reference gene. In the second condition, after cells were allowed to attach overnight, they were switched to differentiation media ( $\alpha$ MEM with $10 \%$ FBS, $50 \mu \mathrm{g} / \mathrm{mL}$ ascorbic acid and $10 \mathrm{mmol} \beta$-glycerophosphate) and grown for 6 days, with a media change on the third day. Differentiating osteoblasts were then stimulated in differentiation media supplemented with $2 \%$ seasonal bear serum for 3 hours. Real-time PCR was performed on Akt, BAD, BAK, BAX, Bcl-XL, c-fos, MCSF, OCN, OPG, p53, Per1, TLR4, and ubiquitin. Samples were normalized to the geometric mean of 2 reference genes ( $\beta$-actin and cyclophilin). In the third condition, after cells were allowed to attach overnight, undifferentiated pre-osteoblasts were stimulated in normal growth media supplemented with $2 \%$ bear serum for 24 hours. Real-time PCR was performed on ADR $\beta 2$, Akt, BAD, BAK, BAX, Bcl-2, Bcl-XL, Bmall, Coll, Cyclin D1, M-CSF, OCN, OPG, OPN, p53, Per1, Per2, PTH1R, RANKL, Runx2, Smurf1, TLR4, and ubiquitin. Samples were normalized to the reference gene $\beta$-actin. In the fourth condition, after cells were allowed to attach overnight, media was replaced with differentiation media containing $2 \%$ bear serum (instead of FBS). Cells were allowed to differentiate in bear serum for 6 days, with a media change on day 3. Real-time PCR was performed on BAD, BAX, Bcl-2, c-fos, Coll, Cyclin D1, OCN, OPG, OPN, Per1, 
PTH1R, RANKL, Runx2, Smurf1, TLR4, and ubiquitin. Cyclophilin was used as the reference gene.

All statistical analyses were performed using JMP 7 software. Data were presented as the $\mathrm{LSM} \pm \mathrm{SE}$. The units were relative since all samples were normalized to reference genes and to a reference (FBS) sample. All available samples from all bears were grouped by season (i.e. prehibernation, hibernation, and post-hibernation) and analyzed with a single-factor ANOVA, blocking by bear, with a Tukey's post-hoc. Graphs are represented with a point for each serum sample, and a smoothed average curve generated with JMP software by a cubic spline.

\subsection{Results}

In the first condition (undifferentiated pre-osteoblasts stimulated for 3 hours in seasonal bear serum), there were no seasonal trends (Table 6.2). In the second study (differentiated osteoblasts stimulated for 3 hours in seasonal bear serum), ubiquitin expression increased from $0.998+0.058$ in osteoblasts cultured in prehibernation serum to $1.32 \pm 0.10$ in osteoblasts cultured in post-hibernation serum $(p=0.0341)$. Expression of ubiquitin in osteoblasts cultured in hibernation serum was not different from either active season (Table 6.3). In the third study (undifferentiated pre-osteoblasts stimulated for 24 hours in seasonal bear serum) (Table 6.4), Akt expression increased from $0.796 \pm 0.102$ in cells cultured in hibernating bear serum to $1.55 \pm 0.182$ in cells cultured in posthibernation serum; there was no significant difference in Akt gene expression in cells cultured in prehibernation bear serum compared to hibernation serum $(p=0.0046)$. Cyclin D1 gene expression increased from $0.950+0.032$ in cells cultured in hibernation serum to $1.12+0.05$ in cells cultured in post-hibernation serum; Cyclin D1 expression was not different in cells cultured in prehibernation serum compared to those in hibernation nor post-hibernation serum $(p=0.0177)$. In the fourth condition (differentiated in bear serum for 6 days) (Table 6.5), expression of the markers for osteoblast differentiation Runx2 and OCN were upregulated in post-hibernation compared to prehibernation and hibernation seasons. Runx2 increased from $0.741 \pm 0.069$ in cells cultured in hibernation serum to $1.13 \pm 0.12$ in cells cultured in post-hibernation serum; Runx2 gene expression did not change in cells cultured in prehibernation serum 
compared to those in hibernation serum $(p=0.0103)$. OCN gene expression increased from $0.055 \pm 0.004$ in osteoblasts cultured in hibernation serum to $0.098 \pm 0.01$ in osteoblasts cultured in post-hibernation serum; there was no difference in OCN expression between cells cultured in prehibernation serum and those in hibernation serum $(p<0.0001)$.

\subsection{Discussion}

The goal of this study was to determine whether serum from hibernating bears contained factors which suppress proliferation, apoptosis, and differentiation of cultured osteoblasts when compared to serum from active bears. There were no gene expression changes between osteoblasts cultured in hibernation serum compared to prehibernation serum; however, there were several genes which were upregulated in MC3T3-E1 cells cultured in post-hibernation serum. In differentiated osteoblasts cultured in seasonal bear serum for three hours, the expression of ubiquitin increased throughout the timeframe of the study, with a significant increase between osteoblasts in post-hibernation serum compared to those in prehibernation serum. This increase in ubiquitin suggests that the metabolism of osteoblasts may be stimulated by post-hibernation serum. Ubiquitin is a small protein which is covalently linked to proteins as a tag for proteolysis. In osteoblasts, it is ligated to several vital regulators of differentiation including Runx2, Smad1, and MEKK2 [292-294]. Ubiquitin also tags cell cycle (e.g. Cyclin D1) and clock proteins (e.g. Per1, Per2, Bmal1) [306, 307] for proteolysis. The efficient recycling of these cell cycle and clock genes is necessary for metabolically active cells. Therefore, an increase in ubiquitin expression during post-hibernation is indicative of an increase in the cycle of protein production and breakdown which is necessary in any active cell. Fitting with this suggestion of high osteoblast metabolism in post-hibernation serum, Cyclin D1 and Akt are upregulated in undifferentiated osteoblasts cultured in posthibernation serum at the 24 hour time-point. Cyclin D1 signals cells to progress past the G1/S checkpoint (for review see: [286, 287]), and Akt promotes cell proliferation and metabolism (for review see: [308]). Thus, increases in these genes in post-hibernation serum suggest that serum-borne factors in post-hibernation circulation stimulate osteoblast proliferation and activity. Finally, expression of the osteoblast differentiation 
factors Runx2 and OCN also increase in osteoblasts differentiated in post-hibernation serum, further supporting the idea of increased osteoblast activity in this season.

In summary, the gene expression studies suggest that factors circulating in bears in the weeks immediately following hibernation promote a hypermetabolic state in osteoblasts. Differentiated osteoblasts have higher expression of ubiquitin and differentiation markers, suggesting active protein metabolism and bone formation during post-hibernation. Undifferentiated osteoblasts have higher expression of Akt and Cyclin D1, suggesting active proliferation of osteoblasts during post-hibernation. These data fit an earlier report of high bone turnover rate in spring-time bears [35].

\subsection{Tables and figures}

Table 6.1-Summary of assays

The number of bears and assays that were performed in each hibernation season. The number of bears that gave birth to cubs is in parentheses. Unknown values are indicated as "UK." Assays in undifferentiated cells are labeled "UD," and assays in differentiated cells are labeled "D."

\begin{tabular}{ccccc} 
Season & Bears & $\begin{array}{c}\text { Age } \\
\text { (years) }\end{array}$ & Assays & Data Location \\
\hline $2006-2007$ & $2(1)$ & UK & 3hr UD, 3hr D, 24hr UD, 6 day D & Table 6.2-6.5 \\
\hline $2007-2008$ & $4(3)$ & $5-14$ & 24hr UD & Table 6.4
\end{tabular}


Table 6.2-Gene expression 3 hour undifferentiated

Data are represented as LSM \pm SE. The total number of samples included in the ANOVA is indicated below the mean concentrations. The $p$-value reported is for the partial F-test for the serum factor. Ubiquitin is abbreviated "UBQ."

\begin{tabular}{|c|c|c|c|c|c|c|}
\hline $\begin{array}{l}\text { Serum } \\
\text { Factor }\end{array}$ & & $\begin{array}{c}\text { Fall } \\
\text { (Active) }\end{array}$ & $\begin{array}{c}\text { Winter } \\
\text { (Hibernation) }\end{array}$ & $\begin{array}{c}\text { Spring } \\
\text { (Active) }\end{array}$ & $\mathbf{p}$ & Power \\
\hline \multirow{2}{*}{ BAD } & $\mathrm{LSM} \pm \mathrm{SE}$ & $0.972 \pm 0.064$ & $1.02 \pm 0.06$ & $0.850 \pm 0.110$ & \multirow{2}{*}{0.4310} & \multirow{2}{*}{0.1704} \\
\hline & $\mathrm{N}_{\text {samples }}$ & $\overline{6}$ & $\overline{7}$ & 2 & & \\
\hline \multirow{2}{*}{$\mathrm{Bcl}-2$} & LSM+SE & $0.873 \pm 0.160$ & $0.924 \pm 0.148$ & $1.12 \pm 0.277$ & \multirow{2}{*}{0.7452} & \multirow{2}{*}{0.0874} \\
\hline & $\mathrm{N}_{\text {samples }}$ & 6 & 7 & 2 & & \\
\hline \multirow{2}{*}{ Cyclin D1 } & $\mathrm{LSM} \pm \mathrm{SE}$ & $1.00 \pm 0.132$ & $1.01 \pm 0.122$ & $1.02 \pm 0.229$ & \multirow{2}{*}{0.9975} & \multirow{2}{*}{0.0503} \\
\hline & $\mathrm{N}_{\text {samples }}$ & 6 & 7 & 2 & & \\
\hline \multirow{2}{*}{ Per1 } & LSM+SE & $1.17 \pm 0.270$ & $1.49 \pm 0.250$ & $1.20 \pm 0.47$ & \multirow{2}{*}{0.6601} & \multirow{2}{*}{0.1043} \\
\hline & $\mathrm{N}_{\text {samples }}$ & 6 & 7 & 2 & & \\
\hline \multirow{2}{*}{ PTH1R } & LSM+SE & $0.892+0.107$ & $0.950 \pm 0.099$ & $1.28+0.185$ & \multirow{2}{*}{0.2255} & \multirow{2}{*}{0.2867} \\
\hline & $\mathrm{N}_{\text {samples }}$ & 6 & 7 & 2 & & \\
\hline \multirow{2}{*}{ Runx2 } & LSM+SE & $0.509 \pm 0.119$ & $0.677 \pm 0.110$ & $0.911 \pm 0.206$ & \multirow{2}{*}{0.2552} & \multirow{2}{*}{0.2633} \\
\hline & $\mathrm{N}_{\text {samples }}$ & 6 & 7 & 2 & & \\
\hline \multirow{2}{*}{ Smurf1 } & LSM $\pm S E$ & $1.15 \pm 0.146$ & $0.840 \pm 0.135$ & $1.25 \pm 0.253$ & \multirow{2}{*}{0.2293} & \multirow{2}{*}{0.2836} \\
\hline & $\mathrm{N}_{\text {samples }}$ & 6 & 7 & 2 & & \\
\hline \multirow{2}{*}{ UBQ } & $\mathrm{LSM} \pm \mathrm{SE}$ & $0.911 \pm 0.093$ & $0.939 \pm 0.086$ & $0.981 \pm 0.161$ & \multirow{2}{*}{0.9283} & \multirow{2}{*}{0.0590} \\
\hline & $\mathrm{N}_{\text {samples }}$ & 6 & 7 & 2 & & \\
\hline
\end{tabular}


Table 6.3-Gene expression 3 hour differentiated

Data are represented as $L S M+S E$. The total number of samples included in the ANOVA is indicated below the mean concentrations. Letters (A, B, C) represent values that are significantly different from each other at $\alpha=0.05$. Ubiquitin is abbreviated "UBQ."

\begin{tabular}{|c|c|c|c|c|c|c|}
\hline $\begin{array}{l}\text { Serum } \\
\text { Factor }\end{array}$ & & $\begin{array}{c}\text { Fall } \\
\text { (Active) }\end{array}$ & $\begin{array}{c}\text { Winter } \\
\text { (Hibernation) }\end{array}$ & $\begin{array}{l}\text { Spring } \\
\text { (Active) }\end{array}$ & p & Power \\
\hline \multirow{2}{*}{ Akt } & $\mathrm{LSM} \pm \mathrm{SE}$ & $0.933 \pm 0.073$ & $0.850 \pm 0.073$ & $0.616 \pm 0.126$ & \multirow{2}{*}{0.1169} & \multirow{2}{*}{0.4289} \\
\hline & $\mathrm{N}_{\text {samples }}$ & $\overline{12}$ & $\overline{12}$ & $\overline{4}$ & & \\
\hline \multirow{2}{*}{ BAD } & LSM+SE & $0.744 \pm 0.103$ & $0.466 \pm 0.103$ & $0.884 \pm 0.179$ & \multirow{2}{*}{0.0771} & \multirow{2}{*}{0.5069} \\
\hline & $\mathrm{N}_{\text {samples }}$ & 12 & 12 & 4 & & \\
\hline \multirow{2}{*}{ BAK } & $\mathrm{LSM} \pm \mathrm{SE}$ & $0.860 \pm 0.108$ & $0.971 \pm 0.108$ & $0.690 \pm 0.188$ & \multirow{2}{*}{0.4261} & \multirow{2}{*}{0.1842} \\
\hline & $\mathrm{N}_{\text {samples }}$ & 12 & 12 & 4 & & \\
\hline \multirow{2}{*}{ BAX } & $\mathrm{LSM} \pm \mathrm{SE}$ & $0.860 \pm 0.108$ & $0.971 \pm 0.108$ & $0.690 \pm 0.188$ & \multirow{2}{*}{0.1842} & \multirow{2}{*}{0.4261} \\
\hline & $\mathrm{N}_{\text {samples }}$ & 12 & 12 & 4 & & \\
\hline \multirow{2}{*}{ Bcl-XL } & $\mathrm{LSM} \pm \mathrm{SE}$ & $1.16 \pm 0.16$ & $1.26 \pm 0.16$ & $0.779 \pm 0.273$ & \multirow{2}{*}{0.3329} & \multirow{2}{*}{0.2289} \\
\hline & $\mathrm{N}_{\text {samples }}$ & 12 & 12 & 4 & & \\
\hline \multirow{2}{*}{ c-fos } & $\mathrm{LSM} \pm \mathrm{SE}$ & $0.963 \pm 0.135$ & $0.689 \pm 0.135$ & $0.783 \pm 0.234$ & \multirow{2}{*}{0.3700} & \multirow{2}{*}{0.2095} \\
\hline & $\mathrm{N}_{\text {samples }}$ & 12 & 12 & 4 & & \\
\hline \multirow{2}{*}{ M-CSF } & $\mathrm{LSM} \pm \mathrm{SE}$ & $1.15 \pm 0.159$ & $1.02 \pm 0.159$ & $1.25 \pm 0.275$ & \multirow{2}{*}{0.7252} & \multirow{2}{*}{0.0959} \\
\hline & $\mathrm{N}_{\text {samples }}$ & 12 & 12 & 4 & & \\
\hline \multirow{2}{*}{$\mathrm{OCN}$} & $\mathrm{LSM} \pm \mathrm{SE}$ & $1.11 \pm 0.19$ & $1.23 \pm 0.19$ & $1.93 \pm 0.34$ & \multirow{2}{*}{0.1248} & \multirow{2}{*}{0.4163} \\
\hline & $\mathrm{N}_{\text {samples }}$ & 12 & 12 & 4 & & \\
\hline \multirow{2}{*}{ OPG } & $\mathrm{LSM} \pm \mathrm{SE}$ & $1.12 \pm 0.20$ & $0.704 \pm 0.201$ & $0.663 \pm 0.348$ & \multirow{2}{*}{0.2867} & \multirow{2}{*}{0.2567} \\
\hline & $\mathrm{N}_{\text {samples }}$ & 12 & $\overline{12}$ & $\overline{4}$ & & \\
\hline \multirow{2}{*}{ p53 } & $\mathrm{LSM} \pm \mathrm{SE}$ & $1.27 \pm 0.24$ & $1.04 \pm 0.24$ & $1.00 \pm 0.42$ & \multirow{2}{*}{0.7679} & \multirow{2}{*}{0.0873} \\
\hline & $\mathrm{N}_{\text {samples }}$ & $\overline{12}$ & $\overline{12}$ & $\overline{4}$ & & \\
\hline \multirow{2}{*}{ Per1 } & LSM+SE & $3.02 \pm 0.59$ & $4.88 \pm 0.59$ & $2.81 \pm 1.01$ & \multirow{2}{*}{0.0658} & \\
\hline & $\mathrm{N}_{\text {samples }}$ & 12 & 12 & 4 & & 0.5356 \\
\hline TI R4 & $\mathrm{LSM} \pm \mathrm{SE}$ & $1.28 \pm 0.35$ & $1.65 \pm 0.35$ & $1.68+0.61$ & 07215 & 00961 \\
\hline ILR4 & $\mathrm{N}_{\text {samples }}$ & 12 & 12 & 4 & 0.1245 & 0.0961 \\
\hline & $\mathrm{LSM} \pm \mathrm{SE}$ & $0.998 \pm 0.058^{B}$ & $1.08 \pm 0.06^{\mathrm{AB}}$ & $1.32 \pm 0.10^{A}$ & & \\
\hline UBQ & $\mathrm{N}_{\text {samples }}$ & 12 & 12 & 4 & 0.0341 & $0.64 / 2$ \\
\hline
\end{tabular}


Table 6.4-Gene expression 24 hour undifferentiated

Data are represented as LSM \pm SE. The total number of samples included in the ANOVA is indicated below the mean concentrations. Letters (A, B, C) represent values that are significantly different from each other at $\alpha=0.05$. Ubiquitin is abbreviated "UBQ."

\begin{tabular}{|c|c|c|c|c|c|c|}
\hline $\begin{array}{l}\text { Serum } \\
\text { Factor }\end{array}$ & & $\begin{array}{c}\text { Fall } \\
\text { (Active) }\end{array}$ & $\begin{array}{c}\text { Winter } \\
\text { (Hibernation) }\end{array}$ & $\begin{array}{l}\text { Spring } \\
\text { (Active) }\end{array}$ & p & Power \\
\hline \multirow{2}{*}{ ADR $\beta 2$} & LSM+SE & $1.70 \pm 0.19$ & $1.56 \pm 0.17$ & $1.55 \pm 0.232$ & \multirow{2}{*}{0.8378} & \multirow{2}{*}{0.0726} \\
\hline & $\mathrm{N}_{\text {samples }}$ & $\overline{11}$ & $\overline{16}$ & $\overline{5}$ & & \\
\hline \multirow{2}{*}{ Akt } & LSM+SE & $0.976 \pm 0.123^{B}$ & $0.796 \pm 0.102^{B}$ & $1.55 \pm 0.182^{\mathrm{A}}$ & \multirow{2}{*}{0.0046} & \multirow{2}{*}{0.8767} \\
\hline & $\mathrm{N}_{\text {samples }}$ & 11 & $\overline{16}$ & 5 & & \\
\hline \multirow{2}{*}{ BAD } & $\mathrm{LSM} \pm \mathrm{SE}$ & $1.46 \pm 0.22$ & $1.50 \pm 0.18$ & $1.23 \pm 0.32$ & \multirow{2}{*}{0.7639} & \multirow{2}{*}{0.0887} \\
\hline & $\mathrm{N}_{\text {samples }}$ & 11 & 16 & $\overline{5}$ & & \\
\hline \multirow{2}{*}{ BAK } & $\mathrm{LSM} \pm \mathrm{SE}$ & $1.53 \pm 0.13$ & $1.30 \pm 0.10$ & $1.15 \pm 0.19$ & \multirow{2}{*}{0.1959} & \multirow{2}{*}{0.3317} \\
\hline & $\mathrm{N}_{\text {samples }}$ & 11 & 16 & 5 & & \\
\hline \multirow{2}{*}{ BAX } & $\mathrm{LSM} \pm \mathrm{SE}$ & $1.50 \pm 0.09$ & $1.30 \pm 0.08$ & $1.28 \pm 0.14$ & \multirow{2}{*}{0.2152} & \multirow{2}{*}{0.3137} \\
\hline & $\mathrm{N}_{\text {samples }}$ & 11 & 16 & 5 & & \\
\hline \multirow{2}{*}{$\mathrm{Bcl}-2$} & $\mathrm{LSM} \pm \mathrm{SE}$ & $1.38 \pm 0.14$ & $1.13 \pm 0.12$ & $0.948 \pm 0.206$ & \multirow{2}{*}{0.1832} & \multirow{2}{*}{0.3447} \\
\hline & $\mathrm{N}_{\text {samples }}$ & 11 & 16 & 5 & & \\
\hline \multirow{2}{*}{ Bcl-XL } & $\mathrm{LSM} \pm \mathrm{SE}$ & $1.32 \pm 0.10$ & $1.38+0.08$ & $1.16 \pm 0.15$ & \multirow{2}{*}{0.1690} & \multirow{2}{*}{0.4691} \\
\hline & $\mathrm{N}_{\text {samples }}$ & 11 & $\overline{16}$ & $\overline{5}$ & & \\
\hline \multirow{2}{*}{ Bmall } & $\mathrm{LSM}+\mathrm{SE}$ & $1.96 \pm 0.14$ & $2.11 \pm 0.11$ & $1.67 \pm 0.20$ & O 1830 & 3449 \\
\hline & $\mathrm{N}_{\text {samples }}$ & 11 & 16 & 5 & 0.1830 & 0.3449 \\
\hline Coll & $\mathrm{LSM} \pm \mathrm{SE}$ & $2.80 \pm 0.28$ & $2.73 \pm 0.23$ & $1.92 \pm 0.41$ & 1841 & 03437 \\
\hline Coll & $\mathrm{N}_{\text {samples }}$ & 11 & 16 & 5 & 0.1841 & 0.3431 \\
\hline Culin R1 & $\mathrm{LSM} \pm \mathrm{SE}$ & $1.01 \pm 0.04^{A B}$ & $0.950 \pm 0.032^{B}$ & $1.12 \pm 0.05^{\mathrm{A}}$ & 00177 & 07266 \\
\hline Cyclin DT & $\mathrm{N}_{\text {samples }}$ & 33 & 48 & 19 & $0.01 / 7$ & $0.126 b$ \\
\hline M-CSF & $\mathrm{LSM}+\mathrm{SE}$ & $0.733 \pm 0.061$ & $0.643 \pm 0.050$ & $0.676 \pm 0.090$ & & \\
\hline IVI-CSF & $\mathrm{N}_{\text {samples }}$ & 11 & $\overline{16}$ & $\overline{5}$ & 0.5321 & $0.14 / 2$ \\
\hline $\mathrm{CCN}$ & $\mathrm{LSM} \pm \mathrm{SE}$ & $7.74 \pm 1.13$ & $5.22 \pm 0.94$ & $3.98+1.7$ & & \\
\hline UCN & $\mathrm{N}_{\text {samples }}$ & 11 & 16 & 5 & 0.1285 & $0.4 T 21$ \\
\hline OPG & $\mathrm{LSM} \pm \mathrm{SE}$ & $0.568 \pm 0.051$ & $0.489 \pm 0.043$ & $0.606 \pm 0.076$ & 03101 & 02443 \\
\hline UPG & $\mathrm{N}_{\text {samples }}$ & 11 & 16 & 5 & 0.3101 & 0.2443 \\
\hline OPN & $\mathrm{LSM} \pm \mathrm{SE}$ & $1.37 \pm 0.26$ & $1.39 \pm 0.21$ & $1.58 \pm 0.38$ & 08944 & 00655 \\
\hline & $\mathrm{N}_{\text {samples }}$ & 11 & 16 & 5 & 0.8944 & \\
\hline 553 & $\mathrm{LSM} \pm \mathrm{SE}$ & $1.01 \pm 0.07$ & $1.05 \pm 0.05$ & $0.919 \pm 0.096$ & 04942 & 1599 \\
\hline & $\mathrm{N}_{\text {samples }}$ & 11 & 16 & 5 & & \\
\hline Per1 & $\mathrm{LSM} \pm \mathrm{SE}$ & $1.65 \pm 0.11$ & $1.73 \pm 0.089$ & $1.47 \pm 0.16$ & O 3730 & (2096 \\
\hline Per'1 & $\mathrm{N}_{\text {samples }}$ & 10 & 16 & 5 & 0.3730 & 0.2096 \\
\hline Por? & $\mathrm{LSM} \pm \mathrm{SE}$ & $3.03 \pm 0.55$ & $3.05 \pm 0.45$ & $2.37 \pm 0.82$ & & 00916 \\
\hline Per2 & $\mathrm{N}_{\text {samples }}$ & 10 & $\overline{16}$ & $\overline{5}$ & 0.1494 & 0.0916 \\
\hline PTH1R & $\mathrm{LSM} \pm \mathrm{SE}$ & $0.969 \pm 0.041$ & $1.04 \pm 0.03$ & $0.920 \pm 0.054$ & O 1110 & 04479 \\
\hline PIATR & $\mathrm{N}_{\text {samples }}$ & 33 & 48 & 19 & 0.7710 & $0.44 / 9$ \\
\hline RANKI & $\mathrm{LSM} \pm \mathrm{SE}$ & $0.180 \pm 0.227$ & $0.500 \pm 0.189$ & $0.743 \pm 0.338$ & 3480 & \\
\hline RANKL & $\mathrm{N}_{\text {samples }}$ & 11 & 16 & 5 & 0.3480 & 0.2228 \\
\hline Runx? & $\mathrm{LSM}+\mathrm{SE}$ & $0.770 \pm 0.030$ & $0.727 \pm 0.025$ & $0.750 \pm 0.040$ & & \\
\hline Runx2 & $\mathrm{N}_{\text {samples }}$ & $\overline{33}$ & $\overline{48}$ & $\overline{19}$ & 0.5560 & 0.1456 \\
\hline Smurf1 & LSM $\pm S E$ & $0.927 \pm 0.045$ & $0.875+0.038$ & $0.826 \pm 0.0610$ & 03919 & 02096 \\
\hline smurt'1 & $\mathrm{N}_{\text {samples }}$ & 34 & 48 & 19 & 0.3919 & 0.2096 \\
\hline TIR4 & $\mathrm{LSM} \pm \mathrm{SE}$ & $1.10 \pm 0.07$ & $1.14 \pm 0.06$ & $1.28 \pm 0.10$ & 03507 & 02214 \\
\hline ILR4 & $\mathrm{N}_{\text {samples }}$ & 11 & 16 & 5 & 0.3507 & 0.2214 \\
\hline UBO & $\mathrm{LSM} \pm \mathrm{SE}$ & $1.02 \pm 0.06$ & $1.03 \pm 0.044$ & $1.18 \pm 0.08$ & 02108 & 03172 \\
\hline$U B Q$ & $\mathrm{~N}_{\text {samples }}$ & 34 & 48 & 19 & 0.2108 & $0.31 / 2$ \\
\hline
\end{tabular}


Table 6.5-Gene expression 6 day differentiated

Data are represented as LSM $\pm S E$. The total number of samples included in the ANOVA is indicated below the mean concentrations. Letters (A, B, C) represent values that are significantly different from each other at $\alpha=0.05$. Ubiquitin is abbreviated "UBQ."

\begin{tabular}{|c|c|c|c|c|c|c|}
\hline $\begin{array}{l}\text { Serum } \\
\text { Factor }\end{array}$ & & $\begin{array}{c}\text { Fall } \\
\text { (Active) }\end{array}$ & $\begin{array}{c}\text { Winter } \\
\text { (Hibernation) }\end{array}$ & $\begin{array}{c}\text { Spring } \\
\text { (Active) }\end{array}$ & $\mathbf{p}$ & Power \\
\hline \multirow{2}{*}{ BAD } & LSM \pm SE & $1.08 \pm 0.06$ & $1.01 \pm 0.05$ & $1.09 \pm 0.084$ & \multirow{2}{*}{0.5550} & \multirow{2}{*}{0.1400} \\
\hline & $\mathrm{N}_{\text {samples }}$ & 11 & 16 & 5 & & \\
\hline \multirow{2}{*}{ BAX } & LSM $\pm S E$ & $1.39 \pm 0.15$ & $1.42 \pm 0.123$ & $1.84 \pm 0.22$ & \multirow{2}{*}{0.2149} & \multirow{2}{*}{0.3139} \\
\hline & $\mathrm{N}_{\text {samples }}$ & $\overline{11}$ & $\overline{16}$ & $\overline{5}$ & & \\
\hline \multirow{2}{*}{ Bcl-2 } & LSM+SE & $0.628 \pm 0.076$ & $0.605 \pm 0.063$ & $0.812 \pm 0.113$ & \multirow{2}{*}{0.2821} & \multirow{2}{*}{0.2620} \\
\hline & $\mathrm{N}_{\text {samples }}$ & $\overline{11}$ & $\overline{16}$ & $\overline{5}$ & & \\
\hline \multirow{2}{*}{ c-fos } & LSM $\pm S E$ & $1.07 \pm 0.09$ & $1.06 \pm 0.073$ & $1.34 \pm 0.13$ & \multirow{2}{*}{0.1771} & \multirow{2}{*}{0.3512} \\
\hline & $\mathrm{N}_{\text {samples }}$ & $\overline{11}$ & 16 & $\overline{5}$ & & \\
\hline \multirow{2}{*}{ Coll } & LSM+SE & $1.26 \pm 0.120$ & $1.05 \pm 0.10$ & $1.39 \pm 0.18$ & \multirow{2}{*}{0.1824} & \multirow{2}{*}{0.3455} \\
\hline & $\mathrm{N}_{\text {samples }}$ & 11 & $\overline{16}$ & $\overline{5}$ & & \\
\hline \multirow{2}{*}{ Cyclin D1 } & $\mathrm{LSM}+\mathrm{SE}$ & $1.30 \pm 0.083$ & $1.09 \pm 0.069$ & $1.29 \pm 0.123$ & \multirow{2}{*}{0.1161} & \multirow{2}{*}{0.4319} \\
\hline & $\mathrm{N}_{\text {samples }}$ & 11 & 16 & 5 & & \\
\hline \multirow{2}{*}{$\mathrm{OCN}$} & LSM+SE & $0.056 \pm 0.005^{\mathrm{B}}$ & $0.055^{-0.004^{\mathrm{B}}}$ & $0.098 \pm 0.01^{A}$ & \multirow{2}{*}{$<0.0001$} & \multirow{2}{*}{0.9994} \\
\hline & $\mathrm{N}_{\text {samples }}$ & $\overline{11}$ & $\overline{16}$ & $\overline{5}$ & & \\
\hline \multirow{2}{*}{ OPG } & $\mathrm{LSM} \pm \mathrm{SE}$ & $1.55 \pm 0.13$ & $1.45 \pm 0.11$ & $1.69 \pm 0.19$ & \multirow{2}{*}{0.5412} & \multirow{2}{*}{0.1443} \\
\hline & $\mathrm{N}_{\text {samples }}$ & $\overline{11}$ & $\overline{16}$ & $\overline{5}$ & & \\
\hline \multirow{2}{*}{ OPN } & LSM $\pm S E$ & $1.09 \pm 0.099$ & $1.11 \pm 0.082$ & $1.41 \pm 0.15$ & \multirow{2}{*}{0.1702} & \multirow{2}{*}{0.3588} \\
\hline & $\mathrm{N}_{\text {samples }}$ & $\overline{11}$ & 16 & $\overline{5}$ & & \\
\hline \multirow{2}{*}{ Per1 } & LSM $\pm S E$ & $1.74 \pm 0.16$ & $2.20 \pm 0.13$ & $2.21 \pm 0.23$ & \multirow{2}{*}{0.0737} & \\
\hline & $\mathrm{N}_{\text {samples }}$ & $\overline{11}$ & $\overline{16}$ & $\overline{5}$ & & 0.5161 \\
\hline & LSM $\pm S E$ & $1.16 \pm 0.06$ & $1.15 \pm 0.05$ & $1.09 \pm 0.09$ & & \\
\hline PTH1R & $\mathrm{N}_{\text {samples }}$ & $\overline{11}$ & $\overline{16}$ & $\overline{5}$ & 0.8342 & 0.0755 \\
\hline & LSM+SE & $3.86 \pm 1.61$ & $2.19 \pm 1.30$ & $0.928+2.166$ & & \\
\hline RANKL & $\mathrm{N}_{\text {samples }}$ & 11 & 16 & 5 & 0.5305 & 0.1462 \\
\hline & LSM+SE & $0.654 \pm 0.083^{B}$ & $0.741 \pm 0.069^{B}$ & $1.13+0.12^{\mathrm{A}}$ & & \\
\hline Runx2 & $\mathrm{N}_{\text {samples }}$ & $\overline{11}$ & 16 & 5 & 0.0103 & 0.8026 \\
\hline Smurf1 & $\mathrm{LSM} \pm \mathrm{SE}$ & $1.09 \pm 0.09$ & $1.03 \pm 0.08$ & $1.40 \pm 0.14$ & 00838 & 04927 \\
\hline smurt1 & $N_{\text {samples }}$ & 11 & 16 & 5 & 0.0030 & 0.4921 \\
\hline TIR4 & LSM+SE & $1.15 \pm 0.07$ & $1.21 \pm 0.06$ & $1.29 \pm 0.10$ & 0 5217 & 01505 \\
\hline ILR4 & $\mathrm{N}_{\text {samples }}$ & $\overline{11}$ & $\overline{16}$ & $\overline{5}$ & 0.5217 & 0.1505 \\
\hline & LSM+SE & $0.918 \pm 0.042$ & $0.794 \pm 0.035$ & $0.905 \pm 0.062$ & & \\
\hline UBQ & $\mathrm{N}_{\text {samples }}$ & 11 & $\overline{16}$ & $\overline{5}$ & $0.065 /$ & 0.5365 \\
\hline
\end{tabular}




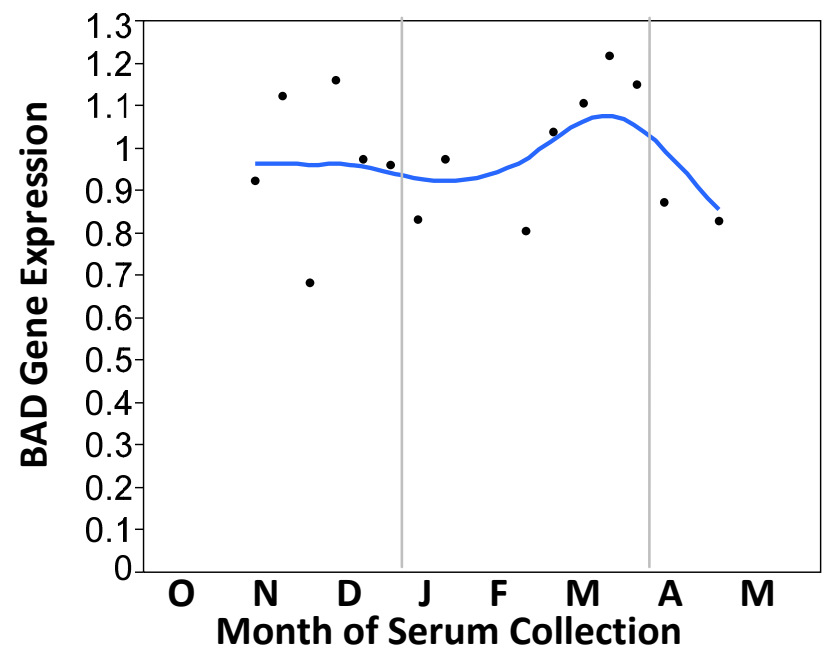

Figure 6.1-Longitudinal analysis of BAD gene expression in undifferentiated cells stimulated for 3 hours in seasonal bear serum

MC3T3-E1 cells were cultured in seasonal bear serum for 3 hours, followed by real-time PCR quantification of relative gene expression. Each point represents the gene expression response from one serum sample. Vertical lines represent transitions between active and hibernating seasons. Samples are from 1 black bear in the 2006/07 season.

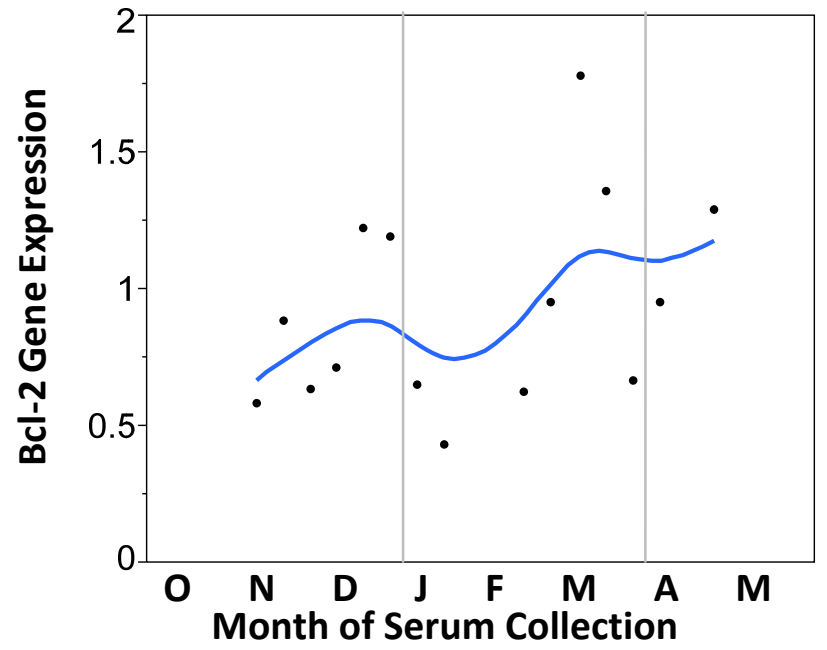

Figure 6.2-Longitudinal analysis of Bcl-2 gene expression in undifferentiated cells stimulated for 3 hours in seasonal bear serum

MC3T3-E1 cells were cultured in seasonal bear serum for 3 hours, followed by real-time PCR quantification of relative gene expression. Each point represents the gene expression response from one serum sample. Vertical lines represent transitions between active and hibernating seasons. Samples are from 2 black bears in the 2006/07 season. 


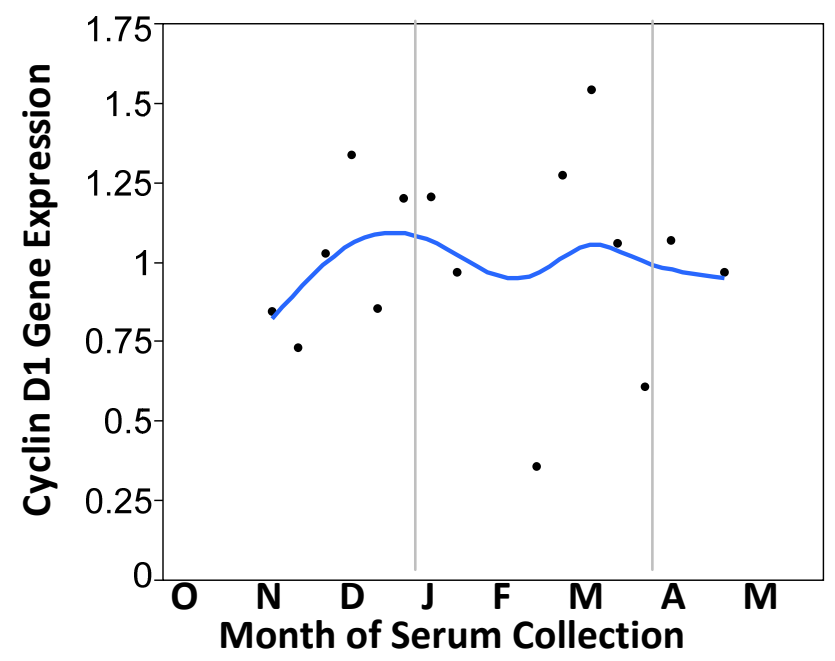

Figure 6.3-Longitudinal analysis of Cyclin D1 gene expression in undifferentiated cells stimulated for 3 hours in seasonal bear serum

MC3T3-E1 cells were cultured in seasonal bear serum for 3 hours, followed by real-time PCR quantification of relative gene expression. Each point represents the gene expression response from one serum sample. Vertical lines represent transitions between active and hibernating seasons. Samples are from 1 black bear in the 2006/07 season.

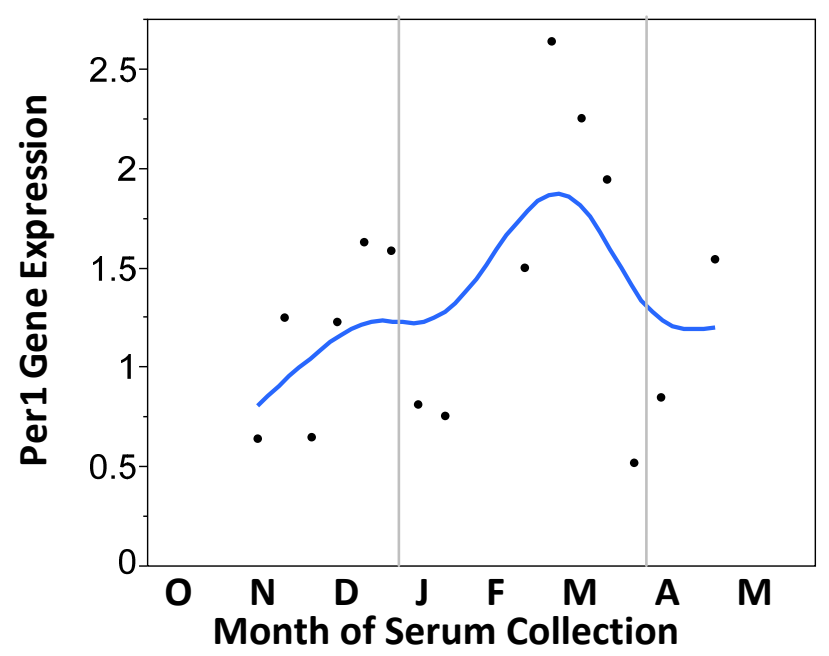

Figure 6.4-Longitudinal analysis of Per1 gene expression in undifferentiated cells stimulated for 3 hours in seasonal bear serum

MC3T3-E1 cells were cultured in seasonal bear serum for 3 hours, followed by real-time PCR quantification of relative gene expression. Each point represents the gene expression response from one serum sample. Vertical lines represent transitions between active and hibernating seasons. Samples are from 2 black bears in the 2006/07 season. 


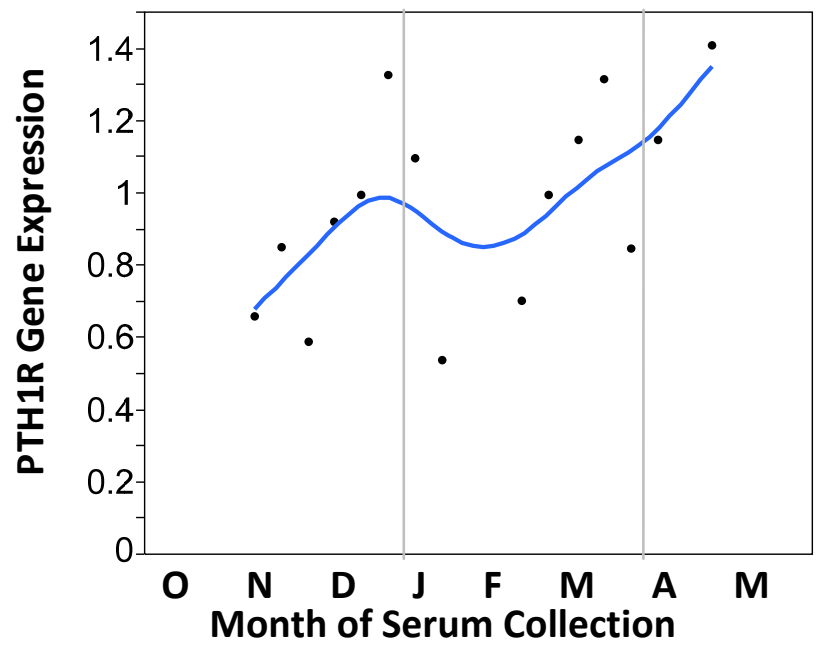

Figure 6.5-Longitudinal analysis of PTH1R gene expression in undifferentiated cells stimulated for 3 hours in seasonal bear serum

MC3T3-E1 cells were cultured in seasonal bear serum for 3 hours, followed by real-time PCR quantification of relative gene expression. Each point represents the gene expression response from one serum sample. Vertical lines represent transitions between active and hibernating seasons. Samples are from 1 black bear in the 2006/07 season.

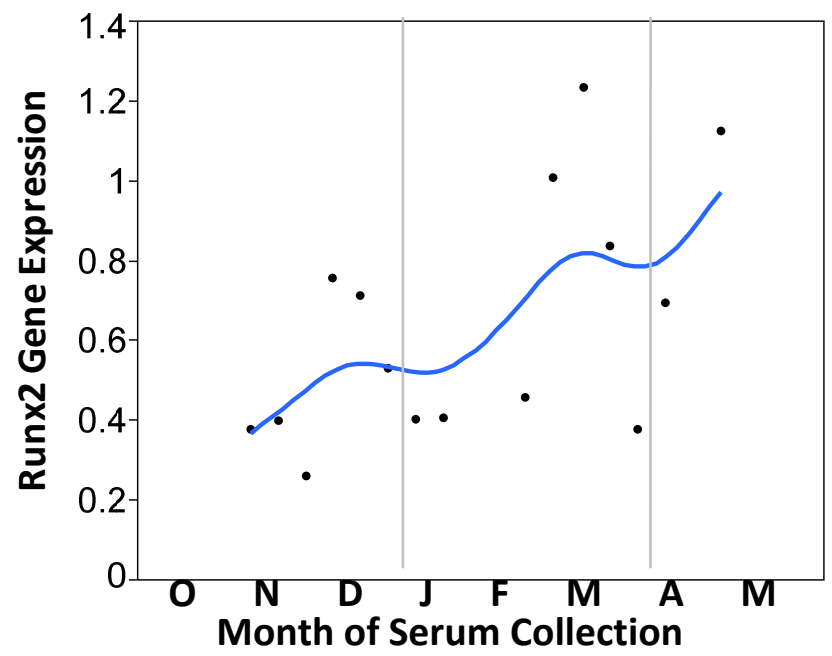

Figure 6.6-Longitudinal analysis of Runx2 gene expression in undifferentiated cells stimulated for 3 hours in seasonal bear serum

MC3T3-E1 cells were cultured in seasonal bear serum for 3 hours, followed by real-time PCR quantification of relative gene expression. Each point represents the gene expression response from one serum sample. Vertical lines represent transitions between active and hibernating seasons. Samples are from 2 black bears in the 2006/07 season. 


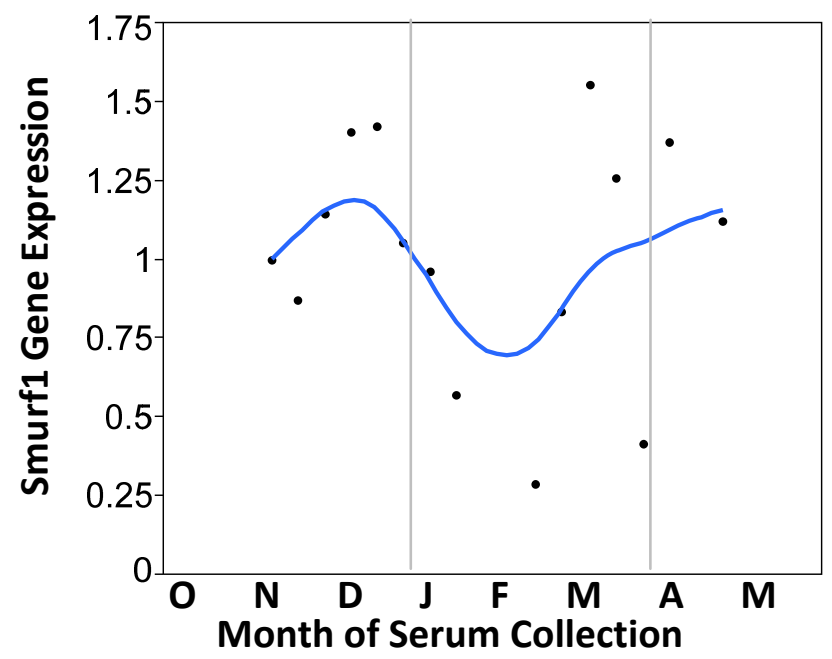

Figure 6.7-Longitudinal analysis of Smurf1 gene expression in undifferentiated cells stimulated for 3 hours in seasonal bear serum

MC3T3-E1 cells were cultured in seasonal bear serum for 3 hours, followed by real-time PCR quantification of relative gene expression. Each point represents the gene expression response from one serum sample. Vertical lines represent transitions between active and hibernating seasons. Samples are from 1 black bear in the 2006/07 season.

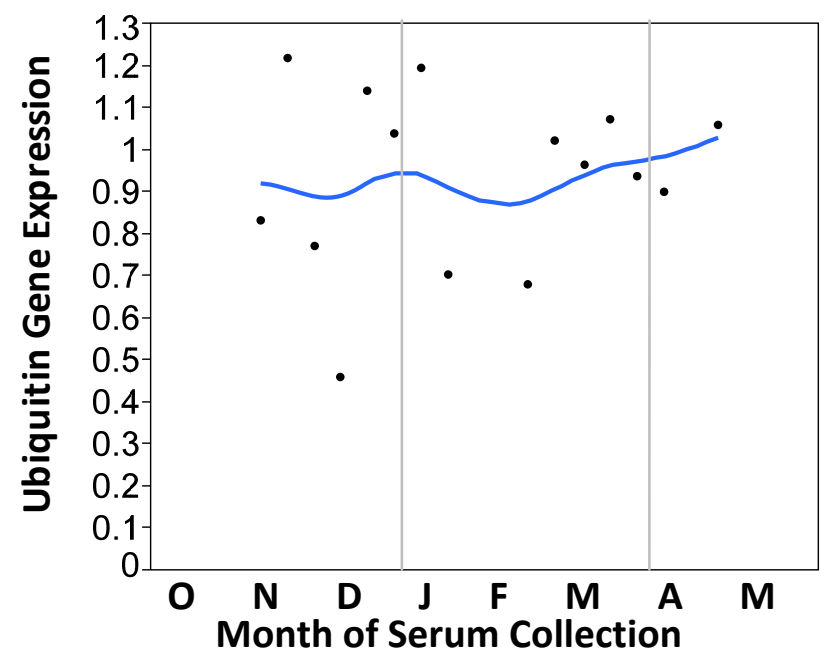

Figure 6.8-Longitudinal analysis of ubiquitin gene expression in undifferentiated cells stimulated for 3 hours in seasonal bear serum

MC3T3-E1 cells were cultured in seasonal bear serum for 3 hours, followed by real-time PCR quantification of relative gene expression. Each point represents the gene expression response from one serum sample. Vertical lines represent transitions between active and hibernating seasons. Samples are from 2 black bears in the 2006/07 season. 


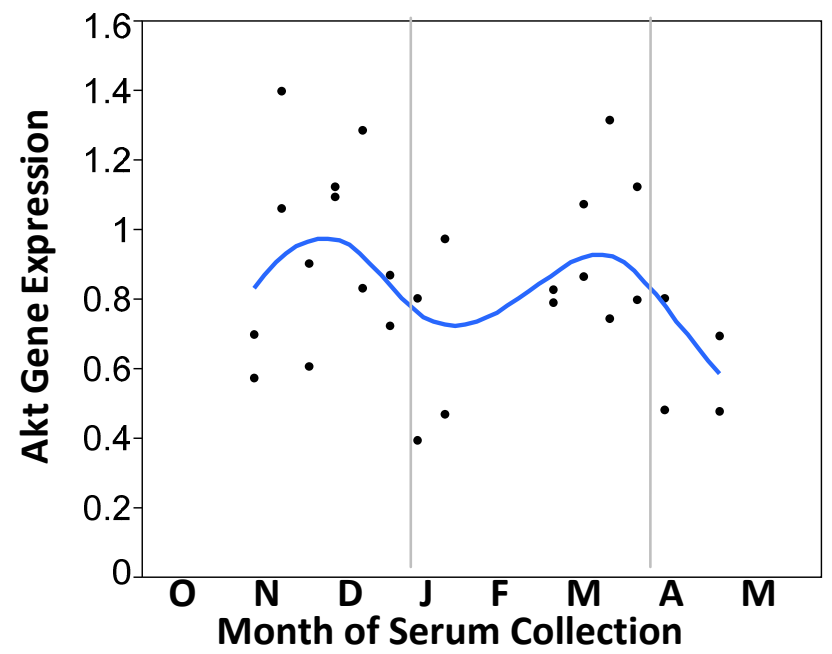

Figure 6.9-Longitudinal analysis of Akt gene expression in differentiated cells stimulated for 3 hours in seasonal bear serum

Differentiated MC3T3-E1 cells were cultured in seasonal bear serum for 3 hours, followed by real-time PCR quantification of relative gene expression. Each point represents the gene expression response from one serum sample. Vertical lines represent transitions between active and hibernating seasons. Samples are from 2 black bears in the 2006/07 season.

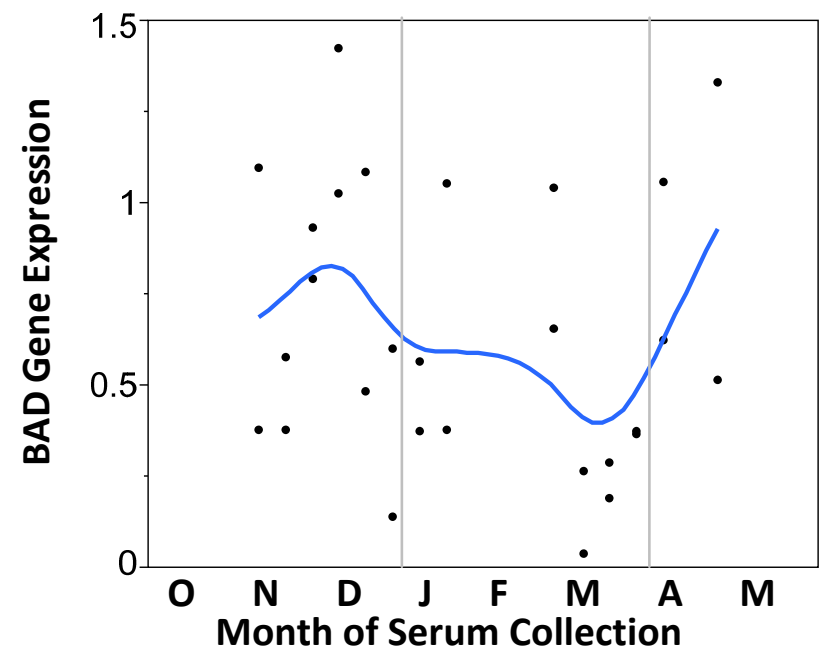

Figure 6.10-Longitudinal analysis of BAD gene expression in differentiated cells stimulated for 3 hours in seasonal bear serum

Differentiated MC3T3-E1 cells were cultured in seasonal bear serum for 3 hours, followed by real-time PCR quantification of relative gene expression. Each point represents the gene expression response from one serum sample. Vertical lines represent transitions between active and hibernating seasons. Samples are from 2 black bears in the 2006/07 season. 


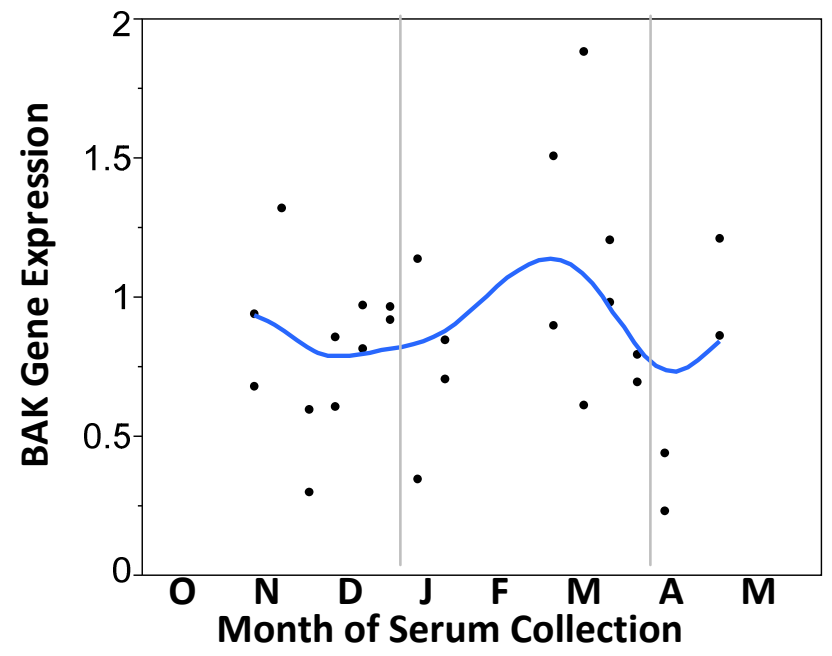

Figure 6.11-Longitudinal analysis of BAK gene expression in differentiated cells stimulated for 3 hours in seasonal bear serum

Differentiated MC3T3-E1 cells were cultured in seasonal bear serum for 3 hours, followed by real-time PCR quantification of relative gene expression. Each point represents the gene expression response from one serum sample. Vertical lines represent transitions between active and hibernating seasons. Samples are from 2 black bears in the 2006/07 season.

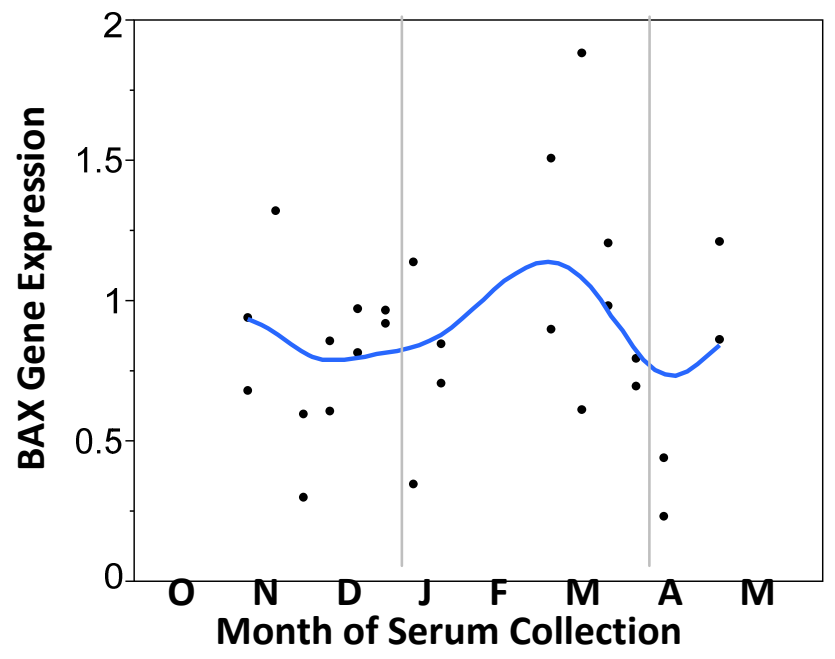

Figure 6.12-Longitudinal analysis of BAX gene expression in differentiated cells stimulated for 3 hours in seasonal bear serum

Differentiated MC3T3-E1 cells were cultured in seasonal bear serum for 3 hours, followed by real-time PCR quantification of relative gene expression. Each point represents the gene expression response from one serum sample. Vertical lines represent transitions between active and hibernating seasons. Samples are from 2 black bears in the 2006/07 season. 


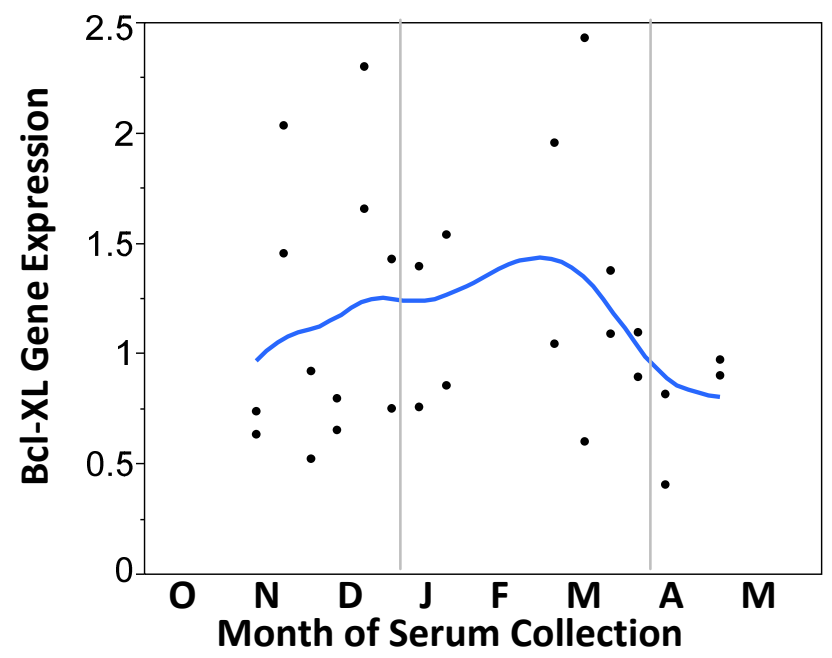

Figure 6.13-Longitudinal analysis of Bcl-XL gene expression in differentiated cells stimulated for 3 hours in seasonal bear serum

Differentiated MC3T3-E1 cells were cultured in seasonal bear serum for 3 hours, followed by real-time PCR quantification of relative gene expression. Each point represents the gene expression response from one serum sample. Vertical lines represent transitions between active and hibernating seasons. Samples are from 2 black bears in the 2006/07 season.

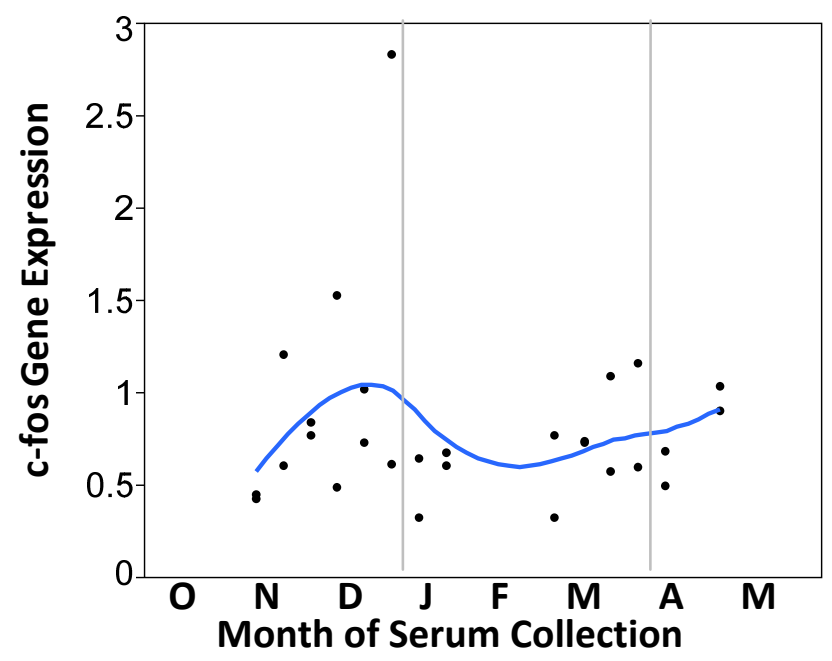

Figure 6.14-Longitudinal analysis of c-fos gene expression in differentiated cells stimulated for 3 hours in seasonal bear serum

Differentiated MC3T3-E1 cells were cultured in seasonal bear serum for 3 hours, followed by real-time PCR quantification of relative gene expression. Each point represents the gene expression response from one serum sample. Vertical lines represent transitions between active and hibernating seasons. Samples are from 2 black bears in the 2006/07 season. 


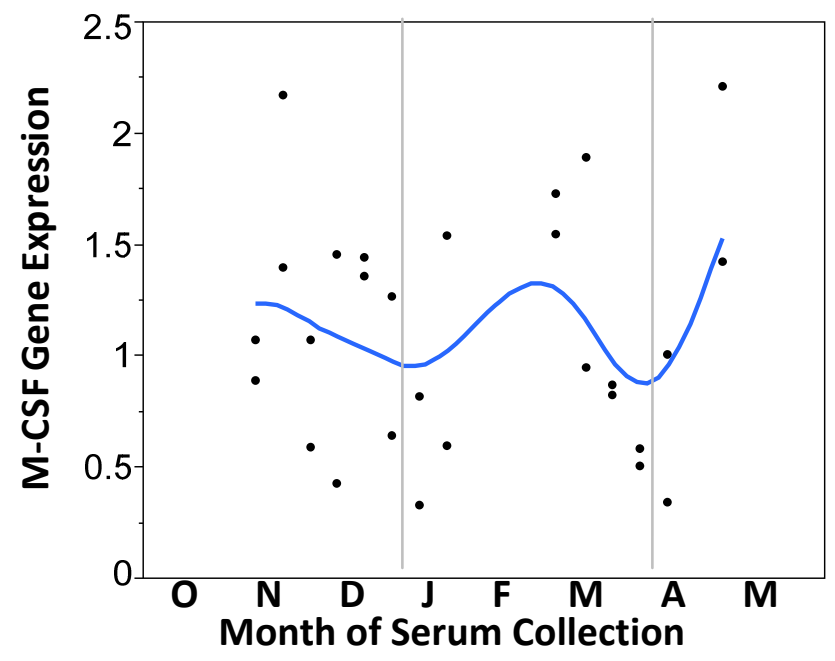

Figure 6.15-Longitudinal analysis of M-CSF gene expression in differentiated cells stimulated for 3 hours in seasonal bear serum

Differentiated MC3T3-E1 cells were cultured in seasonal bear serum for 3 hours, followed by real-time PCR quantification of relative gene expression. Each point represents the gene expression response from one serum sample. Vertical lines represent transitions between active and hibernating seasons. Samples are from 2 black bears in the 2006/07 season.

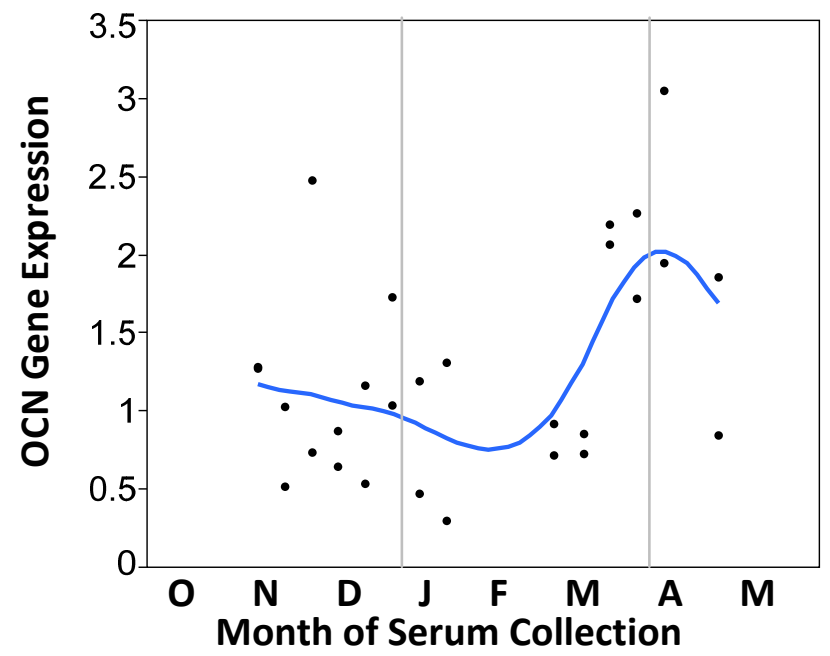

Figure 6.16-Longitudinal analysis of OCN gene expression in differentiated cells stimulated for 3 hours in seasonal bear serum

Differentiated MC3T3-E1 cells were cultured in seasonal bear serum for 3 hours, followed by real-time PCR quantification of relative gene expression. Each point represents the gene expression response from one serum sample. Vertical lines represent transitions between active and hibernating seasons. Samples are from 2 black bears in the 2006/07 season. 


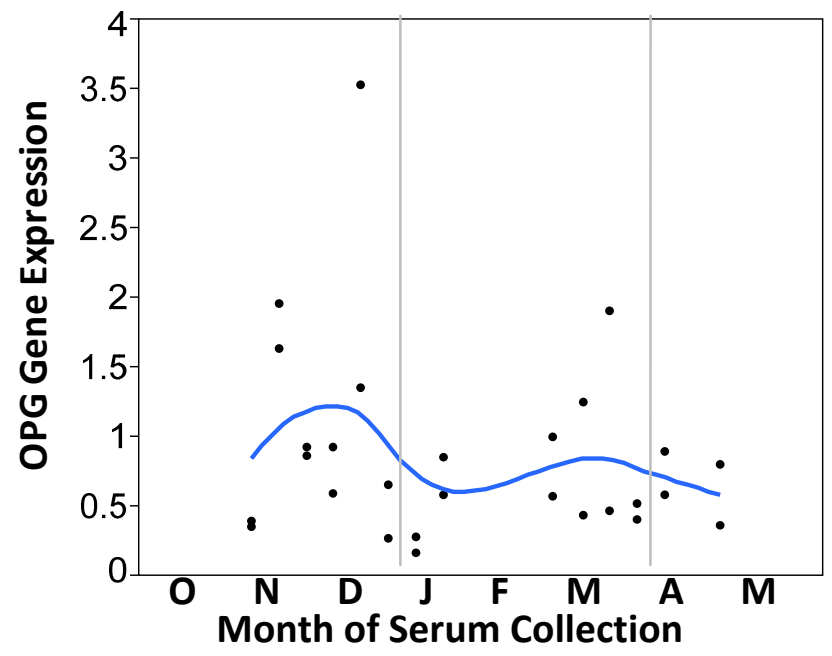

Figure 6.17-Longitudinal analysis of OPG gene expression in differentiated cells stimulated for 3 hours in seasonal bear serum

Differentiated MC3T3-E1 cells were cultured in seasonal bear serum for 3 hours, followed by real-time PCR quantification of relative gene expression. Each point represents the gene expression response from one serum sample. Vertical lines represent transitions between active and hibernating seasons. Samples are from 2 black bears in the 2006/07 season.

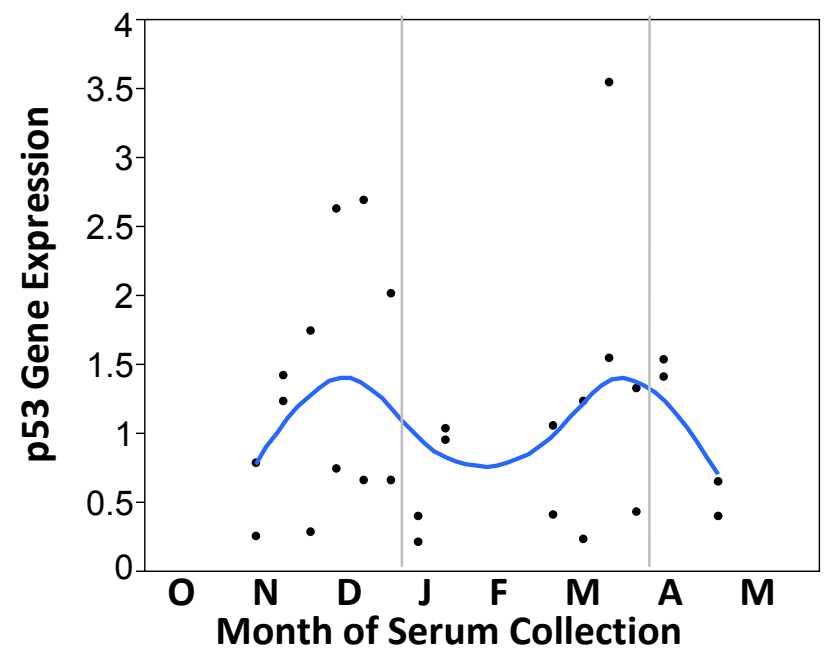

Figure 6.18-Longitudinal analysis of p53 gene expression in differentiated cells stimulated for 3 hours in seasonal bear serum

Differentiated MC3T3-E1 cells were cultured in seasonal bear serum for 3 hours, followed by real-time PCR quantification of relative gene expression. Each point represents the gene expression response from one serum sample. Vertical lines represent transitions between active and hibernating seasons. Samples are from 2 black bears in the 2006/07 season. 


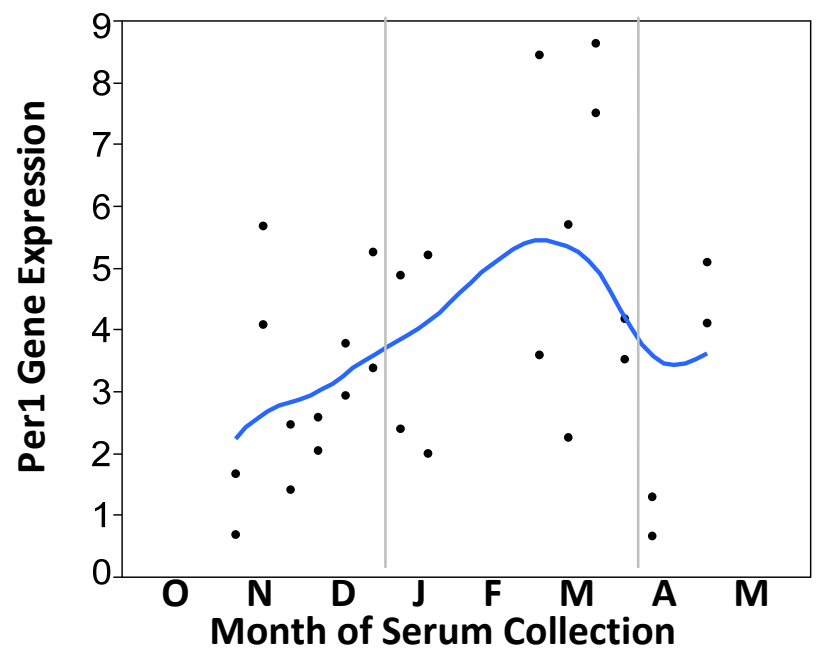

Figure 6.19-Longitudinal analysis of Per1 gene expression in differentiated cells stimulated for 3 hours in seasonal bear serum

Differentiated MC3T3-E1 cells were cultured in seasonal bear serum for 3 hours, followed by real-time PCR quantification of relative gene expression. Each point represents the gene expression response from one serum sample. Vertical lines represent transitions between active and hibernating seasons. Samples are from 2 black bears in the 2006/07 season.

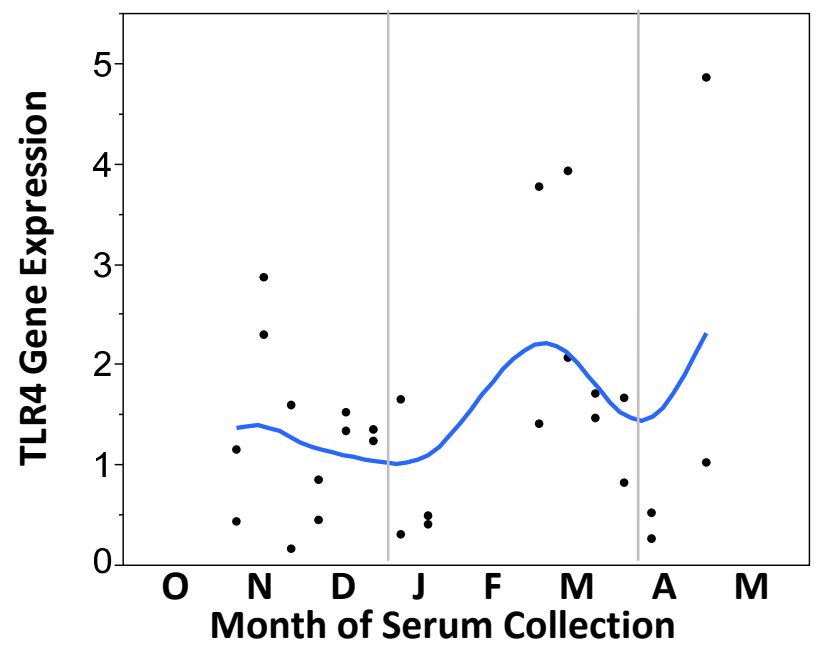

Figure 6.20-Longitudinal analysis of TLR4 gene expression in differentiated cells stimulated for 3 hours in seasonal bear serum

Differentiated MC3T3-E1 cells were cultured in seasonal bear serum for 3 hours, followed by real-time PCR quantification of relative gene expression. Each point represents the gene expression response from one serum sample. Vertical lines represent transitions between active and hibernating seasons. Samples are from 2 black bears in the 2006/07 season. 


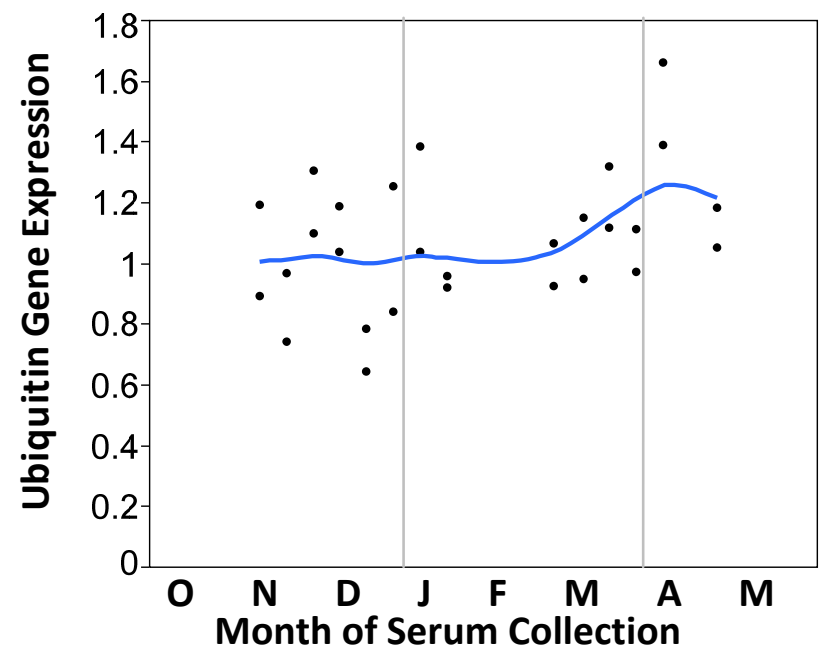

Figure 6.21-Longitudinal analysis of ubiquitin gene expression in differentiated cells stimulated for 3 hours in seasonal bear serum

Differentiated MC3T3-E1 cells were cultured in seasonal bear serum for 3 hours, followed by real-time PCR quantification of relative gene expression. Each point represents the gene expression response from one serum sample. Vertical lines represent transitions between active and hibernating seasons. Samples are from 2 black bears in the 2006/07 season.

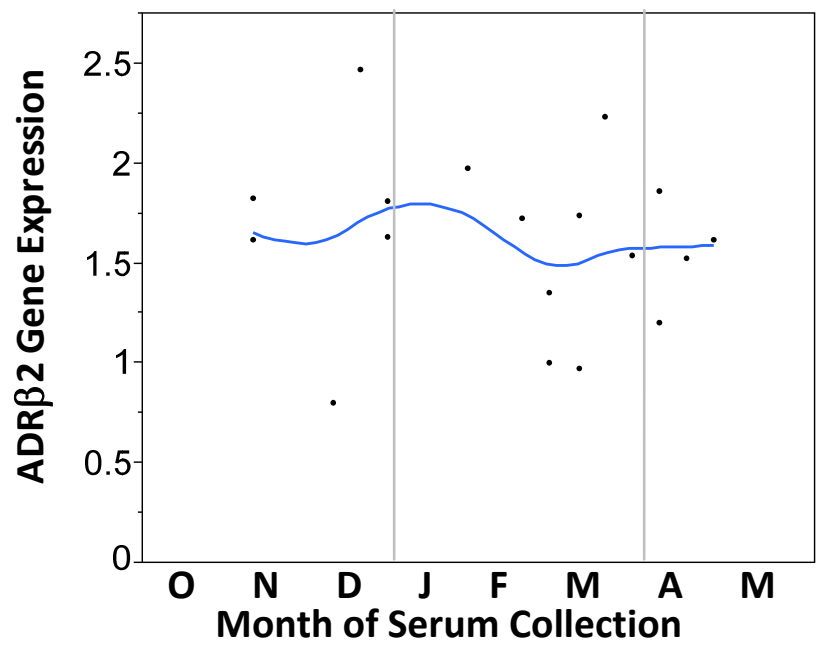

Figure 6.22-Longitudinal analysis of ADR 32 gene expression in undifferentiated cells stimulated for 24 hours in seasonal bear serum

Undifferentiated MC3T3-E1 cells were cultured in seasonal bear serum for 24 hours, followed by real-time PCR quantification of relative gene expression. Each point represents the gene expression response from one serum sample. Vertical lines represent transitions between active and hibernating seasons. Samples are from 2 black bears in the 2006/07 season. 


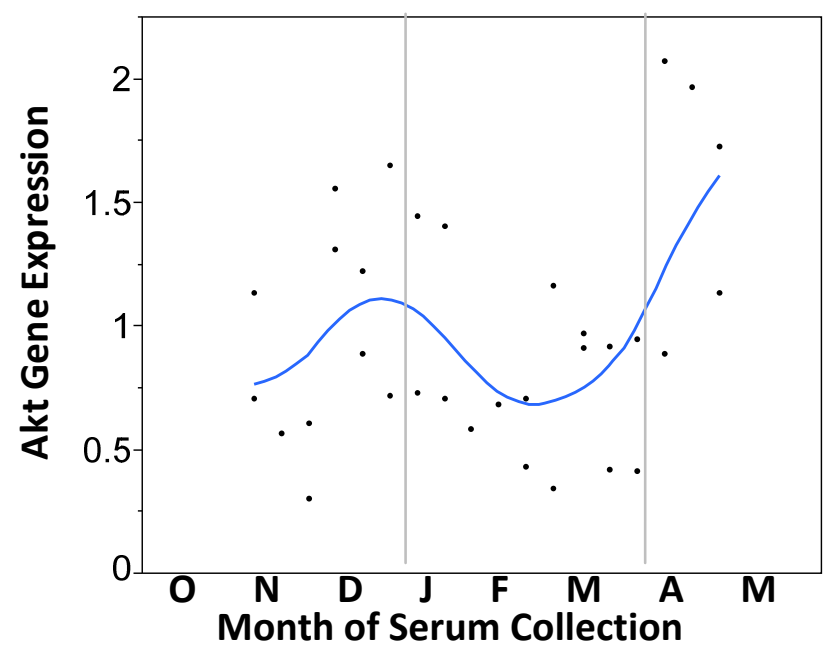

Figure 6.23-Longitudinal analysis of Akt gene expression in undifferentiated cells stimulated for 24 hours in seasonal bear serum

Undifferentiated MC3T3-E1 cells were cultured in seasonal bear serum for 24 hours, followed by real-time PCR quantification of relative gene expression. Each point represents the gene expression response from one serum sample. Vertical lines represent transitions between active and hibernating seasons. Samples are from 2 black bears in the 2006/07 season.

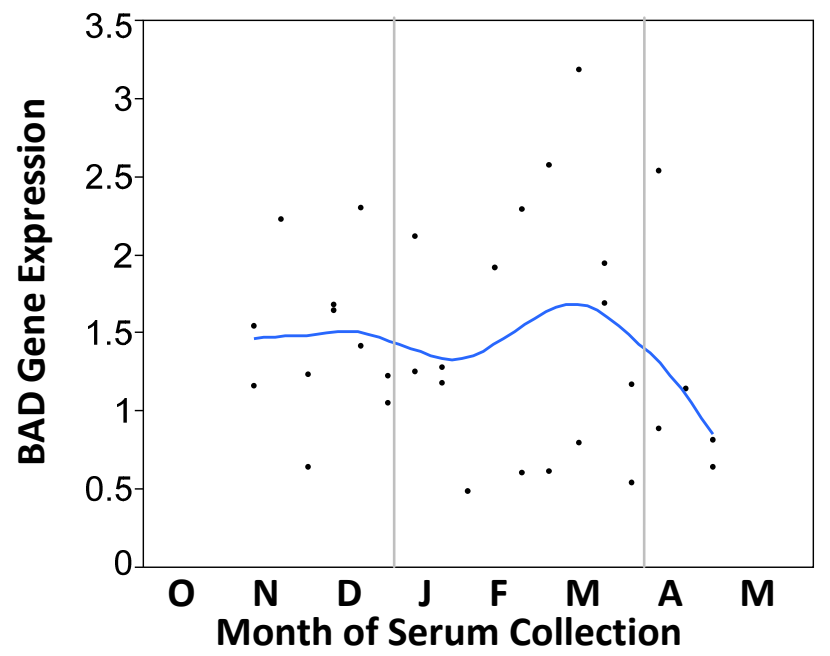

Figure 6.24-Longitudinal analysis of BAD gene expression in undifferentiated cells stimulated for 24 hours in seasonal bear serum

Undifferentiated MC3T3-E1 cells were cultured in seasonal bear serum for 24 hours, followed by real-time PCR quantification of relative gene expression. Each point represents the gene expression response from one serum sample. Vertical lines represent transitions between active and hibernating seasons. Samples are from 2 black bears in the 2006/07 season. 


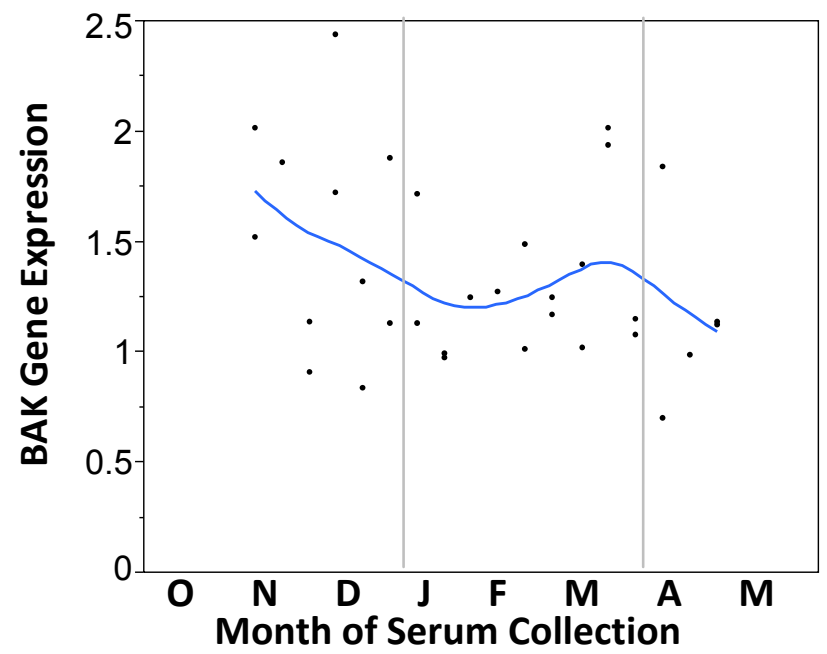

Figure 6.25-Longitudinal analysis of BAK gene expression in undifferentiated cells stimulated for 24 hours in seasonal bear serum

Undifferentiated MC3T3-E1 cells were cultured in seasonal bear serum for 24 hours, followed by real-time PCR quantification of relative gene expression. Each point represents the gene expression response from one serum sample. Vertical lines represent transitions between active and hibernating seasons. Samples are from 2 black bears in the 2006/07 season.

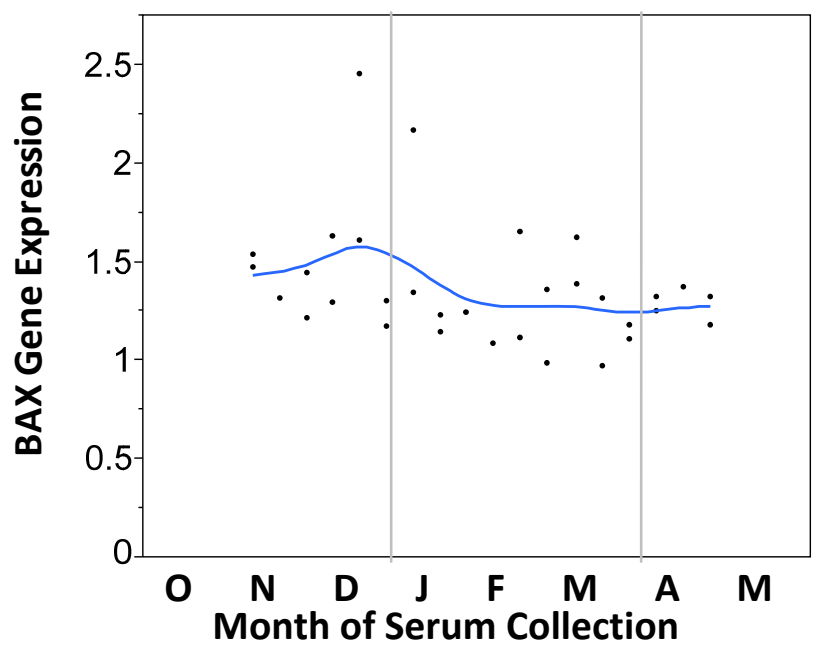

Figure 6.26-Longitudinal analysis of BAX gene expression in undifferentiated cells stimulated for 24 hours in seasonal bear serum

Undifferentiated MC3T3-E1 cells were cultured in seasonal bear serum for 24 hours, followed by real-time PCR quantification of relative gene expression. Each point represents the gene expression response from one serum sample. Vertical lines represent transitions between active and hibernating seasons. Samples are from 2 black bears in the 2006/07 season. 


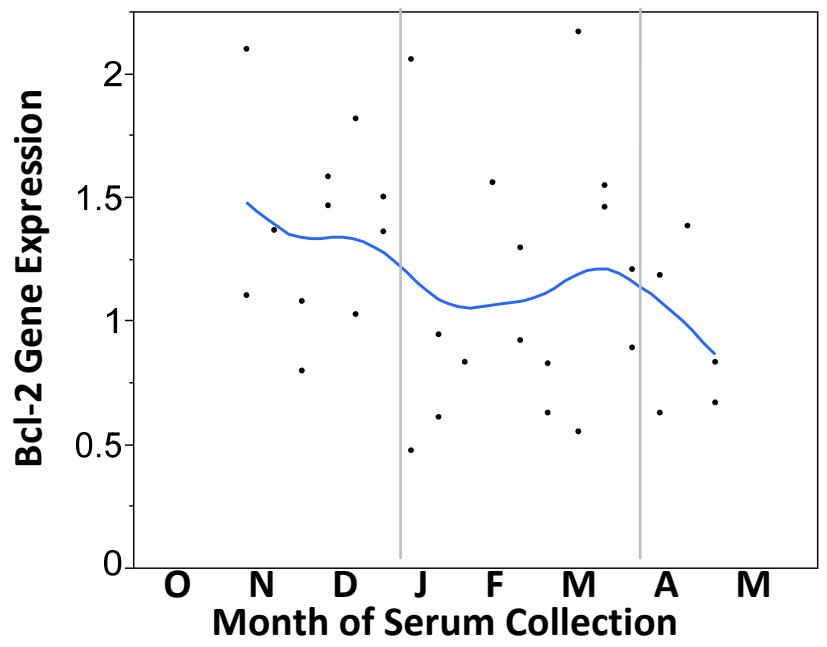

Figure 6.27-Longitudinal analysis of Bcl-2 gene expression in undifferentiated cells stimulated for 24 hours in seasonal bear serum

Undifferentiated MC3T3-E1 cells were cultured in seasonal bear serum for 24 hours, followed by real-time PCR quantification of relative gene expression. Each point represents the gene expression response from one serum sample. Vertical lines represent transitions between active and hibernating seasons. Samples are from 2 black bears in the 2006/07 season.

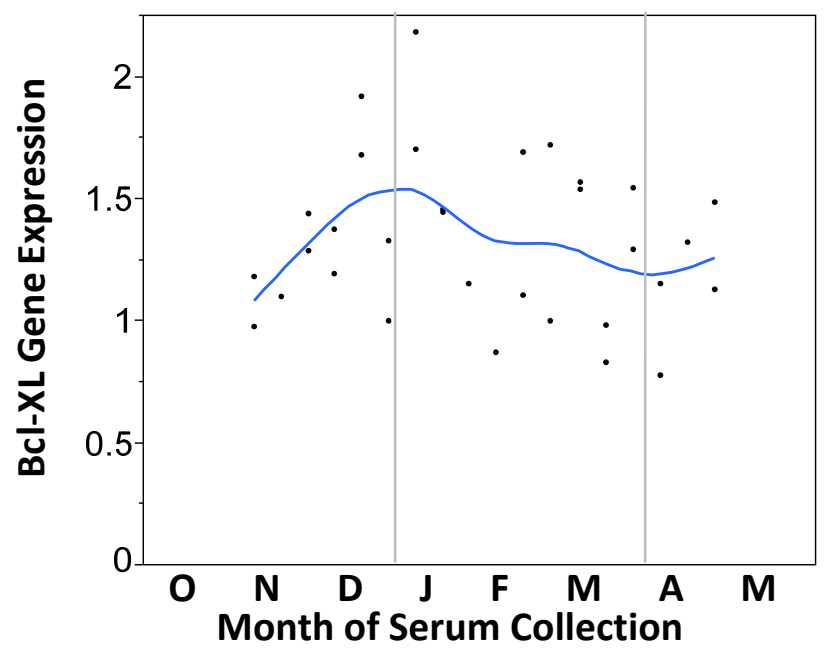

Figure 6.28-Longitudinal analysis of Bcl-XL gene expression in undifferentiated cells stimulated for 24 hours in seasonal bear serum

Undifferentiated MC3T3-E1 cells were cultured in seasonal bear serum for 24 hours, followed by real-time PCR quantification of relative gene expression. Each point represents the gene expression response from one serum sample. Vertical lines represent transitions between active and hibernating seasons. Samples are from 2 black bears in the 2006/07 season. 


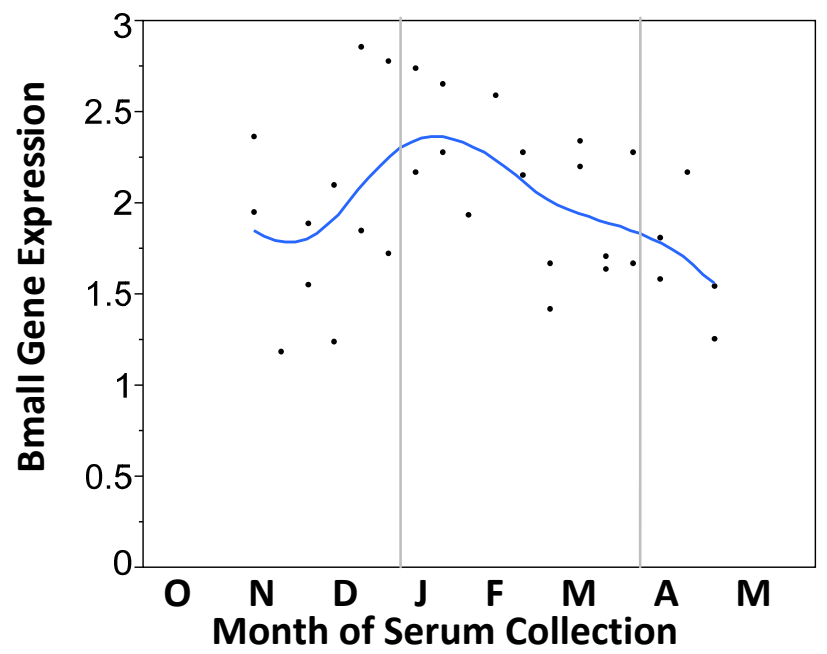

Figure 6.29—Longitudinal analysis of Bmall gene expression in undifferentiated cells stimulated for 24 hours in seasonal bear serum

Undifferentiated MC3T3-E1 cells were cultured in seasonal bear serum for 24 hours, followed by real-time PCR quantification of relative gene expression. Each point represents the gene expression response from one serum sample. Vertical lines represent transitions between active and hibernating seasons. Samples are from 2 black bears in the 2006/07 season.

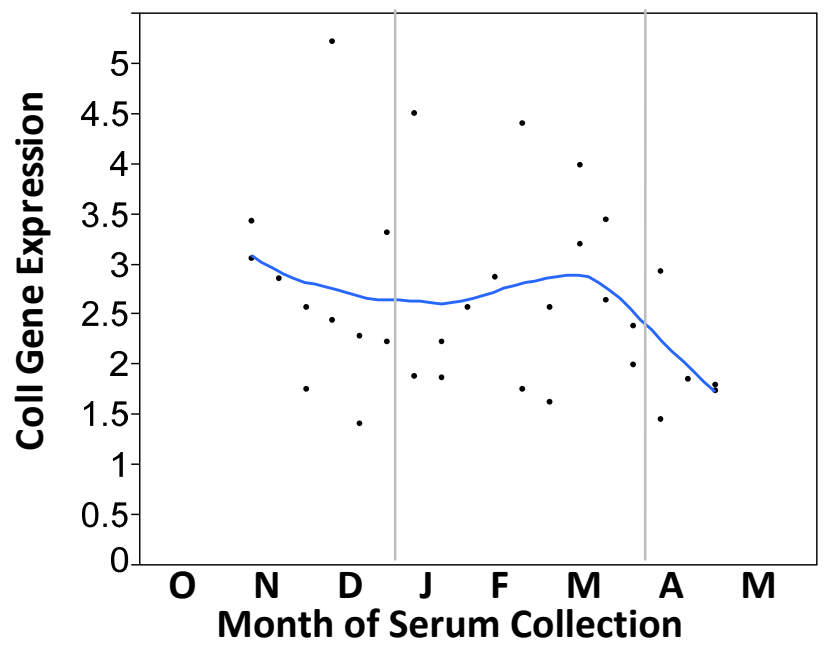

Figure 6.30-Longitudinal analysis of Coll gene expression in undifferentiated cells stimulated for 24 hours in seasonal bear serum

Undifferentiated MC3T3-E1 cells were cultured in seasonal bear serum for 24 hours, followed by real-time PCR quantification of relative gene expression. Each point represents the gene expression response from one serum sample. Vertical lines represent transitions between active and hibernating seasons. Samples are from 2 black bears in the 2006/07 season. 


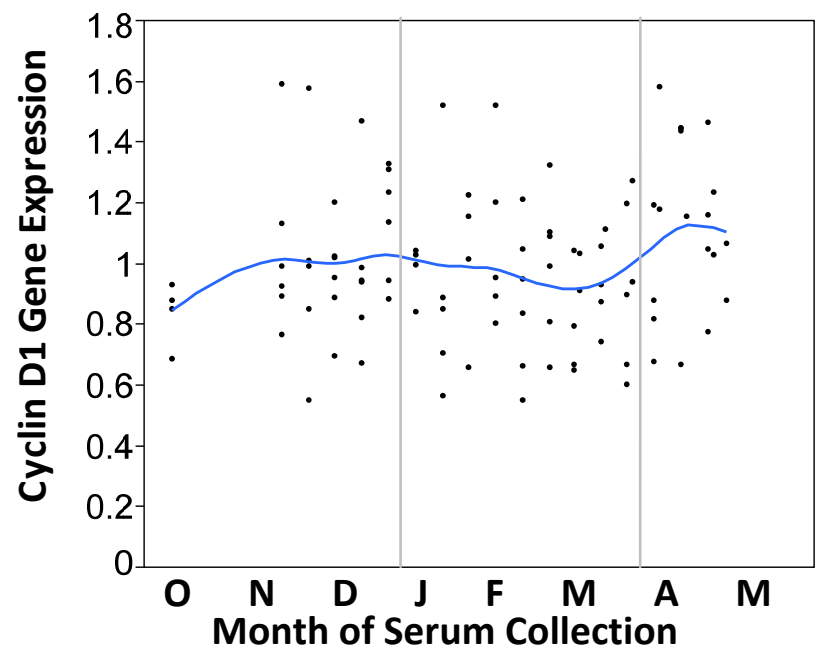

Figure 6.31-Longitudinal analysis of Cyclin D1 gene expression in undifferentiated cells stimulated for 24 hours in seasonal bear serum

Undifferentiated MC3T3-E1 cells were cultured in seasonal bear serum for 24 hours, followed by real-time PCR quantification of relative gene expression. Each point represents the gene expression response from one serum sample. Vertical lines represent transitions between active and hibernating seasons. Samples are from 5 black bears in the 2007/08 season.

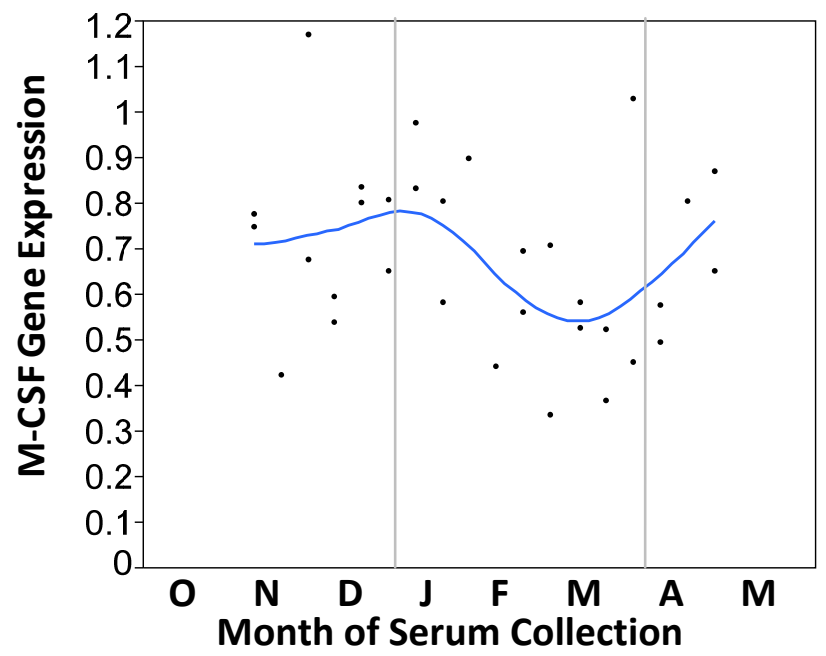

Figure 6.32-Longitudinal analysis of M-CSF gene expression in undifferentiated cells stimulated for 24 hours in seasonal bear serum

Undifferentiated MC3T3-E1 cells were cultured in seasonal bear serum for 24 hours, followed by real-time PCR quantification of relative gene expression. Each point represents the gene expression response from one serum sample. Vertical lines represent transitions between active and hibernating seasons. Samples are from 2 black bears in the 2006/07 season. 


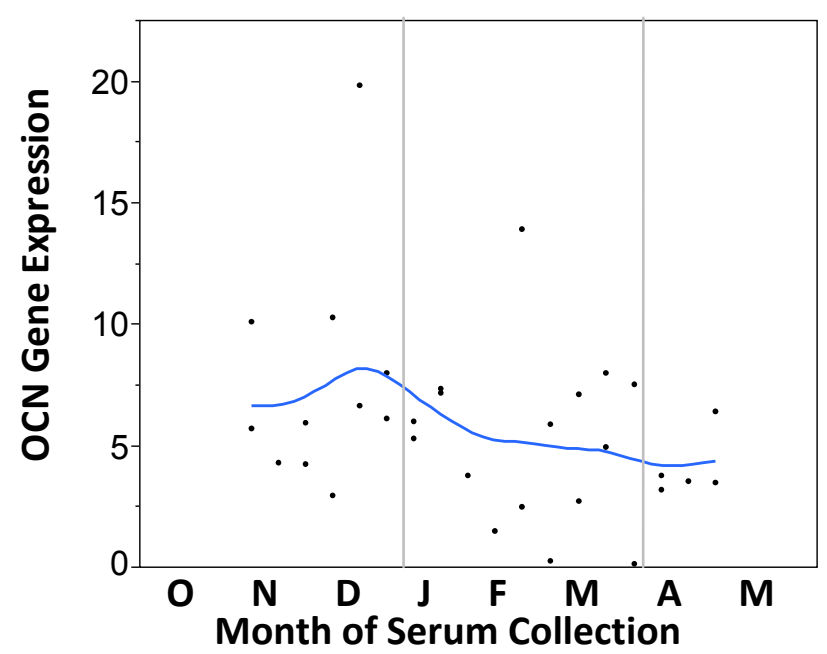

Figure 6.33-Longitudinal analysis of OCN gene expression in undifferentiated cells stimulated for 24 hours in seasonal bear serum

Undifferentiated MC3T3-E1 cells were cultured in seasonal bear serum for 24 hours, followed by real-time PCR quantification of relative gene expression. Each point represents the gene expression response from one serum sample. Vertical lines represent transitions between active and hibernating seasons. Samples are from 2 black bears in the 2006/07 season.

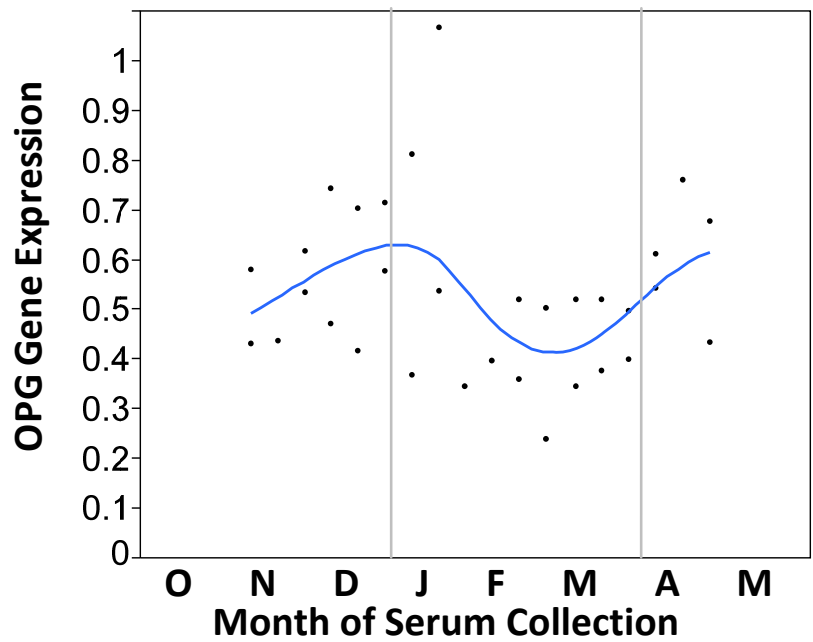

Figure 6.34-Longitudinal analysis of OPG gene expression in undifferentiated cells stimulated for 24 hours in seasonal bear serum

Undifferentiated MC3T3-E1 cells were cultured in seasonal bear serum for 24 hours, followed by real-time PCR quantification of relative gene expression. Each point represents the gene expression response from one serum sample. Vertical lines represent transitions between active and hibernating seasons. Samples are from 2 black bears in the 2006/07 season. 


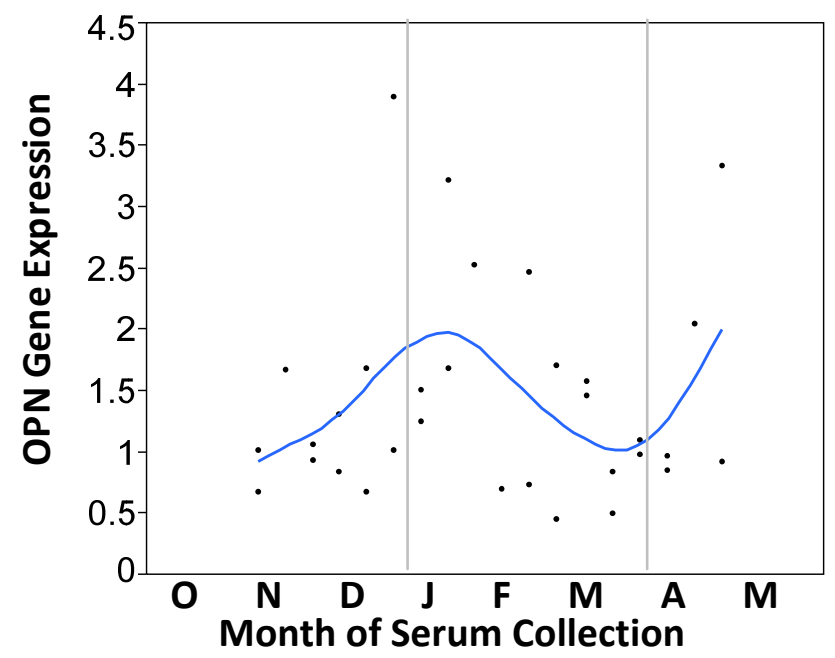

Figure 6.35-Longitudinal analysis of OPN gene expression in undifferentiated cells stimulated for 24 hours in seasonal bear serum

Undifferentiated MC3T3-E1 cells were cultured in seasonal bear serum for 24 hours, followed by real-time PCR quantification of relative gene expression. Each point represents the gene expression response from one serum sample. Vertical lines represent transitions between active and hibernating seasons. Samples are from 2 black bears in the 2006/07 season.

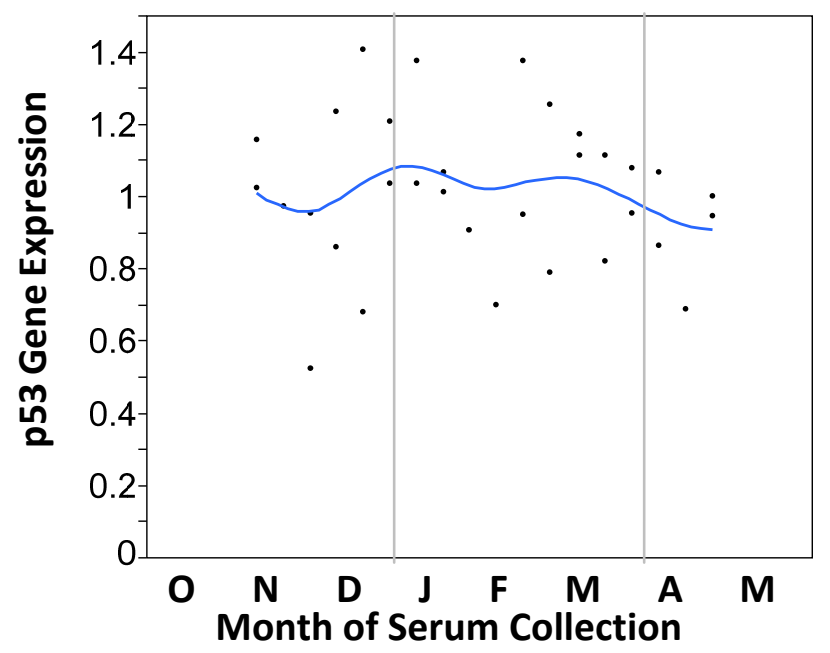

Figure 6.36-Longitudinal analysis of p53 gene expression in undifferentiated cells stimulated for 24 hours in seasonal bear serum

Undifferentiated MC3T3-E1 cells were cultured in seasonal bear serum for 24 hours, followed by real-time PCR quantification of relative gene expression. Each point represents the gene expression response from one serum sample. Vertical lines represent transitions between active and hibernating seasons. Samples are from 2 black bears in the 2006/07 season. 


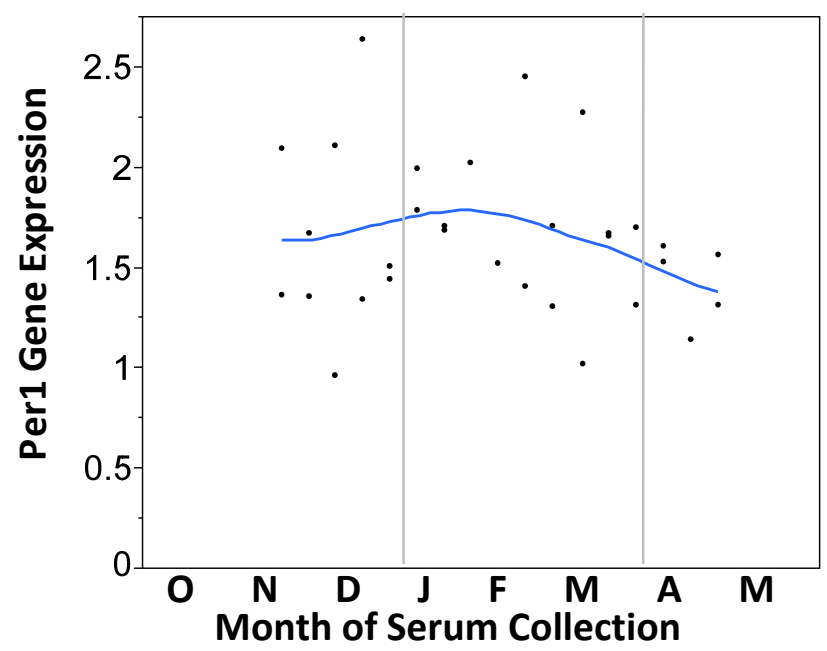

Figure 6.37-Longitudinal analysis of Per1 gene expression in undifferentiated cells stimulated for 24 hours in seasonal bear serum

Undifferentiated MC3T3-E1 cells were cultured in seasonal bear serum for 24 hours, followed by real-time PCR quantification of relative gene expression. Each point represents the gene expression response from one serum sample. Vertical lines represent transitions between active and hibernating seasons. Samples are from 5 black bears in the 2007/08 season.

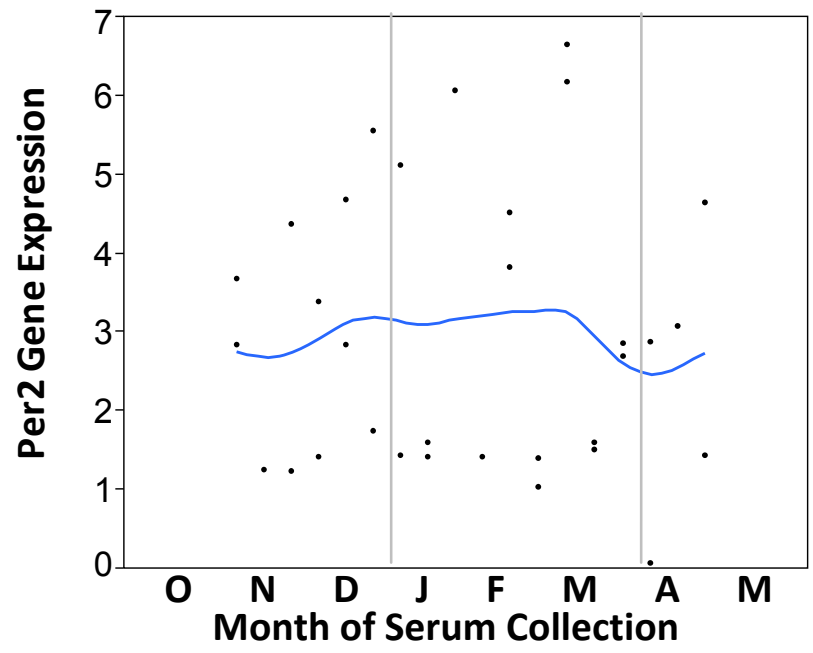

Figure 6.38-Longitudinal analysis of Per2 gene expression in undifferentiated cells stimulated for 24 hours in seasonal bear serum

Undifferentiated MC3T3-E1 cells were cultured in seasonal bear serum for 24 hours, followed by real-time PCR quantification of relative gene expression. Each point represents the gene expression response from one serum sample. Vertical lines represent transitions between active and hibernating seasons. Samples are from 2 black bears in the 2006/07 season. 


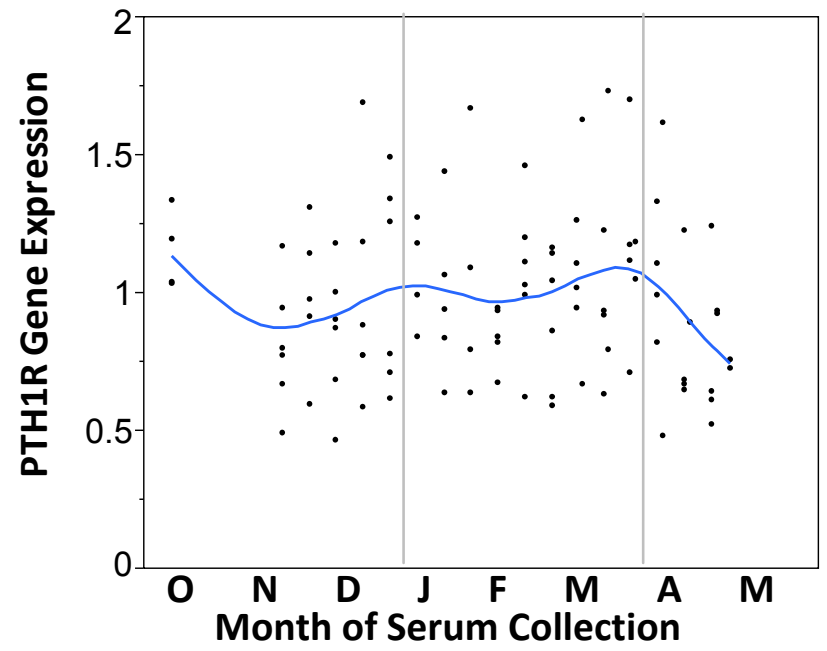

Figure 6.39-Longitudinal analysis of PTH1R gene expression in undifferentiated cells stimulated for 24 hours in seasonal bear serum

Undifferentiated MC3T3-E1 cells were cultured in seasonal bear serum for 24 hours, followed by real-time PCR quantification of relative gene expression. Each point represents the gene expression response from one serum sample. Vertical lines represent transitions between active and hibernating seasons. Samples are from 5 black bears in the 2007/08 season.

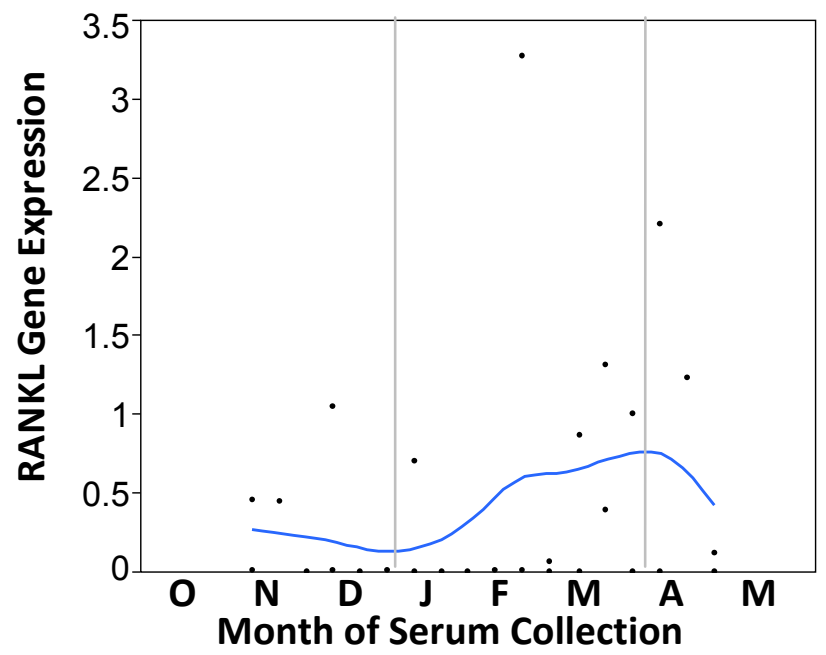

Figure 6.40-Longitudinal analysis of RANKL gene expression in undifferentiated cells stimulated for 24 hours in seasonal bear serum

Undifferentiated MC3T3-E1 cells were cultured in seasonal bear serum for 24 hours, followed by real-time PCR quantification of relative gene expression. Each point represents the gene expression response from one serum sample. Vertical lines represent transitions between active and hibernating seasons. Samples are from 2 black bears in the 2006/07 season. 


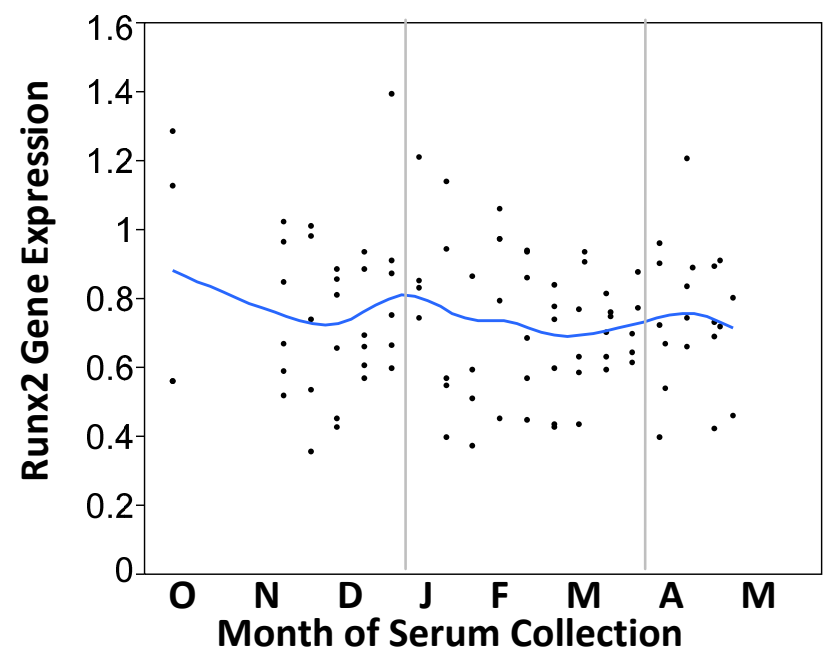

Figure 6.41-Longitudinal analysis of Runx2 gene expression in undifferentiated cells stimulated for 24 hours in seasonal bear serum

Undifferentiated MC3T3-E1 cells were cultured in seasonal bear serum for 24 hours, followed by real-time PCR quantification of relative gene expression. Each point represents the gene expression response from one serum sample. Vertical lines represent transitions between active and hibernating seasons. Samples are from 5 black bears in the 2007/08 season.

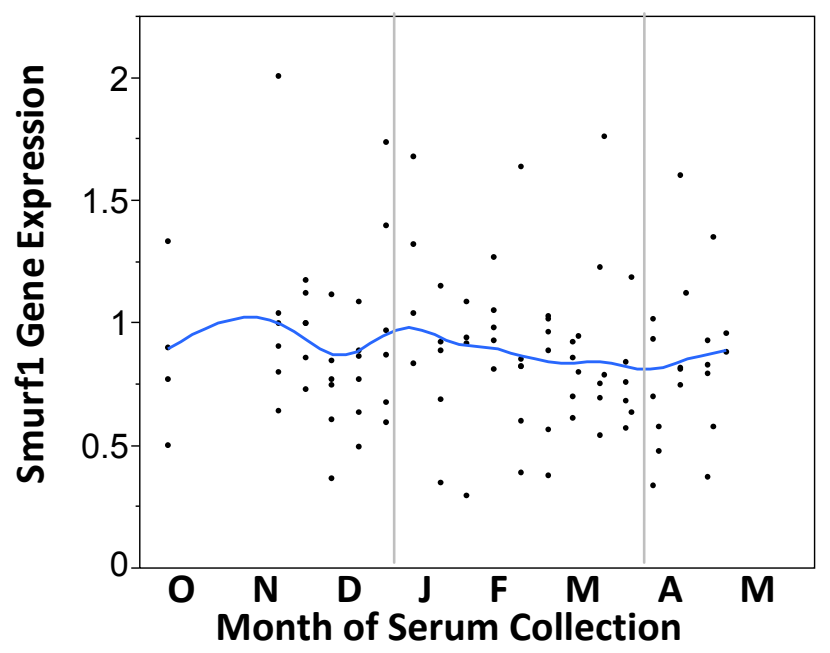

Figure 6.42-Longitudinal analysis of Smurf1 gene expression in undifferentiated cells stimulated for 24 hours in seasonal bear serum

Undifferentiated MC3T3-E1 cells were cultured in seasonal bear serum for 24 hours, followed by real-time PCR quantification of relative gene expression. Each point represents the gene expression response from one serum sample. Vertical lines represent transitions between active and hibernating seasons. Samples are from 5 black bears in the 2007/08 season. 


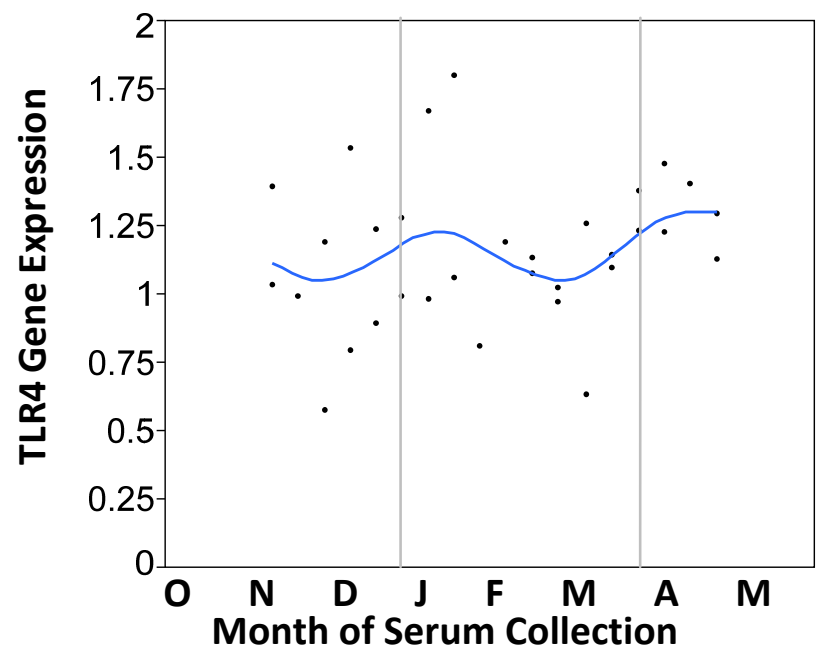

Figure 6.43-Longitudinal analysis of TLR4 gene expression in undifferentiated cells stimulated for 24 hours in seasonal bear serum

Undifferentiated MC3T3-E1 cells were cultured in seasonal bear serum for 24 hours, followed by real-time PCR quantification of relative gene expression. Each point represents the gene expression response from one serum sample. Vertical lines represent transitions between active and hibernating seasons. Samples are from 2 black bears in the 2006/07 season.

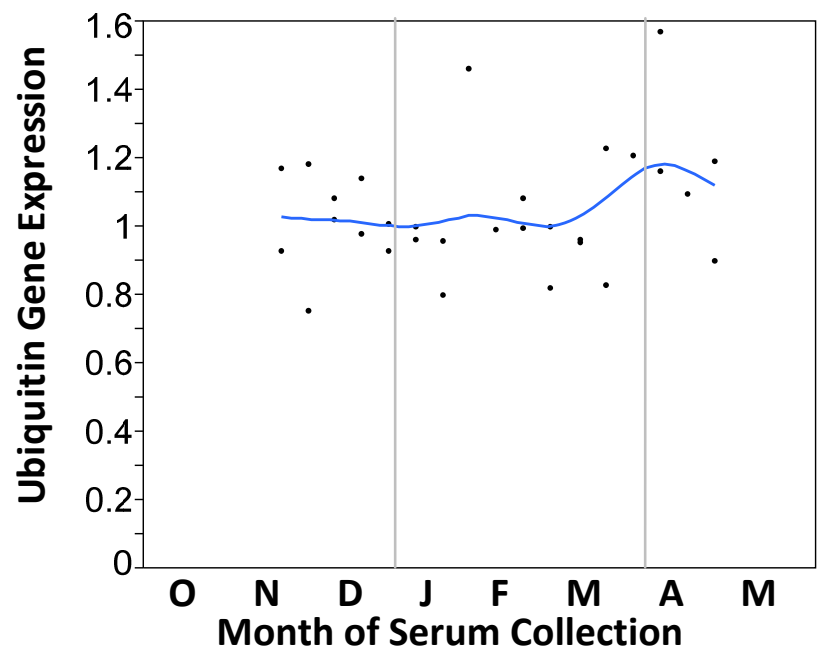

Figure 6.44-Longitudinal analysis of ubiquitin gene expression in undifferentiated cells stimulated for 24 hours in seasonal bear serum

Undifferentiated MC3T3-E1 cells were cultured in seasonal bear serum for 24 hours, followed by real-time PCR quantification of relative gene expression. Each point represents the gene expression response from one serum sample. Vertical lines represent transitions between active and hibernating seasons. Samples are from 5 black bears in the 2007/08 season. 


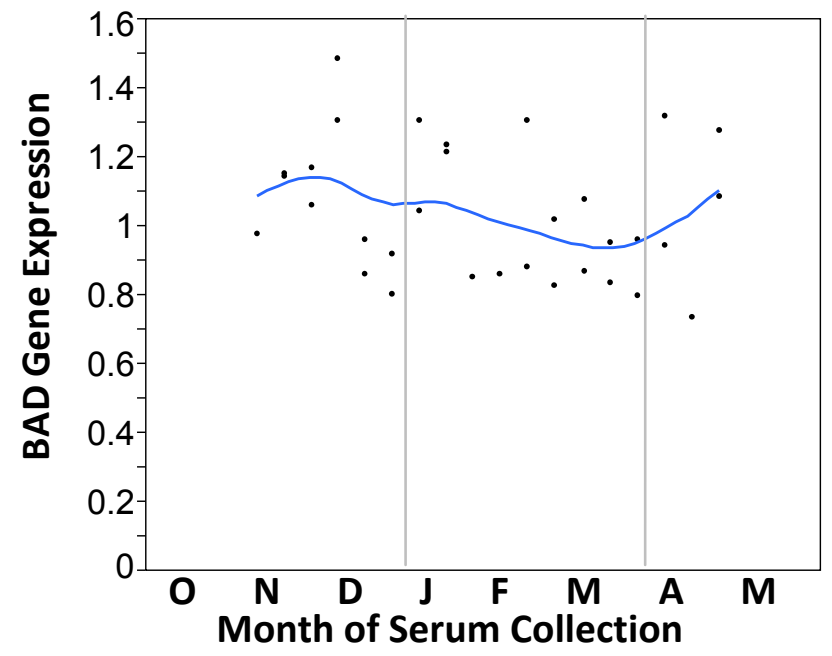

Figure 6.45-Longitudinal analysis of BAD gene expression in cells differentiated for 6 days in seasonal bear serum

MC3T3-E1 cells were differentiated in seasonal bear serum for 6 days, followed by real-time PCR quantification of relative gene expression. Each point represents the gene expression response from one serum sample. Vertical lines represent transitions between active and hibernating seasons. Samples are from 2 black bears in the 2006/07 season.

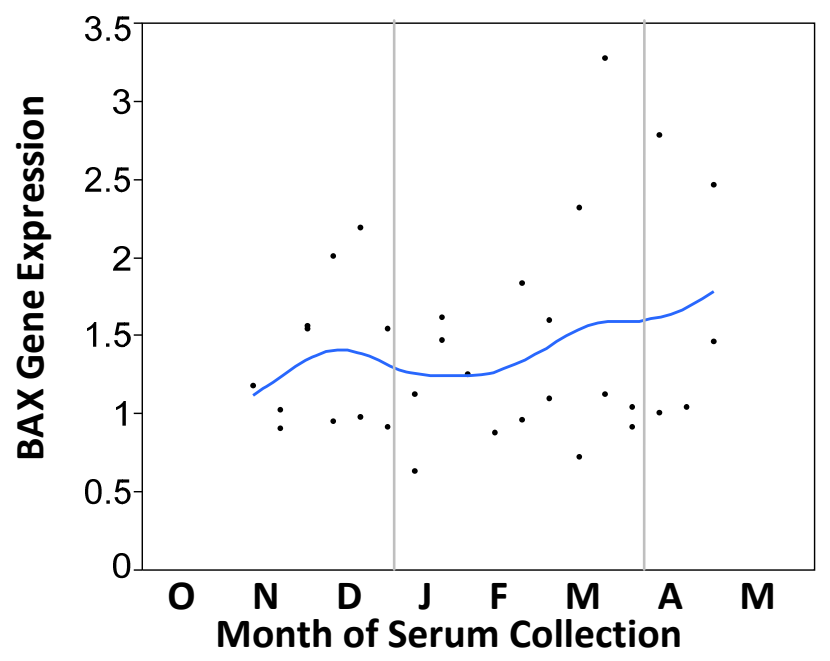

Figure 6.46-Longitudinal analysis of BAX gene expression in cells differentiated for 6 days in seasonal bear serum

MC3T3-E1 cells were differentiated in seasonal bear serum for 6 days, followed by real-time PCR quantification of relative gene expression. Each point represents the gene expression response from one serum sample. Vertical lines represent transitions between active and hibernating seasons. Samples are from 2 black bears in the 2006/07 season. 


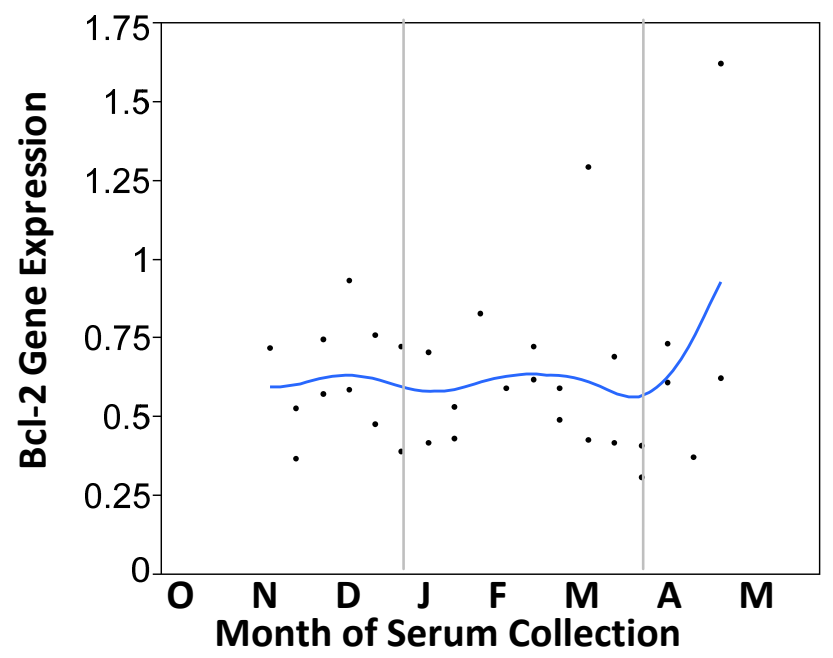

Figure 6.47-Longitudinal analysis of Bcl-2 gene expression in cells differentiated for 6 days in seasonal bear serum

MC3T3-E1 cells were differentiated in seasonal bear serum for 6 days, followed by real-time PCR quantification of relative gene expression. Each point represents the gene expression response from one serum sample. Vertical lines represent transitions between active and hibernating seasons. Samples are from 2 black bears in the 2006/07 season.

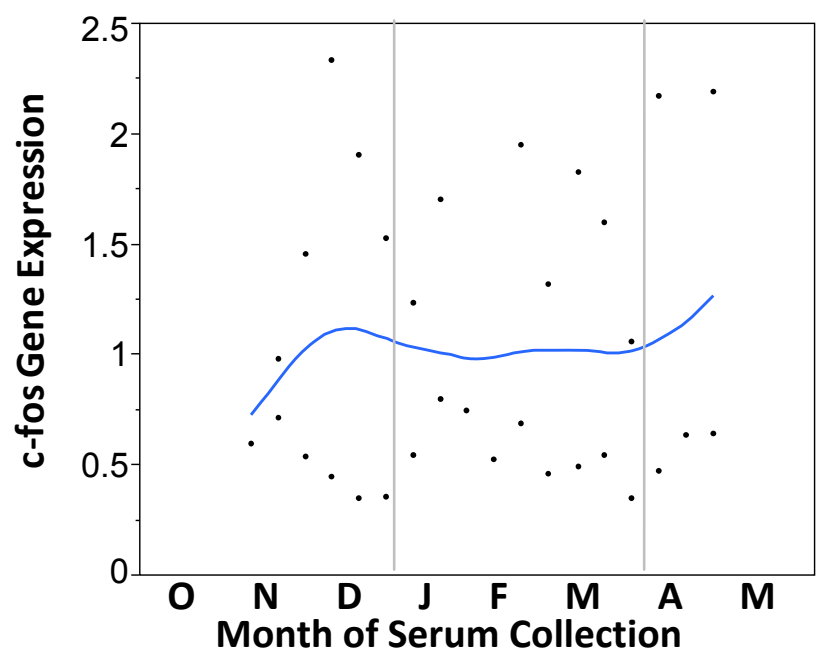

Figure 6.48-Longitudinal analysis of c-fos gene expression in cells differentiated for 6 days in seasonal bear serum

MC3T3-E1 cells were differentiated in seasonal bear serum for 6 days, followed by real-time PCR quantification of relative gene expression. Each point represents the gene expression response from one serum sample. Vertical lines represent transitions between active and hibernating seasons. Samples are from 2 black bears in the 2006/07 season. 


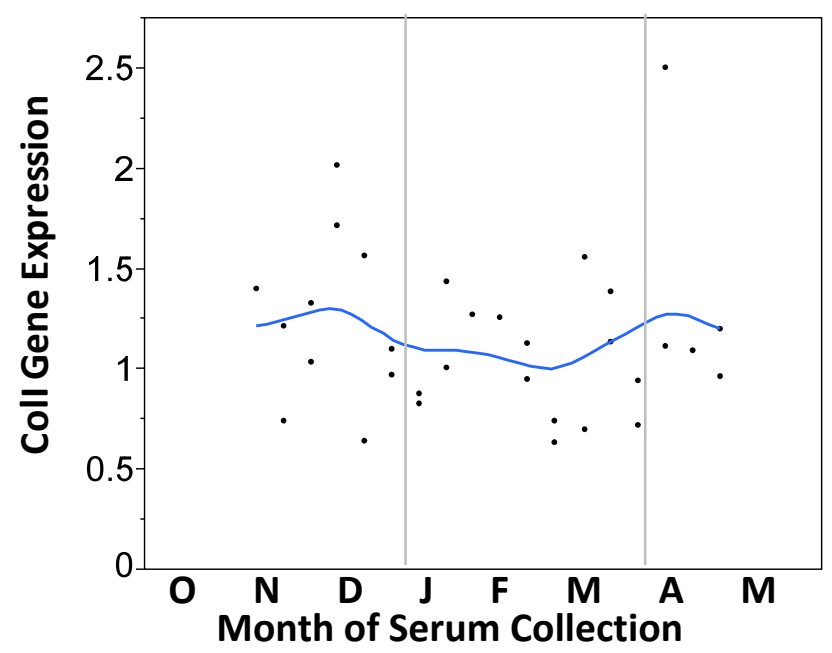

Figure 6.49-Longitudinal analysis of Coll gene expression in cells differentiated for 6 days in seasonal bear serum

MC3T3-E1 cells were differentiated in seasonal bear serum for 6 days, followed by real-time PCR quantification of relative gene expression. Each point represents the gene expression response from one serum sample. Vertical lines represent transitions between active and hibernating seasons. Samples are from 2 black bears in the 2006/07 season.

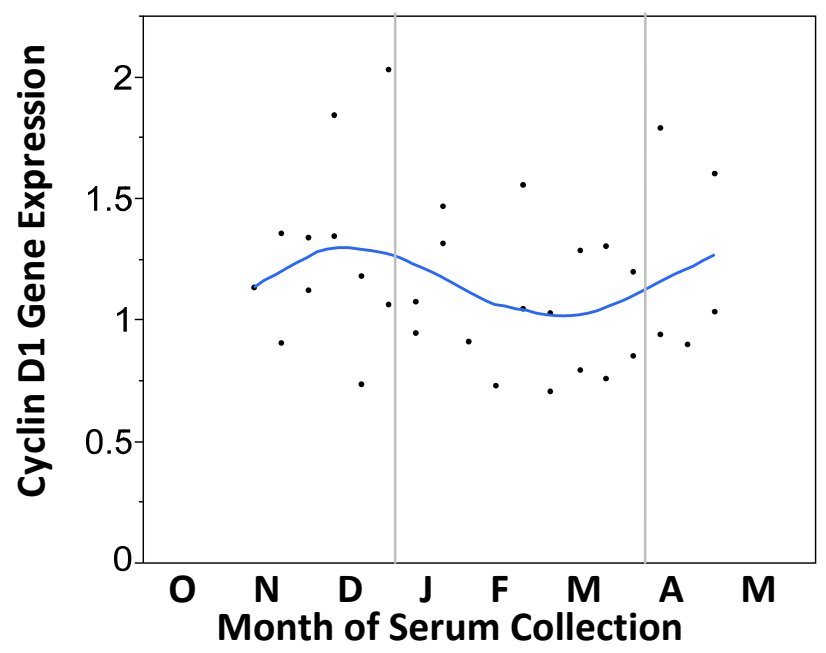

Figure 6.50-Longitudinal analysis of Cyclin D1 gene expression in cells differentiated for 6 days in seasonal bear serum

MC3T3-E1 cells were differentiated in seasonal bear serum for 6 days, followed by real-time PCR quantification of relative gene expression. Each point represents the gene expression response from one serum sample. Vertical lines represent transitions between active and hibernating seasons. Samples are from 2 black bears in the 2006/07 season. 


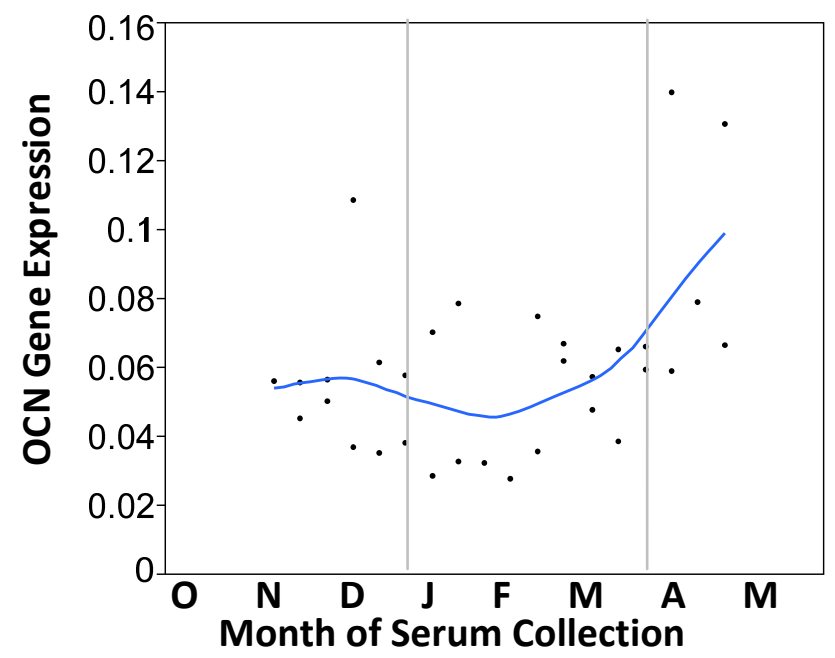

Figure 6.51-Longitudinal analysis of OCN gene expression in cells differentiated for 6 days in seasonal bear serum

MC3T3-E1 cells were differentiated in seasonal bear serum for 6 days, followed by real-time PCR quantification of relative gene expression. Each point represents the gene expression response from one serum sample. Vertical lines represent transitions between active and hibernating seasons. Samples are from 2 black bears in the 2006/07 season.

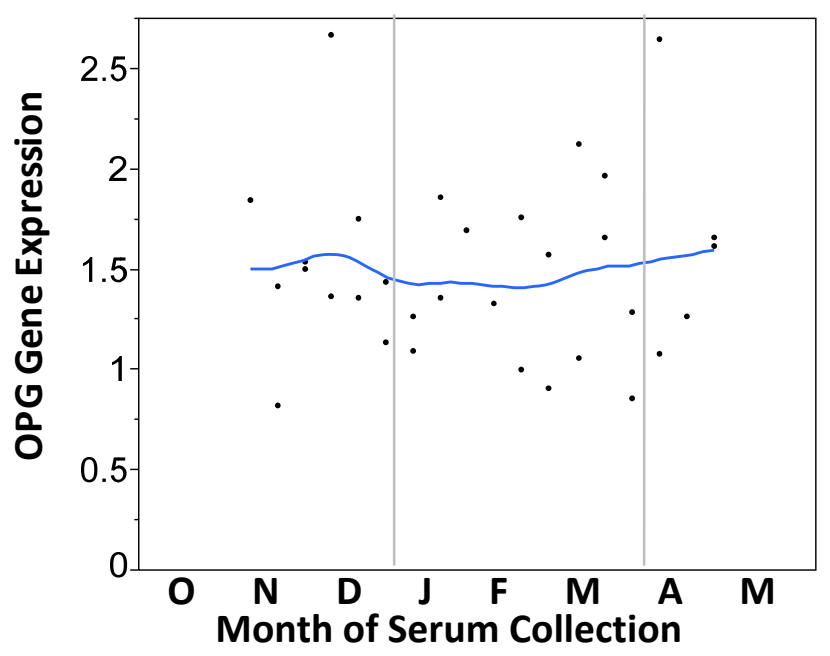

Figure 6.52-Longitudinal analysis of OPG gene expression in cells differentiated for 6 days in seasonal bear serum

MC3T3-E1 cells were differentiated in seasonal bear serum for 6 days, followed by real-time PCR quantification of relative gene expression. Each point represents the gene expression response from one serum sample. Vertical lines represent transitions between active and hibernating seasons. Samples are from 2 black bears in the 2006/07 season. 


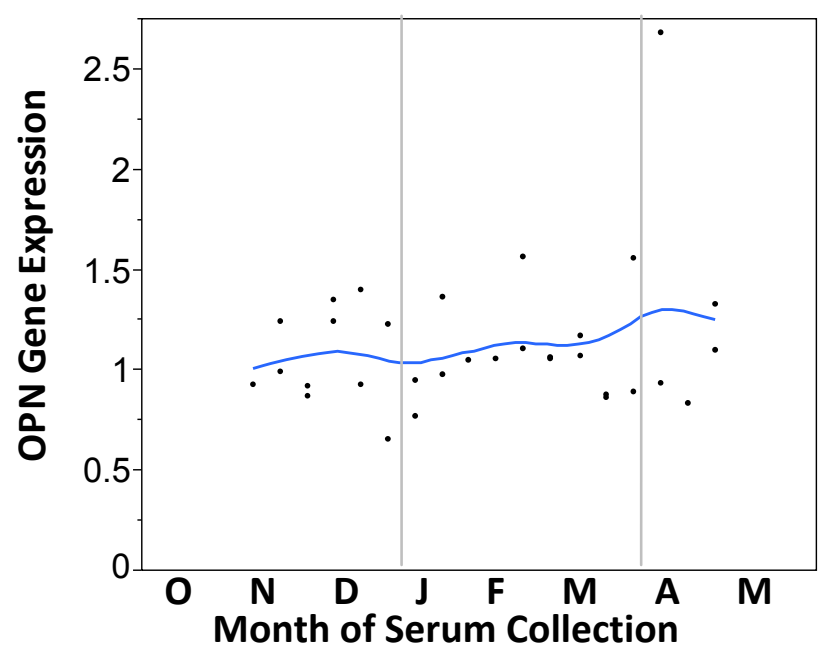

Figure 6.53-Longitudinal analysis of OPN gene expression in cells differentiated for 6 days in seasonal bear serum

MC3T3-E1 cells were differentiated in seasonal bear serum for 6 days, followed by real-time PCR quantification of relative gene expression. Each point represents the gene expression response from one serum sample. Vertical lines represent transitions between active and hibernating seasons. Samples are from 2 black bears in the 2006/07 season.

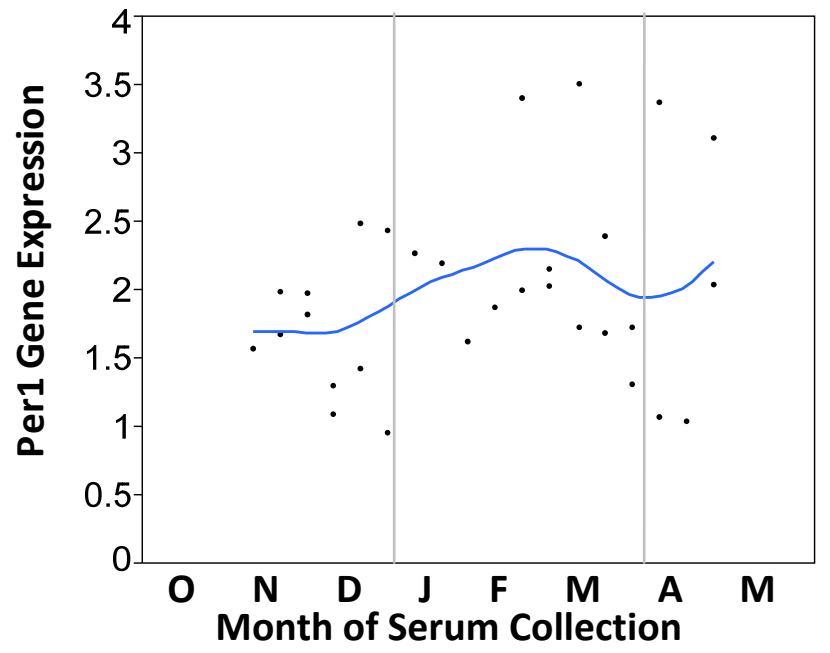

Figure 6.54-Longitudinal analysis of Per1 gene expression in cells differentiated for 6 days in seasonal bear serum

MC3T3-E1 cells were differentiated in seasonal bear serum for 6 days, followed by real-time PCR quantification of relative gene expression. Each point represents the gene expression response from one serum sample. Vertical lines represent transitions between active and hibernating seasons. Samples are from 2 black bears in the 2006/07 season. 


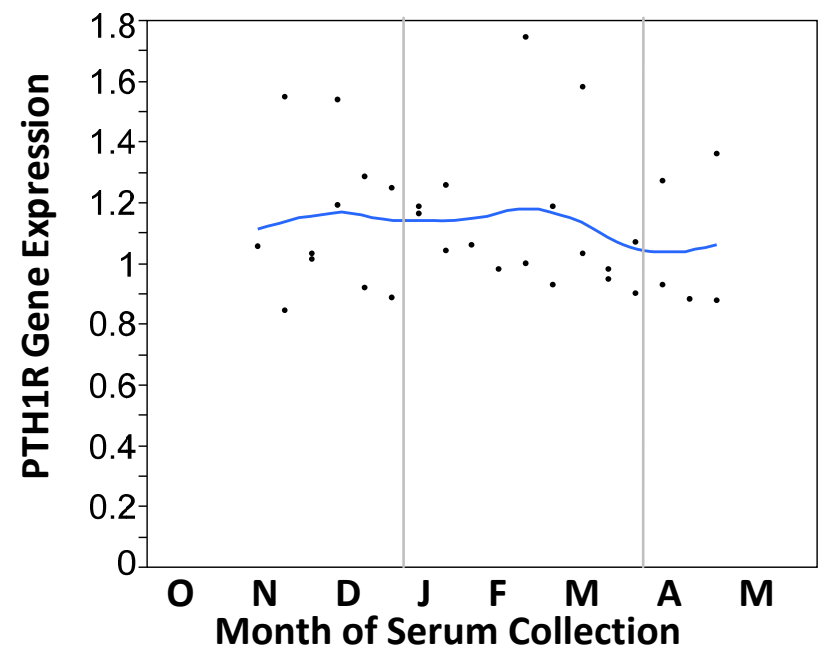

Figure 6.55—Longitudinal analysis of PTH1R gene expression in cells differentiated for 6 days in seasonal bear serum

MC3T3-E1 cells were differentiated in seasonal bear serum for 6 days, followed by real-time PCR quantification of relative gene expression. Each point represents the gene expression response from one serum sample. Vertical lines represent transitions between active and hibernating seasons. Samples are from 2 black bears in the 2006/07 season.

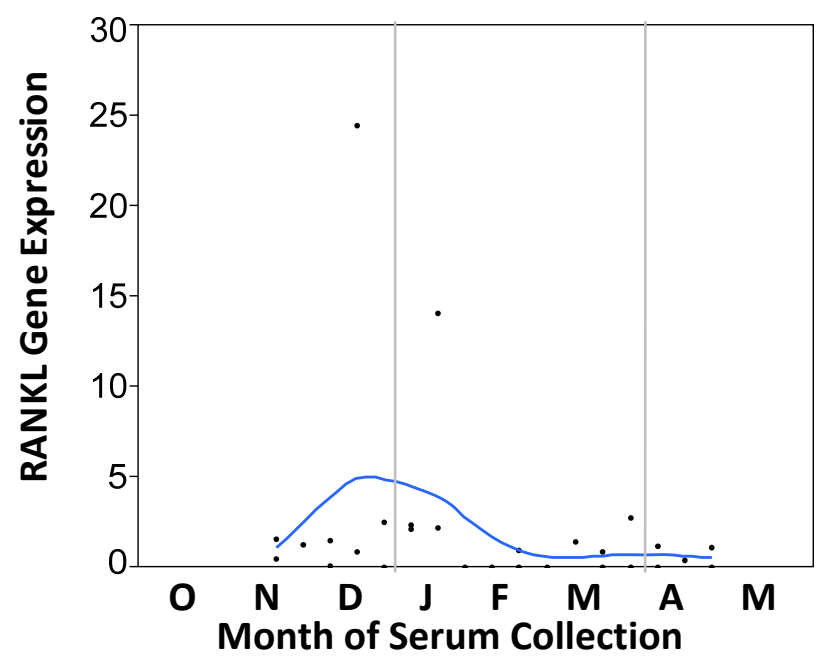

Figure 6.56-Longitudinal analysis of RANKL gene expression in cells differentiated for 6 days in seasonal bear serum

MC3T3-E1 cells were differentiated in seasonal bear serum for 6 days, followed by real-time PCR quantification of relative gene expression. Each point represents the gene expression response from one serum sample. Vertical lines represent transitions between active and hibernating seasons. Samples are from 2 black bears in the 2006/07 season. 


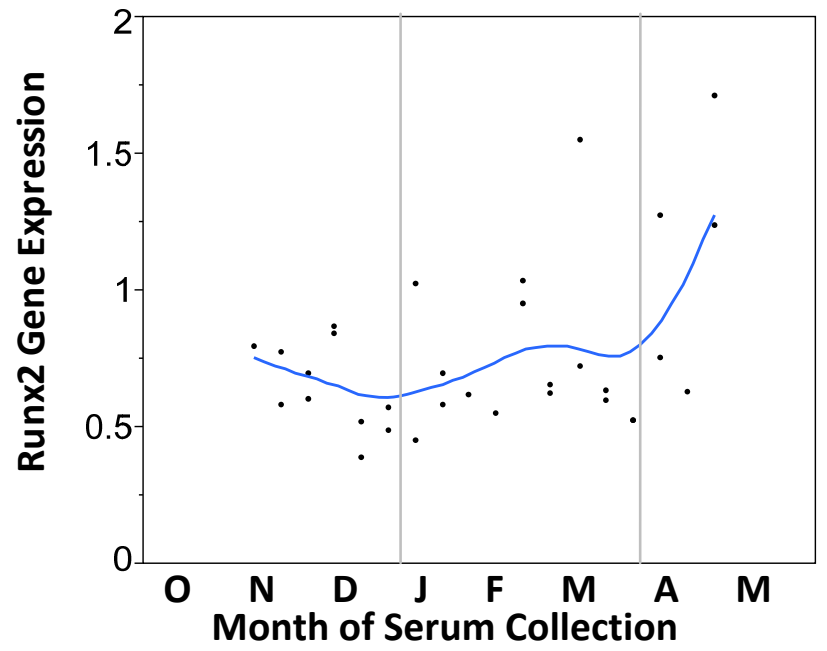

Figure 6.57-Longitudinal analysis of Runx2 gene expression in cells differentiated for 6 days in seasonal bear serum

MC3T3-E1 cells were differentiated in seasonal bear serum for 6 days, followed by real-time PCR quantification of relative gene expression. Each point represents the gene expression response from one serum sample. Vertical lines represent transitions between active and hibernating seasons. Samples are from 2 black bears in the 2006/07 season.

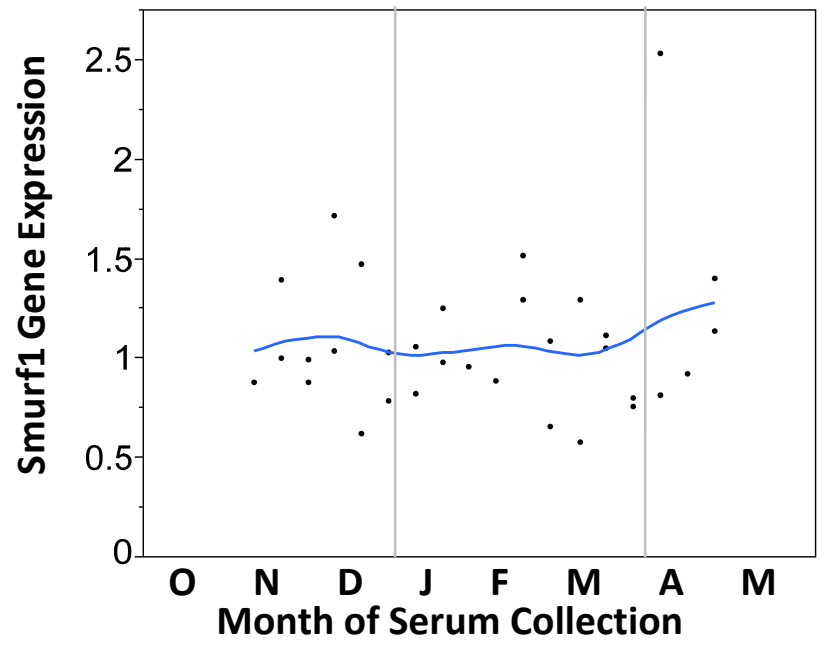

Figure 6.58-Longitudinal analysis of Smurf1 gene expression in cells differentiated for 6 days in seasonal bear serum

MC3T3-E1 cells were differentiated in seasonal bear serum for 6 days, followed by real-time PCR quantification of relative gene expression. Each point represents the gene expression response from one serum sample. Vertical lines represent transitions between active and hibernating seasons. Samples are from 2 black bears in the 2006/07 season. 


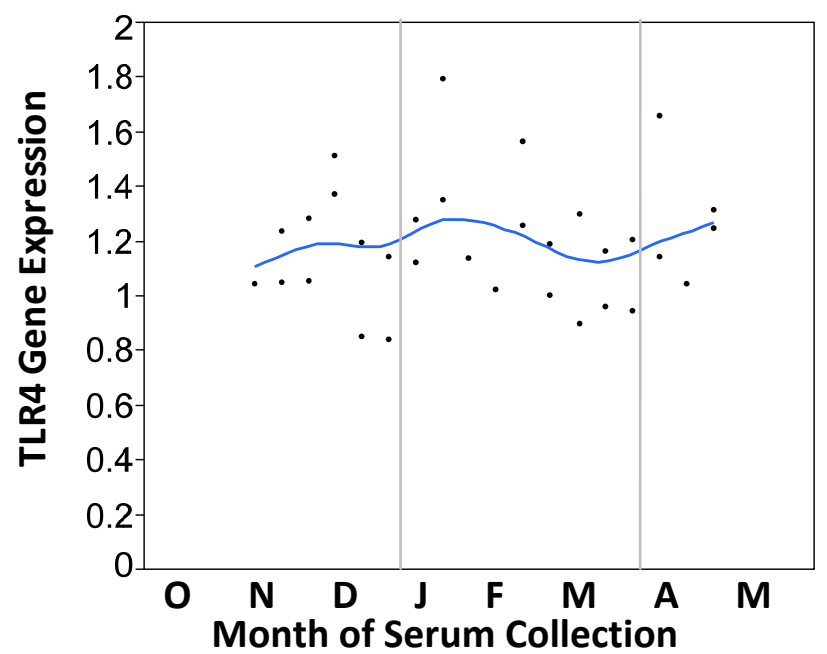

Figure 6.59-Longitudinal analysis of TLR4 gene expression in cells differentiated for 6 days in seasonal bear serum

MC3T3-E1 cells were differentiated in seasonal bear serum for 6 days, followed by real-time PCR quantification of relative gene expression. Each point represents the gene expression response from one serum sample. Vertical lines represent transitions between active and hibernating seasons. Samples are from 2 black bears in the 2006/07 season.

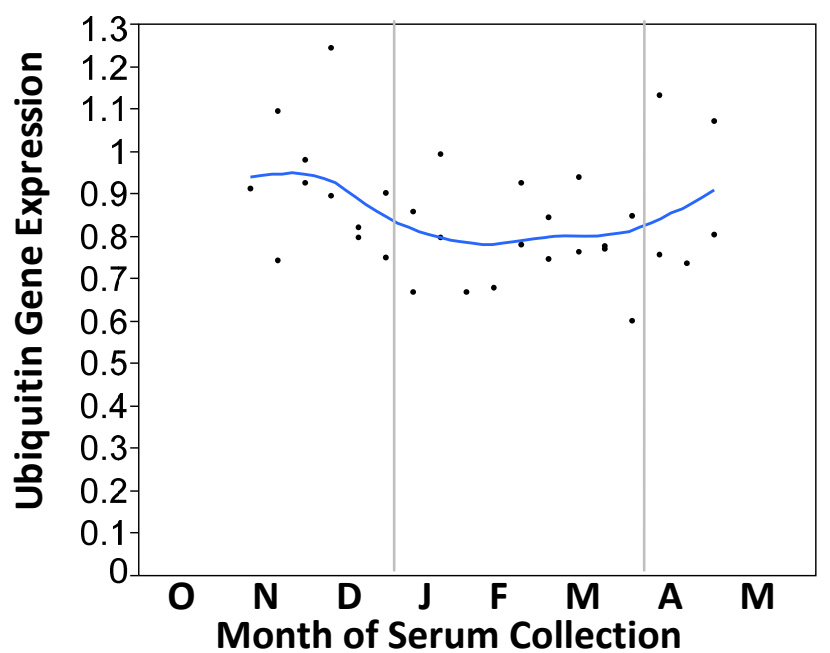

Figure 6.60-Longitudinal analysis of ubiquitin gene expression in cells differentiated for 6 days in seasonal bear serum

MC3T3-E1 cells were differentiated in seasonal bear serum for 6 days, followed by real-time PCR quantification of relative gene expression. Each point represents the gene expression response from one serum sample. Vertical lines represent transitions between active and hibernating seasons. Samples are from 2 black bears in the 2006/07 season. 


\section{Chapter Seven - Conclusion}

The long-term goal of this study is to identify the biological mechanism through which bears maintain bone despite the prolonged mechanical unloading of hibernation. This mechanism could bring insight into new signaling pathway targets for drug development in osteoporosis prevention. This study was broken down into three shortterm Aims. The first Aim was to determine whether serum markers of bone turnover confirmed previously published histomorphometric data $[18,20]$ to suggest that osteoclast and osteoblast activities decrease dramatically during hibernation. The bone formation marker OCN and the resorption marker ICTP both increase during hibernation [34], in apparent conflict with findings in histological studies. However, these turnover markers accumulate in patients with reduced renal function, and hibernating bears can be compared to renal patients because they do not urinate during hibernation. Therefore, serum levels of BSALP, an indicator of osteoblast activity, and TRACP, an indicator of osteoclast number, were quantified in active and hibernating American black bears. Neither of these serum markers is affected by renal function. The hypothesis was that levels of BSALP and TRACP in serum from hibernating bears would be lower compared to levels in active bear serum.

In support of the first hypothesis, this study found that serum BSALP and TRACP levels were significantly decreased during hibernation. These data are mentioned in Chapters 2 and 3. In Chapter 2, positive correlations between the energy homeostasis hormone adiponectin and serum turnover markers were discussed. Such correlations suggest that reduced levels of adiponectin during hibernation may be partially responsible for suppressing bone metabolism at this time of low energy expenditure. This finding supports previous studies which demonstrate a positive relationship between adiponectin and the activities of osteoblasts and osteoclasts [202, 203, 206].

Chapter 3 discusses an inverse correlation between serum levels of the energy homeostasis hormone NPY and bone turnover markers. These relationships suggest that raised levels of NPY may be partially responsible for suppressing bone metabolism during hibernation in bears. These data support a previous study which demonstrates a possible relationship between high serum NPY and adynamic bone disease [248], a 
condition in renal patients in which bone turnover is dramatically decreased. Other possible effectors of low bone turnover during hibernation were discussed in Chapter 3. These include decreased levels of IGF-1 and serotonin in the serum of bears during hibernation. It is likely that a combination of serum factors down-regulates bone metabolism in hibernating bears, and any of these serum factors would be interesting subjects of further study.

The second Aim of this study was to evaluate the inter-relationship of OCN and energy homeostasis hormones. Not only is OCN a vital component of bone's extracellular matrix, it can also act as an energy hormone-increasing adiponectin and insulin secretion and promoting glucose uptake in humans and other animals. In mice, this stimulatory effect on adiponectin and glucose is due to ucOCN [152]. The hypothesis was that total and ucOCN would increase in the serum of hibernating bears, with correlated increases in adiponectin and insulin and a correlated decrease in serum glucose. In Chapter 2, increased serum levels of OCN were reported, but levels of adiponectin and glucose were inversely correlated to total and ucOCN. Insulin levels likewise decreased during hibernation, but with no correlation to OCN. These data suggest that if $\mathrm{OCN}$ acts as an energy homeostasis hormone in bears in the months immediately surrounding and encompassing hibernation, then it does so in a previously unreported manner. It is possible that the unique physiological state of bears in this season is regulated by a unique interaction of $\mathrm{OCN}$ with energy homeostasis. Another surprising finding reported in Chapter 2 is that total and ucOCN were negatively correlated to serum serotonin, and glucose and adiponectin were positively correlated to serotonin. A correlation of serotonin to $\mathrm{OCN}$ has not been reported previously, and earlier studies on the relationship between serotonin and adiponectin would suggest an inverse relationship [189, 190]. Therefore, these relationships, too, may be due to the unique physiological state of the weeks surrounding and encompassing hibernation.

The third Aim of this study was to evaluate serum concentrations of antiapoptotic hormones (e.g. PTH, melatonin) and to determine whether the serum from hibernating bears had a protective effect on cultured osteoblasts submitted to an apoptotic threat. The hypothesis was that serum levels of these anti-apoptotic hormones would increase during hibernation in bears, and that osteoblasts cultured in serum from 
hibernating bears would have a suppressed response to apoptotic threat compared to cells cultured in serum from active bears. Chapter 4 reported that despite previous findings [34], serum PTH had no significant trend by season. The anti-resorptive cterminal fragment of PTH decreased during post-hibernation, which could increase bone metabolism as previously described in post-hibernation bears [35]. Melatonin was below quantifiable levels in all serum samples. Thus, the hormones quantified in this study did not support the hypothesis that hibernating bear serum provides an anti-apoptotic environment for osteoblasts, though many apoptosis regulators remain unquantified.

Despite the failure of the experiments in Chapter 4 to find anti-apoptotic conditions in the serum of hibernating bears, Chapter 5 reports that osteoblasts cultured in serum from hibernating bears were less responsive to apoptotic threat than cells cultured in serum from active bears. This finding was most pronounced in the suppressed caspase -3 and -7 response of osteoblasts grown in hibernating bear serum. A series of experiments were performed to characterize the hormone responsible for this reduced response. A filtration experiment suggested that the hormone of interest may be greater than $10 \mathrm{kD}$ in size, with reduced concentrations in hibernation serum. Serum adiponectin (which is greater than $10 \mathrm{kD}$ and has reduced levels during hibernation) was positively correlated to the caspase-3/7 response. Furthermore, caspase-3/7 response was positively correlated to gene expression of osteoblast differentiation markers OCN and Runx2, as well as to serum levels of BSALP. These correlations suggest that the reduction in caspase-3/7 may be partly due to the reduced differentiation potential of osteoblasts during hibernation. Caspase-3 activation is necessary for differentiation of osteoblasts [283, 284]. Hormonal fluctuations which could suppress osteoblast metabolism during hibernation, such as the reduction in adiponectin levels, may do so by suppressing caspase- 3 activation. Thus, the reduced caspase-3/7 response to apoptotic threat in osteoblasts cultured in hibernating bear serum may be an indication of reduced osteoblast differentiation potential.

The overlying theme of this report is that bone metabolism is decreased during hibernation, and this decrease could be modulated by an array of hormones. Such a decrease in bone metabolism during hibernation would be beneficial, because bears need to conserve as much energy as possible during the prolonged anorectic period of 
hibernation. This report brings to light several potential hormonal effectors of reduced bone turnover, but raises new questions. Is it possible to attenuate disuse-induced bone loss by inducing hypometabolic states in osteoblasts and osteoclasts? If so, such a mechanism could be applied to protect people who are at risk of disuse induced bone loss (e.g. paralyzed patients, astronauts, patients confined to long-term bed-rest, or submariners). Most current studies on the effects of reduced bone turnover on bone mechanical strength and structure suggest that this condition reduces bone strength and BMD; however, these studies tend to take place in young (i.e. rapidly growing) rodents, and there are no known studies on the effects of suppressing bone turnover in conditions of disuse. The hormones brought to light in this study may work together to desensitize bone to mechanical stimulus by inducing hypometabolic states in the osteoblasts and osteoclasts. Studying the effects of these hormones on mechanically unloaded bones could yield intriguing results. Therefore, this report has achieved one small step in the long-term goal to determine the mechanism through which bears maintain bone during hibernation and to develop a treatment for people at risk of disuse osteoporosis. 


\section{References}

1. LeBlanc, A.D., et al., Skeletal responses to space flight and the bed rest analog: a review. J Musculoskelet Neuronal Interact, 2007. 7(1): p. 33-47.

2. Giangregorio, L. and N. McCartney, Bone loss and muscle atrophy in spinal cord injury: epidemiology, fracture prediction, and rehabilitation strategies. J Spinal Cord Med, 2006. 29(5): p. 489-500.

3. Myint, P.K., K.E. Poole, and E.A. Warburton, Hip fractures after stroke and their prevention. Qjm, 2007. 100(9): p. 539-45.

4. Boonyapakorn, T., et al., Bisphosphonate-induced osteonecrosis of the jaws: Prospective study of 80 patients with multiple myeloma and other malignancies. Oral Oncol, 2008.

5. Rossouw, J.E., et al., Risks and benefits of estrogen plus progestin in healthy postmenopausal women: principal results From the Women's Health Initiative randomized controlled trial. Jama, 2002. 288(3): p. 321-33.

6. Anderson, G.L., et al., Effects of conjugated equine estrogen in postmenopausal women with hysterectomy: the Women's Health Initiative randomized controlled trial. Jama, 2004. 291(14): p. 1701-12.

7. Shumaker, S.A., et al., Conjugated equine estrogens and incidence of probable dementia and mild cognitive impairment in postmenopausal women: Women's Health Initiative Memory Study. Jama, 2004. 291(24): p. 2947-58.

8. Shumaker, S.A., et al., Estrogen plus progestin and the incidence of dementia and mild cognitive impairment in postmenopausal women: the Women's Health Initiative Memory Study: a randomized controlled trial. Jama, 2003. 289(20): p. 2651-62.

9. Abrahamsen, B., Adverse Effects of Bisphosphonates. Calcif Tissue Int, epub ahead of print 2010.

10. Hodsman, A.B., et al., Parathyroid hormone and teriparatide for the treatment of osteoporosis: a review of the evidence and suggested guidelines for its use. Endocr Rev, 2005. 26(5): p. 688-703.

11. Blick, S.K., S. Dhillon, and S.J. Keam, Spotlight on teriparatide in osteoporosis. BioDrugs, 2009. 23(3): p. 197-9.

12. Schuler, M. and D.R. Green, Mechanisms of p53-dependent apoptosis. Biochem Soc Trans, 2001. 29(Pt 6): p. 684-8.

13. Nelson, R.A., Winter sleep in the black bear. A physiologic and metabolic marvel. Mayo Clin Proc, 1973. 48(10): p. 733-7. 
14. Kaneps, A.J., S.M. Stover, and N.E. Lane, Changes in canine cortical and cancellous bone mechanical properties following immobilization and remobilization with exercise. Bone, 1997. 21(5): p. 419-23.

15. Allen, M.R., H.A. Hogan, and S.A. Bloomfield, Differential bone and muscle recovery following hindlimb unloading in skeletally mature male rats. $\mathrm{J}$ Musculoskelet Neuronal Interact, 2006. 6(3): p. 217-25.

16. Harvey, K.B., T.D. Drummer, and S.W. Donahue, The tensile strength of black bear (Ursus americanus) cortical bone is not compromised with aging despite annual periods of hibernation. J Biomech, 2005. 38(11): p. 2143-50.

17. Harvey, K.B. and S.W. Donahue, Bending properties, porosity, and ash fraction of black bear (Ursus americanus) cortical bone are not compromised with aging despite annual periods of disuse. J Biomech, 2004. 37(10): p. 1513-20.

18. McGee-Lawrence, M.E., et al., Grizzly bears (Ursus arctos horribilis) and black bears (Ursus americanus) prevent trabecular bone loss during disuse (hibernation). Bone, 2009. 45(6): p. 1186-91.

19. Pardy, C.K.W., G.R.; Ukrainetz, P.J.; Sawers, A.; Boyd, S.K.; Zernicke, R.F., Maintenance of bone mass and architecture in denning black bears (Ursus americanus). J. Zool. Lond., 2004. 263: p. 359-64.

20. McGee, M.E., et al., Decreased bone turnover with balanced resorption and formation prevent cortical bone loss during disuse (hibernation) in grizzly bears (Ursus arctos horribilis). Bone, 2008. 42(2): p. 396-404.

21. McGee-Lawrence, M.E., et al., Six months of disuse during hibernation does not increase intracortical porosity or decrease cortical bone geometry, strength, or mineralization in black bear (Ursus americanus) femurs. J Biomech, 2009. 42(10): p. 1378-83.

22. Robling, A.G., A.B. Castillo, and C.H. Turner, Biomechanical and molecular regulation of bone remodeling. Annu Rev Biomed Eng, 2006. 8: p. 455-98.

23. Sample, S.J., et al., Functional adaptation to loading of a single bone is neuronally regulated and involves multiple bones. J Bone Miner Res, 2008. 23(9): p. 1372-81.

24. Nijweide, P.B., EH. Klein Nulend, J. Van der Plas, A. , The osteocyte, in Principles of Bone Biology, J.R. Bilezikian, LG. Rodan, GA., Editor. 1996, New York: Academic. p. 115-26.

25. Burger, E.H. and J. Klein-Nulen, Responses of bone cells to biomechanical forces in vitro. Adv Dent Res, 1999. 13: p. 93-8.

26. Parfitt, A.M., The cellular basis of bone remodeling: the quantum concept reexamined in light of recent advances in the cell biology of bone. Calcif Tissue Int, 1984. 36 Suppl 1: p. S37-45. 
27. Rodan, G.A. and T.J. Martin, Role of osteoblasts in hormonal control of bone resorption--a hypothesis. Calcif Tissue Int, 1981. 33(4): p. 349-51.

28. Vaananen, K., Osteoclast function: bone biology and mechanisms. , in Principles of Bone Biology, J.R. Bilezikian, LG. Rodan, GA., Editor. 1996, New York: Academic. p. 103-13.

29. Parfitt, A.M., Quantum concept of bone remodeling and turnover: implications for the pathogenesis of osteoporosis. Calcif Tissue Int, 1979. 28(1): p. 1-5.

30. Parfitt, A.M., The mechanism of coupling: a role for the vasculature. Bone, 2000. 26(4): p. 319-23.

31. Caillot-Augusseau, A., et al., Bone formation and resorption biological markers in cosmonauts during and after a 180-day space flight (Euromir 95). Clin Chem, 1998. 44(3): p. 578-85.

32. Sato, Y., et al., Accelerated bone remodeling in patients with poststroke hemiplegia. J Stroke Cerebrovasc Dis, 1998. 7(1): p. 58-62.

33. Maimoun, L., et al., Use of bone biochemical markers with dual-energy x-ray absorptiometry for early determination of bone loss in persons with spinal cord injury. Metabolism, 2002. 51(8): p. 958-63.

34. Donahue, S.W., et al., Parathyroid hormone may maintain bone formation in hibernating black bears (Ursus americanus) to prevent disuse osteoporosis. J Exp Biol, 2006. 209(Pt 9): p. 1630-8.

35. Floyd, T., R.A. Nelson, and G.F. Wynne, Calcium and bone metabolic homeostasis in active and denning black bears (Ursus americanus). Clin Orthop Relat Res, 1990(255): p. 301-9.

36. Pace, N., et al., Effect of 14 days of bed rest on urine metabolite excretion and plasma enzyme levels. Life Sci Space Res, 1975. 13: p. 41-7.

37. Manolagas, S.C., Choreography from the tomb: An emerging role of dying osteocytes in the purposeful, and perhaps not so purposeful, targeting of bone remodeling. BoneKEy-Osteovision, 2006. 3(1): p. 5-14.

38. Burger, E.H., J. Klein-Nulend, and T.H. Smit, Strain-derived canalicular fluid flow regulates osteoclast activity in a remodelling osteon--a proposal. J Biomech, 2003. 36(10): p. 1453-9.

39. Kogianni, G., V. Mann, and B.S. Noble, Apoptotic bodies convey activity capable of initiating osteoclastogenesis and localized bone destruction. J Bone Miner Res, 2008. 23(6): p. 915-27.

40. Heino, T.J., et al., Evidence for the role of osteocytes in the initiation of targeted remodeling. Technol Health Care, 2009. 17(1): p. 49-56. 
41. Chowdhury, I., B. Tharakan, and G.K. Bhat, Current concepts in apoptosis: The physiological suicide program revisited. Cell Mol Biol Lett, 2006. 11(4): p. 506-25.

42. Pagliari, L.J., et al., The multidomain proapoptotic molecules Bax and Bak are directly activated by heat. Proc Natl Acad Sci U S A, 2005. 102(50): p. 17975-80.

43. Oltvai, Z.N., C.L. Milliman, and S.J. Korsmeyer, Bcl-2 heterodimerizes in vivo with a conserved homolog, Bax, that accelerates programmed cell death. Cell, 1993. 74(4): p. 609-19.

44. Burlacu, A., Regulation of apoptosis by Bcl-2 family proteins. J Cell Mol Med, 2003. 7(3): p. 249-57.

45. Fleck, C.C. and H.V. Carey, Modulation of apoptotic pathways in intestinal mucosa during hibernation. Am J Physiol Regul Integr Comp Physiol, 2005. 289(2): p. R586-R595.

46. Lesauskaite, V., et al., Apoptosis of cardiomyocytes in explanted and transplanted hearts. Comparison of results from in situ TUNEL, ISEL, and ISOL reactions. Am J Clin Pathol, 2004. 121(1): p. 108-16.

47. Hedgecock, N.L., et al., Quantitative regional associations between remodeling, modeling, and osteocyte apoptosis and density in rabbit tibial midshafts. Bone, 2007. 40(3): p. 627-37.

48. Aguirre, J.I., et al., Osteocyte apoptosis is induced by weightlessness in mice and precedes osteoclast recruitment and bone loss. J Bone Miner Res, 2006. 21(4): p. 605-15.

49. Bellido, T., et al., Proteasomal degradation of Runx2 shortens parathyroid hormone-induced anti-apoptotic signaling in osteoblasts. A putative explanation for why intermittent administration is needed for bone anabolism. J Biol Chem, 2003. 278(50): p. 50259-72.

50. Basso, N. and J.N. Heersche, Effects of hind limb unloading and reloading on nitric oxide synthase expression and apoptosis of osteocytes and chondrocytes. Bone, 2006. 39(4): p. 807-14.

51. Basso, N., et al., The effect of reloading on bone volume, osteoblast number, and osteoprogenitor characteristics: studies in hind limb unloaded rats. Bone, 2005. 37(3): p. 370-8.

52. Ishijima, M., et al., Osteopontin is associated with nuclear factor kappaB gene expression during tail-suspension-induced bone loss. Exp Cell Res, 2006. 312(16): p. 3075-83.

53. Sakai, A., et al., Disruption of the p53 gene results in preserved trabecular bone mass and bone formation after mechanical unloading. J Bone Miner Res, 2002. 17(1): p. 119-27. 
54. Dufour, C., X. Holy, and P.J. Marie, Skeletal unloading induces osteoblast apoptosis and targets alpha5beta1-PI3K-Bcl-2 signaling in rat bone. Exp Cell Res, 2007. 313(2): p. 394-403.

55. Jilka, R.L., et al., Increased bone formation by prevention of osteoblast apoptosis with parathyroid hormone. J Clin Invest, 1999. 104(4): p. 439-46.

56. Turner, R.T., et al., Dose-response effects of intermittent PTH on cancellous bone in hindlimb unloaded rats. J Bone Miner Res, 2007. 22(1): p. 64-71.

57. Kousteni, S., et al., Reversal of bone loss in mice by nongenotropic signaling of sex steroids. Science, 2002. 298(5594): p. 843-6.

58. Oktem, G., et al., Evaluation of the relationship between inducible nitric oxide synthase (iNOS) activity and effects of melatonin in experimental osteoporosis in the rat. Surg Radiol Anat, 2006. 28(2): p. 157-62.

59. Bikle, D.D., T. Sakata, and B.P. Halloran, The impact of skeletal unloading on bone formation. Gravit Space Biol Bull, 2003. 16(2): p. 45-54.

60. Rucci, N., et al., Modeled microgravity stimulates osteoclastogenesis and bone resorption by increasing osteoblast RANKL/OPG ratio. J Cell Biochem, 2007. 100(2): p. 464-73.

61. Nakamura, H., et al., Suppression of osteoblastic phenotypes and modulation of pro- and anti-apoptotic features in normal human osteoblastic cells under a vector-averaged gravity condition. J Med Dent Sci, 2003. 50(2): p. 167-76.

62. Bucaro, M.A., et al., The effect of simulated microgravity on osteoblasts is independent of the induction of apoptosis. J Cell Biochem, 2007. 102(2): p. 48395.

63. Reiman, M.P., M.E. Rogers, and R.C. Manske, Interlimb differences in lower extremity bone mineral density following anterior cruciate ligament reconstruction. J Orthop Sports Phys Ther, 2006. 36(11): p. 837-44.

64. Smith, S.M., et al., WISE-2005: supine treadmill exercise within lower body negative pressure and flywheel resistive exercise as a countermeasure to bed rest-induced bone loss in women during 60-day simulated microgravity. Bone, 2008. 42(3): p. 572-81.

65. Spector, E.R., S.M. Smith, and J.D. Sibonga, Skeletal effects of long-duration head-down bed rest. Aviat Space Environ Med, 2009. 80(5 Suppl): p. A23-8.

66. Yazicioglu, K., et al., Osteoporosis: A factor on residual limb pain in traumatic trans-tibial amputations. Prosthet Orthot Int, 2008. 32(2): p. 172-8.

67. Luria, T., et al., Effects of a prolonged submersion on bone strength and metabolism in young healthy submariners. Calcif Tissue Int, 2010. 86(1): p. 8-13. 
68. Ashe, M.C., et al., Bone geometric response to chronic disuse following stroke: a pQCT study. J Musculoskelet Neuronal Interact, 2006. 6(3): p. 226-33.

69. Pang, M.Y., M.C. Ashe, and J.J. Eng, Muscle weakness, spasticity and disuse contribute to demineralization and geometric changes in the radius following chronic stroke. Osteoporos Int, 2007. 18(9): p. 1243-52.

70. Maimoun, L., et al., Changes in osteoprotegerin/RANKL system, bone mineral density, and bone biochemicals markers in patients with recent spinal cord injury. Calcif Tissue Int, 2005. 76(6): p. 404-11.

71. Mulsow, J., G.C. O'Toole, and F. McManus, Traumatic lower limb fractures following complete spinal cord injury. Ir Med J, 2005. 98(5): p. 141-2.

72. Logan, W.C., Jr., et al., Incidence of fractures in a cohort of veterans with chronic multiple sclerosis or traumatic spinal cord injury. Arch Phys Med Rehabil, 2008. 89(2): p. 237-43.

73. Rubin, C., et al., Differentiation of the bone-tissue remodeling response to axial and torsional loading in the turkey ulna. J Bone Joint Surg Am, 1996. 78(10): p. 1523-33.

74. Qin, Y.X., C.T. Rubin, and K.J. McLeod, Nonlinear dependence of loading intensity and cycle number in the maintenance of bone mass and morphology. $\mathrm{J}$ Orthop Res, 1998. 16(4): p. 482-9.

75. Lanyon, L.E. and C.T. Rubin, Static vs dynamic loads as an influence on bone remodelling. J Biomech, 1984. 17(12): p. 897-905.

76. Foutz, T., A. Ratterman, and J. Halper, Effects of immobilization on the biomechanical properties of the broiler tibia and gastrocnemius tendon. Poult Sci, 2007. 86(5): p. 931-6.

77. Wimsatt, J., et al., Ultrasound therapy for the prevention and correction of contractures and bone mineral loss associated with wing bandaging in the domestic pigeon (Columba livia). J Zoo Wildl Med, 2000. 31(2): p. 190-5.

78. Freeman, K.P., et al., Right leg muscle atrophy and osteopenia caused by renal adenocarcinoma in a cockatiel (Melopsittacus, undulatus). Vet Radiol Ultrasound, 1999. 40(2): p. 144-7.

79. Thomas, T., et al., Ineffectiveness of calcitonin on a local-disuse osteoporosis in the sheep: a histomorphometric study. Calcif Tissue Int, 1995. 57(3): p. 224-8.

80. Rubin, C.T., et al., Ultrasonic measurement of immobilization-induced osteopenia: an experimental study in sheep. Calcif Tissue Int, 1988. 42(5): p. 309-12. 
81. Thomas, T., et al., Architectural modifications and cellular response during disuse-related bone loss in calcaneus of the sheep. J Appl Physiol, 1996. 80(1): p. 198-202.

82. Delguste, C., et al., Pharmacological effects of tiludronate in horses after longterm immobilization. Bone, 2007. 41(3): p. 414-21.

83. Williams, D.F., L.F. Gore, and G.C. Clark, Quantitative microradiography of cortical bone in disuse osteoporosis following fracture fixation. Biomaterials, 1983. 4(4): p. 285-8.

84. Waters, D.J., D.D. Caywood, and R.T. Turner, Effect of tamoxifen citrate on canine immobilization (disuse) osteoporosis. Vet Surg, 1991. 20(6): p. 392-6.

85. Grynpas, M.D., et al., The effect of pamidronate in a new model of immobilization in the dog. Bone, 1995. 17(4 Suppl): p. 225S-232S.

86. Wronski, T.J. and E.R. Morey, Inhibition of cortical and trabecular bone formation in the long bones of immobilized monkeys. Clin Orthop Relat Res, 1983(181): p. 269-76.

87. Young, D.R., et al., Immobilization-associated osteoporosis in primates. Bone, 1986. 7(2): p. 109-17.

88. Young, D.R., W.J. Niklowitz, and C.R. Steele, Tibial changes in experimental disuse osteoporosis in the monkey. Calcif Tissue Int, 1983. 35(3): p. 304-8.

89. Zerath, E., et al., Effects of spaceflight on bone mineralization in the rhesus monkey. J Appl Physiol, 1996. 81(1): p. 194-200.

90. Abram, A.C., T.S. Keller, and D.M. Spengler, The effects of simulated weightlessness on bone biomechanical and biochemical properties in the maturing rat. J Biomech, 1988. 21(9): p. 755-67.

91. Barou, O., et al., Bisphosphonate effects in rat unloaded hindlimb bone loss model: three-dimensional microcomputed tomographic, histomorphometric, and densitometric analyses. J Pharmacol Exp Ther, 1999. 291(1): p. 321-8.

92. Barou, O., et al., High-resolution three-dimensional micro-computed tomography detects bone loss and changes in trabecular architecture early: comparison with DEXA and bone histomorphometry in a rat model of disuse osteoporosis. Invest Radiol, 2002. 37(1): p. 40-6.

93. Bloomfield, S.A., et al., Site- and compartment-specific changes in bone with hindlimb unloading in mature adult rats. Bone, 2002. 31(1): p. 149-57.

94. Hefferan, T.E., et al., Effect of gender on bone turnover in adult rats during simulated weightlessness. J Appl Physiol, 2003. 95(5): p. 1775-80. 
95. Perrien, D.S., et al., Aging alters the skeletal response to disuse in the rat. Am J Physiol Regul Integr Comp Physiol, 2007. 292(2): p. R988-96.

96. Shaw, S.R., et al., Mechanical, morphological and biochemical adaptations of bone and muscle to hindlimb suspension and exercise. J Biomech, 1987. 20(3): p. 225-34.

97. van der Meulen, M.C., E.R. Morey-Holton, and D.R. Carter, Hindlimb suspension diminishes femoral cross-sectional growth in the rat. J Orthop Res, 1995. 13(5): p. 700-7.

98. Vico, L., et al., Bone histomorphometric comparison of rat tibial metaphysis after 7-day tail suspension vs. 7-day spaceflight. Aviat Space Environ Med, 1991. 62(1): p. 26-31.

99. Amblard, D., et al., Tail suspension induces bone loss in skeletally mature mice in the C57BL/6J strain but not in the C3H/HeJ strain. J Bone Miner Res, 2003. 18(3): p. 561-9.

100. Judex, S., et al., Genetically linked site-specificity of disuse osteoporosis. J Bone Miner Res, 2004. 19(4): p. 607-13.

101. Sakai, A. and T. Nakamura, Changes in trabecular bone turnover and bone marrow cell development in tail-suspended mice. J Musculoskelet Neuronal Interact, 2001. 1(4): p. 387-92.

102. Simske, S.J., A.R. Greenberg, and M.W. Luttges, Effects of suspension-induced osteopenia on the mechanical behaviour of mouse long bones. J Mater Sci Mater Med, 1991. 2(1): p. 43-50.

103. McGee-Lawrence, M.E., H.V. Carey, and S.W. Donahue, Mammalian hibernation as a model of disuse osteoporosis: the effects of physical inactivity on bone metabolism, structure, and strength. Am J Physiol Regul Integr Comp Physiol, 2008. 295(6): p. R1999-2014.

104. Krook, L., et al., Calcitonin and hibernation bone loss in the bat (Myotis lucifugus). Cornell Vet, 1977. 67(2): p. 265-71.

105. Steinberg, B., I.J. Singh, and O.G. Mitchell, The effects of cold-stress. Hibernation, and prolonged inactivity on bone dynamics in the golden hamster, Mesocricetus auratus. J Morphol, 1981. 167(1): p. 43-51.

106. Doty, S.B. and E.A. Nunez, Activation of osteoclasts and the repopulation of bone surfaces following hibernation in the bat, Myotis lucifugus. Anat Rec, 1985. 213(4): p. 481-95.

107. Steinberg, B., I.J. Singh, and O.G. Mitchell, An autoradiographic study of the uptake of tritiated proline by osteoblasts during hibernation. Histol Histopathol, 1986. 1(2): p. 155-60. 
108. Kwiecinski, G.G., L. Krook, and W.A. Wimsatt, Annual skeletal changes in the little brown bat, Myotis lucifugus lucifugus, with particular reference to pregnancy and lactation. Am J Anat, 1987. 178(4): p. 410-20.

109. Haller, A.C. and M.L. Zimny, Effects of hibernation on interradicular alveolar bone. J Dent Res, 1977. 56(12): p. 1552-7.

110. Utz, J.C., et al., Bone strength is maintained after 8 months of inactivity in hibernating golden-mantled ground squirrels, Spermophilus lateralis. J Exp Biol, 2009. 212(17): p. 2746-52.

111. Nelson, R.A., Protein and fat metabolism in hibernating bears. Fed Proc, 1980. 39(12): p. 2955-8.

112. Nelson, R.A., et al., Metabolism of bears before, during, and after winter sleep. Am J Physiol, 1973. 224(2): p. 491-6.

113. Brown, D.C., et al., Renal function in anesthetized dormant and active bears. Am J Physiol, 1971. 220(1): p. 293-8.

114. Nelson, R.A., et al., Nitrogen metabolism in bears: urea metabolism in summer starvation and in winter sleep and role of urinary bladder in water and nitrogen conservation. Mayo Clin Proc, 1975. 50(3): p. 141-6.

115. Carey, H.V., M.T. Andrews, and S.L. Martin, Mammalian hibernation: cellular and molecular responses to depressed metabolism and low temperature. Physiol Rev, 2003. 83(4): p. 1153-81.

116. Geiser, F., Metabolic rate and body temperature reduction during hibernation and daily torpor. Annu Rev Physiol, 2004. 66: p. 239-74.

117. Watts, P. and C. Cuyler, Metabolism of the black bear under simulated denning conditions. Acta Physiol Scand, 1988. 134(1): p. 149-52.

118. Zatzman, M.L., Renal and cardiovascular effects of hibernation and hypothermia. Cryobiology, 1984. 21(6): p. 593-614.

119. Zatzman, M.L. and F.E. South, Renal function of the awake and hibernating marmot Marmota flaviventris. Am J Physiol, 1972. 222(4): p. 1035-9.

120. Epperson, L.E. and S.L. Martin, Quantitative assessment of ground squirrel $m R N A$ levels in multiple stages of hibernation. Physiol Genomics, 2002. 10(2): p. 93-102.

121. French, A.R., Allometries of the durations of torpid and euthermic intervals during mammalian hibernation: a test of the theory of metabolic control of the timing of changes in body temperature. J Comp Physiol B, 1985. 156(1): p. 13-9. 
122. Lesser, R.W., et al., Renal regulation of urea excretion in arousing and homeothermic ground squirrels (Citellus columbianus). Comp Biochem Physiol, 1970. 36(2): p. 291-6.

123. Passmore, J.C., E.W. Pfeiffer, and J.R. Templeton, Urea excretion in the hibernating Columbian ground squirrel (Spermophilus columbianus). J Exp Zool, 1975. 192(1): p. 83-6.

124. Deavers, D.R. and X.J. Musacchia, Water metabolism and renal function during hibernation and hypothermia. Fed Proc, 1980. 39(12): p. 2969-73.

125. Bruce, D.S. and J.E. Wiebers, Calcium and phosphate levels in bats (Myotis lucifugus) as function of season and activity. Experientia, 1970. 26(6): p. 625-7.

126. Whalen, J.P., L. Krook, and E.A. Nunez, A radiographic and histologic study of bone in the active and hibernating bat (Myotis lucifugus). Anat Rec, 1972. 172(1): p. 97-108.

127. Weinreb, M., et al., Short-term healing kinetics of cortical and cancellous bone osteopenia induced by unloading during the reloading period in young rats. Virchows Arch, 1997. 431(6): p. 449-52.

128. Currey, J.D. and G. Butler, The mechanical properties of bone tissue in children. J Bone Joint Surg Am, 1975. 57(6): p. 810-4.

129. Gross, T.S. and C.T. Rubin, Uniformity of resorptive bone loss induced by disuse. J Orthop Res, 1995. 13(5): p. 708-14.

130. Jaworski, Z.F., M. Liskova-Kiar, and H.K. Uhthoff, Effect of long-term immobilisation on the pattern of bone loss in older dogs. J Bone Joint Surg Br, 1980. 62-B(1): p. 104-10.

131. Collet, P., et al., Effects of 1- and 6-month spaceflight on bone mass and biochemistry in two humans. Bone, 1997. 20(6): p. 547-51.

132. Vico, L., et al., Effects of long-term microgravity exposure on cancellous and cortical weight-bearing bones of cosmonauts. Lancet, 2000. 355(9215): p. 160711.

133. Donahue, S.W., et al., Bone formation is not impaired by hibernation (disuse) in black bears Ursus americanus. J Exp Biol, 2003. 206(Pt 23): p. 4233-9.

134. Donahue, S.W., et al., Serum markers of bone metabolism show bone loss in hibernating bears. Clin Orthop Relat Res, 2003(408): p. 295-301.

135. Nelson, R.A., Urea metabolism in the hibernating black bear. Kidney Int Suppl, 1978(8): p. S177-9.

136. Singer, M.A., Of mice and men and elephants: metabolic rate sets glomerular filtration rate. Am J Kidney Dis, 2001. 37(1): p. 164-178. 
137. Nelson, R.A., T.D. Beck, and D.L. Steiger, Ratio of serum urea to serum creatinine in wild black bears. Science, 1984. 226(4676): p. 841-2.

138. Wyss, M. and R. Kaddurah-Daouk, Creatine and creatinine metabolism. Physiol Rev, 2000. 80(3): p. 1107-213.

139. Salgado, J.V., et al., Monitoring renal function: measured and estimated glomerular filtration rates - a review. Braz J Med Biol Res, epub ahead of print 2010. 43(6): p. 528-36.

140. Chu, P., et al., Correlation between histomorphometric parameters of bone resorption and serum type $5 b$ tartrate-resistant acid phosphatase in uremic patients on maintenance hemodialysis. Am J Kidney Dis, 2003. 41(5): p. 1052-9.

141. Urena, P., et al., Serum pyridinoline as a specific marker of collagen breakdown and bone metabolism in hemodialysis patients. J Bone Miner Res, 1995. 10(6): p. 932-9.

142. Mazzaferro, S., et al., Diagnostic value of serum peptides of collagen synthesis and degradation in dialysis renal osteodystrophy. Nephrol Dial Transplant, 1995. 10(1): p. 52-8.

143. Withold, W., W. Friedrich, and S. Degenhardt, Serum bone alkaline phosphatase is superior to plasma levels of bone matrix proteins for assessment of bone metabolism in patients receiving renal transplants. Clin Chim Acta, 1997. 261(2): p. 105-15.

144. Coen, G., et al., Bone markers in the diagnosis of low turnover osteodystrophy in haemodialysis patients. Nephrol Dial Transplant, 1998. 13(9): p. 2294-302.

145. Jarava, C., et al., Bone alkaline phosphatase isoenzyme in renal osteodystrophy. Nephrol Dial Transplant, 1996. 11 Suppl 3: p. 43-6.

146. Delmas, P.D., Biochemical markers of bone turnover: methodology and clinical use in osteoporosis. Am J Med, 1991. 91(5B): p. 59S-63S.

147. Urena, P. and M.C. De Vernejoul, Circulating biochemical markers of bone remodeling in uremic patients. Kidney Int, 1999. 55(6): p. 2141-56.

148. Yamada, S., et al., Utility of serum tartrate-resistant acid phosphatase (TRACP5b) as a bone resorption marker in patients with chronic kidney disease: independence from renal dysfunction. Clin Endocrinol (Oxf), 2008. 69(2): p. 18996.

149. Shidara, K., et al., Serum levels of TRAP5b, a new bone resorption marker unaffected by renal dysfunction, as a useful marker of cortical bone loss in hemodialysis patients. Calcif Tissue Int, 2008. 82(4): p. 278-87.

150. Kawai, M., M.J. Devlin, and C.J. Rosen, Fat targets for skeletal health. Nat Rev Rheumatol, 2009. 5(7): p. 365-72. 
151. Confavreux, C.B., R.L. Levine, and G. Karsenty, A paradigm of integrative physiology, the crosstalk between bone and energy metabolisms. Mol Cell Endocrinol, 2009. 310(1-2): p. 21-9.

152. Lee, N.K., et al., Endocrine regulation of energy metabolism by the skeleton. Cell, 2007. 130(3): p. 456-69.

153. Ferron, M., et al., Osteocalcin differentially regulates beta cell and adipocyte gene expression and affects the development of metabolic diseases in wild-type mice. Proc Natl Acad Sci U S A, 2008. 105(13): p. 5266-70.

154. Yamauchi, M., et al., Relationships between undercarboxylated osteocalcin and vitamin $K$ intakes, bone turnover, and bone mineral density in healthy women. Clin Nutr, epub ahead of print 2010.

155. Karbowska, J. and Z. Kochan, Role of adiponectin in the regulation of carbohydrate and lipid metabolism. J Physiol Pharmacol, 2006. 57 Suppl 6: p. 103-13.

156. Huang, C.Y., et al., Adiponectin increases BMP-2 expression in osteoblasts via AdipoR receptor signaling pathway. J Cell Physiol, 2010. 224(2): p. 475-83.

157. Lee, H.W., et al., Adiponectin stimulates osteoblast differentiation through induction of COX2 in mesenchymal progenitor cells. Stem Cells, 2009. 27(9): p. 2254-62.

158. Kanazawa, I., et al., Adiponectin and AMP kinase activator stimulate proliferation, differentiation, and mineralization of osteoblastic MC3T3-E1 cells. BMC Cell Biol, 2007. 8: p. 51.

159. Lin DC, E.L., Schertenleib KW, Nelson OL, Robbins CT. Intermittent muscle activation in grizzly bears during hibernation: a strategy to prevent muscle atrophy? in Society for Neuroscience Annual Meeting Program. 2004. San Diego, CA.

160. Rubin, C., et al., Mechanical strain, induced noninvasively in the high-frequency domain, is anabolic to cancellous bone, but not cortical bone. Bone, 2002. 30(3): p. 445-52.

161. McGee, M.E.M., K.W.; Miller, D.L.; Maki, A.J.; Donahue, S.W., Despite annual periods of disuse (hibernation), cortical bone porosity decreases and ash fraction, cross-sectional properties, and mechanical properties increase with age in black bear feumrs. Engineering Fracture Mechanics, 2007. 74: p. 1942-52.

162. Emerton, K.B., et al., Osteocyte apoptosis and control of bone resorption following ovariectomy in mice. Bone, 2010. 46(3): p. 577-83.

163. van Breukelen, F., G. Krumschnabel, and J.E. Podrabsky, Vertebrate cell death in energy-limited conditions and how to avoid it: what we might learn from 
mammalian hibernators and other stress-tolerant vertebrates. Apoptosis, 2010. 15(3): p. 386-99.

164. Cai, D., et al., Akt phosphorylation and kinase activity are down-regulated during hibernation in the 13-lined ground squirrel. Brain Res, 2004. 1014(1-2): p. 14-21.

165. Eddy, S.F. and K.B. Storey, Differential expression of Akt, PPARgamma, and PGC-1 during hibernation in bats. Biochem Cell Biol, 2003. 81(4): p. 269-74.

166. Hillion, J.A., et al., Involvement of Akt in preconditioning-induced tolerance to ischemia in PC12 cells. J Cereb Blood Flow Metab, 2006. 26(10): p. 1323-31.

167. Kops, G.J., et al., Forkhead transcription factor FOXO3a protects quiescent cells from oxidative stress. Nature, 2002. 419(6904): p. 316-21.

168. Sato, T., et al., Testicular dynamics in Syrian hamsters exposed to both short photoperiod and low ambient temperature. Anat Histol Embryol, 2005. 34(4): p. 220-4.

169. Cerri, S., et al., Cell proliferation and death in the brain of active and hibernating frogs. J Anat, 2009. 215(2): p. 124-31.

170. Hassager, C., et al., The carboxy-terminal pyridinoline cross-linked telopeptide of type I collagen in serum as a marker of bone resorption: the effect of nandrolone decanoate and hormone replacement therapy. Calcif Tissue Int, 1994. 54(1): p. 30-3.

171. Eriksen, E.F., et al., Serum markers of type I collagen formation and degradation in metabolic bone disease: correlation with bone histomorphometry. J Bone Miner Res, 1993. 8(2): p. 127-32.

172. Sadowski, J.A., et al., Phylloquinone in plasma from elderly and young adults: factors influencing its concentration. Am J Clin Nutr, 1989. 50(1): p. 100-8.

173. Donahue, S.W., et al., Hibernating bears as a model for preventing disuse osteoporosis. J Biomech, 2006. 39(8): p. 1480-8.

174. McGee, M.E., et al., Black bear femoral geometry and cortical porosity are not adversely affected by ageing despite annual periods of disuse (hibernation). J Anat, 2007. 210(2): p. 160-9.

175. Zerwekh, J.E., et al., The effects of twelve weeks of bed rest on bone histology, biochemical markers of bone turnover, and calcium homeostasis in eleven normal subjects. J Bone Miner Res, 1998. 13(10): p. 1594-601.

176. Shackelford, L.C., et al., Resistance exercise as a countermeasure to disuseinduced bone loss. J Appl Physiol, 2004. 97(1): p. 119-29.

177. Loken, H.F., et al., Ultracentrifugal analysis of protein-bound and free calcium in human serum. J Biol Chem, 1960. 235: p. 3654-8. 
178. Toribara, T.Y., A.R. Terepka, and P.A. Dewey, The ultrafiltrable calcium of human serum. I. Ultrafiltration methods and normal values. J Clin Invest, 1957. 36(5): p. 738-48.

179. Katz, S. and I.M. Klotz, Interactions of calcium with serum albumin. Arch Biochem Biophys, 1953. 44(2): p. 351-61.

180. Pittas, A.G., et al., Association between serum osteocalcin and markers of metabolic phenotype. J Clin Endocrinol Metab, 2009. 94(3): p. 827-32.

181. Kindblom, J.M., et al., Plasma osteocalcin is inversely related to fat mass and plasma glucose in elderly Swedish men. J Bone Miner Res, 2009. 24(5): p. 78591.

182. Fernandez-Real, J.M., et al., The relationship of serum osteocalcin concentration to insulin secretion, sensitivity, and disposal with hypocaloric diet and resistance training. J Clin Endocrinol Metab, 2009. 94(1): p. 237-45.

183. Im, J.A., et al., Relationship between osteocalcin and glucose metabolism in postmenopausal women. Clin Chim Acta, 2008. 396(1-2): p. 66-9.

184. Shea, M.K., et al., Gamma-carboxylation of osteocalcin and insulin resistance in older men and women. Am J Clin Nutr, 2009. 90(5): p. 1230-5.

185. Saleem, U., T.H. Mosley, Jr., and I.J. Kullo, Serum osteocalcin is associated with measures of insulin resistance, adipokine levels, and the presence of metabolic syndrome. Arterioscler Thromb Vasc Biol, 2010. 30(7): p. 1474-8.

186. Richards, J.B., et al., Serum adiponectin and bone mineral density in women. J Clin Endocrinol Metab, 2007. 92(4): p. 1517-23.

187. Shetty, S., C.M. Kusminski, and P.E. Scherer, Adiponectin in health and disease: evaluation of adiponectin-targeted drug development strategies. Trends Pharmacol Sci, 2009. 30(5): p. 234-9.

188. Sibilia, V., et al., Linking chronic tryptophan deficiency with impaired bone metabolism and reduced bone accrual in growing rats. J Cell Biochem, 2009. 107(5): p. 890-8.

189. Nomura, S., et al., 5-HT2A receptor antagonist increases circulating adiponectin in patients with type 2 diabetes. Blood Coagul Fibrinolysis, 2005. 16(6): p. 423-8.

190. Uchida-Kitajima, S., et al., 5-Hydroxytryptamine $2 A$ receptor signaling cascade modulates adiponectin and plasminogen activator inhibitor 1 expression in adipose tissue. FEBS Lett, 2008. 582(20): p. 3037-44.

191. Wade, J.M., et al., Synergistic impairment of glucose homeostasis in ob/ob mice lacking functional serotonin 2C receptors. Endocrinology, 2008. 149(3): p. 95561. 
192. Lundberg, D.A., et al., Protein metabolism in the black bear before and during hibernation. Mayo Clin Proc, 1976. 51(11): p. 716-22.

193. Klain, G.J. and B.K. Whitten, Carbon dioxide fixation during hibernation and arousal from hibernation. Comp Biochem Physiol, 1968. 25(1): p. 363-6.

194. Combs, T.P., et al., Endogenous glucose production is inhibited by the adiposederived protein Acrp30. J Clin Invest, 2001. 108(12): p. 1875-81.

195. Combs, T.P., et al., A transgenic mouse with a deletion in the collagenous domain of adiponectin displays elevated circulating adiponectin and improved insulin sensitivity. Endocrinology, 2004. 145(1): p. 367-83.

196. Semple, R.K., et al., Elevated plasma adiponectin in humans with genetically defective insulin receptors. J Clin Endocrinol Metab, 2006. 91(8): p. 3219-23.

197. Leth, H., et al., Elevated levels of high-molecular-weight adiponectin in type 1 diabetes. J Clin Endocrinol Metab, 2008. 93(8): p. 3186-91.

198. Matsubara, M., S. Maruoka, and S. Katayose, Decreased plasma adiponectin concentrations in women with dyslipidemia. J Clin Endocrinol Metab, 2002. 87(6): p. 2764-9.

199. Jurimae, J., et al., Adiponectin is associated with bone mineral density in perimenopausal women. Horm Metab Res, 2005. 37(5): p. 297-302.

200. Lenchik, L., et al., Adiponectin as a novel determinant of bone mineral density and visceral fat. Bone, 2003. 33(4): p. 646-51.

201. Williams, G.A., et al., In vitro and in vivo effects of adiponectin on bone. Endocrinology, 2009. 150(8): p. 3603-10.

202. Luo, X.H., et al., Adiponectin stimulates human osteoblasts proliferation and differentiation via the MAPK signaling pathway. Exp Cell Res, 2005. 309(1): p. 99-109.

203. Peng, X.D., et al., Relationships between serum adiponectin, leptin, resistin, visfatin levels and bone mineral density, and bone biochemical markers in Chinese men. Clin Chim Acta, 2008. 387(1-2): p. 31-5.

204. Zhang, H., et al., Relationships between serum adiponectin, apelin, leptin, resistin, visfatin levels and bone mineral density, and bone biochemical markers in postmenopausal Chinese women. J Endocrinol Invest, epub ahead of print 2010.

205. Wu, N., et al., Relationships between serum adiponectin, leptin concentrations and bone mineral density, and bone biochemical markers in Chinese women. Clin Chim Acta, 2010. 411(9-10): p. 771-5. 
206. Luo, X.H., et al., Adiponectin stimulates RANKL and inhibits OPG expression in human osteoblasts through the MAPK signaling pathway. J Bone Miner Res, 2006. 21(10): p. 1648-56.

207. Sodi, R., et al., The circulating concentration and ratio of total and high molecular weight adiponectin in post-menopausal women with and without osteoporosis and its association with body mass index and biochemical markers of bone metabolism. Clin Biochem, 2009. 42(13-14): p. 1375-80.

208. Novak, J.F., J.D. Hayes, and S.K. Nishimoto, Plasmin-mediated proteolysis of osteocalcin. J Bone Miner Res, 1997. 12(7): p. 1035-42.

209. Garnero, P., et al., Characterization of immunoreactive forms of human osteocalcin generated in vivo and in vitro. J Bone Miner Res, 1994. 9(2): p. 25564.

210. Rosenquist, C., et al., Measurement of a more stable region of osteocalcin in serum by ELISA with two monoclonal antibodies. Clin Chem, 1995. 41(10): p. 1439-45.

211. Ishida, M. and S. Amano, Osteocalcin fragment in bone matrix enhances osteoclast maturation at a late stage of osteoclast differentiation. J Bone Miner Metab, 2004. 22(5): p. 415-29.

212. Cloos, P.A. and S. Christgau, Characterization of aged osteocalcin fragments derived from bone resorption. Clin Lab, 2004. 50(9-10): p. 585-98.

213. Pelleymounter, M.A., et al., Effects of the obese gene product on body weight regulation in ob/ob mice. Science, 1995. 269(5223): p. 540-3.

214. Niswender, K.D. and M.W. Schwartz, Insulin and leptin revisited: adiposity signals with overlapping physiological and intracellular signaling capabilities. Front Neuroendocrinol, 2003. 24(1): p. 1-10.

215. Martin, A., et al., Opposite effects of leptin on bone metabolism: a dosedependent balance related to energy intake and insulin-like growth factor-I pathway. Endocrinology, 2007. 148(7): p. 3419-25.

216. Martin, A., et al., Leptin modulates both resorption and formation while preventing disuse-induced bone loss in tail-suspended female rats. Endocrinology, 2005. 146(8): p. 3652-9.

217. Baek, K. and S.A. Bloomfield, Beta-adrenergic blockade and leptin replacement effectively mitigate disuse bone loss. J Bone Miner Res, 2009. 24(5): p. 792-9.

218. Baldock, P.A., et al., Novel role of $Y 1$ receptors in the coordinated regulation of bone and energy homeostasis. J Biol Chem, 2007. 282(26): p. 19092-102.

219. Gustafsson, B.I., et al., Serotonin and fluoxetine modulate bone cell function in vitro. J Cell Biochem, 2006. 98(1): p. 139-51. 
220. Kondo, $\mathrm{H}_{\text {., }}$ et al., Unloading induces osteoblastic cell suppression and osteoclastic cell activation to lead to bone loss via sympathetic nervous system. J Biol Chem, 2005. 280(34): p. 30192-200.

221. Li, S.H., et al., The stimulatory effect of insulin-like growth factor-1 on the proliferation, differentiation, and mineralisation of osteoblastic cells from Holstein cattle. Vet J, 2009. 179(3): p. 430-6.

222. Slootweg, M.C., et al., Osteoclast formation together with interleukin-6 production in mouse long bones is increased by insulin-like growth factor-I. J Endocrinol, 1992. 132(3): p. 433-8.

223. Mochizuki, H., et al., Insulin-like growth factor-I supports formation and activation of osteoclasts. Endocrinology, 1992. 131(3): p. 1075-80.

224. Hill, P.A., J.J. Reynolds, and M.C. Meikle, Osteoblasts mediate insulin-like growth factor-I and -II stimulation of osteoclast formation and function. Endocrinology, 1995. 136(1): p. 124-31.

225. Donahoo, W.T., et al., Leptin increases skeletal muscle lipoprotein lipase and postprandial lipid metabolism in mice. Metabolism, epub ahead of print 2010.

226. Akasaka, Y., et al., Direct evidence for leptin-induced lipid oxidation independent of long-form leptin receptor. Biochim Biophys Acta, 2010. 1801(10): p. 11151122.

227. Maffei, M., et al., Leptin levels in human and rodent: measurement of plasma leptin and ob RNA in obese and weight-reduced subjects. Nat Med, 1995. 1(11): p. $1155-61$.

228. Considine, R.V., et al., Serum immunoreactive-leptin concentrations in normalweight and obese humans. N Engl J Med, 1996. 334(5): p. 292-5.

229. Dagogo-Jack, S., et al., Plasma leptin and insulin relationships in obese and nonobese humans. Diabetes, 1996. 45(5): p. 695-8.

230. Marie, M., et al., Daily patterns of plasma leptin in sheep: effects of photoperiod and food intake. J Endocrinol, 2001. 170(1): p. 277-86.

231. Kronfeld-Schor, N., et al., Dissociation of leptin secretion and adiposity during prehibernatory fattening in little brown bats. Am J Physiol Regul Integr Comp Physiol, 2000. 279(4): p. R1277-81.

232. Nieminen, P., J. Asikainen, and H. Hyvarinen, Effects of seasonality and fasting on the plasma leptin and thyroxin levels of the raccoon dog (Nyctereutes procyonoides) and the blue fox (Alopex lagopus). J Exp Zool, 2001. 289(2): p. 109-18. 
233. Florant, G.L., et al., Fat-cell mass, serum leptin and adiponectin changes during weight gain and loss in yellow-bellied marmots (Marmota flaviventris). J Comp Physiol B, 2004. 174(8): p. 633-9.

234. Nieminen, P., et al., Seasonal weight regulation of the raccoon dog (Nyctereutes procyonoides): interactions between melatonin, leptin, ghrelin, and growth hormone. J Biol Rhythms, 2002. 17(2): p. 155-63.

235. Concannon, P., et al., Seasonal changes in serum leptin, food intake, and body weight in photoentrained woodchucks. Am J Physiol Regul Integr Comp Physiol, 2001. 281(3): p. R951-9.

236. Hissa, R., et al., Seasonal changes in fatty acids and leptin contents in the plasma of the European brown bear (Ursus arctos arctos). Ann Zool Fennici, 1998. 35: p. 215-224.

237. Tsubota, T., et al., Annual changes in serum leptin concentration in the adult female Japanese black bear (Ursus thibetanus japonicus). J Vet Med Sci, 2008. 70(12): p. 1399-403.

238. Schmidt, K.E. and K.M. Kelley, Down-regulation in the insulin-like growth factor (IGF) axis during hibernation in the golden-mantled ground squirrel, Spermophilus lateralis: IGF-I and the IGF-binding proteins (IGFBPs). J Exp Zool, 2001. 289(1): p. 66-73.

239. Bielohuby, M., et al., Short-term exposure to low-carbohydrate, high-fat diets induces low bone mineral density and reduces bone formation in rats. J Bone Miner Res, 2010. 25(2): p. 275-84.

240. Roach, H.I., et al., Temporal analysis of rat growth plates: cessation of growth with age despite presence of a physis. J Histochem Cytochem, 2003. 51(3): p. 373-83.

241. Bourrin, S., et al., Dietary protein restriction lowers plasma insulin-like growth factor I (IGF-I), impairs cortical bone formation, and induces osteoblastic resistance to IGF-I in adult female rats. Endocrinology, 2000. 141(9): p. 3149-55.

242. Ammann, P., J.P. Bonjour, and R. Rizzoli, Essential amino acid supplements increase muscle weight, bone mass and bone strength in adult osteoporotic rats. J Musculoskelet Neuronal Interact, 2000. 1(1): p. 43-4.

243. Ammann, P., et al., Protein undernutrition-induced bone loss is associated with decreased IGF-I levels and estrogen deficiency. J Bone Miner Res, 2000. 15(4): p. 683-90.

244. Sanchez, C.P., et al., Growth hormone and the skeleton in pediatric renal allograft recipients. Pediatr Nephrol, 2002. 17(5): p. 322-8. 
245. Amano, S., et al., Inhibitory effect of NPY on isoprenaline-induced osteoclastogenesis in mouse bone marrow cells. Biochim Biophys Acta, 2007. 1770(6): p. 966-73.

246. Igwe, J.C., et al., Neuropeptide $Y$ is expressed by osteocytes and can inhibit osteoblastic activity. J Cell Biochem, 2009. 108(3): p. 621-30.

247. Stridsberg, M. and G. Lundqvist, Radioimmunoassay of neuropeptide Y (NPY) in biological fluids. Circulating NPY levels depend on renal function. Clin Chim Acta, 1989. 185(1): p. 61-71.

248. Panuccio, V., et al., Neuropeptide $Y$ and markers of osteoblast activity in dialysis patients: a cross-sectional study. Am J Kidney Dis, 2007. 50(6): p. 1001-8.

249. Reid, M.S., et al., Monoaminc and metabolite levels in the cerebrospinal fluid of hibernating and euthermic marmots. J Sleep Res, 1992. 1(1): p. 45-50.

250. Mann, J.J., et al., Relationship between central and peripheral serotonin indexes in depressed and suicidal psychiatric inpatients. Arch Gen Psychiatry, 1992. 49(6): p. 442-6.

251. Warden, S.J., et al., The emerging role of serotonin (5-hydroxytryptamine) in the skeleton and its mediation of the skeletal effects of low-density lipoprotein receptor-related protein 5 (LRP5). Bone, 2010. 46(1): p. 4-12.

252. Dark, J., et al., Noradrenaline-induced lipolysis in adipose tissue is suppressed at hibernation temperatures in ground squirrels. J Neuroendocrinol, 2003. 15(5): p. 451-8.

253. Uslu, S., et al., Constructive effect of exogenous melatonin against osteoporosis after ovariectomy in rats. Anal Quant Cytol Histol, 2007. 29(5): p. 317-25.

254. McMillin, J.M., et al., Annual testosterone rhythm in the black bear (Ursus americanus). Biol Reprod, 1976. 15(2): p. 163-7.

255. Palmer, S.S., et al., Annual changes in serum sex steroids in male and female black (Ursus americanus) and polar (Ursus maritimus) bears. Biol Reprod, 1988. 38(5): p. 1044-50.

256. Tsubota, T., et al., Sex steroid and prolactin profiles in male American black bears (Ursus americanus) during denning. J Vet Med Sci, 1999. 61(1): p. 81-3.

257. Wiren, K.M., et al., Targeting of androgen receptor in bone reveals a lack of androgen anabolic action and inhibition of osteogenesis: a model for compartment-specific androgen action in the skeleton. Bone, 2008. 43(3): p. 44051.

258. Chen, X., et al., 17beta-estradiol combined with testosterone promotes chicken osteoblast proliferation and differentiation by accelerating the cell cycle and inhibiting apoptosis in vitro. Vet Res Commun, 2010. 34(2): p. 143-52. 
259. Bhasin, S., et al., Older men are as responsive as young men to the anabolic effects of graded doses of testosterone on the skeletal muscle. J Clin Endocrinol Metab, 2005. 90(2): p. 678-88.

260. Ahn, K.H., et al., Effect of adiponectin and sex steroid hormones on bone mineral density and bone formation markers in postmenopausal women with subclinical hyperthyroidism. J Obstet Gynaecol Res, 2010. 36(2): p. 370-6.

261. Liu, S.Z., et al., Analysis of correlation between blood biochemical indicators and bone mineral density of post-menopausal women. Mol Biol Rep, epub ahead of print 2010.

262. Seger, R.L., Elucidating the mechanism for maintaining eucalcemia despite immobility and anuria in the hibernating black bear (Ursus americanus), in Department of Ecology and Environmental Science. 2008, University of Maine. p. 96.

263. D'Amour, P. and J.H. Brossard, Carboxyl-terminal parathyroid hormone fragments: role in parathyroid hormone physiopathology. Curr Opin Nephrol Hypertens, 2005. 14(4): p. 330-6.

264. Yasuma, Y., et al., Effects of plasma from hibernating ground squirrels on monocyte-endothelial cell adhesive interactions. Am J Physiol, 1997. 273(6 Pt 2): p. R1861-9.

265. Fuster, G., et al., Antiproteolytic effects of plasma from hibernating bears: a new approach for muscle wasting therapy? Clin Nutr, 2007. 26(5): p. 658-61.

266. Abdallah, B.M., et al., Inhibition of osteoblast differentiation but not adipocyte differentiation of mesenchymal stem cells by sera obtained from aged females. Bone, 2006. 39(1): p. 181-8.

267. Chen, N.X., et al., Phosphorus and uremic serum up-regulate osteopontin expression in vascular smooth muscle cells. Kidney Int, 2002. 62(5): p. 1724-31.

268. Franceschi, R.T. and B.S. Iyer, Relationship between collagen synthesis and expression of the osteoblast phenotype in MC3T3-E1 cells. J Bone Miner Res, 1992. 7(2): p. 235-46.

269. Pfaffl, M.W., A new mathematical model for relative quantification in real-time RT-PCR. Nucleic Acids Res, 2001. 29(9): p. e45.

270. Bliziotes, M., et al., Serotonin transporter and receptor expression in osteocytic MLO-Y4 cells. Bone, 2006. 39(6): p. 1313-21.

271. Murrills, R.J., et al., Parathyroid hormone synergizes with non-cyclic AMP pathways to activate the cyclic AMP response element. J Cell Biochem, 2009. 106(5): p. 887-95. 
272. Mrak, E., et al., Calcitonin gene-related peptide (CGRP) inhibits apoptosis in human osteoblasts by ss-catenin stabilization. J Cell Physiol, epub ahead of print 2010.

273. $\mathrm{Li}, \mathrm{H}$., et al., beta2- and beta3-, but not beta1-adrenergic receptors are involved in osteogenesis of mouse mesenchymal stem cells via cAMP/PKA signaling. Arch Biochem Biophys, 2010. 496(2): p. 77-83.

274. Franceschi, R.T., et al., Multiple signaling pathways converge on the Cbfa1/Runx2 transcription factor to regulate osteoblast differentiation. Connect Tissue Res, 2003. 44 Suppl 1: p. 109-16.

275. Tobimatsu, T., et al., Parathyroid hormone increases beta-catenin levels through Smad3 in mouse osteoblastic cells. Endocrinology, 2006. 147(5): p. 2583-90.

276. Chae, H.J., et al., Cyclic-AMP inhibits nitric oxide-induced apoptosis in human osteoblast: the regulation of caspase-3, $-6,-9$ and the release of cytochrome $c$ in nitric oxide-induced apoptosis by cAMP. Biol Pharm Bull, 2001. 24(5): p. 453-60.

277. Waters, K.M., et al., DNA microarray analysis reveals a role for lysophosphatidic acid in the regulation of anti-inflammatory genes in MC3T3-E1 cells. Bone, 2007. 41(5): p. 833-41.

278. Lajeunesse, D., et al., Influence of aluminum on the regulation of PTH- and 1,25(OH)2D3-dependent pathways in the rat osteosarcoma cell line ROS 17/2.8. J Bone Miner Res, 1998. 13(6): p. 962-9.

279. Radio, N.M., J.S. Doctor, and P.A. Witt-Enderby, Melatonin enhances alkaline phosphatase activity in differentiating human adult mesenchymal stem cells grown in osteogenic medium via MT2 melatonin receptors and the MEK/ERK (1/2) signaling cascade. J Pineal Res, 2006. 40(4): p. 332-42.

280. Suzuki, A., et al., Regulation of alkaline phosphatase activity by p38 MAP kinase in response to activation of Gi protein-coupled receptors by epinephrine in osteoblast-like cells. Endocrinology, 1999. 140(7): p. 3177-82.

281. Grey, A., et al., The phospholipids sphingosine-1-phosphate and lysophosphatidic acid prevent apoptosis in osteoblastic cells via a signaling pathway involving $\mathrm{G}$ (i) proteins and phosphatidylinositol-3 kinase. Endocrinology, 2002. 143(12): p. 4755-63.

282. Zhang, X. and L.P. Zanello, Vitamin $D$ receptor-dependent 1 alpha,25(OH)2 vitamin D3-induced anti-apoptotic PI3KJAKT signaling in osteoblasts. J Bone Miner Res, 2008. 23(8): p. 1238-48.

283. Mogi, M., et al., Dual roles for NF-kappaB activation in osteoblastic cells by serum deprivation: osteoblastic apoptosis and cell-cycle arrest. Bone, 2004. 35(2): p. 507-16. 
284. Miura, M., et al., A crucial role of caspase-3 in osteogenic differentiation of bone marrow stromal stem cells. J Clin Invest, 2004. 114(12): p. 1704-13.

285. Sancar, A., et al., Circadian clock control of the cellular response to DNA damage. FEBS Lett, 2010. 584(12): p. 2618-25.

286. Fu, M., et al., Minireview: Cyclin D1: normal and abnormal functions. Endocrinology, 2004. 145(12): p. 5439-47.

287. Sherr, C.J., Cancer cell cycles. Science, 1996. 274(5293): p. 1672-7.

288. Fu, L., et al., The circadian gene Period2 plays an important role in tumor suppression and DNA damage response in vivo. Cell, 2002. 111(1): p. 41-50.

289. Rana, S. and S. Mahmood, Circadian rhythm and its role in malignancy. J Circadian Rhythms, 2010. 8: p. 3.

290. Gery, S., et al., The circadian gene per1 plays an important role in cell growth and DNA damage control in human cancer cells. Mol Cell, 2006. 22(3): p. 37582.

291. Komori, T., Regulation of bone development and extracellular matrix protein genes by RUNX2. Cell Tissue Res, 2010. 339(1): p. 189-95.

292. Xing, L., M. Zhang, and D. Chen, Smurf control in bone cells. J Cell Biochem, 2010. 110(3): p. 554-63.

293. Zhao, M., et al., E3 ubiquitin ligase Smurf1 mediates core-binding factor alpha1/Runx2 degradation and plays a specific role in osteoblast differentiation. J Biol Chem, 2003. 278(30): p. 27939-44.

294. Yamashita, M., et al., Ubiquitin ligase Smurf1 controls osteoblast activity and bone homeostasis by targeting MEKK2 for degradation. Cell, 2005. 121(1): p. 101-13.

295. Grigoriadis, A.E., Z.Q. Wang, and E.F. Wagner, Fos and bone cell development: lessons from a nuclear oncogene. Trends Genet, 1995. 11(11): p. 436-41.

296. Demiralp, B., et al., Anabolic actions of parathyroid hormone during bone growth are dependent on c-fos. Endocrinology, 2002. 143(10): p. 4038-47.

297. McCauley, L.K., et al., Proto-oncogene c-fos is transcriptionally regulated by parathyroid hormone (PTH) and PTH-related protein in a cyclic adenosine monophosphate-dependent manner in osteoblastic cells. Endocrinology, 1997. 138(12): p. 5427-33.

298. Deftos, L.J., Bone protein and peptide assays in the diagnosis and management of skeletal disease. Clin Chem, 1991. 37(7): p. 1143-8. 
299. Wright, H.L., et al., RANK, RANKL and osteoprotegerin in bone biology and disease. Curr Rev Musculoskelet Med, 2009. 2(1): p. 56-64.

300. Yavropoulou, M.P. and J.G. Yovos, Osteoclastogenesis--current knowledge and future perspectives. J Musculoskelet Neuronal Interact, 2008. 8(3): p. 204-16.

301. Kikuchi, T., et al., Gene expression of osteoclast differentiation factor is induced by lipopolysaccharide in mouse osteoblasts via Toll-like receptors. J Immunol, 2001. 166(5): p. 3574-9.

302. Kim, Y.S., et al., Increased circulating heat shock protein 60 induced by menopause, stimulates apoptosis of osteoblast-lineage cells via up-regulation of toll-like receptors. Bone, 2009. 45(1): p. 68-76.

303. Peterson, W.J., K.H. Tachiki, and D.T. Yamaguchi, Serial passage of MC3T3-E1 cells down-regulates proliferation during osteogenesis in vitro. Cell Prolif, 2004. 37(5): p. 325-36.

304. Wang, D., et al., Isolation and characterization of MC3T3-E1 preosteoblast subclones with distinct in vitro and in vivo differentiation/mineralization potential. J Bone Miner Res, 1999. 14(6): p. 893-903.

305. Vandesompele, J., et al., Accurate normalization of real-time quantitative RTPCR data by geometric averaging of multiple internal control genes. Genome Biol, 2002. 3(7): p. RESEARCH0034.

306. Obaya, A.J. and J.M. Sedivy, Regulation of cyclin-Cdk activity in mammalian cells. Cell Mol Life Sci, 2002. 59(1): p. 126-42.

307. Ho, M.S., et al., The utility F-box for protein destruction. Cell Mol Life Sci, 2008. 65(13): p. 1977-2000.

308. Liao, Y. and M.C. Hung, Physiological regulation of Akt activity and stability. Am J Transl Res, 2010. 2(1): p. 19-42. 


\section{Appendix A-Complete tables of correlations}

Table A.1-Complete list of TRACP correlations

\begin{tabular}{ccccccc}
$\begin{array}{c}\text { Dep. } \\
\text { Variable }\end{array}$ & $\begin{array}{c}\text { Indep. } \\
\text { Variable }\end{array}$ & $\mathbf{N}_{\text {bears }}$ & $\boldsymbol{\beta}$ & $\mathbf{r}$ & $\mathbf{p}$ & Power \\
\hline BSALP & TRACP & 9 & 22.7 & 0.723 & $<0.0001$ & 1 \\
Total ALP & TRACP & 9 & 25.4 & 0.726 & $<0.0001$ & 1 \\
TRACP & Adiponectin & 9 & 0.000117 & 0.430 & 0.0222 & 0.6313 \\
TRACP & NPY & 8 & -0.00328 & -0.528 & $<0.0001$ & 0.9986 \\
PTH1R Gene & & & & & & \\
Expression & TRACP & 4 & -0.216 & -0.602 & 0.0267 & 0.6088 \\
24hr UD & & & & & &
\end{tabular}

Table A.2-Complete list of BSAP correlations

\begin{tabular}{ccccccc}
$\begin{array}{c}\text { Dep. } \\
\text { Variable }\end{array}$ & $\begin{array}{c}\text { Indep. } \\
\text { Variable }\end{array}$ & $\mathbf{N}_{\text {bears }}$ & $\boldsymbol{\beta}$ & $\mathbf{r}$ & $\mathbf{p}$ & Power \\
\hline BSALP & TRACP & 9 & 22.7 & 0.723 & $<0.0001$ & 1 \\
Total ALP & BSALP & 9 & 1.076 & 0.981 & $<0.0001$ & 1 \\
BSALP & Total Calcium & 4 & -5.79 & -0.687 & 0.0307 & 0.6000 \\
BSALP & Adiponectin & 9 & 0.00676 & 0.627 & 0.0012 & 0.9077 \\
BSALP & Glucose & 9 & 0.0524 & 0.602 & 0.0290 & 0.5917 \\
BSALP & NPY & 8 & -0.128 & -0.713 & $<0.0001$ & 0.9990 \\
BSALP & Albumin & 4 & -7.82 & -0.753 & 0.0034 & 0.8838 \\
BSALP & Total Protein & 4 & -6.10 & -0.794 & 0.0006 & 0.9699 \\
Globulin & BSALP & 4 & -0.0283 & -0.748 & 0.0209 & 0.6652 \\
BSALP & AST/ALT & 4 & 5.91 & 0.712 & 0.0089 & 0.7855 \\
BSALP & Sodium & 4 & 1.08 & 0.695 & 0.0244 & 0.6396 \\
BSALP & Chloride & 4 & 0.994 & 0.703 & 0.0192 & 0.6788 \\
Caspase-3/7 & BSALP & 4 & 0.130 & 0.728 & 0.0066 & 0.8214
\end{tabular}


Table A.3-Complete list of total ALP correlations

\begin{tabular}{ccccccc}
$\begin{array}{c}\text { Dep. } \\
\text { Variable }\end{array}$ & $\begin{array}{c}\text { Indep. } \\
\text { Variable }\end{array}$ & $\mathbf{N}_{\text {bears }}$ & $\boldsymbol{\beta}$ & $\mathbf{r}$ & $\mathbf{p}$ & Power \\
\hline Total ALP & TRACP & 9 & 25.4 & 0.726 & $<0.0001$ & 1 \\
Total ALP & BSALP & 9 & 1.076 & 0.981 & $<0.0001$ & 1 \\
Total ALP & Adiponectin & 9 & 0.00840 & 0.638 & 0.0003 & 0.9611 \\
Insulin & Total ALP & 9 & 0.0344 & 0.686 & 0.0112 & 0.7235 \\
Total ALP & NPY & 8 & -0.146 & -0.718 & $<0.0001$ & 0.9995 \\
Total ALP & Albumin & 4 & -9.23 & -0.744 & 0.0018 & 0.9288 \\
Total ALP & Total Protein & 4 & -6.54 & -0.753 & 0.0013 & 0.9446 \\
Total ALP & AST/ALT & 4 & 6.10 & 0.418 & 0.0182 & 0.6856 \\
Total ALP & BUN & 4 & 0.356 & 0.687 & 0.0109 & 0.7611 \\
Total ALP & Crn & 4 & -5.79 & -0.743 & 0.0018 & 0.9268 \\
Total ALP & BUN/Crn & 4 & 0.501 & 0.683 & 0.0065 & 0.8214 \\
Total ALP & Sodium & 4 & 1.13 & 0.642 & 0.0361 & 0.5709 \\
Total ALP & Potassium & 4 & 7.07 & 0.649 & 0.0302 & 0.6025 \\
Total ALP & Chloride & 4 & 1.04 & 0.648 & 0.0311 & 0.5976 \\
Caspase-3/7 & Total ALP & 9 & 0.0609 & 0.731 & $<0.0001$ & 0.9993
\end{tabular}

Table A.4-Complete list of total calcium correlations

\begin{tabular}{ccccccc}
$\begin{array}{c}\text { Dep. } \\
\text { Variable }\end{array}$ & $\begin{array}{c}\text { Indep. } \\
\text { Variable }\end{array}$ & $\mathbf{N}_{\text {bears }}$ & $\boldsymbol{\beta}$ & $\mathbf{r}$ & $\mathbf{p}$ & Power \\
\hline BSALP & Total Calcium & 4 & -5.79 & -0.687 & 0.0307 & 0.6000 \\
Ionized Calcium & Total Calcium & 4 & 0.175 & 0.542 & 0.0041 & 0.8399 \\
Total Calcium & Total OCN & 4 & -0.00522 & -0.417 & 0.0119 & 0.7269 \\
Glucose & Total Calcium & 4 & 57.8 & 0.536 & 0.0042 & 0.8386 \\
Total Calcium & NPY & 4 & 0.00348 & 0.421 & 0.0154 & 0.6933 \\
Albumin & Total Calcium & 4 & 0.683 & 0.682 & $<0.0001$ & 0.9999 \\
Total Calcium & Total Protein & 4 & 0.348 & 0.623 & $<0.0001$ & 0.9985 \\
Globulin & Total Calcium & 4 & 0.312 & 0.635 & 0.0298 & 0.5929 \\
ALT & Total Calcium & 4 & 10.5 & 0.525 & 0.0023 & 0.8848 \\
AST/ALT & Total Calcium & 4 & -0.752 & -0.635 & $<0.0001$ & 0.9887 \\
Chloride & Total Calcium & 4 & -2.26 & -0.562 & 0.0156 & 0.6915
\end{tabular}


Table A.5-Complete list of ionized calcium correlations

\begin{tabular}{|c|c|c|c|c|c|c|}
\hline $\begin{array}{c}\text { Dep. } \\
\text { Variable }\end{array}$ & $\begin{array}{l}\text { Indep. } \\
\text { Variable }\end{array}$ & $N_{\text {bears }}$ & $\beta$ & $\mathbf{r}$ & $\mathbf{p}$ & Power \\
\hline Ionized Calcium & Total Calcium & 4 & 0.175 & 0.542 & 0.0041 & 0.8399 \\
\hline Ionized Calcium & Adiponectin & 4 & $9.05 e-5$ & 0.487 & 0.0277 & 0.6047 \\
\hline Ionized Calcium & Glucose & 4 & 0.00106 & 0.508 & 0.0150 & 0.6961 \\
\hline Ionized Calcium & Total Protein & 4 & -0.115 & -0.574 & 0.0012 & 0.9241 \\
\hline Globulin & Ionized Calcium & 4 & -1.32 & -0.744 & $<0.0001$ & 0.9960 \\
\hline Ionized Calcium & BUN & 4 & 0.00704 & 0.507 & 0.0152 & 0.6942 \\
\hline Ionized Calcium & Crn & 4 & -0.102 & -0.520 & 0.0095 & 0.7552 \\
\hline Ionized Calcium & BUN:Crn & 4 & 0.0104 & 0.517 & 0.0107 & 0.7403 \\
\hline Chloride & Ionized Calcium & 4 & 4.95 & 0.553 & 0.0229 & 0.6352 \\
\hline Ionized Calcium & $\begin{array}{c}\text { Runx2 Gene } \\
\text { Expression } 24 \mathrm{hr} \text { UD }\end{array}$ & 6 & 0.198 & 0.989 & 0.0189 & 0.6584 \\
\hline Ionized Calcium & $\begin{array}{c}\text { UBQ Gene } \\
\text { Expression 6day D }\end{array}$ & 2 & -0.237 & -0.540 & 0.0013 & 0.9335 \\
\hline $\begin{array}{l}\text { Coll Gene } \\
\text { Expression } \\
\text { 6day D }\end{array}$ & Ionized Calcium & 2 & -2.56 & -0.345 & 0.0362 & 0.5655 \\
\hline $\begin{array}{c}\text { BAD Gene } \\
\text { Expression } \\
\text { 6day D }\end{array}$ & Ionized Calcium & 2 & -1.29 & -0.467 & 0.0186 & 0.6748 \\
\hline $\begin{array}{c}\text { Smurf1 Gene } \\
\text { Expression } \\
\text { 6day D }\end{array}$ & Ionized Calcium & 2 & -2.08 & -0.576 & 0.0348 & 0.5723 \\
\hline
\end{tabular}


Table A.6-Complete list of osteocalcin correlations

\begin{tabular}{|c|c|c|c|c|c|c|}
\hline $\begin{array}{l}\text { Dependent } \\
\text { Variable }\end{array}$ & $\begin{array}{c}\text { Independent } \\
\text { Variable }\end{array}$ & $\mathbf{N}_{\text {bears }}$ & $\beta$ & $\mathbf{r}$ & $\mathbf{p}$ & Power \\
\hline Total Calcium & Total OCN & 4 & -0.00522 & -0.417 & 0.0119 & 0.7269 \\
\hline ucOCN & Total OCN & 4 & 0.272 & 0.874 & $<0.0001$ & 1 \\
\hline Adiponectin & Total OCN & 4 & -10.43 & -0.521 & $<0.0001$ & 0.9863 \\
\hline Glucose & Total OCN & 4 & -1.11 & -0.627 & $<0.0001$ & 0.9883 \\
\hline Total OCN & IGF-1 & 5 & -0.0502 & -0.485 & 0.0265 & 0.6109 \\
\hline Serotonin & Total OCN & 4 & -3.87 & -0.513 & $<0.0001$ & 0.9890 \\
\hline AST & Total OCN & 4 & -0.288 & -0.483 & 0.0074 & 0.7837 \\
\hline ALT & Total OCN & 4 & -0.231 & -0.699 & $<0.0001$ & 0.9999 \\
\hline AST/ALT & Total OCN & 4 & 0.0124 & 0.475 & $<0.0001$ & 0.9993 \\
\hline BUN & Total OCN & 4 & -0.167 & -0.539 & $<0.0001$ & 0.9893 \\
\hline Crn & Total OCN & 4 & 0.0111 & 0.477 & 0.0004 & 0.9618 \\
\hline BUN/Crn & Total OCN & 4 & -0.102 & -0.458 & 0.0012 & 0.9218 \\
\hline Total OCN & Sodium & 4 & 2.982 & 0.242 & 0.0371 & 0.5566 \\
\hline Potassium & Total OCN & 4 & -0.00392 & -0.322 & 0.0487 & 0.5091 \\
\hline Total OCN & Caspase-3/7 & 4 & -6.20 & -0.426 & 0.0135 & 0.7113 \\
\hline Adiponectin & ucOCN & 4 & -26.4 & -0.443 & 0.0020 & 0.8873 \\
\hline Glucose & ucOCN & 4 & -2.628 & -0.533 & 0.0048 & 0.8259 \\
\hline Serotonin & ucOCN & 4 & -11.2 & -0.473 & 0.0003 & 0.9622 \\
\hline ALT & ucOCN & 4 & -0.486 & -0.525 & 0.0023 & 0.8846 \\
\hline AST/ALT & ucOCN & 4 & 0.0295 & 0.581 & 0.0011 & 0.9625 \\
\hline ucOCN & BUN & 4 & -0.439 & -0.446 & 0.0021 & 0.8899 \\
\hline ucOCN & Crn & 4 & 7.18 & 0.527 & 0.0002 & 0.9799 \\
\hline ucOCN & BUN/Crn & 4 & -0.523 & -0.396 & 0.0072 & 0.7861 \\
\hline ucOCN & Caspase-3/7 & 4 & -2.10 & -0.527 & 0.0037 & 0.8502 \\
\hline Adiponectin & \%ucOCN & 4 & -23.4 & -0.484 & 0.0004 & 0.9573 \\
\hline Glucose & $\%$ ucOCN & 4 & -2.23 & -0.554 & 0.0021 & 0.8907 \\
\hline Insulin & \%ucOCN & 4 & -0.0517 & -0.499 & 0.0283 & 0.6008 \\
\hline Serotonin & $\%$ ucOCN & 4 & -8.41 & -0.460 & 0.0006 & 0.9462 \\
\hline AST & $\%$ ucOCN & 4 & -0.535 & -0.175 & 0.0500 & 0.5044 \\
\hline ALT & \%ucOCN & 4 & -0.439 & -0.575 & 0.0003 & 0.9667 \\
\hline AST/ALT & $\%$ ucOCN & 4 & 0.0223 & 0.571 & 0.0016 & 0.9056 \\
\hline BUN & $\%$ ucOCN & 4 & -0.362 & -0.468 & 0.0008 & 0.9420 \\
\hline Crn & $\%$ ucOCN & 4 & 0.0301 & 0.523 & $<0.0001$ & 0.9871 \\
\hline BUN/Crn & \%ucOCN & 4 & -0.222 & -0.403 & 0.0053 & 0.8168 \\
\hline$\%$ ucOCN & Caspase-3/7 & 4 & -2.67 & -0.491 & 0.0035 & 0.8549 \\
\hline
\end{tabular}


Table A.7-Complete list of adiponectin correlations

\begin{tabular}{|c|c|c|c|c|c|c|}
\hline $\begin{array}{c}\text { Dep. } \\
\text { Variable }\end{array}$ & $\begin{array}{l}\text { Indep. } \\
\text { Variable }\end{array}$ & $N_{\text {bears }}$ & $\beta$ & $\mathbf{r}$ & $\mathbf{p}$ & Power \\
\hline TRACP & Adiponectin & 9 & 0.000117 & 0.430 & 0.0222 & 0.6313 \\
\hline BSALP & Adiponectin & 9 & 0.00676 & 0.627 & 0.0012 & 0.9077 \\
\hline Total ALP & Adiponectin & 9 & 0.00840 & 0.638 & 0.0003 & 0.9611 \\
\hline Ionized Calcium & Adiponectin & 4 & $9.05 e-5$ & 0.487 & 0.0277 & 0.6047 \\
\hline Adiponectin & Total OCN & 4 & -10.43 & -0.521 & $<0.0001$ & 0.9863 \\
\hline Adiponectin & ucOCN & 4 & -26.4 & -0.443 & 0.0020 & 0.8873 \\
\hline Adiponectin & $\%$ ucOCN & 4 & -23.4 & -0.484 & 0.0004 & 0.9573 \\
\hline Glucose & Adiponectin & 4 & 0.0291 & 0.427 & 0.0014 & 0.9004 \\
\hline Insulin & Adiponectin & 9 & 0.00143 & 0.709 & $<0.0001$ & 0.9837 \\
\hline Adiponectin & Serotonin & 4 & 0.899 & 0.411 & 0.0065 & 0.7918 \\
\hline AST & Adiponectin & 4 & 0.0161 & 0.527 & 0.0016 & 0.9056 \\
\hline ALT & Adiponectin & 4 & 0.00677 & 0.500 & 0.0054 & 0.8153 \\
\hline Adiponectin & BUN & 4 & 36.3 & 0.551 & $<0.0001$ & 0.9899 \\
\hline Adiponectin & Crn & 4 & -454 & -0.506 & 0.0003 & 0.9661 \\
\hline BUN:Crn & Adiponectin & 4 & 0.00475 & 0.448 & 0.0016 & 0.9063 \\
\hline Potassium & Adiponectin & 4 & 0.000232 & 0.379 & 0.0148 & 0.6980 \\
\hline Caspase-3/7 & Adiponectin & 4 & 0.000936 & 0.493 & 0.0131 & 0.7158 \\
\hline
\end{tabular}

Table A.8-Complete list of glucose correlations

\begin{tabular}{ccccccc}
$\begin{array}{c}\text { Dep. } \\
\text { Variable }\end{array}$ & $\begin{array}{c}\text { Indep. } \\
\text { Variable }\end{array}$ & $\mathbf{N}_{\text {bears }}$ & $\boldsymbol{\beta}$ & $\mathbf{r}$ & $\mathbf{p}$ & Power \\
\hline BSALP & Glucose & 9 & 0.0524 & 0.602 & 0.0290 & 0.5917 \\
Glucose & $\begin{array}{c}\text { Total Calcium } \\
\text { lonized }\end{array}$ & 4 & 57.8 & 0.536 & 0.0042 & 0.8386 \\
Galcium & Glucose & 4 & 0.00106 & 0.508 & 0.0150 & 0.6961 \\
Glucose & Total OCN & 4 & -1.11 & -0.627 & $<0.0001$ & 0.9883 \\
Glucose & ucOCN & 4 & -2.628 & -0.533 & 0.0048 & 0.8259 \\
Glucose & \%ucOCN & 4 & -2.23 & -0.554 & 0.0021 & 0.8907 \\
Glucose & Adiponectin & 9 & 0.0291 & 0.427 & 0.0014 & 0.9004 \\
Glucose & Serotonin & 4 & 0.103 & 0.570 & 0.0011 & 0.9258 \\
Glucose & ALT & 4 & 2.70 & 0.576 & 0.0009 & 0.9368 \\
AST/ALT & Glucose & 4 & -0.00580 & -0.674 & $<0.0001$ & 0.9982 \\
Glucose & Crn & 4 & -40.1 & -0.558 & 0.0018 & 0.9006 \\
Glucose & Sodium & 4 & -8.51 & -0.544 & 0.0032 & 0.8616 \\
Caspase-3/7 & Glucose & 9 & 0.0147 & 0.569 & 0.0010 & 0.9290
\end{tabular}


Table A.9-Complete list of insulin correlations

\begin{tabular}{ccccccc}
$\begin{array}{c}\text { Dep. } \\
\text { Variable }\end{array}$ & $\begin{array}{c}\text { Indep. } \\
\text { Variable }\end{array}$ & $\mathbf{N}_{\text {bears }}$ & $\boldsymbol{\beta}$ & $\mathbf{r}$ & $\mathbf{p}$ & Power \\
\hline Insulin & Total ALP & 9 & 0.0344 & 0.686 & 0.0112 & 0.7235 \\
Insulin & \%ucOCN & 4 & -0.0517 & -0.499 & 0.0283 & 0.6008 \\
Insulin & Adiponectin & 9 & 0.00143 & 0.709 & $<0.0001$ & 0.9837 \\
Insulin & ALT & 4 & 0.0643 & 0.506 & 0.0429 & 0.5324 \\
Insulin & BUN & 4 & 0.106 & 0.575 & 0.0042 & 0.8419 \\
Insulin & Crn & 4 & -1.20 & -0.539 & 0.0146 & 0.7027 \\
Insulin & BUN:Crn & 4 & 0.118 & 0.535 & 0.0170 & 0.6810 \\
Insulin & Caspase-3/7 & 9 & 0.256 & 0.759 & 0.0422 & 0.5329 \\
Smurf1 Gene & & & & & & \\
Expression & Insulin & 4 & 0.0362 & 0.606 & 0.0229 & 0.6337 \\
24hr UD & & & & & &
\end{tabular}

Table A.10-Complete list of leptin and IGF-1 correlations

\begin{tabular}{ccccccc}
$\begin{array}{c}\text { Dep. } \\
\text { Variable }\end{array}$ & $\begin{array}{c}\text { Indep. } \\
\text { Variable }\end{array}$ & $\mathbf{N}_{\text {bears }}$ & $\boldsymbol{\beta}$ & $\mathbf{r}$ & $\mathbf{p}$ & Power \\
\hline $\begin{array}{c}\text { Total OCN } \\
\text { Leptin }\end{array}$ & IGF-1 & 5 & -0.0502 & -0.485 & 0.0265 & 0.6109 \\
& IGF-1 & 5 & -0.00144 & -0.568 & 0.0023 & 0.884
\end{tabular}

Table A.11-Complete list of NPY correlations

\begin{tabular}{ccccccc}
$\begin{array}{c}\text { Dep. } \\
\text { Variable }\end{array}$ & $\begin{array}{c}\text { Indep. } \\
\text { Variable }\end{array}$ & $\mathbf{N}_{\text {bears }}$ & $\boldsymbol{\beta}$ & $\mathbf{r}$ & $\mathbf{p}$ & Power \\
\hline TRACP & NPY & 8 & -0.00328 & -0.528 & $<0.0001$ & 0.9986 \\
BSAP & NPY & 8 & -0.128 & -0.713 & $<0.0001$ & 0.9990 \\
Total ALP & NPY & 8 & -0.146 & -0.718 & $<0.0001$ & 0.9995 \\
Total Calcium & NPY & 4 & 0.00348 & 0.421 & 0.0154 & 0.6933 \\
NPY & Albumin & 4 & 51.7 & 0.649 & $<0.0001$ & 0.9881 \\
NPY & Total Protein & 4 & 25.6 & 0.582 & 0.0021 & 0.8914 \\
NPY & ALT & 4 & 1.24 & 0.508 & 0.0372 & 0.5563 \\
NPY & AST/ALT & 4 & -25.1 & -0.532 & 0.0153 & 0.6934 \\
NPY & Sodium & 4 & -6.48 & -0.593 & 0.0013 & 0.9190 \\
NPY & Chloride & 4 & -5.41 & -0.533 & 0.0147 & 0.6995 \\
Caspase-3/7 & NPY & 4 & -0.0107 & -0.437 & 0.0496 & 0.5061
\end{tabular}


Table A.12-Complete list of norepinephrine correlations

\begin{tabular}{ccccccc}
$\begin{array}{c}\text { Dep. } \\
\text { Variable }\end{array}$ & $\begin{array}{c}\text { Indep. } \\
\text { Variable }\end{array}$ & $\mathbf{N}_{\text {bears }}$ & $\boldsymbol{\beta}$ & $\mathbf{r}$ & $\mathbf{p}$ & Power \\
\hline Norepinephrine & Total Protein & 4 & 5.78 & 0.378 & 0.0390 & 0.5481 \\
& & & & & & \\
Norepinephrine & Sodium & 4 & -1.86 & -0.452 & 0.0057 & 0.8098 \\
$\begin{array}{c}\text { PTH1R gene } \\
\text { expression }\end{array}$ & Norepinephrine & 2 & 0.0696 & 0.535 & 0.0366 & 0.5649 \\
$\begin{array}{l}\text { 6 day diff } \\
\text { p53 gene }\end{array}$ & Norepinephrine & 2 & -0.0910 & -0.429 & 0.0090 & 0.7775 \\
$\begin{array}{c}\text { expression } \\
\text { 24hr non-diff }\end{array}$ & & & & & &
\end{tabular}

Table A.13-Complete list of serotonin correlations

\begin{tabular}{ccccccc}
$\begin{array}{c}\text { Dep. } \\
\text { Variable }\end{array}$ & $\begin{array}{c}\text { Indep. } \\
\text { Variable }\end{array}$ & $\mathbf{N}_{\text {bears }}$ & $\boldsymbol{\beta}$ & $\mathbf{r}$ & $\mathbf{p}$ & Power \\
\hline Serotonin & Total OCN & 4 & -3.87 & -0.513 & $<0.0001$ & 0.9890 \\
Serotonin & ucOCN & 4 & -11.2 & -0.473 & 0.0003 & 0.9622 \\
Serotonin & ucOCN :Total OCN & 4 & -8.41 & -0.460 & 0.0006 & 0.9462 \\
Adiponectin & Serotonin & 4 & 0.899 & 0.411 & 0.0065 & 0.7918 \\
Glucose & Serotonin & 4 & 0.103 & 0.570 & 0.0011 & 0.9258 \\
Serotonin & Total Bilirubin & 4 & -1673 & -0.437 & 0.0161 & 0.6870 \\
ALT & Serotonin & 4 & 0.0165 & 0.521 & 0.0027 & 0.8746 \\
AST/ALT & Serotonin & 4 & -0.00127 & -0.657 & $<0.0001$ & 0.9957 \\
Serotonin & BUN & 4 & 9.39 & 0.364 & 0.0270 & 0.6089 \\
Serotonin & Creatinine & 4 & -176 & -0.467 & 0.0019 & 0.8975 \\
BAD gene & Serotonin & 2 & 0.000414 & 0.515 & 0.0169 & 0.6898 \\
expression & & & & & & \\
6 day diff. & & & & & & \\
Cyclin D1 gene & Serotonin & 2 & 0.000954 & 0.438 & 0.0073 & 0.8004 \\
expression & & & & & & \\
24hr non-diff & & & & & &
\end{tabular}


Table A.14-Complete list of caspase-3/7 correlations

\begin{tabular}{ccccccc}
$\begin{array}{c}\text { Dep. } \\
\text { Variable }\end{array}$ & $\begin{array}{c}\text { Indep. } \\
\text { Variable }\end{array}$ & $\mathbf{N}_{\text {bears }}$ & $\boldsymbol{\beta}$ & $\mathbf{r}$ & $\mathbf{p}$ & Power \\
\hline Caspase-3/7 & Glucose & 9 & 0.0147 & 0.569 & 0.0010 & 0.9290 \\
Caspase-3/7 & Total protein & 4 & -1.02 & -0.412 & 0.0128 & 0.7268 \\
Caspase-3/7 & Albumin & 4 & -1.76 & -0.415 & 0.0120 & 0.7349 \\
Caspase-3/7 & Globulin & 4 & -1.51 & -0.348 & 0.0334 & 0.5783 \\
Caspase-3/7 & BUN & 4 & 0.0907 & 0.430 & 0.0094 & 0.7661 \\
Caspase-3/7 & Creatinine & 4 & -1.55 & -0.583 & 0.0568 & 0.976 \\
Caspase-3/7 & Potassium & 4 & 1.41 & 0.328 & 0.0431 & 0.534 \\
Caspase-3/7 & NPY & 8 & -0.0133 & -0.609 & 0.0057 & 0.804 \\
Caspase-3/7 & Insulin & 9 & 0.270 & 0.610 & 0.0422 & 0.533 \\
Caspase-3/7 & ucOCN & 4 & -0.0853 & -0.483 & 0.0037 & 0.851 \\
Caspase-3/7 & Adiponectin & 9 & 0.00149 & 0.660 & $<0.0001$ & 0.990 \\
Caspase-3/7 & C-terminal PTH & 2 & -0.176 & -0.439 & 0.0104 & 0.758
\end{tabular}

